\title{
DEVELOPMENT OF ELECTROCHEMICAL DEVICES FOR THE Determination of DRUgs of AbUSE
}

Laura Asturias Arribas

Tesis Doctoral

Burgos, 2014 



\section{UNIVERSIDAD DE BURGOS}

DePartamento DE QuímicA

Memoria de investigación titulada "Development of electrochemical devices for the determination of drugs of abuse" presentada para optar al Grado de Doctora en la Universidad de Burgos.

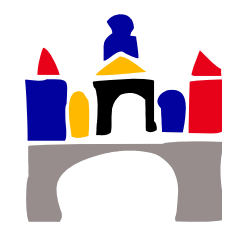

Fdo.: Laura Asturias Arribas 



\section{UNIVERSIDAD DE BURGOS}

DEPARTAMENTO DE QUÍMICA

Dña. M. Julia Arcos Martínez, Catedrática de Universidad del Departamento de Química de la Universidad de Burgos, y Dña. M. Asunción Alonso Lomillo, Profesora Titular del Departamento de Química de la Universidad de Burgos,

INFORMAN FAVORABLEMENTE sobre la presente Tesis Doctoral, titulada "Development of electrochemical devices for the determination of drugs of abuse”, realizada en el Área de Química Analítica del Departamento de Química de la Universidad de Burgos por Dña. Laura Asturias Arribas.

Y para que así conste, firman el presente informe en Burgos, a 24 de abril de 2014.

Fdo.: M. Julia Arcos Martínez Fdo.: M. Asunción Alonso Lomillo 

A mis padres y mi hermano. 

Me gustaría expresar en estas líneas mi agradecimiento a todas aquellas personas e instituciones que, de una forma $\mathrm{u}$ otra, han estado presentes en el proceso y realización de este trabajo de doctorado.

En primer lugar me gustaría agradecer a mis directoras de tesis, M. Julia Arcos Martínez y M. Asunción Alonso Lomillo, por acercarme la electroquímica y dirigirme en este trabajo, además de su apoyo y ánimo a experimentar sobre las inquietudes que surgían en el camino en el desarrollo de este trabajo.

Al profesor Jean-Michel Kauffmann, por haberme brindado la posibilidad de trabajar en su grupo de investigación y aportarme diferentes y nuevas visiones sobre los biosensores y las técnicas usadas.

Al grupo del profesor Juan Ramón Castillo Suárez de la universidad de Zaragoza, por acercarme al mundo de los immunosensores.

A mis compañeros y profesores del área de Química Analítica, por los debates constructivos y el intercambio de ideas.

A mis padres, familiares y amigos, por todo su apoyo, consideración y cariño.

Y por último, agradecer al ministerio de Educación, Cultura y Deporte por la financiación obtenida a través de una beca FPU.

\section{Gracias.}





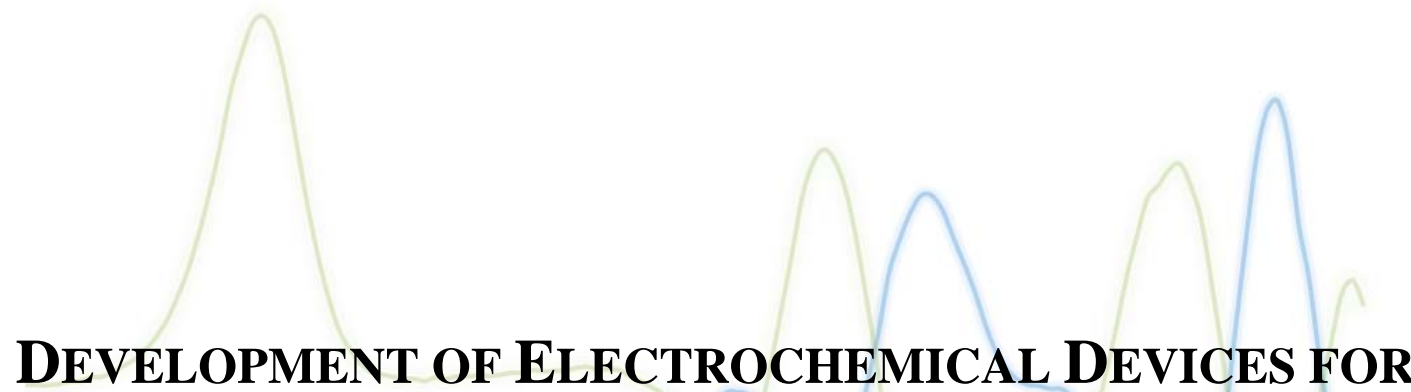
THE DETERMINATION OF DRUgS OF ABUSE

Laura Asturias Arribas 



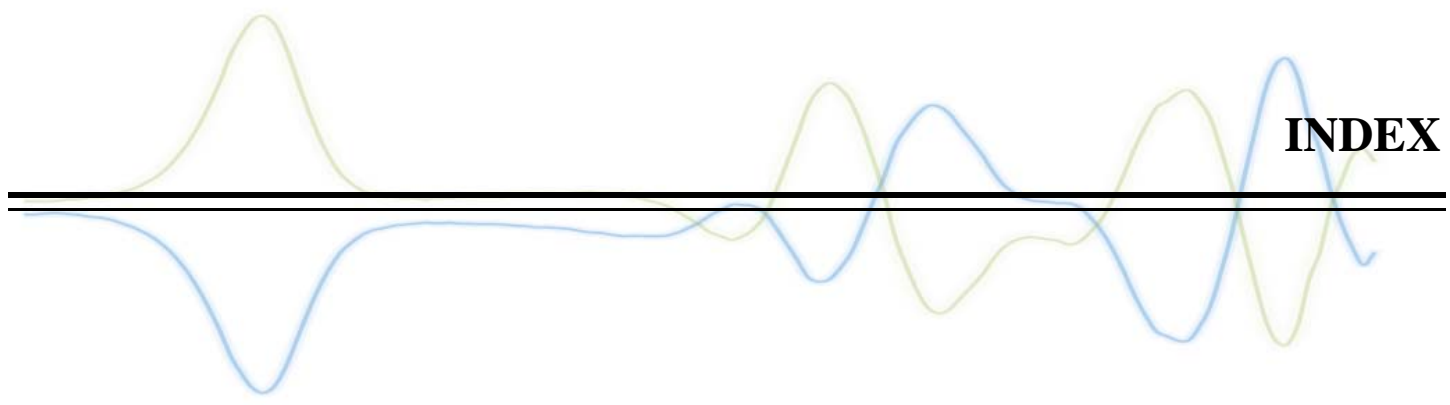





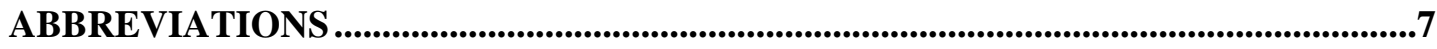

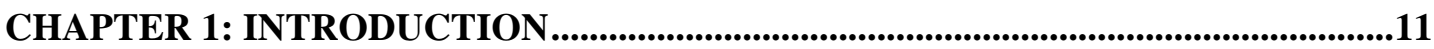

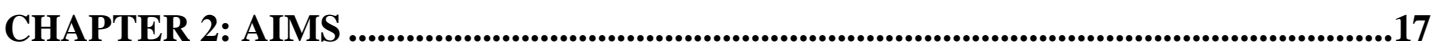

CHAPTER 3: GENERAL THEORETICAL FOUNDATIONS........................................21

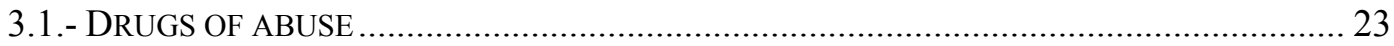

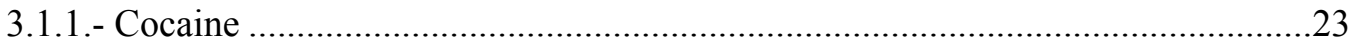

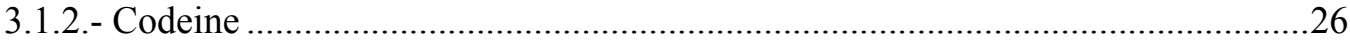

3.1.3.- Analytical determinations of cocaine and codeine.............................................29

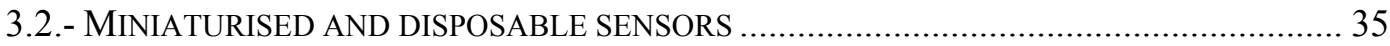

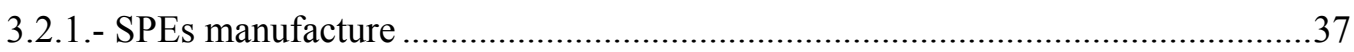

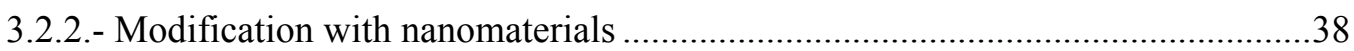

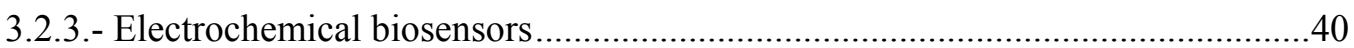

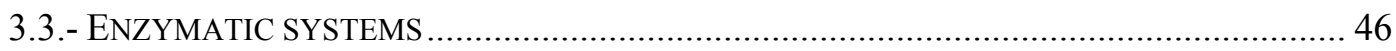

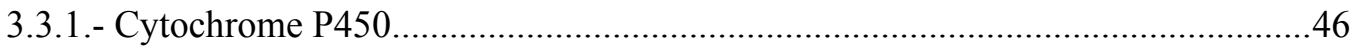

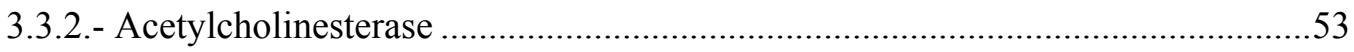

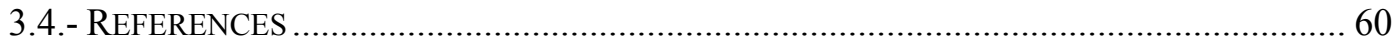

\section{CHAPTER 4: SENSITIVE AND SELECTIVE COCAINE}

ELECTROCHEMICAL DETECTION USING DISPOSABLE SENSORS................75

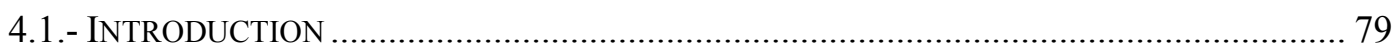

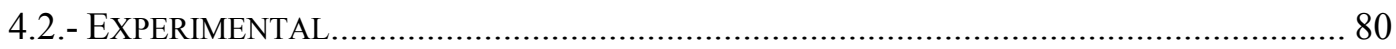

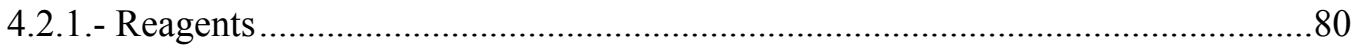

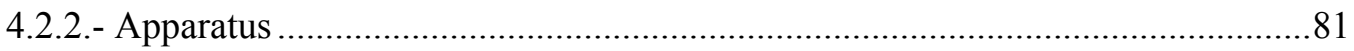

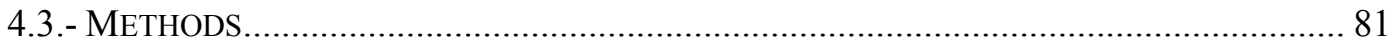

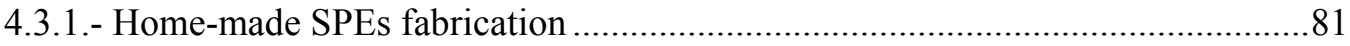

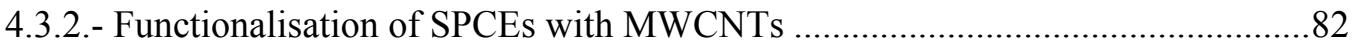

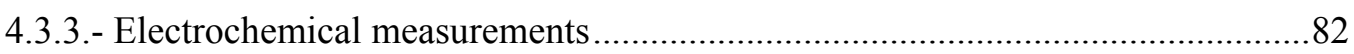

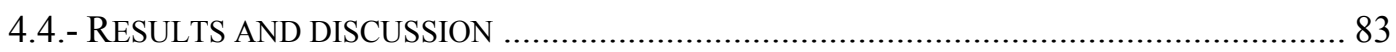

4.4.1.- Optimisation of the $\mathrm{pH}$ of the supporting electrolyte...........................................83

4.4.2.- Influence of the nature of the screen-printed working electrode in the

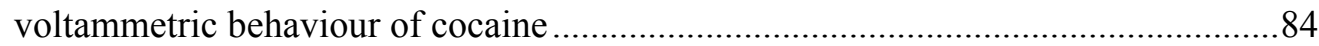

4.4.3.- Influence of the solvent used in the dispersion of MWCNTs for the

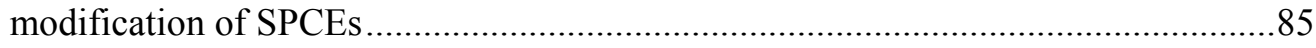

4.4.4.- Influence of the concentration of MWCNTs in the modification of SPCEs.......86 
4.4.5.- Cocaine detection using SPCEs and MWCNTs-SPCEs by square-wave voltammetry..... .89

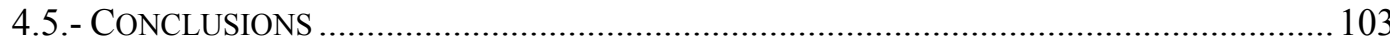

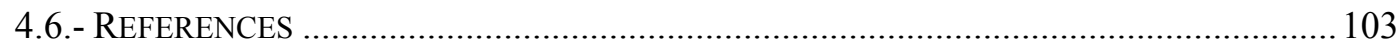

\section{CHAPTER 5: CYP450 BIOSENSORS BASED ON SCREEN-PRINTED}

CARBON ELECTRODES FOR THE DETERMINATION OF COCAINE ........... 111

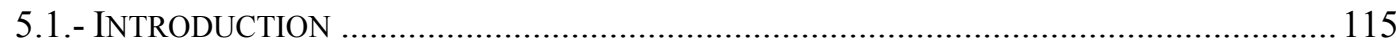

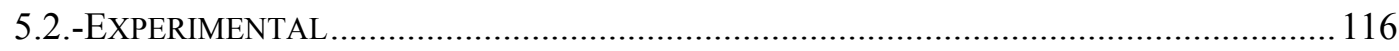

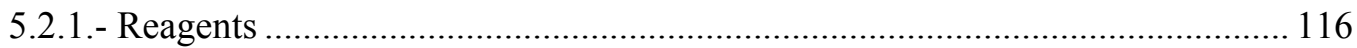

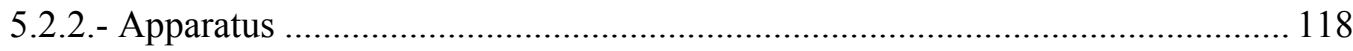

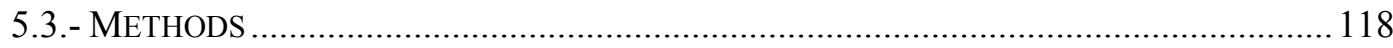

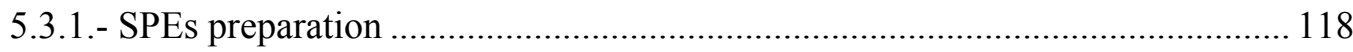

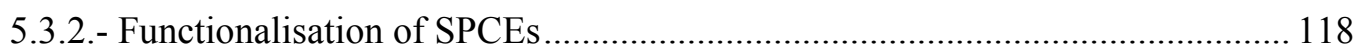

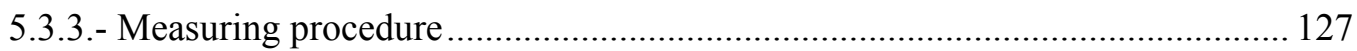

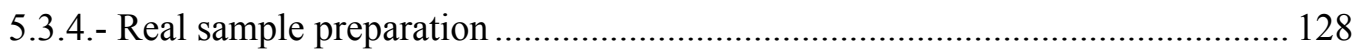

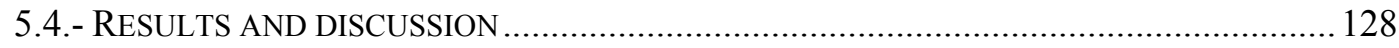

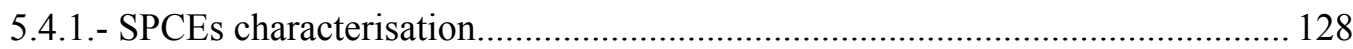

5.4.2.- Optimisation of the influential variables on the chronoamperometric

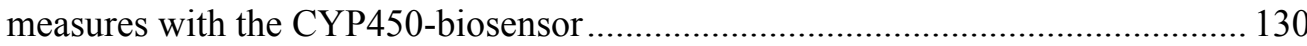

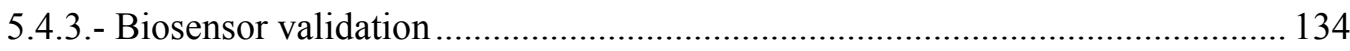

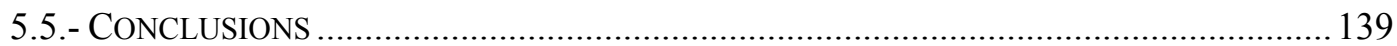

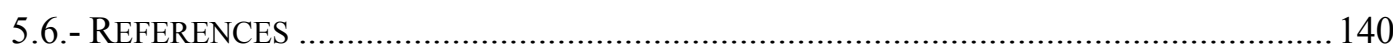

CHAPTER 6: ELECTROCHEMICAL DETERMINATION OF COCAINE USING SCREEN-PRINTED CYP2B4 BASED BIOSENSORS ................................... 145

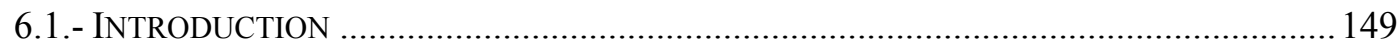

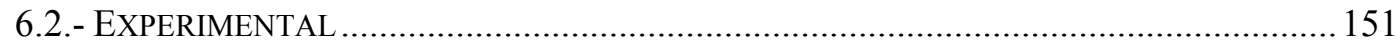

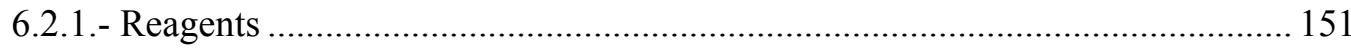

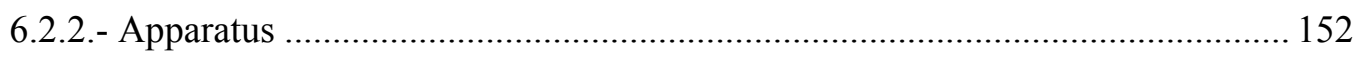

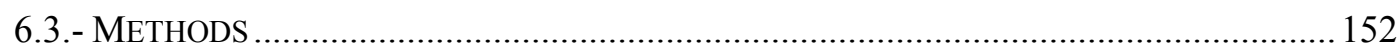

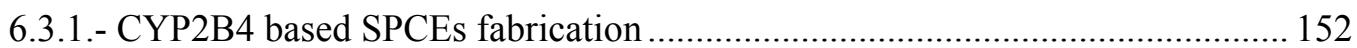

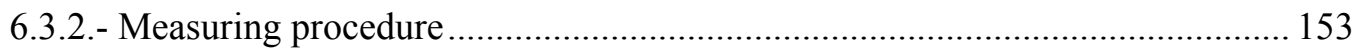

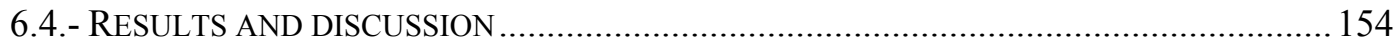

6.4.1.- Characterisation of the biosensor ............................................................... 154

6.4.2.- Optimisation of the chronoamperometric variables ......................................... 156 
6.4.3.- Spectrophotometric study of CYP2B4 based biosensor 158

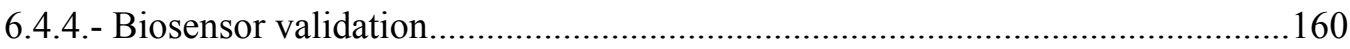

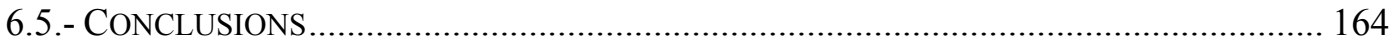

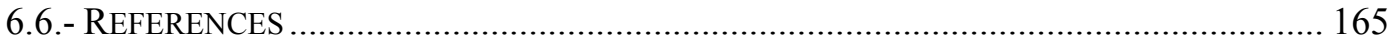

CHAPTER 7: SCREEN-PRINTED BIOSENSOR BASED ON THE INHIBITION

OF THE ACETYLCHOLINESTERASE ACTIVITY FOR THE DETERMINATION OF CODEINE ....................................................................169

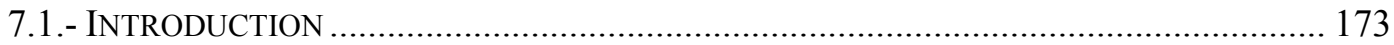

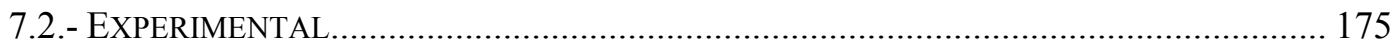

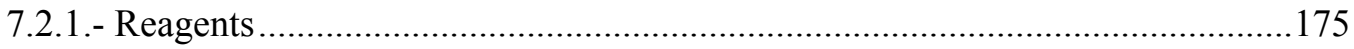

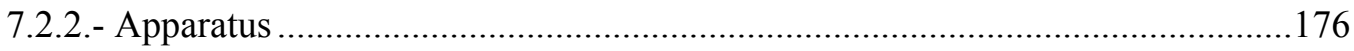

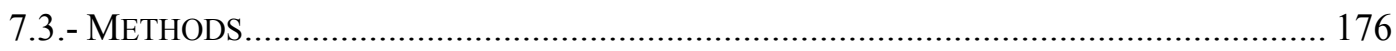

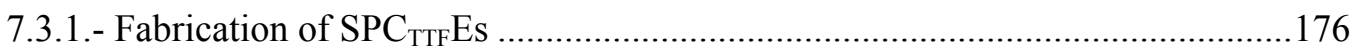

7.3.2.- Immobilisation of the enzyme $\mathrm{AChE}$ onto $\mathrm{SPC}_{\mathrm{TTF}} \mathrm{Es}$.....................................176

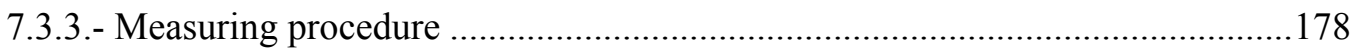

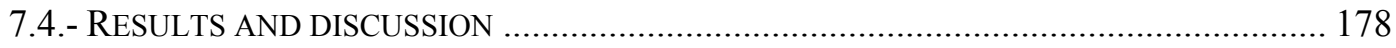

7.4.1.- Electrochemical behaviour of codeine in SPCEs .................................................178

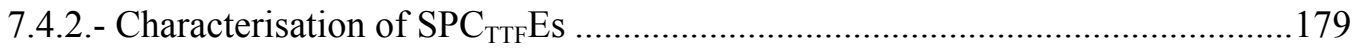

7.4.3.- Optimisation of the enzymatic immobilisation stage ........................................180

7.4.4.- Optimisation of the chronoamperometric variables .........................................181

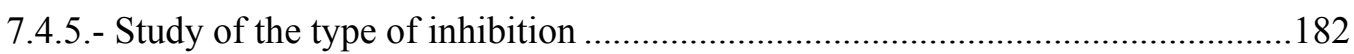

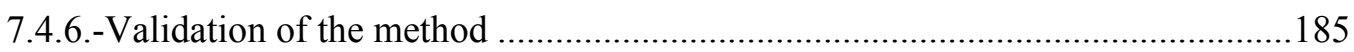

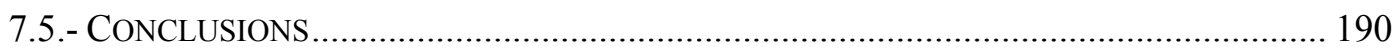

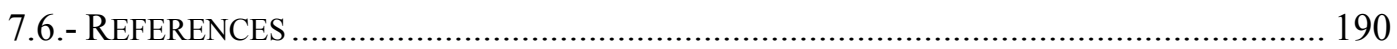

CHAPTER 8: CYTOCHROME P450 2D6 BASED ELECTROCHEMICAL SENSOR FOR THE DETERMINATION OF CODEINE .............................................197

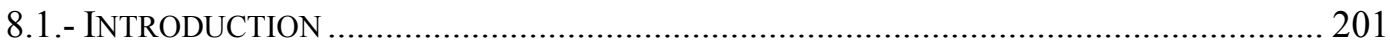

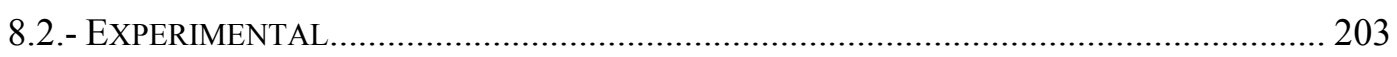

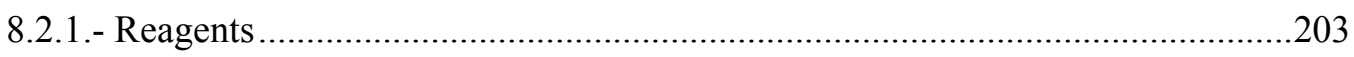

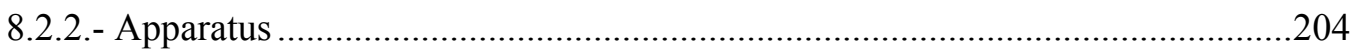

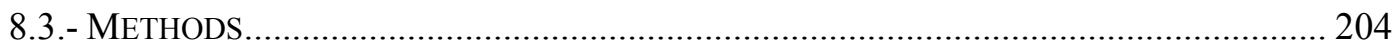

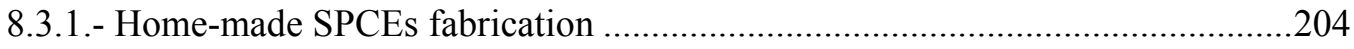

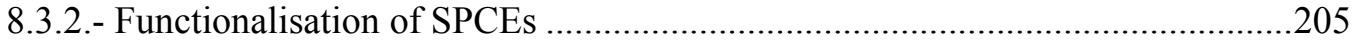

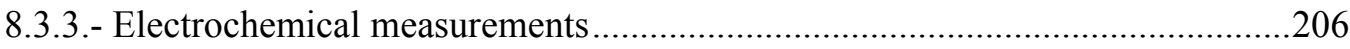




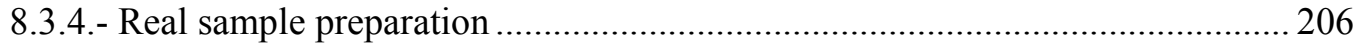

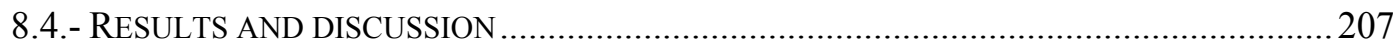

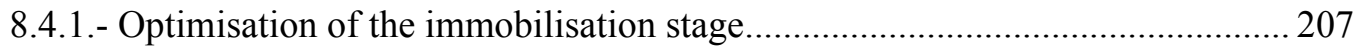

8.4.2.- Optimisation of the chronoamperometric experimental variables ................... 207

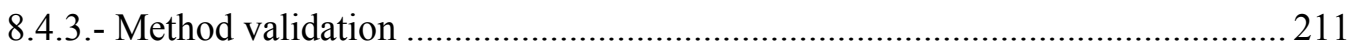

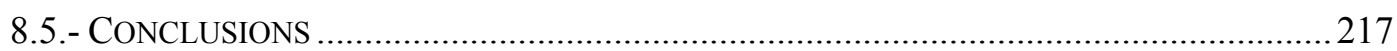

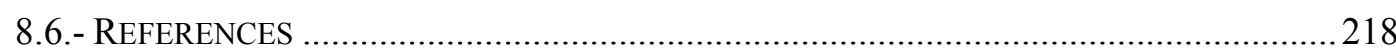

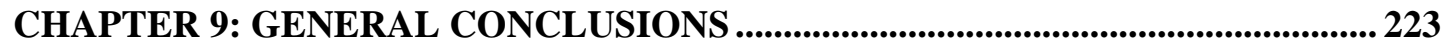

ANNEX: IMMUNOSENSORS FOR COCAINE DETECTION .................................... 229

A.1.- DEVELOPMENT OF IMMUNOSENSORS: AN INTRODUCTION .....................................223

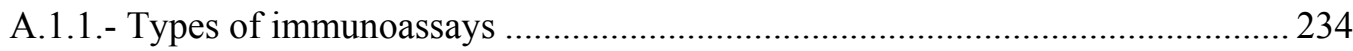

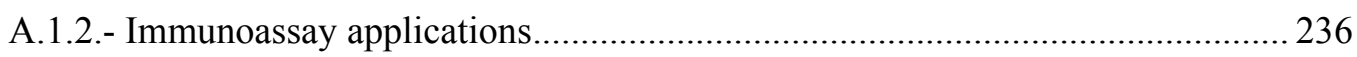

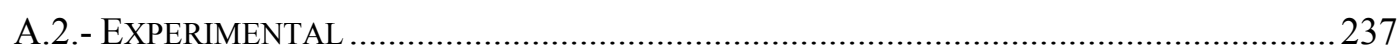

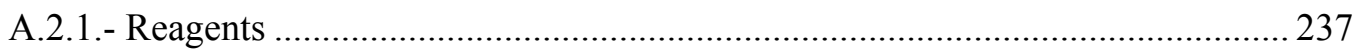

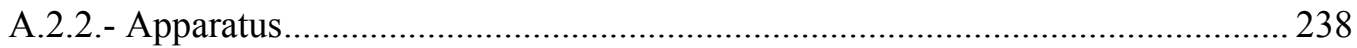

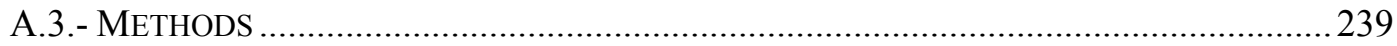

A.3.1.- Immobilisation of the antibody onto the magnetic microparticles ................. 239

A.3.2.- Blockage of the polystyrene microtiters ........................................................ 240

A.3.3.- Direct competitive assay of cocaine ............................................................... 241

A.3.4.- Spiked urine sample preparation ............................................................... 244

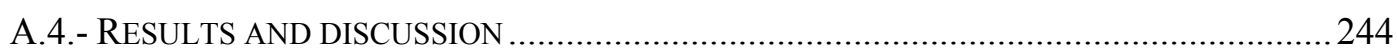

A.4.1.- Study of the blockage of the ELISA plate ...................................................... 244

A.4.2.- Optimisation of the experimental variables................................................... 245

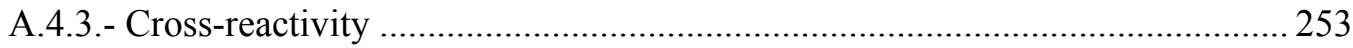

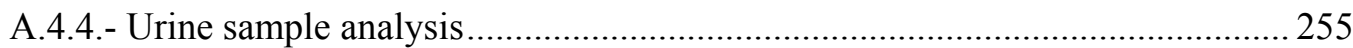

A.4.5.- Validation of the cocaine immunosensor ...................................................... 256

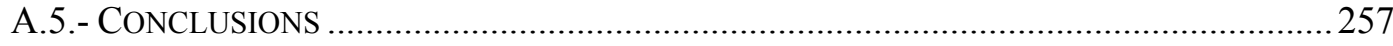

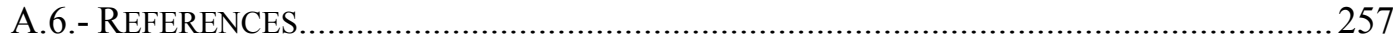




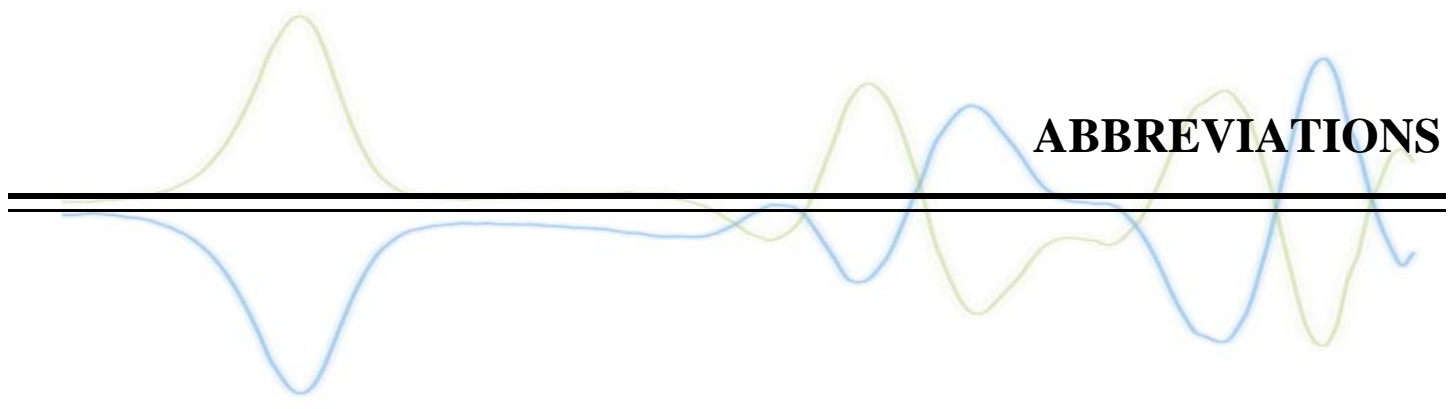





\begin{tabular}{|c|c|}
\hline ABBREVIATION & FULL NAME \\
\hline $\mathrm{AChE}$ & Acetylcholinesterase \\
\hline $\mathrm{Ag} / \mathrm{AgCl} \mathrm{SPE}$ & Screen-printed $\mathrm{Ag} / \mathrm{AgCl}$ reference electrode \\
\hline ATI & Acetylthiocholine iodide \\
\hline BSA & Bovine serum albumin \\
\hline CNTs & Carbon nanotubes \\
\hline coc-HRP & Cocaine horseradish peroxidase conjugate \\
\hline CYP450 & Cytochrome P450 \\
\hline CYP2B4 & Cytochrome P450 subfamily 2B4 \\
\hline CYP2D6 & Cytochrome P450 subfamily 2D6 \\
\hline DMF & Dimethylformamide \\
\hline EDC & $N$-(3-dimethylaminopropyl)- $N$ '-ethylcarbodiimide \\
\hline GA & Glutaraldehyde \\
\hline HRP & Horseradish peroxidase \\
\hline MBs & Magnetic beads \\
\hline MWCNTs & Multi-walled carbon nanotubes \\
\hline NADPH & Nicotinamide adenine dinucleotide phosphate \\
\hline NHS & $N$-Hydroxysuccinimide \\
\hline OLS & Ordinary least squares regression \\
\hline pAbcoc & Polyclonal cocaine antibody \\
\hline PLS & Partial least squares regression \\
\hline RSD & Relative standard deviation \\
\hline SPAuE & Screen-printed gold electrode \\
\hline SPCE & Screen-printed carbon electrode \\
\hline $\mathrm{SPC}_{\mathrm{CYP}} \mathrm{E}$ & Screen-printed carbon-cytochrome $\mathrm{P} 450$ 2B4-composite electrode \\
\hline $\mathrm{SPC}_{\mathrm{Pt}} \mathrm{E}$ & Screen-printed platinised carbon electrode \\
\hline $\mathrm{SPC}_{\mathrm{TTF}} \mathrm{E}$ & Screen-printed carbon electrode modified with tetrathiafulvalene \\
\hline SPE & Screen-printed electrode \\
\hline TMB & $3,3^{\prime}, 5,5^{\prime}$-tetramethylbenzidine \\
\hline TTF & Tetrathiafulvalene \\
\hline
\end{tabular}





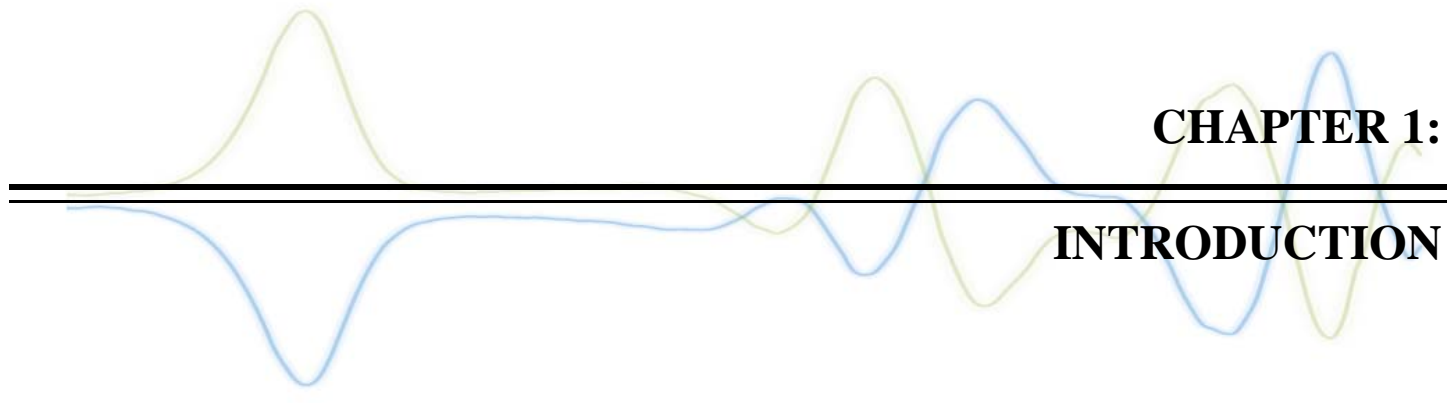



Drug abuse is a global problem that affects all kind of social classes, since these substances produce addictive effects. The misuse and trafficking of these drugs have very strong and severe consequences on victims, such as social exclusion, imprisonment for drug possession or for driving under their influence, health problems or even death. Thus, research works have been orientated towards the development of analytical methodologies to accurately and precisely determine these compounds.

Electrochemical sensors have been described as ideal devices to be routinely used, thanks to their simplicity and small size, for in situ and on line analysis, as a screening test, but with the additional advantage of quantification. Moreover, it should be taken into account the characteristics that the screen-printing technology provides to the manufacture of transducers, such as the disposable nature. A wide choice of designs, sizes and materials allows the screen-printing fabrication of electrochemical devices, according to the requirements of the analysis.

Additionally, the signal of these sensors can be improved, in terms of sensitivity and selectivity, by modifying their working surface. On one hand, carbon nanomaterials, which have shown excellent thermal and electrical conductivity and mechanical resistance, have opened a wide investigation field applied to analytical sensors. On the other hand, the incorporation of biological components through different immobilisation techniques has given as a result high selective biosensors to be used in complex matrixes.

Experimental design methodology has been presented as a useful tool for the optimisation of experimental variables in the amperometric studies, where factors such as $\mathrm{pH}$ of the media or applied working potential have great influence in the response of the electrochemical sensor. The performance of the sensor is studied through its validation in terms of precision, capability of detection and accuracy, which allows knowing the applicability of the device in real-life samples, such as pharmaceutical drugs and biological samples. 
This $\mathrm{PhD}$ thesis gathers the experimental results of successive studies in the development of electrochemical devices for the determination of illegal and legal drugs of abuse, such as cocaine and codeine. The use of the screen-printing technology has permitted to obtain miniaturised sensors with different characteristics, depending on the requirements of the study. In this way, carbon or gold pastes have been used in the manufacture of working electrodes, in some cases mixing these inks with redox mediators or biological elements to confer additional features to the sensor, leading to more sensitive analyses.

The experimental methodology carried out in the development of the different electrochemical sensors can be summarised in the following stages:

- Fabrication of the miniaturised screen-printed devices consisting of a threeelectrode system.

- Immobilisation of nanomaterials or a biological element with a suitable method of immobilisation.

- Optimisation of the experimental variables and subsequent validation of the method.

- Application of the sensors in the determination of the studied analyte in complex matrixes.

In consequence, chapter 4 shows the results obtained in the determination of cocaine in confiscated street samples, taking into consideration the possible interaction with other compounds in these kinds of samples, such as paracetamol, codeine and caffeine. Two different solutions have been attempted to solve this problem. On one hand, the modification of disposable carbon sensors with carbon nanotubes (CNTs) has allowed the voltammetric quantification of cocaine by using ordinary least squares (OLS) regressions. On the other hand, partial least squares (PLS) regressions have been used for the resolution of the overlapped voltammetric 
signals when using screen-printed carbon electrodes (SPCEs) without any modification.

Then, chapters 5 and 6 illustrate the development of two modified biosensors based on the enzyme cytochrome P450 2B4 (CYP2B4) for the simple and selective determination of cocaine, and its application in street samples. Chronoamperometric and voltammetric measurements have been used to study the biotransformation of the drug.

Chapter 7 is devoted to the detection of a different drug, codeine. This work describes the development of a redox-mediated biosensor based on the enzyme acetylcholinesterase (AChE) for codeine quantification, monitoring the inhibitory response produced on the activity of enzyme.

Next, chapter 8 presents the selective determination of codeine in pharmaceutical and biological samples using an enzymatic biosensor based on the isoform 2D6 of the cytochrome P450 (CYP2D6), which is responsible of the transformation of codeine into morphine.

Finally, the preliminary results obtained during an academic visit in the University of Zaragoza are shown. The aim of the research was to develop an optical and electrochemical immunosensor for cocaine determination in biological samples. 



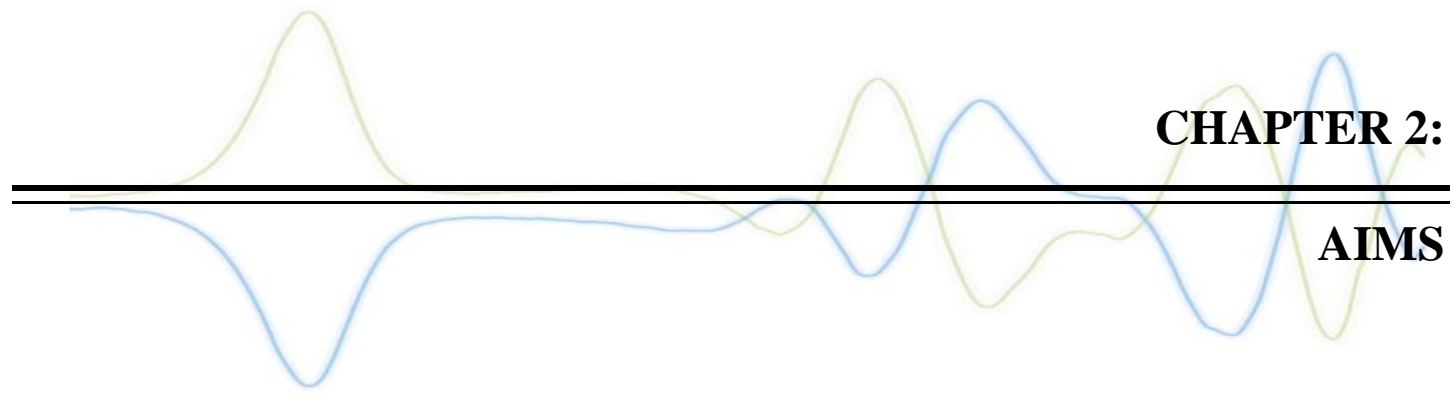



The main goal of the proposed research activity is the creation of new knowledge that enables significant scientific and technological developments in the area of electrochemical biosensors and immunosensors, to determine different compounds of interest in clinical analysis. This global objective implies the achievement of specific ones, which are here described:

- Study of the influence of different materials and curing conditions in the screen-printing manufacture of electrochemical devices.

- Functionalisation of the electrochemical sensors with CNTs, redox mediators and biorecognition elements, which implies the study of different modification strategies.

- Optimisation of the different experimental variables that have a strong influence on the electrochemical response.

- Validation of the developed screen-printed sensors in terms of:

$\checkmark$ Precision, including reproducibility and repeatability.

$\checkmark$ Capability of detection.

$\checkmark$ Accuracy, applying the sensors in the determination of cocaine and codeine in cocaine street samples, pharmaceutical drugs and biological samples. 

CHAPTER 3:

GENERAL THEORETICAL FOUNDATIONS 



\section{1.- DRUGS OF ABUSE}

One of the main social problems, which is spread all over the world and affects all kind of societies, cultures and social classes, is the dealing and consumption of drugs of abuse. These substances damage not only human health but also have disastrous social consequences that are reflected in the deterioration of the individuals and their families or even the appearing of a criminal behaviour. This problem affects to individuals as well as whole countries, distorting its economy and complicating international relationships between countries [1].

However, not all drugs classified as drugs of abuse are illicit ones. There are some drugs, such as alcohol, tobacco or codeine, which are abused although its distribution and sale is permitted.

Drugs of abuse are psychoactive or psychotropic substances that stimulate the central nervous system producing pleasant effects and that is the reason why they are used in excess and, sometimes, without any control (self-medication). Their analysis is essential in areas such as medicine, forensic science or criminology, and consequently, it is of a great importance to control and determine this kind of substances.

\subsection{1.- COCAINE}

\subsubsection{1.- Historical events}

Cocaine is one of the 14 alkaloids found in the leaves of the Erythroxylon coca plant. The Erythroxylon coca plant is native from South America (Bolivia, Colombia, Ecuador and Peru), Mexico and Indonesia. Ancient civilisations used these leaves in religious ceremonies and chewed them to free their active principle, obtaining benefits like physical resistance and appetite suppression [2, 3]. It was not until 1859 that a German chemist called Albert Niemann (1834 - 1861) isolated the 
alkaloid cocaine from the leaves of the Erythroxylon coca plant [4]. Then, Carl Koller, who was a Viennese ophthalmologist, used it for the first time as a local anaesthetic in 1884 [5]. In 1891, two hundred intoxication cases, thirteen of which ended in death, were reported due to this drug. For that reason, at the end of the 19th century, it was demonstrated that this substance possessed several undesirable effects such as addiction and its use was stopped in medicine giving way to less toxic local anaesthetics $[5,6]$.

\subsubsection{2.- Cocaine: action and effects}

Cocaine, whose scientific name is bezoylmethylecgonine $\left(\mathrm{C}_{17} \mathrm{H}_{21} \mathrm{NO}_{4}\right)$, acts as an analgesic or a local anaesthetic (Figure 3.1). It soothes pain, suppresses the sensitivity in the place where it is applied and acts as a vasoconstrictor. It blocks the capture of dopamine and other biogenic amines, such as noradrenalin and serotonin, producing an increase in the concentration of this neurotransmitter in the synapse and increasing the activity among the nerve pathways in which it is involved. This blockage triggers the sensation of euphoria which leads to addition [7], besides distorting functions involved in the modulation of the movement, the affective live or the pleasure.

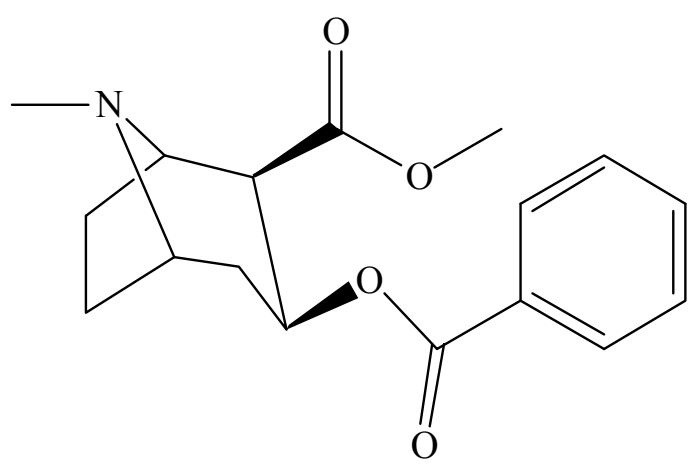

Figure 3.1.- Cocaine structure.

Cocaine is metabolised in humans by two different pathways: hydrolytic reactions and oxidative processes focused on the tropanic nitrogen atom. However, 
while the hydrolytic pathway pharmacologically inactivates cocaine; the oxidative route mediated by the enzyme cytochrome P450 (CYP450) is responsible for this drug hepatotoxicity (Figure 3.2) [8].

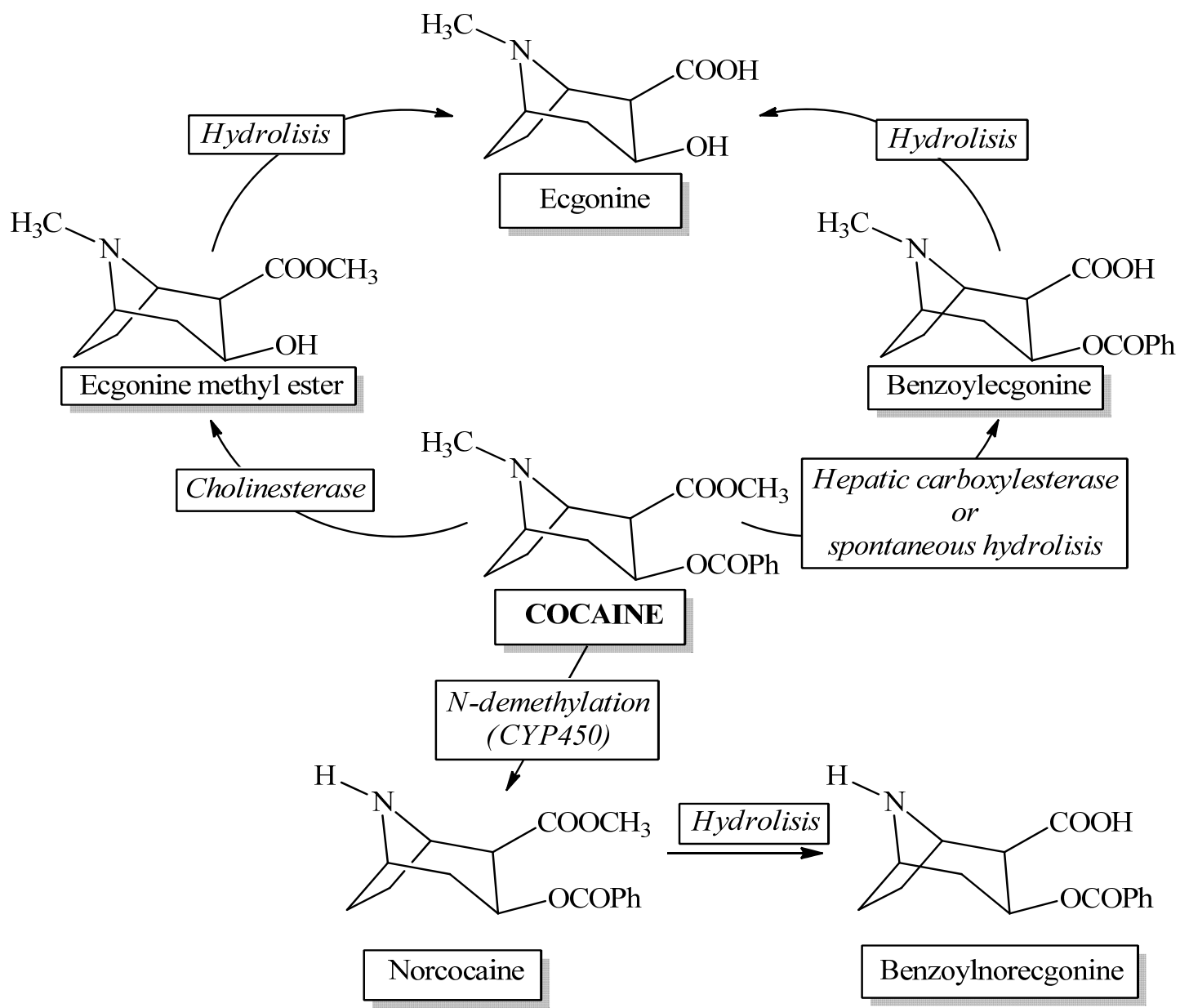

Figure 3.2.- Metabolism of cocaine in human body.

This drug can produce psychological effects such as euphoria, loquacity, sociability increase, mental acceleration, hyperactivity and sexual desire increase. On the other hand, the most important physiological effects are fatigue reduction, appetite inhibition, sleeping time decrease, arterial pressure increase and even death $[3]$. 


\subsubsection{3.- Cocaine street samples}

Cocaine has been turned into one of the most consumed illegal drugs in the history [9].

Every single confiscated street sample contains a percentage of adulterants, in the range from 16 to $85 \%$ [10].

According to Shannon [9], the adulterants in cocaine street samples can be divided in five general categories: local anaesthetics (lidocaine, benzocaine and procaine), sugars (lactose, sucrose and mannitol), stimulants (caffeine, ephedrine or even amphetamine), toxins (quinine and strychnine) and inert compounds (inositol, talc and starch). Other substances, which have been determined in adulterated cocaine samples, are: analgesics and anti-inflammatories (paracetamol and acetylsalicylic acid), by-products of morphine (codeine and heroin), sedative drugs (methaqualone), stimulants (pemoline), drugs with hallucinogen and neurotoxic effects (phencyclidine), flour, ascorbic acid, boric acid, calcium, potassium, thallium, sodium bicarbonate, plaster, magnesium sulphate, dust brick and benzene $[9,11,12]$.

\subsection{2.- CODEINE}

\subsubsection{1.- Historical events}

Codeine is an alkaloid that is extracted from opium Papaver somniferum poppy. Besides codeine, other alkaloids are found in this plant, namely morphine, papaverine and thebaine, among others [13]. Opioids have been used for several years to treat different kinds of pain. Even the ancient Egyptians used natural opioids with this aim [14].

In 1832, the French chemist Pierre Jean Robiquet $(1780-1840)$ identified and isolated the alkaloid codeine [15]. Additionally, between the 1800s and 1900s, 
synthetic and semi-synthetic derivatives from morphine and codeine were produced in an attempt to obtain compounds with higher anaesthetic effect and less side effects [13].

\subsubsection{2.- Codeine: action and effects}

Codeine, or 3-methylmorphine, is one of the most common used antitussive drugs, having analgesic and antidiarrheal properties (Figure 3.3) [16, 17]. Although it belongs to the same opium family as morphine and heroin, codeine is used for the treatment of moderated pain and induces less euphoria and sedation than the firsts. Nevertheless, it can also induce addiction. Although codeine does not produce as strong effects as heroin, it is also considered a drug of abuse [18].

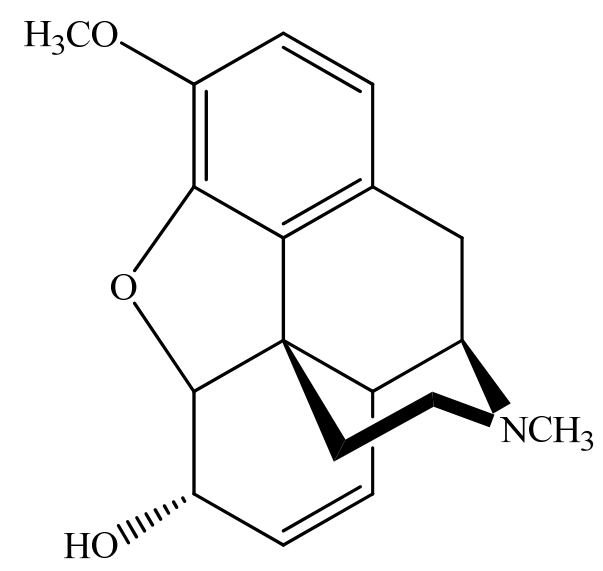

Figure 3.3.- Codeine structure.

Codeine is metabolised in humans through three different main routes; two of them carried out by CYP450s and the other by glucuronosyltransferases (Figure 3.4). 

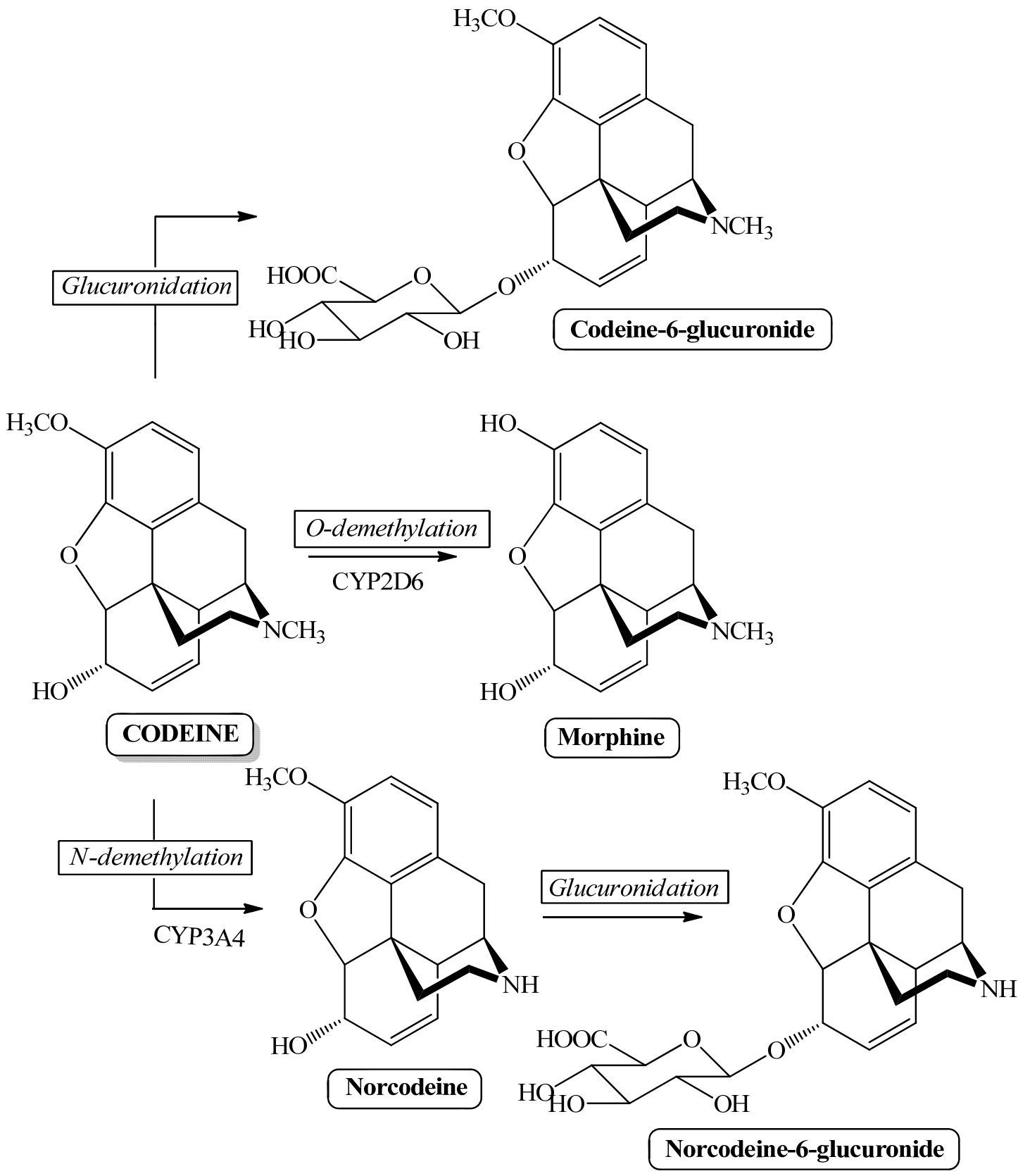

Figure 3.4.- Codeine metabolism in human body.

Nevertheless, the analgesic effect of codeine is just associated to the formation of morphine. This reaction is mediated by the enzyme CYP2D6 [19].

The side effects that this drug can produce are nausea, vomiting, dizziness, drowsiness, constipation, euphoria, dysphoria and pruritus. At high dosage, the 
patient can experiment respiratory depression, stupor or coma, dependence, bradycardia, apnoea, circulatory collapse, cardiac arrest or even death [20].

\subsubsection{3.- Pharmaceutical preparations}

Codeine is sold in pharmaceutical preparations as syrups and pills for the treatment of cough and light to moderated pain. Additionally, some other active principles and different excipients can be also added to these preparations. Active principles such as acetaminophen, acetylsalicylic acid or caffeine, among others, can be mixed with codeine in this kind of drugs [21]. Sodium benzoate, sucrose, ethanol, glycerol, sorbitol, among others, can be found as excipients accompanying the active principles [20].

\subsection{3.- ANALYTICAL DETERMINATIONS OF COCAINE AND CODEINE}

Due to the increase in the consumption of drugs of abuse, a great control of these kinds of analytes is required, so that new methods of detection in different matrixes have been developed.

The determination of cocaine and its metabolites has been performed in different complex matrixes by raman spectroscopy [22], chromatography [22-25], capillary electrophoresis [26, 27], electrochemistry [28-53], aptasensors [54-62], as well as optical [63-67], piezoelectric [68-70] and radio-immunoassays [22].

As for codeine, the main methodologies reported for its determination in biological and pharmaceutical samples have been gas chromatography [71], liquid chromatography [72], electrophoresis [26], chemiluminescence [73] or electrochemistry [18, 21, 74-92]. In some cases, two or more of these techniques have been combined to improve the analysis [72, 93]. 


\subsubsection{1.- Electrochemical determinations of cocaine and codeine}

Nowadays, the development of chemical sensors is presented as one of the most active areas in Analytical Chemistry, being used in wide application fields such as industry, environment, agro-alimentary and clinical branches [94]. Among these types of sensors, electrochemical ones (mainly amperometric and voltammetric sensors) are some of the most studied devices [95].

A chemical sensor is a small device that can be used in order to perform a direct measurement in the matrix of a sample and is capable of decode that chemical information into an analytical signal $[95,96]$. It consists of two basic components: a receptor, which interacts with the analyte, and a transducer that takes the chemical signal and changes it into an analytical signal that is registered in a processor. According to the transducer, the chemical sensors can be classified in optical, electrochemical, piezoelectric and thermal ones.

The simplicity of the electrochemical techniques, their low cost and their relative short time of performance, have provided a great advantage in the use of these robust devices in several fields compared to the rest of transducers and even, to chromatographic techniques [28].

These electrochemical transducers, which can be divided in conductometric, potentiometric and amperometric transducers, consists of two or three main electrodes connected between them forming a closed circuit when they are submerged in solution [97].

Electrochemical methods can be probably found among the oldest measurement techniques, being used in a very wide range of analytical possibilities thanks to the recent technological developments in signal processing and electronic systems [98]. In this way, electroanalytical techniques have also played a significant role in the development of detectors for chromatographic methods and have been an important branch in biosensor development $[38,96]$. 


\section{Electrochemical determinations for cocaine}

The structure of cocaine contains several functional groups that can suffer redox reactions (Figure 3.1). These reactions can be divided into two electrochemical procedures:

- Reactions based on the oxidation of the tertiary amine [28, 33, 34, 38]. This irreversible signal has been registered around $+1 \mathrm{~V}$ using carbon paste $[28$, $33,38]$ and glassy carbon electrodes $[33,34,38]$, in buffer solutions at $\mathrm{pH}$ values higher than 6.5. Additionally, working electrodes have been modified with Uranyl Schiff base films [30, 31] and hexacyanoferrate films [36] in an attempt to lower the oxidation potential and obtain a better capability of detection.

- Reactions based on the reduction of the ester groups, registered between - 1 and $-1.5 \mathrm{~V}$ in buffer solutions at $\mathrm{pH}$ values higher than 7 , using mercury electrodes [35, 37].

Electrochemical techniques, such as cyclic voltammetry [28, 30, 31], squarewave voltammetry [37], differential pulse voltammetry [34] and chronoamperometry $[33,38]$, have been used in these electrochemical procedures.

Besides that, other procedures have been described for the determination of cocaine, such as the use of potentiometric selective membrane electrodes [32, 39]. The reported cocaine-selective membrane electrode barely presented any interference with other substances, such as morphine, codeine or methamphetamine [39]. Additionally, a PVC matrix-type cocainium ion selective electrode was described for determining cocaine in some illicit powders [32].

Moreover, electrochemical biosensors, mainly aptasensors [29, 40-48, 50, 52, $53]$ and immunosensors $[49,51,66]$, have been reported for the determination of this drug in different matrixes. Gold electrodes have been mostly used in the 
development of cocaine aptasensors [29, 41-43, 46-48, 52, 53]. Besides, indium tin oxide [40], glassy carbon [44, 45] and graphene modified SPCEs [50] have been also used, being additionally modified with gold nanoparticles [40, 45, 50] or CdS quantum dots [44]. Labels such as horseradish peroxidase (HRP) [47, 53], alkaline phosphatase [50], methylene blue [29, 41, 46, 48, 52] and platinum nanoparticles [42] have been utilised for the monitoring of these biosensors (Figure 3.5.A-B). Label free immunoassays have been also reported using electrochemical probes based in the electrochemical response of ferrocene $[40,43],\left[\mathrm{Fe}(\mathrm{CN})_{6}\right]^{4-3-}[44,45]$ and $\left[\mathrm{Ru}\left(\mathrm{NH}_{3}\right)_{6}\right]^{3+}[44]$ (Figure 3.5.C).

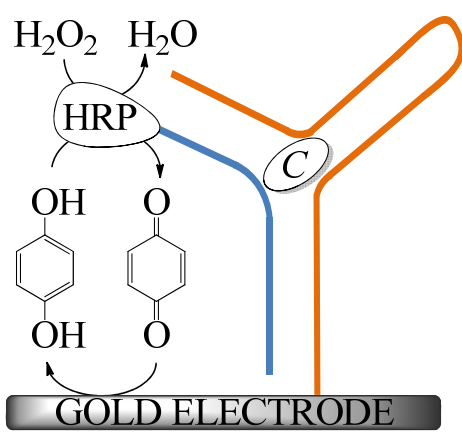

A)

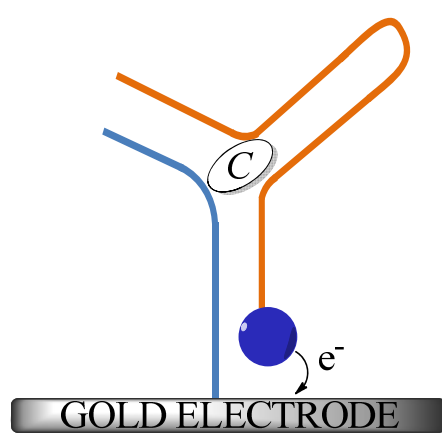

B)

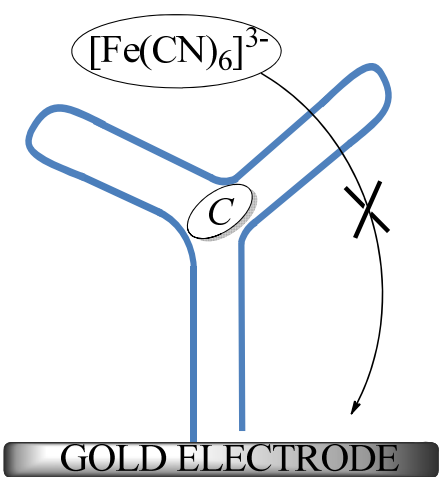

C)

Figure 3.5.- General schemes of the aforementioned aptasensors: A) Enzyme-labelled aptasensor based on the monitoring of the product of the enzymatic reaction, in this case, the monitoring of the HRP oxidised p-benzoquinone in hydroquinone. B) Aptasensor based on the monitoring of a redox label. C) Aptasensor based on an analytical probe, such as $\left[\mathrm{Fe}(\mathrm{CN})_{6}\right]^{3-}$.

Furthermore, two immunoassays have been reported for the determination of this drug:

- The first one is based on the co-immobilisation of the enzyme HRP with the benzoylecgonine antibody in an affinity membrane on an oxygen electrode. The amperometric signal of the sensor is due to the response of the HRP to 
$\mathrm{H}_{2} \mathrm{O}_{2}$, which decreases when cocaine is linked to the immobilised antibody [51].

- The second work couples the use of a flow immunoassay based on an alkaline phosphatase labelled anti-cocaine antibody with a biosensor based on the enzymes tyrosinase and glucose dehydrogenase immobilised on a Clack-type oxygen electrode as amperometric detector (Figure 3.6) $[49,66]$.

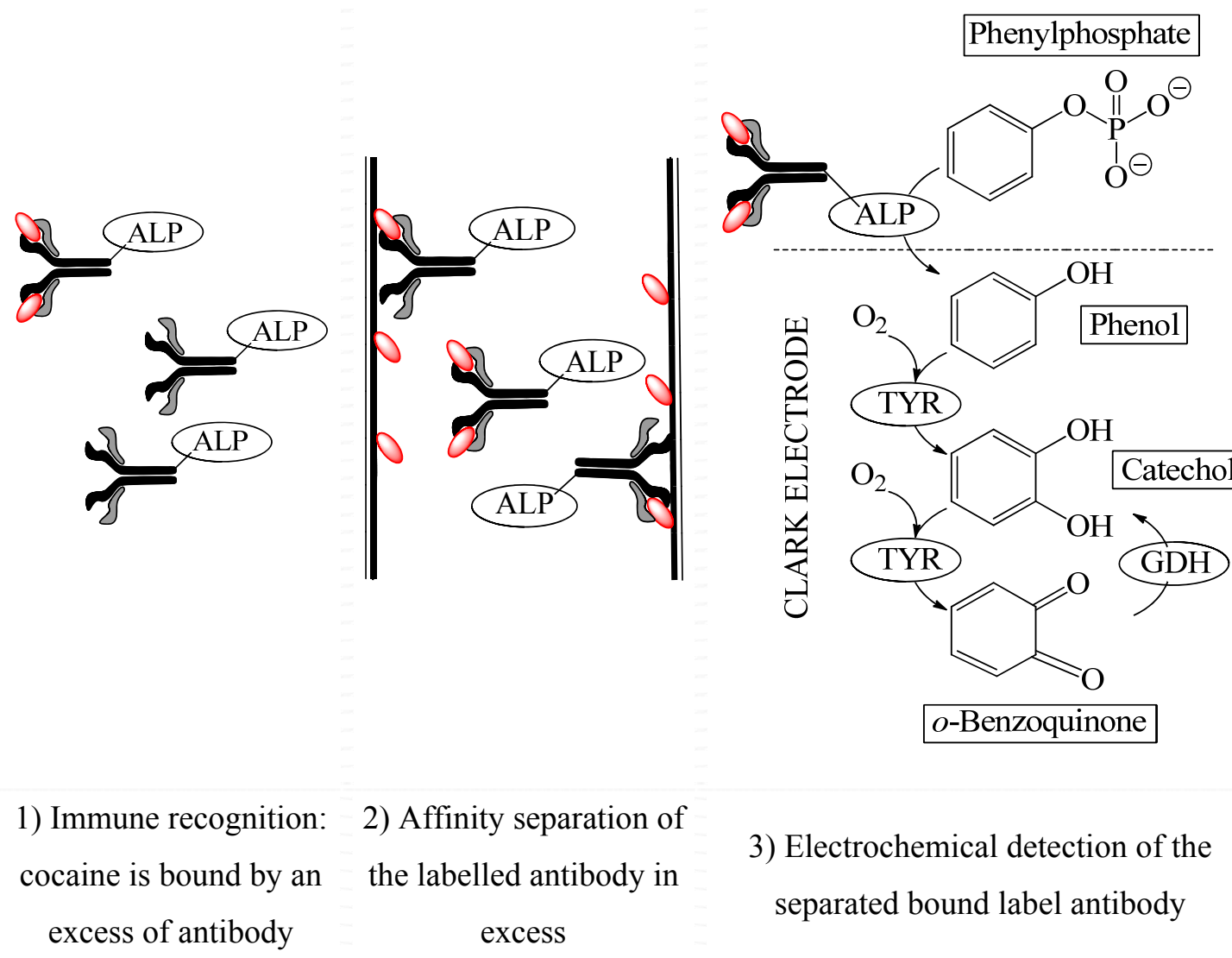

Figure 3.6.- Schematic representation of the procedure performed using a flow immunoassay coupled with a bienzymatic biosensor for cocaine detection. (ALP: alkaline phosphatase, TYR: tyrosinase, GDH: glucose dehydrogenase). 


\section{Electrochemical determinations for codeine}

Analogously, codeine can suffer electrochemical transformations due to the different redox groups that it contains (Figure 3.3). Oxidation of the three organic groups has been reported. Peaks associated to these groups have been seen to be influenced by the $\mathrm{pH}$ of the media so that, depending on the $\mathrm{pH}$ of the buffer solution, these peaks are overlapped (acid pHs) or separated (from neutral to basic pHs) [18]. Oxidation peaks appeared between +0.9 and $+1.2 \mathrm{~V}$, depending on the $\mathrm{pH}$ and the working electrode. Aluminium [76], platinum [74], gold [74], borondoped diamond film [85], carbon [78] and graphite [80] electrodes have been reported for codeine electrochemical determination, but the most common used electrode has been glassy carbon electrode [18, 21, 77, 79, 84, 86]. The working surface has been also modified with carbon $[77,81,83,88]$ or metallic nanomaterials $[76,86]$. In addition, the miniaturisation of these transducers has been also applied for the determination of this analyte [84], being the main electrochemical techniques cyclic voltammetry $[76,79,80]$, differential pulse voltammetry $[18,88,91]$, squarewave voltammetry [21, 81, 84, 86] and chronoamperometry [77, 92].

The incorporation of bioelements, enzymes, aptamers or antibodies, to the electrochemical transducers can sometimes improve the sensitivity of the signal and, consequently, avoid possible interferences [82, 87, 89, 90]. Two aptasensors have been reported for the determination of codeine, in which the aptamers have been immobilised in a gold electrode [82] or a gold-mesoporous silica-nanoparticles modified glassy carbon electrode [90]. In the first aptasensor, the cocaine monitoring was carried out thanks to the ferrocene carboxylic acid, with which the RNA sequence was labelled (Figure 3.5.B) [82]. In the second biosensor, the determination was monitored through an electroactive redox probe, $\left[\mathrm{Fe}(\mathrm{CN})_{6}\right]^{4-3-}$ (Figure 3.5.C) [90].

In addition, two enzymatic biosensors have been described in bibliography. One of them is based on a biosensor flow injection system coupled with a Clark type oxygen electrode, on which the enzymes morphine dehydrogenase and salicylate 
hydroxylase were immobilised (Figure 3.7) [87]. Another enzymatic amperometric sensor based on morphine dehydrogenase has been described to determine codeine using planar devices and phenazine methosulphate as redox mediator (Figure 3.8) [89].

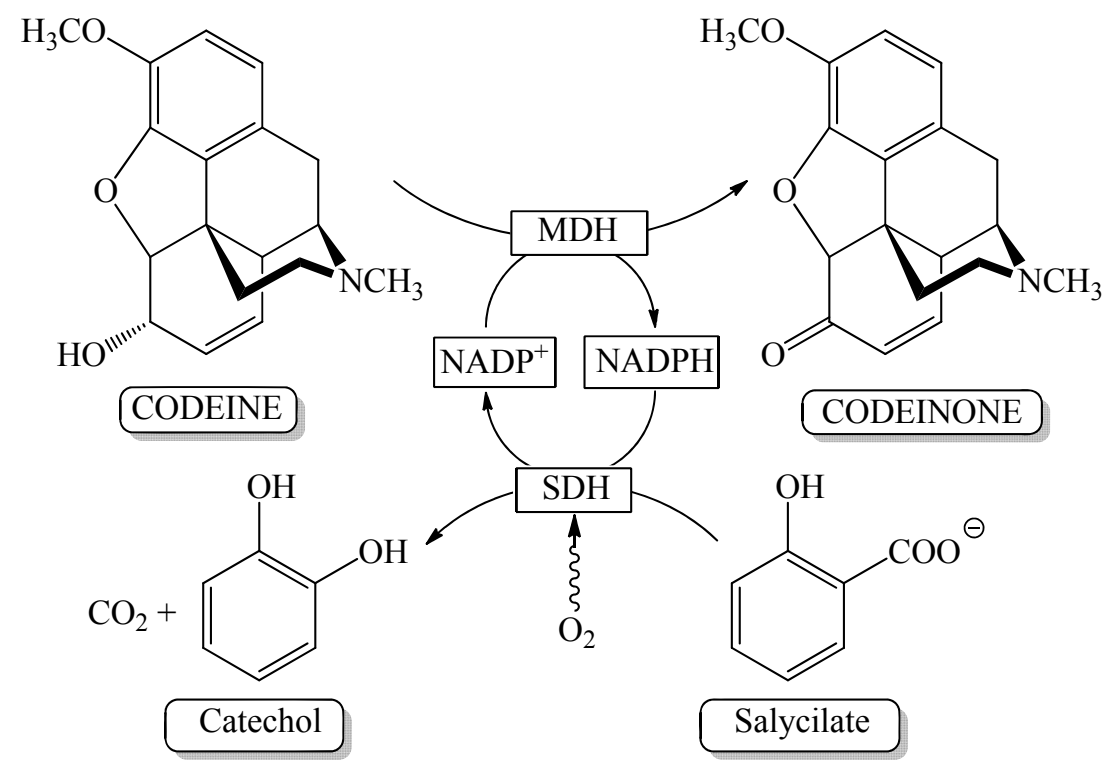

Figure 3.7.- Enzymatic scheme of the biosensor described for the determination of codeine in a Clark-type oxygen electrode (MDH: morphine dehydrogenase, SDH: salicylate dehydroxylase, NADPH: nicotinamide adenine dinucleotide phosphate).

\section{2.- MINIATURISED AND DISPOSABLE SENSORS}

The utilisation of electrochemical sensors in several analytical areas has required an improvement in some of the characteristics of the conventional electrodes, such as the tedious cleaning and recovery stages.

An attractive alternative to the use of conventional electrodes lies in the possibility of fabricating miniaturised disposable devices [99-101]. 


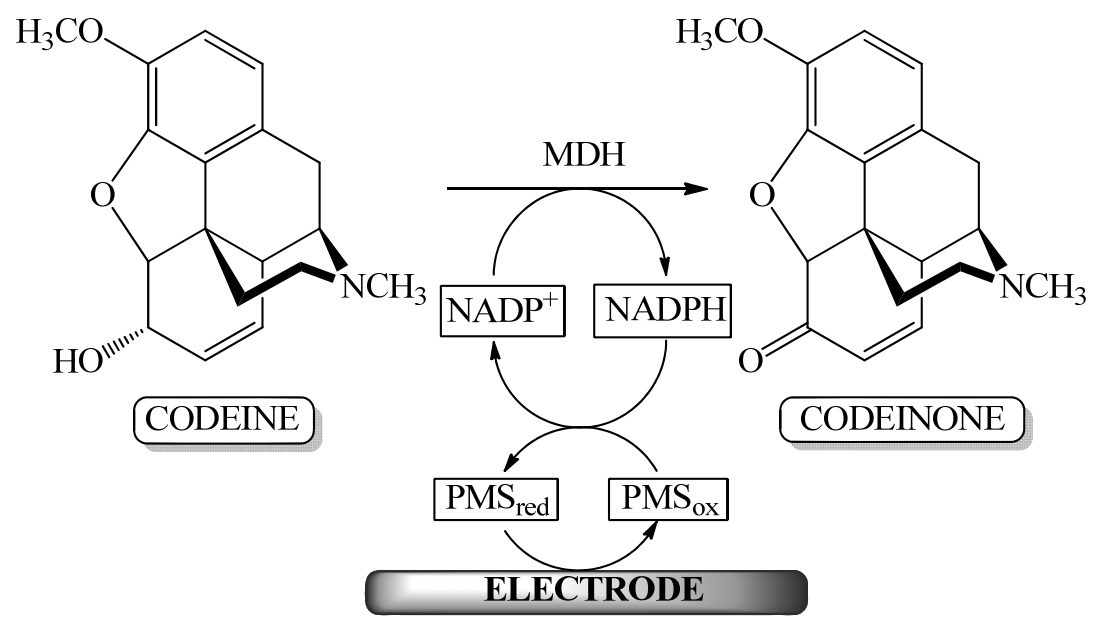

Figure 3.8.- Scheme of the enzymatic biosensor described for the determination of codeine (MDH: morphine dehydrogenase, PMS: phenazine methosulphate).

Screen-printing technology infers important characteristics to the fabrication of miniaturised sensors:

- Great flexibility in the electrode design in terms of spatial distribution, form and area.

- A wide range of materials for their fabrication.

- Low cost production.

- Disposable nature, which avoids cleaning stages.

- Better reproducibility.

- Possible usage for in situ analysis.

- Possible additional modification to develop sensitive and selective biosensors.

Taking into account these characteristics, a great investigation field based on screen-printed electrodes (SPEs) is presented, with analogous applications as for the conventional ones. 


\subsection{1.- SPES MANUFACTURE}

SPEs are obtained through ink printing on a flat surface or substrate. Screenprinting technology is based on forcing the flow of a paste through a mesh that defines a particular part of the transducer (Figure 3.9).

A)

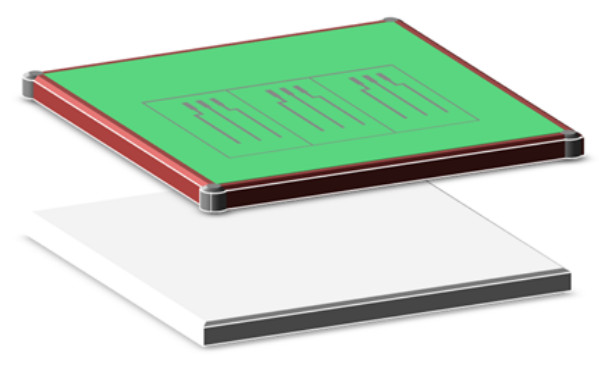

C)

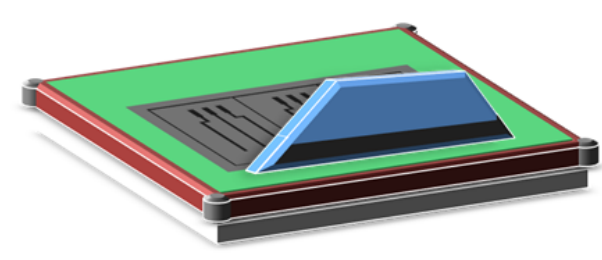

B)

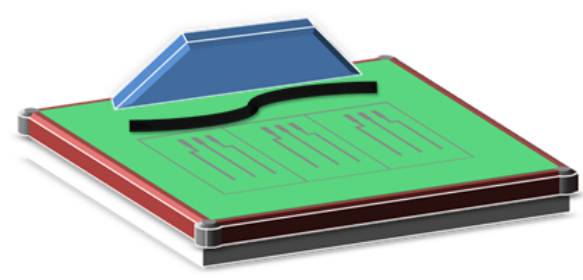

D)

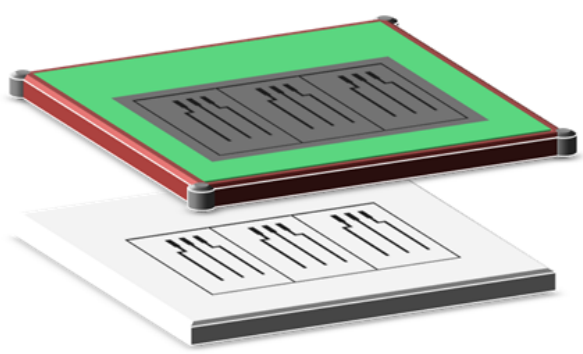

Figure 3.9.- Printing procedure. (A) The substrate is placed under the mesh, which has the desire pattern that will define one or more components of the transducer. (B) The corresponding ink is deposited on the mesh. (C) Straightaway, a squeegee sweeps the ink from one side to another, forcing the ink to pass through the mesh. (D) The ink is deposited on the surface of the substrate.

The inks or pastes, which have different characteristics depending on which component of the sensor is printed, are sequentially deposited on the substrate. In general, the pastes can be divided into conductive and isolating inks [102]. Figure 3.10 represents a SPE and the sequential deposition of the inks that define each of the parts of the device. This sequence can vary depending on the specifications of the ink 
(time and temperature of curing), to avoid possible degradation of the other parts of the transducer.

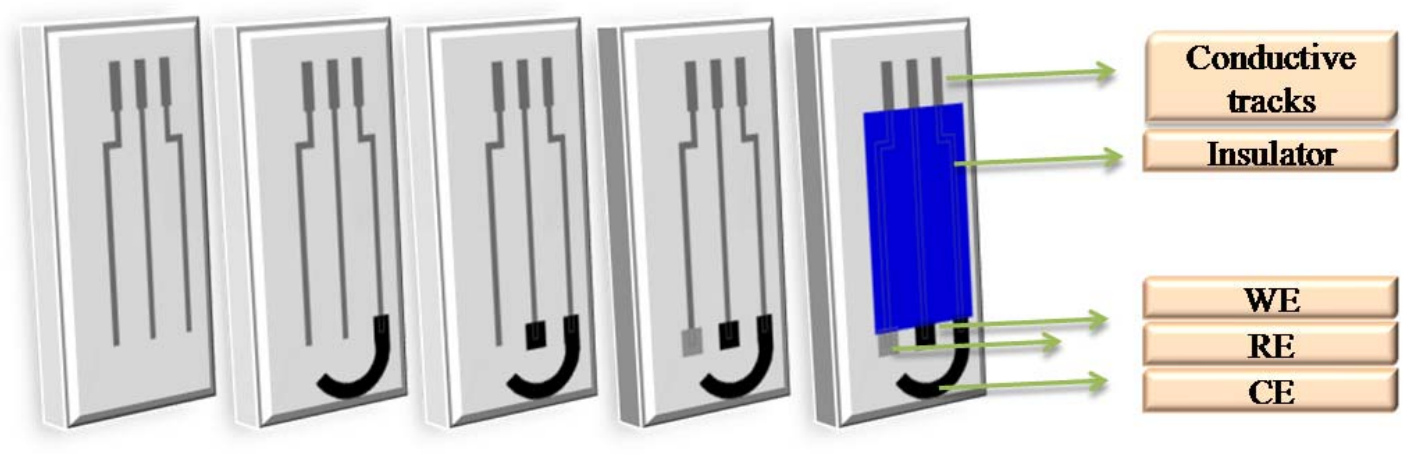

Figure 3.10.- Sequential deposition of the different inks that define an ordinary electrochemical transducer.

As it has been previously mentioned, these devices can be easily modified with bioelements, carbon nanomaterials, metallic nanoparticles or metallic nanofilms in order to improve their sensitivity and/or selectivity.

\subsection{2.- MODIFICATION WITH NANOMATERIALS}

Nanotechnology has become one of the most interesting fields in Analytical Chemistry. This awaken interest for nanomaterials is not only due to its wide variety of sizes, forms and composition, but also due to its properties [103].

Carbon nanomaterials have been employed in electrochemistry research since they are chemically inert, have a wide potential window and are suitable for different types of analysis. 
Owing to their unique properties, carbon nanomaterials have been extensively used for the modification of electrodes. The primarily carbon namomaterials used for this aim are graphene, CNTs, fullerenes $\mathrm{C}_{60}$ and carbon nanofibres (CNFs) (Figure $3.11)$.
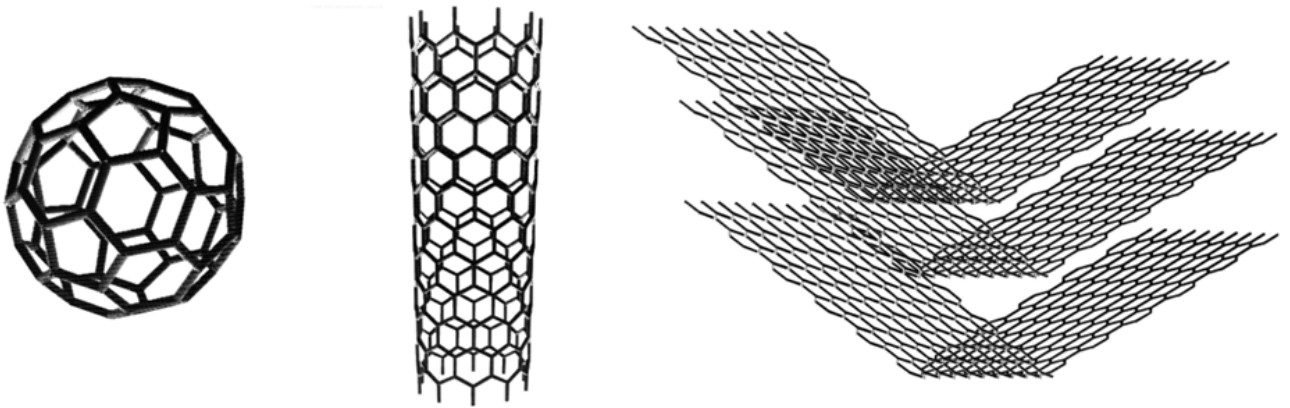

Figure 3.11.- Structure of fullerene, a single-walled CNT and the stacking of graphene sheets to form nanofibres.

CNTs can be divided in two categories: single-walled CNTs and multi-walled CNTs (MWCNTs), being the last formed by concentric cylindrical structures.

CNTs are presented as a new carbon based material with better characteristics than other carbon materials normally used in electrochemistry, such as glassy carbon or graphite [104]. They have been used in different devices due to their structure and their interesting physical properties: excellent thermal conductivity, good mechanical resistance and semi-conductive or conductive nature, which depend on the structure, defects and impurities on the matrix of the material [105].

CNTs have been applied in fields like energy storage, energy conversion and chemical sensors, among others [104]. However, according to the analytical applications, this type of materials has been used in the construction of gas sensors, 
electrochemical detectors and biosensors [106, 107]. Their applications in amperometric and voltammetric methods are especially favourable [107].

The use of CNTs in electrochemical measurements leads to an increase of the active surface of the electrode and an improvement of the electron transference between the electrode and the solution, as well as in the process reversibility [107].

\subsection{3.- ELECTROCHEMICAL BIOSENSORS}

A biosensor is an analytical device that combines a biologically sensitive material with an appropriate transducer system, which transforms the biochemical response into an electrical or optical signal (Figure 3.12) [95].

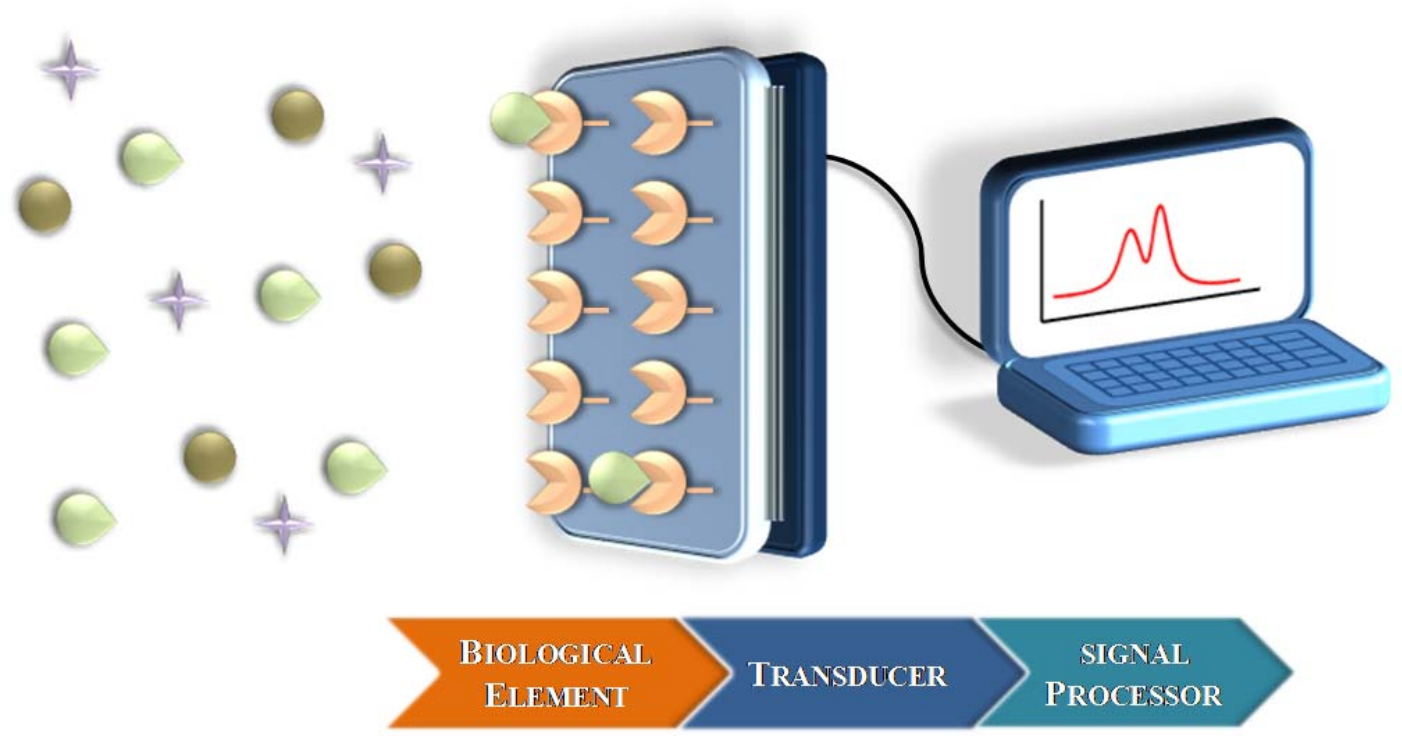

Figure 3.12.- Biosensor scheme.

Electrochemical biosensors are a type of chemical sensors that combine the analytical potential of the electrochemical techniques with the specificity of 
biological processes, due to the biospecific agent immobilised or retained in a suitable electrode [95].

\subsubsection{1.- Biologically sensitive elements}

The most important component in a biosensor is the biological element. The wide variety of bioelements used in biosensors allows its classification in two main groups [108]:

- Catalytic biosensors: enzymes, tissues or microorganisms and biological receptors.

- Affinity biosensors: nucleic acids and antibodies.

Catalytic biosensors have been the most developed ones and, among them all, the enzymatic ones have been technologically advanced due to its low cost and availability in market [109]. Enzymes are catalysts of numerous biochemical reactions, being a lot of them specific to just one substrate.

Organic tissues or microorganisms, which contain several enzymes in their composition, can be directly used as biosensors, although they are not as selective as the purified enzymes [110].

Receptors, which are placed through the lipid bilayer in the cellular membrane, are proteins that present molecular recognition properties, giving affinity and specificity values comparable to the antibody ones.

Antibodies, which bonds specifically to their corresponding antigen, confer high sensitivity to the biosensors. 


\subsubsection{2.- Immobilisation methods}

In order to obtain an effective biosensor, a close contact must be established between the biological element and the transducer. For that reason, the immobilisation method is a crucial stage in the fabrication of these devices, affecting characteristic parameters from the biosensor, such as lifetime and sensitivity [111].

Different types of immobilisation of the biological component have been described: adsorption, microencapsulation, entrapment, cross-linking, covalent bonding or composite.

\section{Adsorption immobilisation}

The immobilisation is produced due to a superficial phenomenon in which the biological element is attached on the transducer surface. This methodology is used in cases where substances have a tendency of being adhered to the surface of the transducer. Although it is one of the simplest procedures to modify the surface of the electrode, its mayor inconvenient is, in general, the weak bond formed between the biologic element and the electrode, giving less stable biosensors.

The adsorption step can be influenced by the variation in temperature, type of biological material and electrode nature [112].

\section{Microencapsulation immobilisation}

In the microencapsulation methodology, the biological material is in contact with the transducer though adsorption processes and then, protected with a membrane permeable to the analyte. Glucose acetate, collagen, Teflon and Nafion are the most common materials used as such membranes. 
In general, this type of immobilisation origins biosensors that are more stable in time than the previous ones, since the enzyme is preserved and is not in direct contact with the solution that contains the analyte. In overall, this physical separation makes the response to be slower, but not less sensitive [99].

\section{Entrapment immobilisation}

In this type of immobilisation, the biological element is trapped in a polymeric compound formed by the electro- or photopolymerisation of its monomer. This polymerisation is executed in presence of the biological element, so that it gets trapped in the matrix formed by the polymer.

This technique is easy to perform from an experimental point of view and does not require a big amount of biological material. Additionally, the biologic component does not suffer any structural alteration. Nevertheless, the created barrier complicates the diffusion of the analyte towards the biocomponet and consequently, the response time of the sensor increases [99].

\section{Cross-linking immobilisation}

This method of immobilisation provides an additional stabilisation to the proteins adsorbed on the transducer surface thanks to the incorporation of a bifunctional compound. In this way, a true chemical bond is formed between both the protein and the binder, forming a net [113].

Glutaraldehyde (GA) is one of the most used bifunctional agents. These biosensors are more stable in time, but the biological component can be denatured by the cross-linking agent [111]. Lysine-rich proteins, such as bovine serum albumin (BSA), are frequently added together with the biorecognition element to prevent this effect [99]. 


\section{Covalent bond immobilisation}

The covalent bond established between the biological component and the transducer is a more complicated immobilisation method than the previous ones, but it origins more stable biosensors. It is based on a previous activation of chemical groups from the surface of the electrode, which will react with the nucleophilic groups of the biological element. This method leads to an orientated immobilisation and, therefore, these biosensors lead to more reproducible results [112].

\section{Composite}

The biological element can be homogenously mixed with the paste that will be part of the working electrode of the transducer. The stability of the biosensor will depend on the nature of the bioelement, the composition of the paste and the ink curing process [102].

\subsubsection{3.- Miniaturised amperometric enzymatic biosensors}

Electrochemical biosensors have acquired special importance in several industrial applications due to the use of miniaturisation technologies in the manufacture of electrodes, which facilitates mass production of biosensors, reducing fabrication costs and assuring a good reproducibility [114].

One of the most promising electrochemical biosensors in terms of sensitivity is the amperometric one, which combines the high selectivity of enzymes with the simplicity of amperometric transducers. These biosensors monitor faradaic currents that are the result of electron exchanges between the biological system and the electrode, which maintain an appropriate constant potential [108]. Thus, the enzyme interacts with the analyte, producing species that can be oxidised or reduced in the 
working electrode. Therefore, the produced current is proportional to the concentration of the analyte [111].

Amperometric enzymatic biosensors can be classified in three main groups depending on the mechanism of the electron transfer between the bioelement and the transducer (Figure 3.13) [95, 115]:

- First generation biosensors:

The monitoring of the signal is performed thanks to the detection of the cofactor or one of the products of the enzymatic reaction.

- Second generation biosensors:

The enzymatic reaction is mediated by a redox species, which improves the electron exchange between the enzyme and the transducer.

- Third generation biosensors:

The enzymatic reaction is monitored through direct electron exchange between the enzyme and the electrode surface.

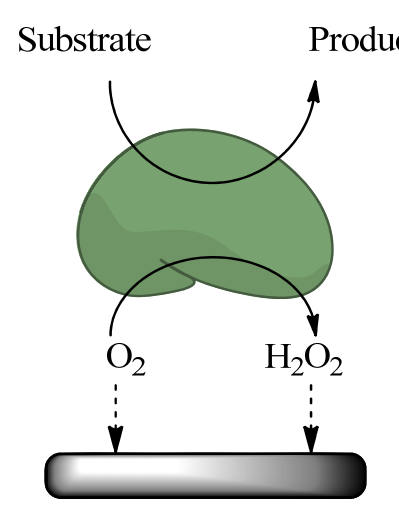

A

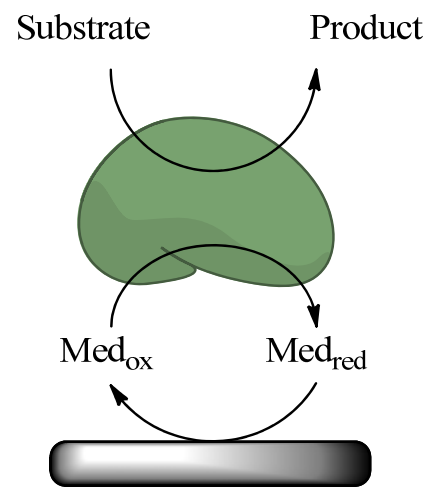

B

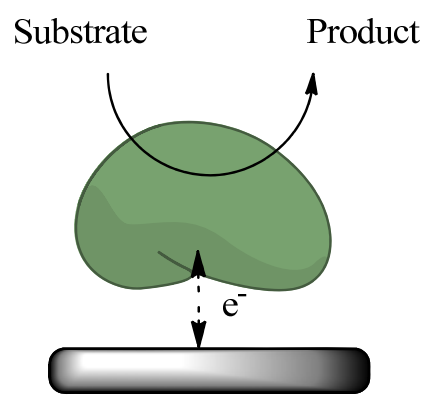

C

Figure 3.13.- Representation of the three types of amperometric enzymatic biosensors. First $(A)$, second (B) and third (C) generation biosensors. 


\section{3.- ENZYMATIC SYSTEMS}

Human body is every day in contact with a broad variety of xenobiotics, not only from food components but also from pharmaceuticals and environmental toxins. The detoxification of these substances is carried out by complex enzymatic mechanisms that are performed in different parts of the body [116]. These enzymatic mechanisms are divided into two main phases [117]:

- Phase I, in which xenobiotics are biotransformed into an inactive compound or a toxic one, with the same activity or even more active than the initial substance.

- Phase II, in which the metabolite from phase I is conjugated with an endogenous substrate such as gluconic acid, acetic acid or sulphuric acid, in order to facilitate its excretion.

The enzymatic system CYP450 is mainly responsible for phase I mechanism. This mechanism can be slow down or inhibited by some xenobiotics, which can be substrates from one enzyme, but inhibitors from other.

\subsection{1.- CYTOCHROME P450}

CYP450 system was discovered at the end of the 1950s decade by David Garfinkel and Martin Klingenberg [118]. CYP450 was initially thought to be a single enzyme, but soon enough multiple forms of this enzyme were found. Each of these forms differs from the rest in its substrate selectivity and certain physicochemical characteristics [118].

This group of enzymes can be found mainly in liver and intestinal mucosa, controlling and metabolising a wide range of endogenous substances and xenobiotic compounds. This system has a very high affinity for carbon monoxide. For that 
reason, when it interacts with such gas, a reduced compound is formed and presents a Soret band in the ultraviolet-visible spectrum. Its maximum absorption band is set at $450 \mathrm{~nm}$, which gives the name of CYP450 to these enzymes [119].

\subsubsection{1.- CYP450: structure and function}

Porphine is a tetrapyrrolic macrocycle that acts like a four-position chelating ligand. All derivatives from porphine have the name of porphyrin. One of the most important porphyrins is protoporphyrin IX, which is part of the heme group (Figure 3.14) [120].<smiles></smiles>

A)

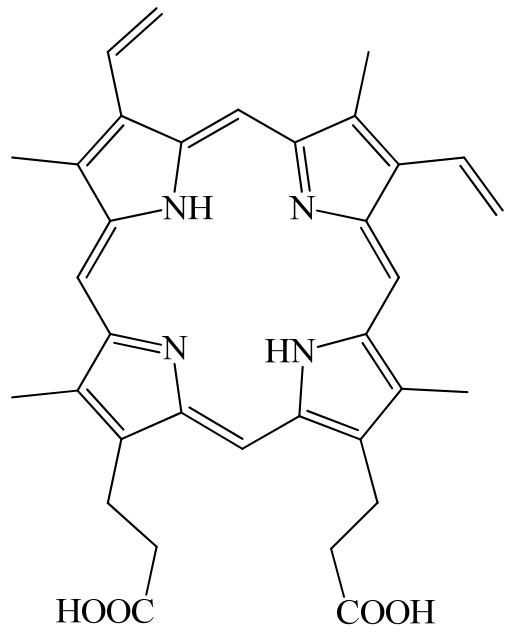

B)

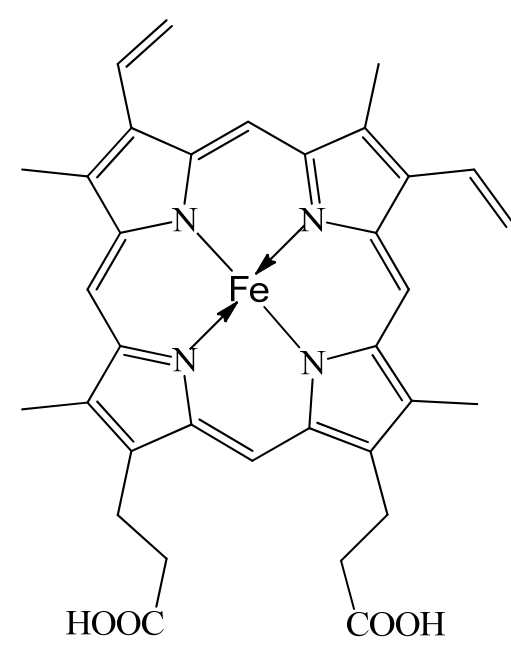

C)

Figure 3.14.- Macrocyclic structures of porphine (A), protoporphyrin $I X(B)$ and heme group $(C)$.

CYP450s are hemeproteins that contain one single heme prosthetic group. This group is formed by an iron atom in a protoporphyrin IX. The iron atom is linked to a cysteine residue, which is in the proximity of a terminal carbon from the polypeptide chain of the apoprotein. These enzymes act in the mitochondrial electron 
transport, being associated to the redox pair $\mathrm{Fe}^{(\mathrm{III})} / \mathrm{Fe}^{(\mathrm{III})}$, and weigh around 12000 Daltons (Figure 3.15) [118].

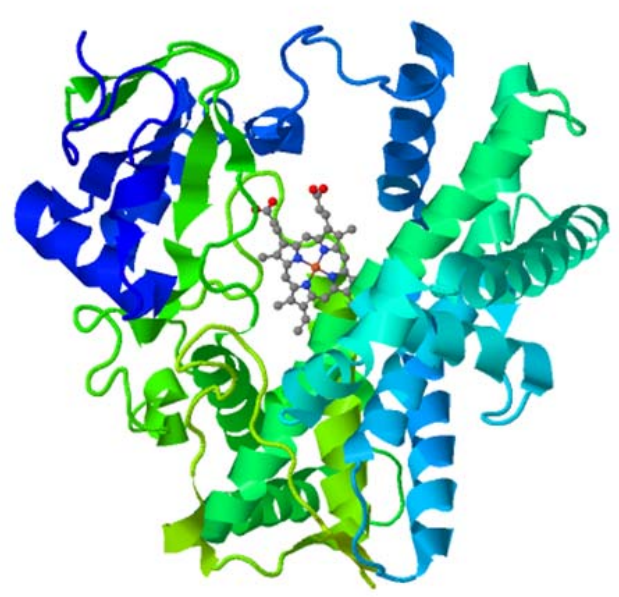

A)

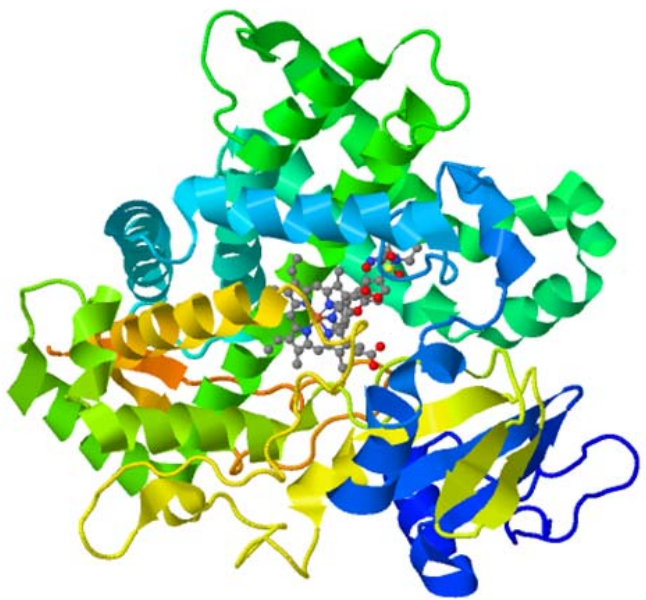

B)

Figure 3.15.- Structural conformation of mammal CYP2B4 [121] (A) and human CYP2D6 [122] (B).

Small and crucial changes within the catalytic centre of the CYP450s are what differentiate the diverse cytochromes. These variations modify the catalytic activity, the substrate specificity, the redox potential, the spin-state equilibrium and the spectral properties $[118,119]$.

\subsubsection{2.- Cytochrome P450 subfamilies}

As it has been previously said, CYP450 is not a single identity, but a wide group of enzymes (more than 1000 different forms) [119]. Five CYP450 isoforms $(1 \mathrm{~A} 2,2 \mathrm{C} 9,2 \mathrm{C} 19,2 \mathrm{D} 6$ and $3 \mathrm{~A} 4)$ are responsible for approximately $95 \%$ of the drug metabolism that is mediated by this enzyme in the human body. [123]. For instance, CYP450 2B subfamily and CY2D6 are the enzymes responsible for the toxic biotransformation of drugs such as cocaine and codeine, respectively [119]. 


\section{CYP450 2B subfamily}

CYP450 2B subfamily is the main hepatic CYP450 isoform in animals but it is poorly expressed in humans (CYP450 2B6 isoform). This subfamily is inducible by phenobarbital and other barbiturates. Substrates like cocaine, nicotine, phenobarbital and testosterone, among others, are metabolised by this enzyme [119].

\section{CYP450 2D subfamily}

CYP2D6 is one of the isoforms that plays a very important role in the detoxification of xenobiotics in human body, although it is expressed at lower levels in the liver by comparison with the rest of this family of enzymes [124]. This enzyme metabolises over 50 drugs clinically used and xenobiotics that contain a highly protonated nitrogen atom at physiological $\mathrm{pH}$, such as codeine, dextromethorphan, imipramine and metoprolol, among others $[119,124]$.

\subsubsection{3.- Catalytic cycle}

CYP450 presents a great functional versatility, fact that is reflected in the wide variety of catalytic processes that can be carried out and also, in the wide range of substrates that can be metabolised [125].

The oxidative biotransformations that are catalysed by the CYP450 are aromatic and aliphatic hydroxylations, $\mathrm{N}$ - and $\mathrm{S}$-oxidations, epoxidations, $\mathrm{O}-\mathrm{,} \mathrm{N}$ - and $S$-dealkylations, deaminations, desulfurations, dehalogenations and dehydrogenations [126].

According to the CYP450 catalytic cycle (Figure 3.16), the organic substrate (R-H) is firstly attached to the metallic centre of the heme group producing a conformational change in the protein structure, around the iron atom (A). An 
electrode is then transferred to the system in order to reduce the iron atom from the ferric state $\left(\mathrm{Fe}^{3+}\right)$ to the ferrous one $\left(\mathrm{Fe}^{2+}\right)(\mathrm{B})$. This new state and the high affinity of the iron for the oxygen permit the union of an oxygen molecule to the metallic site (C). A second reduction leads to a superoxide formation (D), in which an internal electronic transference is produced between the iron and the superoxide to obtain the active species $\left(\mathrm{Fe}^{3+}-\mathrm{O}\right)(\mathrm{E})$. This compound is the responsible for the substrate transformation into the oxidised product (F-G) [119].

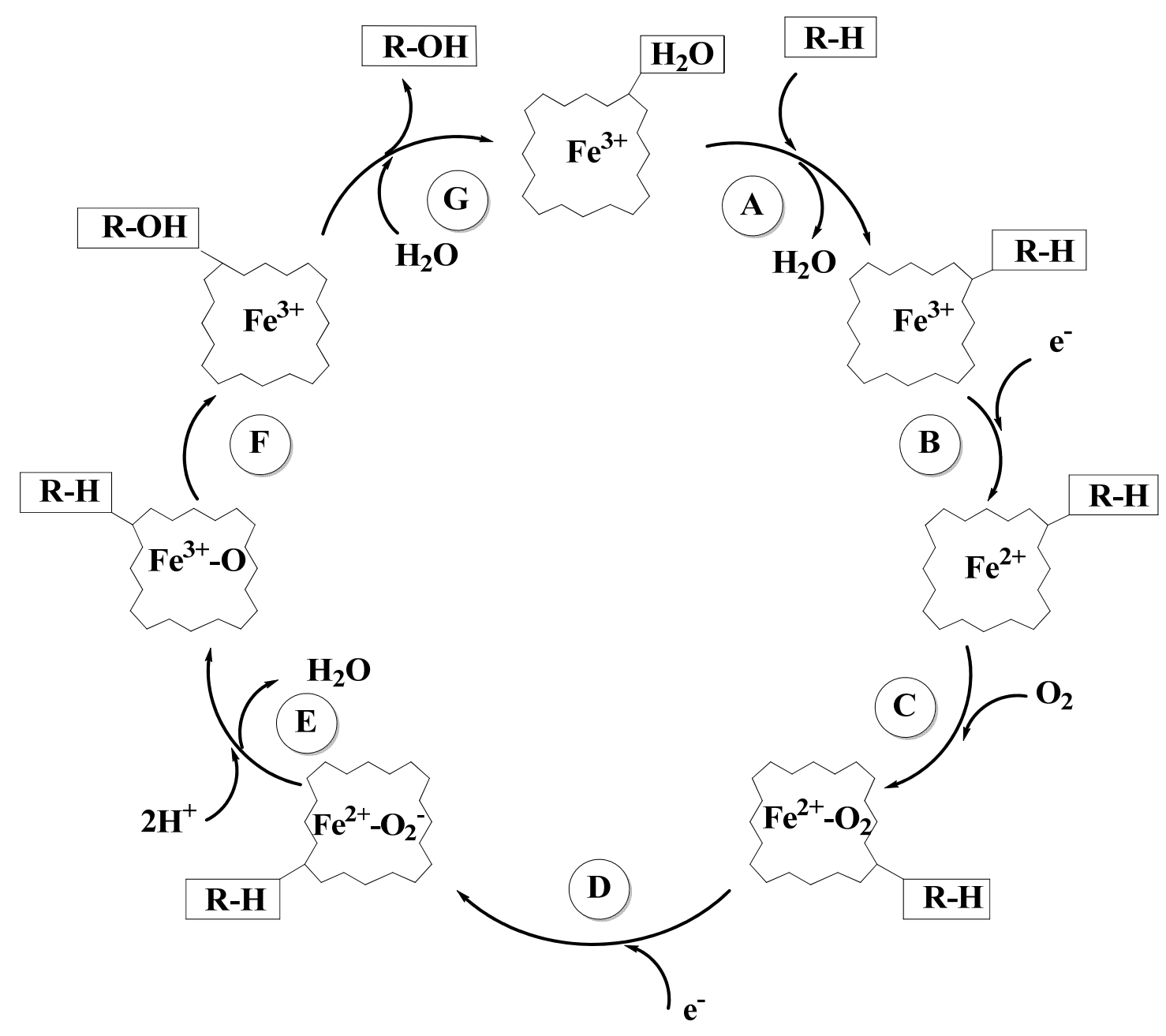

Figure 3.16.- CYP450 generic catalytic cycle.

In summary, the reaction between the cytochrome and its substrate $(\mathrm{R}-\mathrm{H})$ requires the combination of oxygen with the organic substrate in order to give a 
monoxygenated metabolite. Additionally, two electron equivalents are supplied by a cofactor (nicotinamide adenine dinucleotide (NADH) or NADPH, depending on the CYP450 system) and transferred in two consecutive stages.

In the case of the transformation of cocaine, the last two steps (F-G) from the cycle can be explained through the following sequence in which cocaine is transformed in norcocaine, giving formaldehyde as subproduct of the metabolism (Figure 3.17) [127].

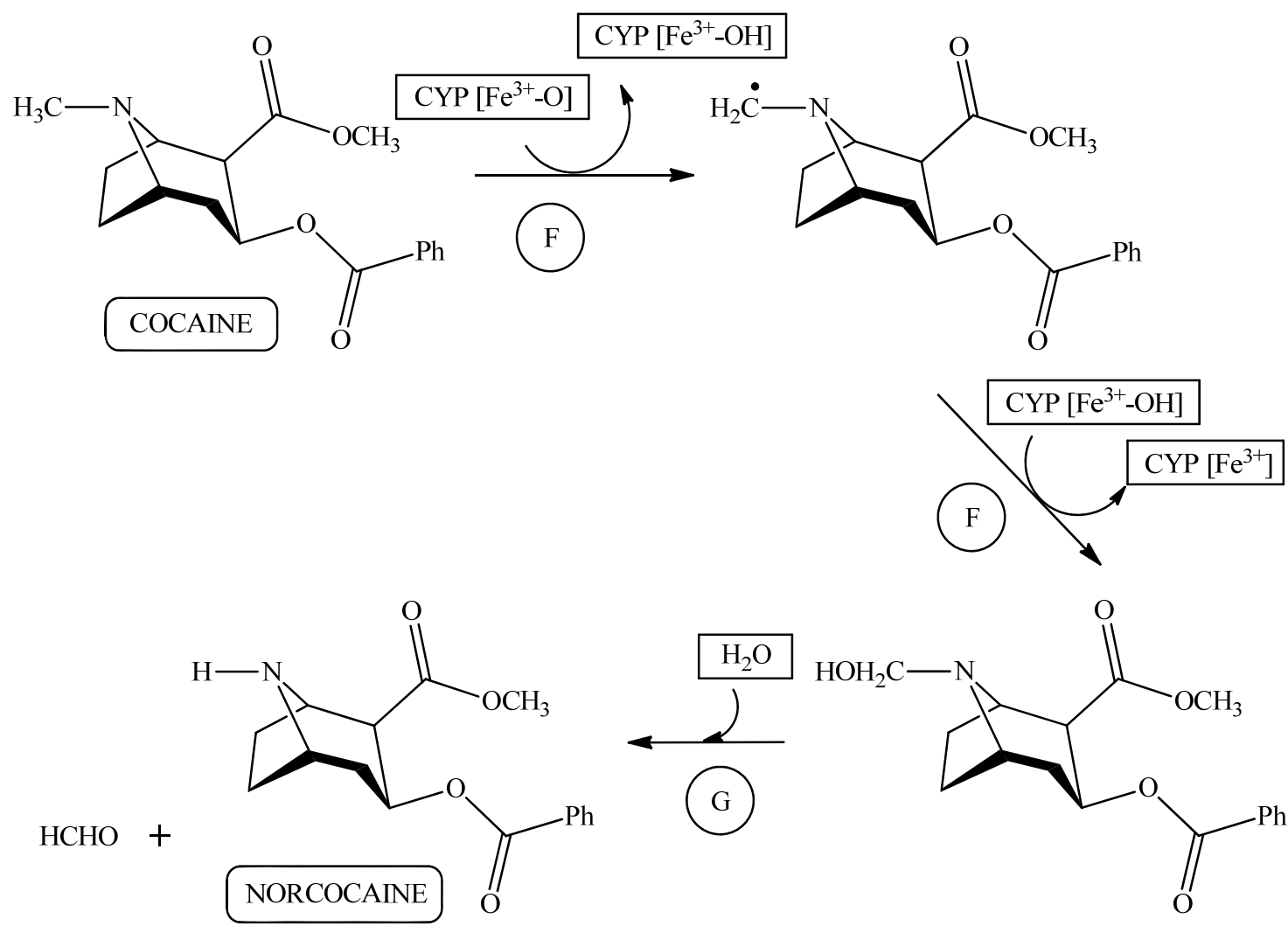

Figure 3.17.- Cocaine demethylation mediated by CYP450 2B subfamily to obtain norcocaine. $F$ and $G$, steps of the CYP450 generic catalytic cycle.

As it has been said in section 3.1.1.2, the $N$-dealkylation of cocaine by CYP450 triggers its hepatotoxicity. Moreover, once norcocaine is generated, further metabolism produces $N$-hydroxynorcocaine and this, in turn, generates norcocaine 
nitroxide and norcocaine nitrous ion. These last two metabolites are responsible for the hepatotoxicity of this illegal drug $[8,128]$.

In the same way, codeine transformation by CYP2D6 leads to the formation of morphine and also formaldehyde as subproduct of the biological reaction (Figure $3.18)$.

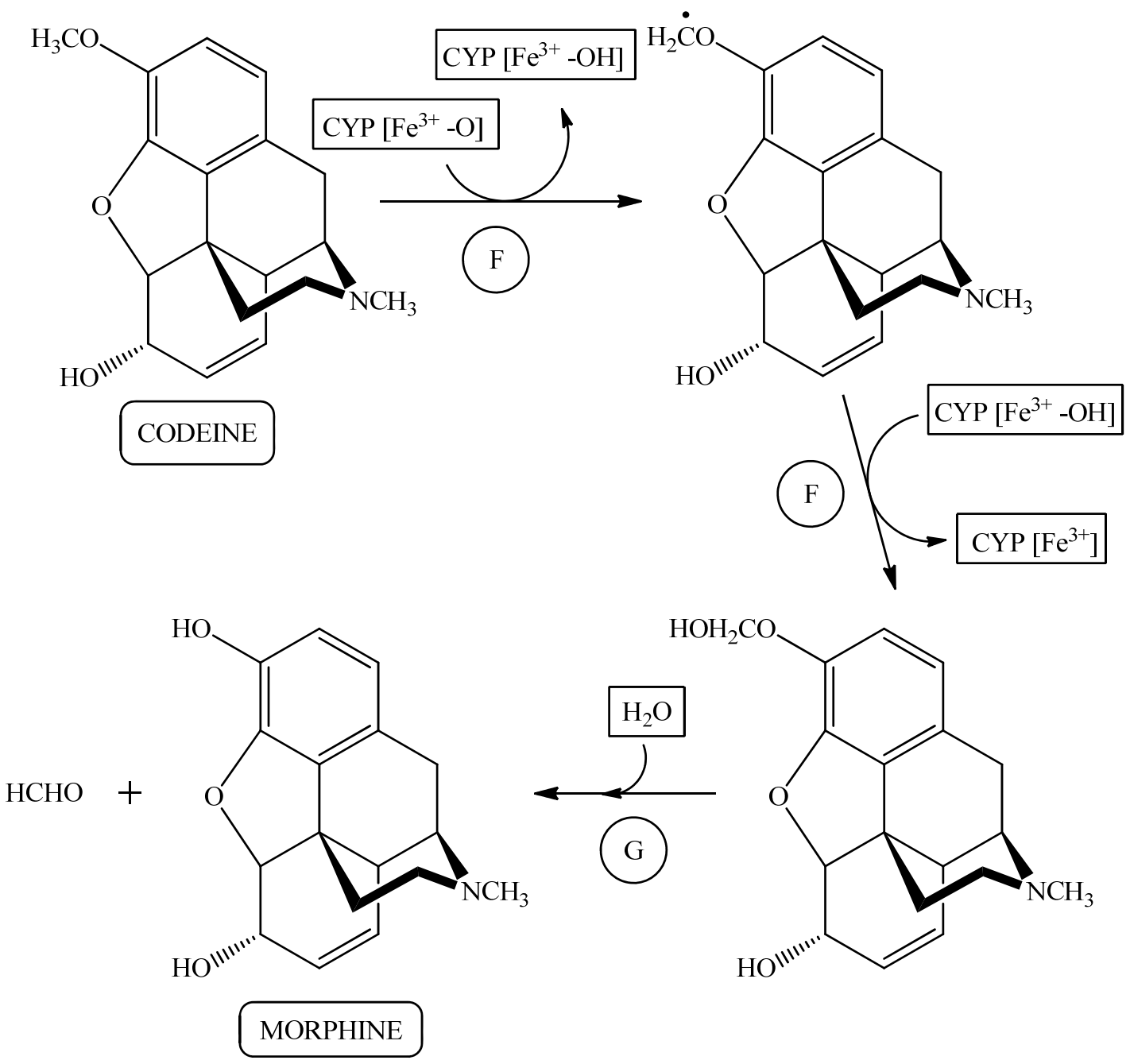

Figure 3.18.- Codeine biotransformation into morphine by CYP2D6. $F$ and $G$, steps of the CYP450 generic catalytic cycle. 
Once codeine is metabolised into morphine, this one is transformed in two different glucoronidic forms: morphine-3-glucuronide (M3G) and morphine-6glucuronide (M6G). While M6G exhibits even greater analgesic properties than morphine, M3G is thought to produce the side effects of this drug [129].

As it has been previously said, each enzyme can metabolise more than one substrate, as well as a substrate can be metabolised by more than one enzyme. Thus, cocaine is $N$-demethylated by both CYP2B4 and CYP450 3A4 isoforms (Figure 3.2) $[119,130]$. Meanwhile, codeine can be $N$-demethylated by CYP3A4 and $O$ demethylated by CYP2D6, leading to different products (Figure 3.4) [130].

\subsection{2.- ACETYLCHOLINESTERASE}

Acetylcholinesterases along with butyrylcholinesterases are the two main groups of cholinesterases. These enzymes transform the neurotransmitter acetylcholine into choline and acetic acid and have a special interest in fields such as toxicology, pharmacology and neurobiology (Figure 3.19) [131-133].

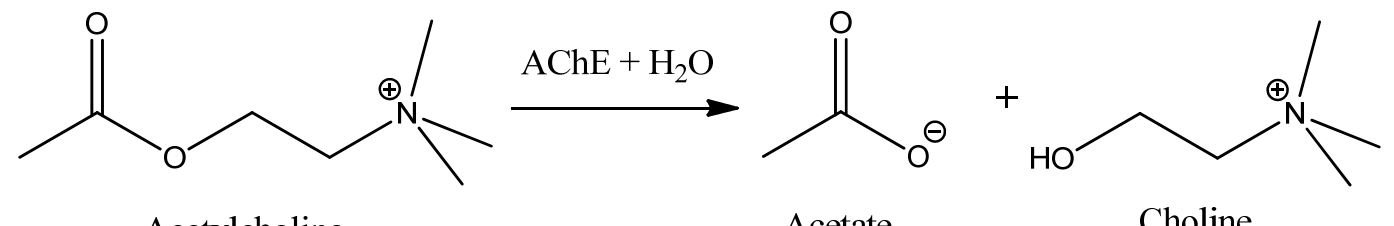

Acetylcholine

Acetate

Choline

Figure 3.19.- Transformation of acetylcholine by AChE.

\subsubsection{1.- Acetylcholinesterase: structure and function}

AChE is a polymorphic enzyme that consists of four globular catalytic subunits (Figure 3.20) [134]. Its active centre is formed by two subsites, the anionic 
binding site and the esteratic site [135]. Besides, AChE is a serine hydrolase that plays a very important role in the cholinergic transmission.

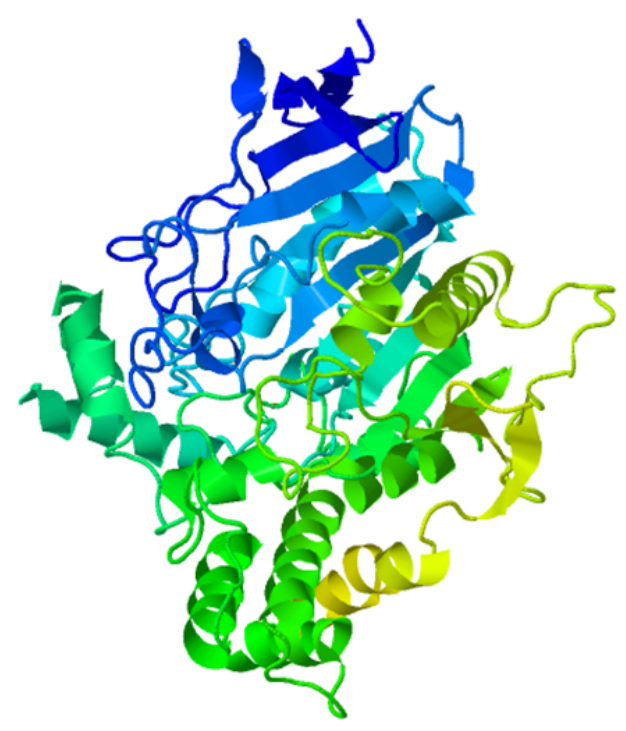

Figure 3.20.- Structural conformation of AChE [136].

Nerve impulses stimulate the release of acetylcholine, which transmits the stimulus across the synapse from a nerve cell to a muscle one, where it binds to the acetylcholine receptor [137]. After the acetylcholine arrives to the other side of the synapse and passes the information, the AChE is responsible for hydrolysing the neurotransmitter, which is recycled to form new neurotransmitters for the next message [136, 138].

\subsubsection{2.- Acetylcholinesterase inhibition}

Several compounds have been described as AChE inhibitors, such as mercury, procaine, cocaine, nicotine, morphine, codeine, caffeine, urea, organophosphorous compounds, etc. [139]. 
$\mathrm{AChE}$ inhibitors can be divided in reversible and irreversible inhibitors, containing most of them at least one positively charged nitrogen group [131].

The inhibition of this enzyme gives, as a result, the accumulation of the neurotransmitter at the synapse. This accumulation leads to the blockage of the neurotransmission and even the death of the individual. Consequently, this inhibition can produce damages in nervous, respiratory and muscular functions [137]. For instance, pesticides are based on the inhibition of this enzyme producing the insect death [140]. Nevertheless, medical studies are nowadays focused on the inhibition of this enzyme for the treatment of different neuromuscular disorders [135], especially in an attempt to invert the symptoms of Alzheimer's disease. People, who suffer from this degenerative disease, lose many nerve cells. Selecting an inhibitory drug, which could block the activity of the enzyme, would raise the levels of the neurotransmitter acetylcholine. This inhibition can potentiate cholinergic neurotransmission and strengthen the nerve signals that remain, which in turn produces improvement in memory and goal-direct thought $[136,141]$.

\subsubsection{3.- Types of inhibition}

Inhibition is an important process that controls the biological activity of cells. The study of the inhibition not only has interest in controlling the cells but also in knowing the behaviour of the enzymes. Enzymes can be inhibited through different procedures.

When the enzymatic kinetics is represented in terms of reaction speed versus the concentration of the substrate, the graphical representation describes a hyperbole (Figure 3.21).

The enzymatic reaction can be expressed as the following scheme:

$$
E+S \leftrightarrow E S \rightarrow P+E
$$


where $E$ is the enzyme, $S$ the substrate and $P$ the product of the enzymatic transformation.

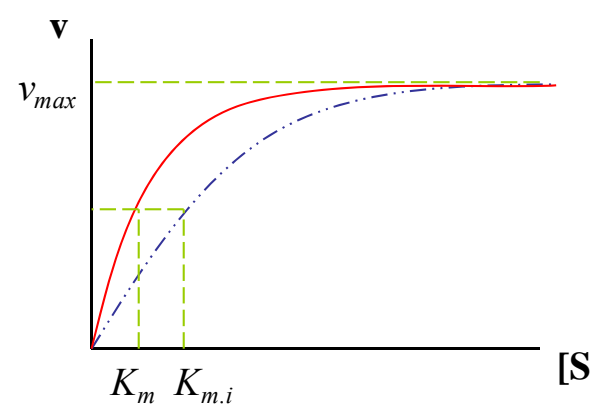

(A)

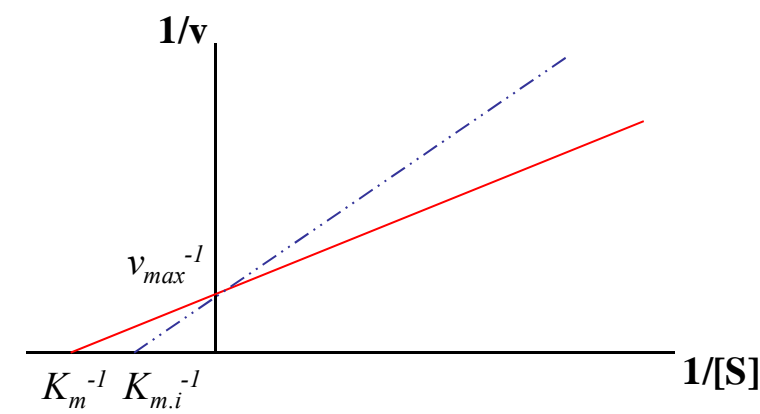

(B)

Figure 3.21.- Kinetics representation (A) and Lineweaver-Burk plot (B) of a competitive inhibition.

The Michaelis-Menten linear equation (Eq. 3.1) describes the reaction rate versus the substrate concentration of a great variety of enzymatic reactions. Nonetheless, the Lineweaver-Burk plot (Eq. 3.2), which is a graphical representation used to calculate the kinetic parameters of the interaction between an enzyme and the substrate, is frequently used.

$$
\text { (Eq.3.1) } \quad v=v_{\max } \frac{[S]+K_{m}}{[S]} \quad \text { (Eq.3.2) } \quad \frac{1}{v}=\frac{1}{v_{\max }}+\frac{1}{K_{m}}[S]
$$

where $v_{\max }$ is the maximum speed of a reaction catalysed by an enzyme when it is totally saturated by its substrate and $K_{m}$ (Michaelis constant) is the concentration of substrate that is necessary to achieve half the $v_{\max }$ (or saturate half of the active sites). It also gives information about the affinity of the enzyme for the substrate. According to this, two main types of inhibition are described and characterised depending on the $v_{\max }$ and $K_{m}$, namely reversible and irreversible inhibition. 


\subsubsection{1.- Reversible inhibition}

In the reversible inhibition, the inhibitory molecule paralyses or slows down the enzymatic activity, but this action is reversible and the inhibitor can be separated from the enzyme, restoring the enzyme activity to its initial value. The bonds that are established between the enzyme and the inhibitor are non-covalent.

Depending on the binding site, inhibitors can be competitive and noncompetitive. However, there are variations in the way that the different inhibitors bind to the enzyme or to the system enzyme-substrate [142].

\section{Competitive inhibitor}

The inhibitor and the substrate compete for the active centre of the enzyme, so that the number of substrate molecules that are capable of attaching to the active site decreases. The competitive inhibition is reversible when increasing the substrate concentration.

Kinetically speaking, the $v_{\max }$ of the enzyme does not vary in presence of a competitive inhibitor, but the $K_{m}$ increases with the amount of inhibitor since the affinity for the substrate is less (Figure 3.21).

\section{Non-competitive inhibitor}

In this case, the substrate and the inhibitor do not compete for the active centre. The inhibitor is attached to the enzyme through a site different from the active site, so that the inhibitor modifies the structure of the active centre and makes the enzyme less capable of transforming the substrate. This type of inhibition does not reverse when the concentration of substrate is increased. 
The affinity of the enzyme for the substrate $\left(K_{m}\right)$ does not change, but the $v_{\max }$ is decreased proportionally with the presence of the inhibitor (Figure 3.22).

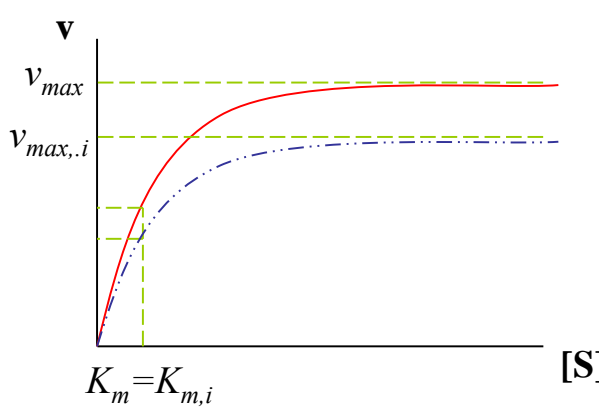

(A)

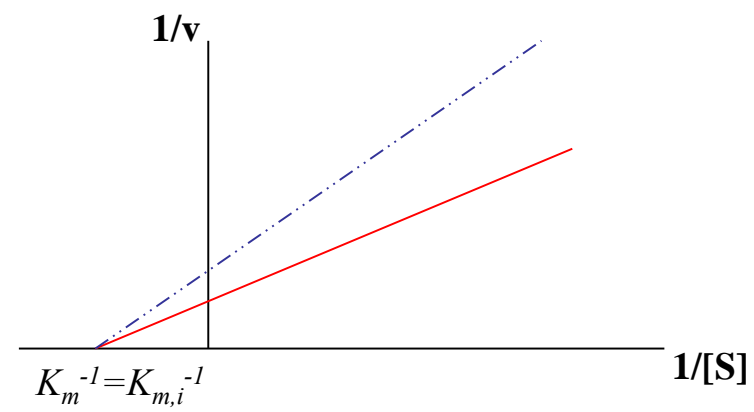

(B)

Figure 3.22.- Kinetics representation (A) and Lineweaver-Burk plot (B) of a non-competitive inhibition.

\section{Uncompetitive inhibitor}

The inhibitor binds to the system enzyme-substrate, but it is not able to bind to the free enzyme [143]. This type of inhibition does not reverse by increasing the substrate concentration.

Lineweaver-Burk plot shows parallel lines and the kinetic parameters $\left(v_{\max }\right.$ and $K_{m}$ ) decrease by the same factor (Figure 3.23).

\section{Mixed inhibitor}

As the non-competitive inhibitor, the mixed inhibitor binds at a different site from the active centre, which provokes changes in the structure of the enzyme, 
leading to a decrease in the enzymatic activity. The inhibition cannot be overcome by high substrate concentration [142].

In the Lineweaver-Burk plot, while the $v_{\max }$ decreases, $K_{m}$ increases (Figure $3.24)$.

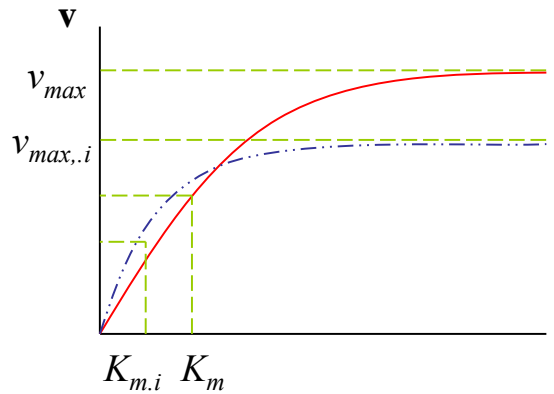

(A)

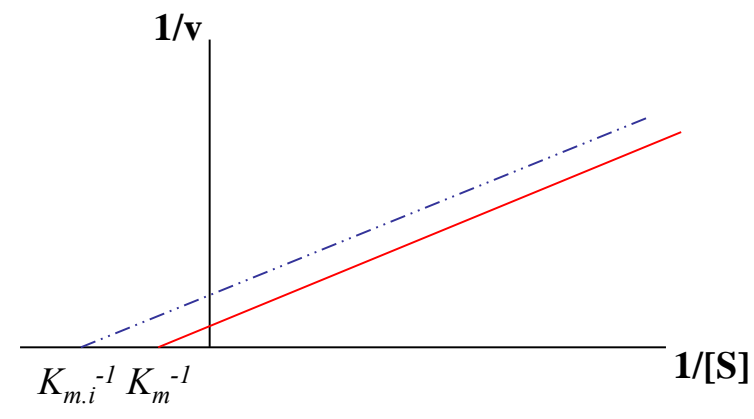

(B)

Figure 3.23.- Kinetics representation (A) and Lineweave-Burk plot (B) of a uncompetitive inhibition.

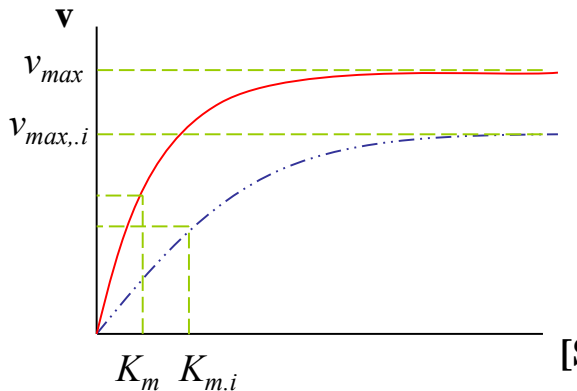

(A)

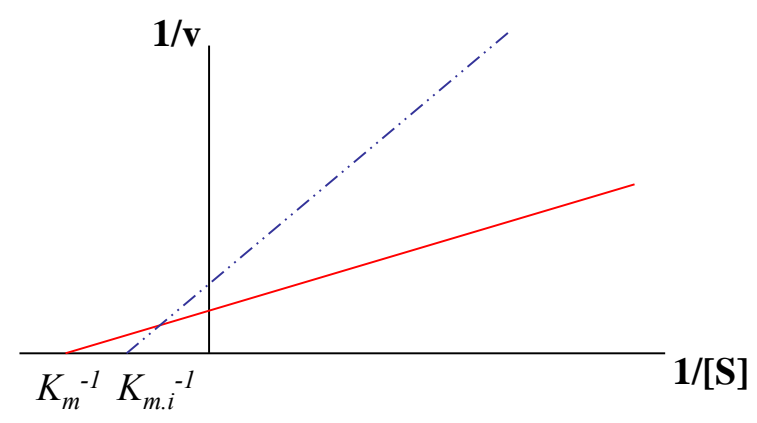

(B)

Figure 3.24.- Kinetics representation (A) and Lineweaver-Burk plot (B) of a mixed inhibition. 


\subsubsection{2.- Irreversible inhibition}

The molecules bind covalently to the enzyme, avoiding its freedom without damaging the enzyme. Consequently, the effect of an irreversible inhibitor is permanent [144].

\section{4.- REFERENCES}

1. Pascual Simón, J.R. and B.L. Fernández Rodríguez, Consideraciones Generales sobre Drogas de Abuso. Medisan 6, 2002, p. 58-71.

2. Goldstein, R.A., C. DesLauriers, and A.M. Burda, Cocaine: History, Social Implications, and Toxicity-A Review. Disease-a-Month 55, 2009, p. 6-38.

3. Pascual, C., et al., Drogas: + información - riesgos. 2001: Plan Nacional sobre Drogas, Ministerio de Interior - Gobierno de España.

4. Niemann, A., Über eine neue organische Base in den Cocablättern. Archiv der Pharmazie 153, 1860, p. 288-292.

5. Dillane, D. and B.T. Finucane, Local anesthetic systemic toxicity. Canadian Journal of Anesthesia 57, 2010, p. 368-380.

6. Grzybowski, A., Cocaine and the eye: A historical overview. Ophthalmologica 222, 2008, p. 296-301.

7. Komorsky-Lovric, S., I. Galic, and R. Penovski, Voltammetric determination of cocaine microparticles. Electroanalysis 11, 1999, p. 120-123.

8. Kloss, M.W., G.M. Rosen, and E.J. Rauckman, Cocaine-mediated hepatotoxicity. A critical review. Biochemical Pharmacology 33, 1984, p. 169-173.

9. Shannon, M., Clinical toxicity of cocaine adulterants. Annals of Emergency Medicine 17, 1988, p. 1243-1247. 
10. UNODC, World Drug Report, (United Nations publication). 2012: Vienna.

11. Doweiko, H.E., Concepts of chemical dependency. 8th ed. 2012, Belmont, CA (USA): Brooks/Cole.

12. Evrard, I., S. Legleye, and A. Cadet-Taïrou, Composition, purity and perceived quality of street cocaine in France. International Journal of Drug Policy 21, 2010, p. 399-406.

13. Stout, P.R. and L.J. Farrel, Opioids - Effects on Human Performance and Behavior. Forensic Science Review 15, 2002, p. 29-59.

14. Trescot, A.M., et al., Opioid pharmacology. Pain Physician 11, 2008, p. S133-S153.

15. Robiquet, P.J., Nouvelles observations sur les principaux produits de l'opium. Annales de Chimie et de Physique 51, 1832, p. 225-267.

16. López Castellano, A.C., L. Moreno Royo, and V. Villagrasa Sebastián, Manual de Farmacología: Guía para el uso racional del medicamento. 2006, Madrid: Elsevier.

17. Velázquez, B.L., et al., Farmacología Básica y Clínica. 18th ed. 2008, Madrid: Médica Panamericana.

18. Garrido, J.M.P.J., et al., Voltammetric oxidation of drugs of abuse: II. Codeine and metabolites. Electroanalysis 16, 2004, p. 1427-1433.

19. Frost, J., et al., Investigation of morphine and morphine glucuronide levels and cytochrome P450 isoenzyme 2D6 genotype in codeine-related deaths. Forensic Science International 220, 2012, p. 6-11.

20. Vidal Vademecum Spain S.A.; Available from: http://www.vademecum.es.

21. Garrido, J.M.P.J., et al., Electroanalytical determination of codeine in pharmaceutical preparations. Analytical Letters 35, 2002, p. 2487-2498. 
22. Mali, N., M. Karpe, and V. Kadam, A review on biological matrices and analytical methods used for determination of drug of abuse. Journal of Applied Pharmaceutical Science 1, 2011, p. 58-65.

23. Maurer, H.H., Multi-analyte procedures for screening for and quantification of drugs in blood, plasma, or serum by liquid chromatography-single stage or tandem mass spectrometry (LC-MS or LC-MS/MS) relevant to clinical and forensic toxicology. Clinical Biochemistry 38, 2005, p. 310-318.

24. Janicka, M., A. Kot-Wasik, and J. Namieśnik, Analytical procedures for determination of cocaine and its metabolites in biological samples. TrAC Trends in Analytical Chemistry 29, 2010, p. 209-224.

25. Pal, R., et al., Illicit drugs and the environment - A review. Science of the Total Environment 463-464, 2013, p. 1079-1092.

26. Cruces-Blanco, C. and A.M. García-Campaña, Capillary electrophoresis for the analysis of drugs of abuse in biological specimens of forensic interest. TrAC - Trends in Analytical Chemistry 31, 2012, p. 85-95.

27. Pascali, J.P., F. Bortolotti, and F. Tagliaro, Recent advances in the application of CE to forensic sciences, an update over years 2009-2011. Electrophoresis 33, 2012, p. 117-126.

28. Abedul, M.T.F., et al., Voltammetric determination of cocaine in confiscated samples. Electroanalysis 3, 1991, p. 409-412.

29. Baker, B.R., et al., An electronic, aptamer-based small-molecule sensor for the rapid, label-free detection of cocaine in adulterated samples and biological fluids. Journal of the American Chemical Society 128, 2006, p. 3138-3139.

30. de Oliveira, L.S., et al., Voltammetric analysis of cocaine using platinum and glassy carbon electrodes chemically modified with Uranyl Schiff base films. Microchemical Journal 110, 2013, p. 374-378. 
31. de Oliveira, L.S., et al., Voltammetric determination of cocaine in confiscated samples using a carbon paste electrode modified with different $\mathrm{HOO}_{2}(\mathrm{X}$ MeOSalen) $\left.\left(\mathrm{H}_{2} \mathrm{O}\right)\right] \cdot \mathrm{H}_{2} \mathrm{O}$ complexes. Sensors (Switzerland) 13, 2013, p. 76687679.

32. Elnemma, E.M., M.A. Hamada, and S.S.M. Hassan, Liquid and poly (vinyl chloride) matrix membrane electrodes for the selective determination of cocaine in illicit powders. Talanta 39, 1992, p. 1329-1335.

33. Fernández-Abedul, M.T. and A. Costa-García, Flow injection analysis with amperometric detection of cocaine in confiscated samples. Analytica Chimica Acta 328, 1996, p. 67-71.

34. Garrido, J.M.P.J., et al., Spectroscopic and electrochemical studies of cocaine-opioid interactions. Analytical and Bioanalytical Chemistry 388, 2007, p. 1799-1808.

35. Kalvoda, R., Absorptive accumulation in stripping voltammetry. Analytica Chimica Acta 138, 1982, p. 11-18.

36. Oiye, E.N., et al., Voltammetric determination of cocaine in confiscated samples using a cobalt hexacyanoferrate film-modified electrode. Forensic Science International 192, 2009, p. 94-97.

37. Pavlova, V., et al., Studying electrode mechanism and analytical determination of cocaine and its metabolites at the mercury electrode using square-wave voltammetry. Analytica Chimica Acta 512, 2004, p. 49-56.

38. Schwartz, R.S. and K.O. David, Liquid chromatography of opium alkaloids, heroin, cocaine, and related compounds using electrochemical detection. Analytical Chemistry 57, 1985, p. 1362-1366.

39. Watanabe, K., et al., New cocaine-selective membrane electrode. Analytica Chimica Acta 316, 1995, p. 371-375. 
40. Du, Y., et al., Solid-state probe based electrochemical aptasensor for cocaine: A potentially convenient, sensitive, repeatable, and integrated sensing platform for drugs. Analytical Chemistry 82, 2010, p. 1556-1563.

41. Freeman, R., et al., Self-assembly of supramolecular aptamer structures for optical or electrochemical sensing. Analyst 134, 2009, p. 653-656.

42. Golub, E., et al., Electrochemical, Photoelectrochemical, and Surface Plasmon Resonance Detection of Cocaine Using Supramolecular Aptamer Complexes and Metallic or Semiconductor Nanoparticles. Analytical Chemistry 81, 2009, p. 9291-9298.

43. He, J.L., et al., Electrochemical aptameric sensor based on the Klenow fragment polymerase reaction for cocaine detection. Biosensors and Bioelectronics 26, 2011, p. 4222-4226.

44. Hua, M., et al., Quantum dots as immobilized substrate for electrochemical detection of cocaine based on conformational switching of aptamer. Journal of Electroanalytical Chemistry 662, 2011, p. 306-311.

45. Hua, M., et al., Label-free electrochemical cocaine aptasensor based on a target-inducing aptamer switching conformation. Analytical Sciences 26, 2010, p. 1265-1270.

46. Swensen, J.S., et al., Continuous, real-time monitoring of cocaine in undiluted blood serum via a microfluidic, electrochemical aptamer-based sensor. Journal of the American Chemical Society 131, 2009, p. 4262-4266.

47. Wen, Y., et al., DNA nanostructure-decorated surfaces for enhanced aptamer-target binding and electrochemical cocaine sensors. Analytical chemistry 83, 2011, p. 7418-7423.

48. White, R.J., et al., Optimization of electrochemical aptamer-based sensors via optimization of probe packing density and surface chemistry. Langmuir 24, 2008, p. 10513-10518. 
49. Bauer, C.G., et al., Automated amplified flow immunoassay for cocaine. Analytical Chemistry 70, 1998, p. 4624-4630.

50. Jiang, B., et al., Highly sensitive electrochemical detection of cocaine on graphene/AuNP modified electrode via catalytic redox-recycling amplification. Biosensors and Bioelectronics 32, 2012, p. 305-308.

51. Suleiman, A.A. and Y. Xu, An amperometric immunosensor for cocaine. Electroanalysis 10, 1998, p. 240-243.

52. White, R.J. and K.W. Plaxco, Engineering new aptamer geometries for electrochemical aptamer-based sensors. Proceedings of SPIE - The International Society for Optical Engineering 7321, 2009, p. 732105.

53. Zhang, D.W., et al., An electrochemical aptasensor based on enzyme linked aptamer assay. Biosensors and Bioelectronics 31, 2012, p. 363-368.

54. Zhou, J., et al., Aptamer sensor for cocaine using minor groove binder based energy transfer. Analytica Chimica Acta 719, 2012, p. 76-81.

55. Li, Y., X. Ji, and B. Liu, Chemiluminescence aptasensor for cocaine based on double-functionalized gold nanoprobes and functionalized magnetic microbeads. Analytical and Bioanalytical Chemistry 401, 2011, p. 213-219.

56. Hilton, J.P., et al., A microfluidic affinity sensor for the detection of cocaine. Sensors and Actuators, A: Physical 166, 2011, p. 241-246.

57. Yan, X., et al., DNA aptamer folding on magnetic beads for sequential detection of adenosine and cocaine by substrate-resolved chemiluminescence technology. Analyst 135, 2010, p. 2400-2407.

58. Stojanovic, M.N. and D.W. Landry, Aptamer-based colorimetric probe for cocaine. Journal of the American Chemical Society 124, 2002, p. 9678-9679. 
59. Stojanovic, M.N., P. de Prada, and D.W. Landry, Aptamer-based folding fluorescent sensor for cocaine. Journal of the American Chemical Society 123, 2001, p. 4928-4931.

60. Ma, C., et al., Cocaine detection via rolling circle amplification of short DNA strand separated by magnetic beads. Biosensors and Bioelectronics 26, 2011, p. 3309-3312.

61. Cai, Q., et al., Determination of cocaine on banknotes through an aptamerbased electrochemiluminescence biosensor. Analytical and Bioanalytical Chemistry 400, 2011, p. 289-294.

62. Li, Y., et al., Electrogenerated chemiluminescence aptamer-based biosensor for the determination of cocaine. Electrochemistry Communications 9, 2007, p. 2571-2575.

63. Yamaguchi, M., et al., A rapid enzyme immunoassay for cocaine and benzoylecgonine using glucose oxidase. Journal of Health Science 47, 2001, p. 419-423.

64. Rabbany, S.Y., et al., Binding kinetics of immobilized antibodies in a flow immunosensor. Sensors and Actuators: B. Chemical 29, 1995, p. 72-78.

65. Toppozada, A.R., et al., Evaluation of a fiber optic immunosensor for quantitating cocaine in coca leaf extracts. Biosensors and Bioelectronics 12, 1997, p. 113-124.

66. Eremenko, A.V., et al., The development of a non-competitive immunoenzymometric assay of cocaine. Analytica Chimica Acta 358, 1998, p. 5-13.

67. Wenger, B., et al., Au-labeled antibodies to enhance the sensitivity of a refractometric immunoassay: Detection of cocaine. Biosensors and Bioelectronics 34, 2012, p. 94-99. 
68. Attili, B.S. and A.A. Suleiman, A piezoelectric immunosensor for the detection of cocaine. Microchemical Journal 54, 1996, p. 174-179.

69. Halámek, J., et al., Highly sensitive detection of cocaine using a piezoelectric immunosensor. Biosensors and Bioelectronics 17, 2002, p. 1045-1050.

70. Halámek, J., et al., Piezoelectric affinity sensors for cocaine and cholinesterase inhibitors. Talanta 65, 2005, p. 337-342.

71. Wasels, R. and F. Belleville, Gas chromatographic-mass spectrometric procedures used for the identification and determination of morphine, codeine and 6- monoacetylmorphine. Journal of Chromatography A 674, 1994, p. 225-234.

72. Bosch, M.E., et al., Morphine and its metabolites: Analytical methodologies for its determination. Journal of Pharmaceutical and Biomedical Analysis 43, 2007, p. 799-815.

73. Francis, P.S., et al., Chemiluminescence detection of opium poppy (Papaver somniferum) alkaloids. Journal of Pharmaceutical and Biomedical Analysis 48, 2008, p. 508-518.

74. Bishop, E. and W. Hussein, Anodic voltammetry of codeine and dihydrocodeine at rotating disc electrodes of platinum and gold. Analyst 109, 1984, p. 143-145.

75. Garrido, J.M.P.J., et al., Electrochemical Analysis of Opiates - An Overview. Analytical Letters 37, 2004, p. 831-844.

76. Pournaghi-Azar, M.H., S. Kheradmandi, and A. Saadatirad, Simultaneous voltammetry of paracetamol, ascorbic acid, and codeine on a palladiumplated aluminum electrode: Oxidation pathway and kinetics. Journal of Solid State Electrochemistry 14, 2010, p. 1689-1695. 
77. Babaei, A., et al., A sensor for simultaneous determination of acetaminophen and codeine at glassy carbon electrode modified with multi-walled carbon nanotubes. Sensor Letters 10, 2012, p. 1039-1046.

78. Bani-Yaseen, A.A.D., Fabrication and characterization of fully integrated microfluidic device with carbon sensing electrode for the analysis of selected biomedical targets. IEEE Sensors Journal 9, 2009, p. 81-86.

79. Campean, A., M. Tertis, and R. Sandulescu, Voltammetric determination of some alkaloids and other compounds in pharmaceuticals and urine using an electrochemically activated glassy carbon electrode. Central European Journal of Chemistry 9, 2011, p. 688-700.

80. Komorsky-Lovric, S., N. Vukasinovic, and R. Penovski, Voltammetric determination of microparticles of some local anesthetics and antithusics immobilized on the graphite electrode. Electroanalysis 15, 2003, p. 544-547.

81. Li, Y., et al., Electrochemical behavior of codeine and its sensitive determination on graphene-based modified electrode. Sensors and Actuators, B: Chemical 182, 2013, p. 401-407.

82. Saberian, M., et al., Establishment of an electrochemical RNA aptamer-based biosensor to trace nanomolar concentrations of codeine. Turkish Journal of Chemistry 37, 2013, p. 366-373.

83. Salimi, A., R. Hallaj, and G.R. Khayatian, Amperometric detection of morphine at preheated glassy carbon electrode modified with multiwall carbon nanotubes. Electroanalysis 17, 2005, p. 873-879.

84. Shih, Y., J.M. Zen, and H.H. Yang, Determination of codeine in urine and drug formulations using a clay-modified screen-printed carbon electrode. Journal of Pharmaceutical and Biomedical Analysis 29, 2002, p. 827-833.

85. Švorc, L., et al., Rapid and sensitive electrochemical determination of codeine in pharmaceutical formulations and human urine using a borondoped diamond film electrode. Electrochimica Acta 87, 2013, p. 503-510. 
86. Zen, J.M., et al., Determination of Codeine in Human Plasma and Drug Formulation Using a Chemically Modified Electrode. Electroanalysis 10, 1998, p. 536-540.

87. Bauer, C.G., et al., New enzyme sensors for morphine and codeine based on morphine dehydrogenase and laccase. Fresenius' Journal of Analytical Chemistry 364, 1999, p. 179-183.

88. Habibi, B., M. Abazari, and M.H. Pournaghi-Azar, Simultaneous determination of codeine and caffeine using single-walled carbon nanotubes modified carbon-ceramic electrode. Colloids and Surfaces B: Biointerfaces 114, 2014, p. 89-95.

89. Holt, P.J., et al., An amperometric opiate assay. Biosensors \& Bioelectronics 10, 1995, p. 517-526.

90. Huang, L., et al., A label-free electrochemical biosensor based on a DNA aptamer against codeine. Analytica Chimica Acta 787, 2013, p. 203-210.

91. Pournaghi-Azar, M.H. and A. Saadatirad, Simultaneous determination of paracetamol, ascorbic acid and codeine by differential pulse voltammetry on the aluminum electrode modified by thin layer of palladium. Electroanalysis 22, 2010, p. 1592-1598.

92. Pournaghi-Azar, M.H. and A. Saadatirad, Simultaneous voltammetric and amperometric determination of morphine and codeine using a chemically modified-palladized aluminum electrode. Journal of Electroanalytical Chemistry 624, 2008, p. 293-298.

93. Zhou, T., et al., Determination of codeine and its metabolite in human urine by $C E$ with amperometric detection. Journal of Pharmaceutical and Biomedical Analysis 30, 2002, p. 13-19.

94. Banica, F.-G., Chemical sensors and biosensors: Fundamentals and applications. 2012, UK: WILEY. 
95. Wang, J., Analytical Electrochemistry. 2nd ed. 2000, New York: Wiley$\mathrm{VCH}$.

96. Kellner, R., et al., Analytical Chemistry. 2nd ed. A Modern Approach to Analytical Science. 2004, Germany: Wiley-VCH.

97. Harris, D.C., Análisis Químico Cuantitativo. 2nd ed. 2001, Barcelona: Reverté S.A.

98. Scozzari, A., Electrochemical sensing methods: A brief review, in Algal Toxins: Nature, Occurrence, Effect and Detection, V. Evangelista, et al., Editors. 2008, Springer: Pisa, Italy. p. 335-351.

99. Alonso-Lomillo, M.A., O. Domínguez Renedo, and M.J. Arcos-Martínez, Enzyme modified screen printed electrodes, in Biosensors: Properties, Materials and Applications, R. Comeaux and P. Novotny, Editors. 2009, Nova Publishers: Hauppauge NY. p. 1-52.

100. Li, M., et al., Recent developments and applications of screen-printed electrodes in environmental assays-A review. Analytica Chimica Acta 734, 2012, p. 31-44.

101. Domínguez-Renedo, O., M.A. Alonso-Lomillo, and M.J. Arcos-Martínez, Recent developments in the field of screen-printed electrodes and their related applications. Talanta 73, 2007, p. 202-219.

102. Cooper, J. and T. Cass, Biosensors: A Practical Approach. 2nd ed. 2004, New York: Oxford University Press.

103. Wang, J., Nanomaterial-based electrochemical biosensors. Analyst 130, 2005, p. 421-426.

104. Gong, K., et al., Electrochemistry and electroanalytical applications of carbon nanotubes: A review. Analytical Sciences 21, 2005, p. 1383-1393. 
105. Kordás, K., et al., Inkjet printing of electrically conductive patterns of carbon nanotubes. Small 2, 2006, p. 1021-1025.

106. Putzbach, W. and N.J. Ronkainen, Immobilization techniques in the fabrication of nanomaterial-based electrochemical biosensors: a review. Sensors 13, 2013, p. 4811-4840.

107. Trojanowicz, M., Analytical applications of carbon nanotubes: a review. TrAC - Trends in Analytical Chemistry 25, 2006, p. 480-489.

108. Pingarrón Carrazón, J.M. and P. Sánchez Batanero, Química electroanalítica, Fundamentos y aplicaciones. 2003, Madrid: Editorial Síntesis.

109. Mulaa, F.J. and P.M. Krämer, Biosensors, in Handbook of food safety engineering, D.-W. Sun, Editor. 2012, Wiley-Blackwell: West Sussex, UK. p. 313-351.

110. Eggins, B., Biosensors: An Introduction. 1996, New York: Wiley Teubner.

111. Mikkelsen, S.R. and E. Corton, Bioanalytical Chemistry. 2004, New Jersey: Wiley-Intersciece.

112. Cao, L., Carrier-bound Immobilized Enzymes: Principles, Applications and Design. 2005, Weinheim, Germany: Wiley-VCH.

113. Alegret, S., M. del Valle, and A. Merkoçi, Sensores electroquímicos. Col·lecció Materials 147. 2004, Bellaterra, Barcelona, Spain: Servei de Publicacions.

114. Borgmann, S., et al., Amperometric Biosensors, in Advances in Electrochemical Science and Engineering: Bioelectrochemistry, R.C. Alkire, D.M. Kolb, and J. Lipkowski, Editors. 2011, Wiley-VCH: Germany. p. 1-83.

115. Eggins, B.R., Chemical Sensors and Biosensors. 2004, UK: John Wiley \& Sons, LTD. 
116. Liska, D.J., The detoxification enzyme systems. Alternative Medicine Review 3, 1998, p. 187-198.

117. del Arco, C., Metabolismo de los Fármacos, in Farmacología humana, J. Flórez, J.A. Armijo, and Á. Mediavilla, Editors. 2005, Masson: Barcelona.

118. Lewis, D.F.V., Cytochromes P450, Structure, Function and Mechanism. 1996, UK: Taylor \& Francis.

119. Lewis, D.F.V., Guide to Cytochromes P450: Structure and Function. 2001, Florida: CRC Press, Boca Ratón.

120. Mathews, C.K., K.E. van Holde, and K.G. Ahern, Bioquímica. 3rd ed. 2002, Madrid, Spain: Addison Wesley.

121. Scott, E.E., et al., An open conformation of mammalian cytochrome P450 2B4 at 1.6-A resolution. Proceedings of the National Academy of Sciences of the United States of America 100, 2003, p. 13196-13201.

122. Wang, A., et al., Crystal structure of human cytochrome P450 2D6 with prinomastat bound. Journal of Biological Chemistry 287, 2012, p. 1083410843.

123. Schneider, E. and D.S. Clark, Cytochrome P450 (CYP) enzymes and the development of CYP biosensors. Biosensors and Bioelectronics 39, 2013, p. $1-13$.

124. Zanger, U.M., The CYP2D Subfamily, in Cytochromes P450, Role in the Metabolism and Toxicity of Drugs and other Xenobiotics, C. Ioannides, Editor. 2008, SRC Publishing: Cambridge, UK.

125. Donato, M.T., ¿Qué es el citocromo P-450 y cómo funciona?, in Monografía XIV de la Real Academia Nacional de Farmacia. 2004.

126. Silverman, R.B., The Organic Chemistry of Enzyme-Catalyzed Reactions. 2002, USA: Elsevier Science - Academic Press. 
127. Testa, B. and J. Caldwell, The Metabolism of Drugs and Other Xenobiotics. Biochemistry of Redox Reactions. 1995, London: Academic Press.

128. Rodés, J., et al., Tratado de hepatología Clínica. $2^{\mathrm{a}}$ ed. 2001: Masson.

129. Holmquist, G.L., Opioid metabolism and effects of cytochrome P450. Pain Medicine 10, 2009, p. S20-S29.

130. Flockhart, D.A. Drug Interactions: Cytochrome P450 Drug Interaction Table. 2007 [cited 2013; Available from: http://medicine.iupui.edu/ clinpharm/ddis/table.aspx].

131. Miao, Y., N. He, and J.J. Zhu, History and new developments of assays for cholinesterase activity and inhibition. Chemical Reviews 110, 2010, p. 52165234.

132. Nunes-Tavares, N., Inhibition of Acetylcholinesterase: New Insights, in Recent Trends in the Acetylcholinesterase System, M. Parveen and S. Kumar, Editors. 2005, IOS Press: Amsterdam, The Netherlands.

133. Parsajoo, C. and J.M. Kauffmann, Development of an acetylcholinesterase immobilized flow through amperometric detector based on thiocholine detection at a silver electrode. Talanta 109, 2013, p. 116-120.

134. Quinn, D.M., Acetylcholinesterase: Enzyme structure, reaction dynamics, and virtual transition states. Chemical Reviews 87, 1987, p. 955-979.

135. Dvir, H., et al., Acetylcholinesterase: From 3D structure to function. Chemico-Biological Interactions 187, 2010, p. 10-22.

136. Goodsell, D. Acetylcholinesterase, June 2004 molecule of the month. 2004 [cited 2013; Available from: http://www.rcsb.org/pdb/101/motm.do?momID $=54]$. 
137. Hassanein, H.M.A., Acetylcholinesterase Inhibition, in Recent Trends in the Acetylcholinesterase System, M. Parveen and S. Kumar, Editors. 2005, IOS Press: Amsterdam, The Netherlands.

138. Talesa, V.N., Acetylcholinesterase in Alzheimer's disease. Mechanisms of Ageing and Development 122, 2001, p. 1961-1969.

139. Repetto, M., Toxicología avanzada. 1995, Madrid: Diaz de Santos.

140. Pundir, C.S. and N. Chauhan, Acetylcholinesterase inhibition-based biosensors for pesticide determination: A review. Analytical Biochemistry 429, 2012, p. 19-31.

141. Sadock, B.J. and V. Alcott Sadock, Kaplan \& Sadock's Concise Textbook of Clinical Psychiatry. 3rd ed. 2008, Philadelphia, USA: Lippincott Williams \& Wilkins.

142. Turdean, G.L., Design and Development of Biosensors for the Detection of Heavy Metal Toxicity. International Journal of Electrochemistry 2011, 2011, p. 1-15.

143. Campbell, M.K. and S.O. Farrel, Biochemistry. 7th ed. 2012, Belmont, USA: Books/Cole, Cengage Learning.

144. Kent, M., Advanced biology. 2000, UK: Oxford University Press. 
CHAPTER 4:

SENSITIVE AND SELECTIVE COCAINE ELECTROCHEMICAL DETECTION USING DISPOSABLE SENSORS 

As it has been previously mentioned, one of the most widely used illegal drugs, cocaine, has been electrochemically detected using voltammetric procedures with conventional electrodes, such as carbon paste, glassy carbon and mercury (Section 3.1.3.1). However, this analyte has not been deeply studied in presence of other substances that cocaine street samples can contain.

This chapter describes the voltammetric determination of cocaine in presence of codeine, paracetamol or caffeine, possible substances present in street samples and whose oxidation peaks may overlap and lead to false positives. This work reports two different solutions to this problem:

- The modification of disposable carbon sensors with CNTs allowing the voltammetric quantification of cocaine by using OLS regressions.

- The use of PLS regressions for the resolution of the overlapped voltammetric signals when using SPCEs without any modification.

Both procedures have been successfully applied to the evaluation of the purity of two types of cocaine street samples.

Part of this work has been recently accepted for publication in Analytica Chimica Acta. 



\section{1.- INTRODUCTION}

Drug abuse is a worldwide problem that claims thousands of lives each year; causing the devastation of families and the suffering of thousands of people. Around half of these deaths are caused by fatal overdoses in young victims [1]. Cocaine is one of the most widely used illegal drugs that acts as a local anaesthetic and stimulates the brain causing euphoria, which leads to its addiction [2]. In the worst case, this addiction can lead to cardiac arrest or seizures followed by respiratory arrest and death. It must be taking into account that the effects of cocaine street samples are not only induced by the drug itself but also by the adulterants that they contain. Furthermore, these adverse effects are increased due to the combination of cocaine with other drugs or alcohol [3].

The determination of the concentration of cocaine has been checked through analytical techniques such as gas chromatography [4-6], HPLC [7-9] or even capillary electrophoresis [10]. These analyses, requested in fields such as forensic science or criminology, have been applied to biological samples as well as to the evaluation of the purity of street samples.

Electrochemical techniques have been also used in the determination of this drug. However, interferences from substances with a redox potential close to the cocaine one would make this analysis more difficult. This complication has been sometimes solved by the modification of the working electrode with polymers [1113], Schiff bases [14, 15] or biomolecules [16-32], which provide selectivity to the electrochemical system. In this way, nanotechnology has become one of the most interesting fields in analytical chemistry due to the advantages that provide the use of CNTs in electrochemical measurements [33]. These nanomaterials offer characteristics such as the increase of the active surface of the electrode, the improvement of the electronic transference between the electrode and the solution and the enhancement of the reversibility of the process [34]. Thus, one of the aims of this work is to determine the purity of cocaine street samples, by square-wave voltammetry, using MWCNTs modified SPCEs. 
Moreover, the discrimination between the overlapped signals of the analyte and the interferences, especially in voltammetry, can be solved by using multivariate analysis, such as PLS regressions. This work also describes the successful determination of the purity of cocaine street samples, by square-wave voltammetry, using SPEs.

\section{2.- EXPERIMENTAL}

\subsection{1.- REAGENTS}

Different home-made screen-printed transducers were built using the following commercial inks: carbon ink C2000802P2, gold ink C2041206D2, platinised carbon ink C2050804D9 and dielectric ink D2071120D1 (Gwent Group, Torfaen, UK), silver ink Electrodag 418SS and $\mathrm{Ag} / \mathrm{AgCl}$ ink Electrodag $6037 \mathrm{SS}$ (Acheson Colloiden, Scheemda, The Netherlands), and dielectric ink 242-SB (ESL Europe, Agmet Ltd, Reading, UK).

MWCNTs were purchase from DropSens S.L. (Oviedo, Spain) and dispersions of different concentration were prepared in dimethylformamide (DMF, Panreac, Barcelona, Spain), acetone (Merck, Darmstadt, Germany), tetrahydrofuran (THF, Panreac, Barcelona, Spain) or chloroform (VWR Prolabo, Haasrode, Belgium).

Stock standard solutions of $5.0 \mathrm{mM}$ cocaine hydrochloride (Sigma, SigmaAldrich, Steinheim, Germany), $5.0 \mathrm{mM}$ codeine hydrochloride (Alcaliber S.A., Madrid, Spain), 5.0 mM paracetamol (Fluka, Sigma-Aldrich, Steinheim, Germany) and $7.5 \mathrm{mM}$ caffeine anhydrous (Fluka, Sigma-Aldrich, Steinheim, Germany) were prepared by dissolving the adequate amount of each compound in Milli-Q water.

A solution containing $50.0 \mathrm{mM}$ phosphate buffer (Merck, Darmstadt, Germany) and $100.0 \mathrm{mM} \mathrm{KCl}$ (Merck, Darmstadt, Germany), adjusted to the desired 
$\mathrm{pH}$ value with a $1.0 \mathrm{M} \mathrm{NaOH}$ (J.T. Baker, Deventer, The Netherlands) solution, was used as a supporting electrolyte.

A potassium ferricyanide (Merck, Darmstadt, Germany) solution in 100.0 $\mathrm{mM} \mathrm{KNO}_{3}$ (Merck, Darmstadt, Germany) was used to characterise the electrochemical behaviour of the different electrodes.

\subsection{2.- APPARATUS}

A DEK 248 screen-printing machine (DEK, Weymouth, UK) was used for the fabrication of the screen-printed transducers.

Voltammetric measurements were performed with a $\mu$ Autolab Type II potentiostat/galvanostat with GPES software (Eco Chemie, Utrecht, The Netherlands).

Chronocoulometric measurements were performed with a BASi Epsilon Electrochemical Workstation (Bioanalytical Systems Inc, USA).

The $\mathrm{pH}$ of the solutions was measured with a Crison Model $2002 \mathrm{pH}$ meter (Barcelona, Spain).

\section{3.- METHODS}

\subsection{1.- HOME-MADE SPES FABRICATION}

The versatility of screen-printing technology in the fabrication of electrochemical transducers is well-known in terms of design and size of the device [35-38]. Electrodes of different nature and characteristics can be easily manufactured by using diverse kinds of inks. In this way, SPEs based on a three-electrode 
configuration (working, reference and counter electrodes) have been built by sequential layer deposition according to previously described procedures [39-41]. Gold, platinised carbon and carbon inks have been used to define the working electrode, which led to 3 different devices: screen-printed gold electrodes (SPAuEs) [39], screen-printed platinised carbon electrodes ( $\left.\mathrm{SPC}_{\mathrm{Pt}} \mathrm{Es}\right)$ [41] and SPCEs [40].

Due to the nature of the gold ink, SPAuEs requested both mechanical and electrochemical activation. First, the working electrode was sanded with a thin grain sandpaper to obtain a shiny surface. Then, the working electrode surface was activated by recording 8 cyclic voltammograms between +800 and $-800 \mathrm{mV}$ vs. $\mathrm{Ag} / \mathrm{AgCl} \mathrm{SPE}$, scan rate $100 \mathrm{mV} \mathrm{s}^{-1}$, in $100 \mu \mathrm{L}$ of a $5.7 \mathrm{mM}$ ferricyanide solution in $100.0 \mathrm{mM} \mathrm{KNO}_{3} . \mathrm{SPC}_{\mathrm{Pt}} \mathrm{Es}$ and SPCEs were used without any pretreatment.

\subsection{2.- FUNCTIONALISATION OF SPCES WITH MWCNTS}

In order to modify the working electrode of SPCEs with MWCNTs, the nanomaterials were dispersed in an organic solvent. Different solvents and MWCNTs concentrations were analysed. It was found that a $3.0 \mathrm{mg} / \mathrm{mL}$ dispersion of MWCNTs in DMF was the optimum one. Thus, $5 \mu \mathrm{L}$ of the dispersion were dropped on the working electrode and the solvent was left to dry at room temperature.

\subsection{3.- ELECTROCHEMICAL MEASUREMENTS}

Cyclic voltammetric measurements were made in a $100 \mu \mathrm{L}$ drop of a solution containing $5.7 \mathrm{mM}$ ferricyanide in $100.0 \mathrm{mM} \mathrm{KNO}_{3}$ and scanning the potential between $+800 \mathrm{mV}$ and $-800 \mathrm{mV}$ vs. $\mathrm{Ag} / \mathrm{AgCl} \mathrm{SPE}$ at a scan rate of $100 \mathrm{mV} \mathrm{s}^{-1}$.

Chronocoulometric measurements were performed in $5 \mathrm{~mL}$ of a $10.0 \mathrm{mM}$ phosphate and $100.0 \mathrm{mM} \mathrm{KCl}$ solution $\mathrm{pH} 7$, containing $250.0 \mu \mathrm{M}$ of ferrycyanide. 
Initial and final potentials were 0 and $+400 \mathrm{mV}$ vs. $\mathrm{Ag} / \mathrm{AgCl} \mathrm{SPE}$ respectively, with a pulse width of $250 \mathrm{~ms}$.

Square-wave voltammetric measurements were carried out in a cell containing $5 \mathrm{~mL}$ of the supporting electrolyte solution of the selected $\mathrm{pH}$, at a frequency of $25 \mathrm{~Hz}$, step potential of $12 \mathrm{mV}$, amplitude of $25 \mathrm{mV}$ and potential from 0.0 to $+1.5 \mathrm{~V}$ vs. $\mathrm{Ag} / \mathrm{AgCl} \mathrm{SPE}$.

All measurements were performed at room temperature.

\section{4.- RESULTS AND DISCUSSION}

\subsection{1.- OPTIMISATION OF THE PH OF THE SUPPORTING ELECTROLYTE}

As it has been previously reported, cocaine is an electroactive substance that presents an electrochemical peak around $+1 \mathrm{~V}$, depending on the $\mathrm{pH}$ of the media, which is associated to the oxidation of its tertiary amine [42-44]. This peak is visible at $\mathrm{pH}$ values higher than 6.5 [42], but cocaine hydrochloride precipitates at very basic $\mathrm{pH}$ giving cocaine base [45]. Consequently, the behaviour of the oxidation signal of the cocaine hydrochloride was checked using SPCEs at $\mathrm{pH} 7,8,9$ and 10. The square-wave voltammograms recorded from 0.0 to $+1.5 \mathrm{~V}$ vs. $\mathrm{Ag} / \mathrm{AgCl} \mathrm{SPE}$ showed that the more basic the media was, the higher the oxidation signal for cocaine was (Figure 4.1A). Thus, the optimum pH value for the buffer solution was 10 .

Nonetheless, the $\mathrm{pH}$ of the media could have an influence on the peaks of the rest of the analytes present in the media. As it is shown in figure 4.1, the variation in the $\mathrm{pH}$ of the media had no influence in the intensity of the peak of paracetamol (Figure 4.1.B), although it had a remarkable influence in the potential, in which the peak appeared. Nevertheless, as it has been already said in section 3.1.3.1, the voltammetric peak of codeine depends on the $\mathrm{pH}$ of the media, and that is why two peaks appeared at $\mathrm{pH} 7$, while three well-defined peaks appeared at $\mathrm{pH} 10$ (Figure 
4.1.C). Although caffeine presented a peak at $\mathrm{pH} 10$, the intensity at this $\mathrm{pH}$ did not correspond to the maximum (Figure 4.1.D).
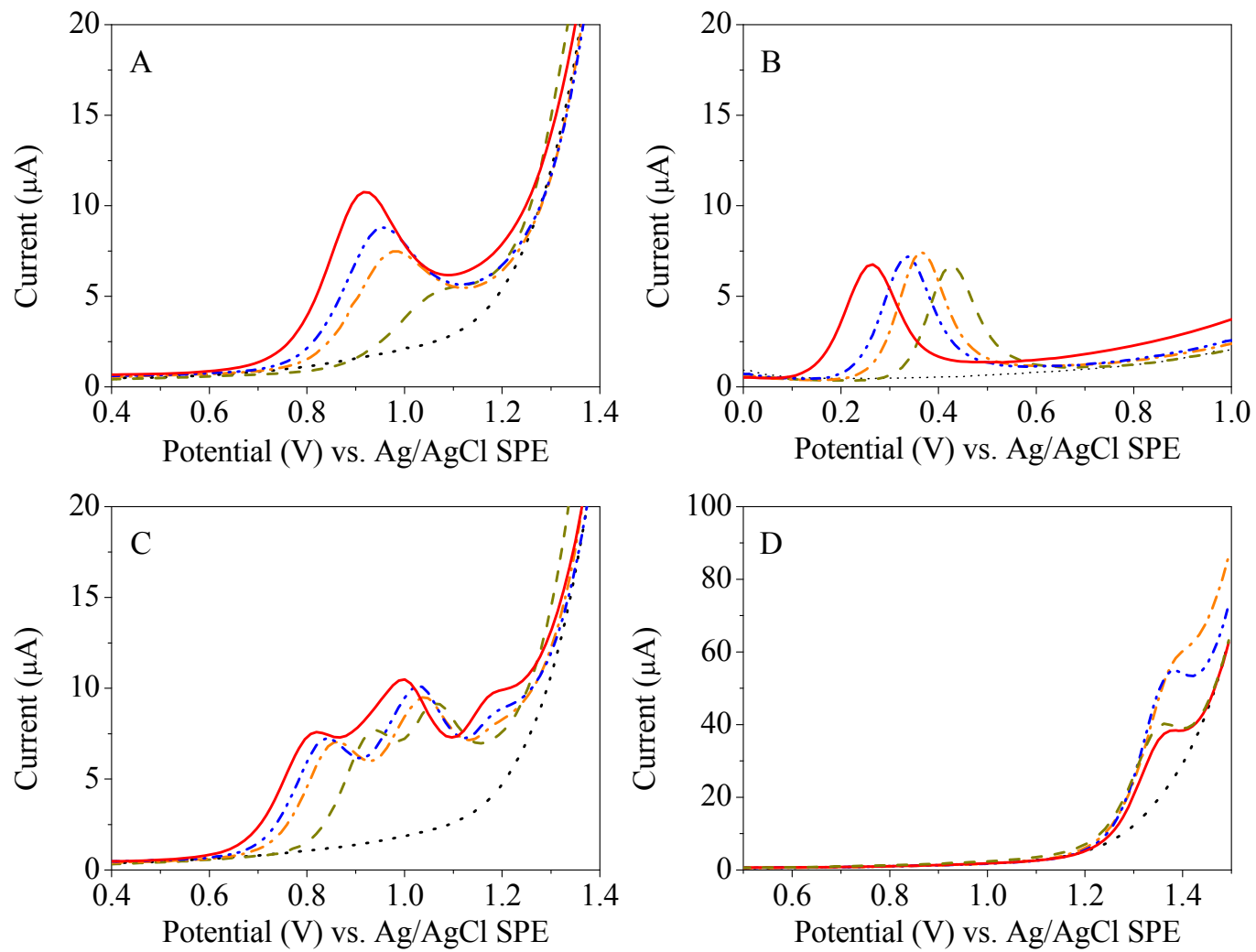

Figure 4.1.- Square-wave voltammograms of $98.0 \mu \mathrm{M}$ cocaine (A), $98.0 \mu \mathrm{M}$ paracetamol (B), $98.0 \mu M$ codeine (C) and 147.0 $\mu M$ caffeine (D); in $5 \mu L$ of a supporting electrolyte solution (....) recorded with a SPCE at pH 7 (---), pH 8.0 (--.), pH 9 (-..-.) and pH $10(\longrightarrow)$.

\subsection{2.- INFLUENCE OF THE NATURE OF THE SCREEN-PRINTED WORKING ELECTRODE IN THE VOLTAMMETRIC BEHAVIOUR OF COCAINE}

SPAuEs, $\mathrm{SPC}_{\mathrm{Pt}}$ Es and SPCEs were used for the voltammetric determination of cocaine. The main difference among them is the nature of the working electrode, which may be crucial in the detection of any analyte. 
Square-wave voltammograms of a $98.0 \mu \mathrm{M}$ cocaine solution in supporting electrolyte $\mathrm{pH} 10$ were recorded using the different SPEs.

SPAuEs presented a peak around $+1 \mathrm{~V}$ vs. $\mathrm{Ag} / \mathrm{AgCl} \mathrm{SPE}$ caused by the oxidation of the gold surface, close to the oxidation peak of cocaine, which led to an irreproducible working surface. Thus, SPAuEs were not suitable for this analysis, as well as $\mathrm{SPC}_{\mathrm{Pt}}$ Es where the cocaine oxidation peak was not observed.

Additionally, gold and platinum chips were checked in the same conditions, obtaining the same results as with the disposable gold and platinised ones.

On the contrary, a well-defined oxidation peak of cocaine was recorded by using SPCEs, with a stable and clear background current (Figure 4.1.A).

\subsection{3.- INFLUENCE OF THE SOLVENT USED IN THE DISPERSION OF MWCNTS FOR THE MODIFICATION OF SPCES}

Immobilisation by casting is one of the easiest and most used methods to attach carbon nanomaterials to the electrochemical surface. This method requires the previous dispersion of MWCNTs in organic solvents, such as DMF [46-48], THF [49], chloroform [50] or acetone [51]. These four solvents were then checked in order to choose the best one to cast the MWCNTs on the surface of the disposable carbon working electrodes, using ferricyanide as test solution.

A drop of $5 \mu \mathrm{L}$ of each of the selected organic solvents was deposited on top of the screen-printed carbon working electrodes and left to evaporate. Then, voltammetric measurements were recorded in a ferricyanide solution.

It was observed that THF and chloroform attacked the working electrode ink, making the ferricyanide initial signal lose intensity (Figure 4.2). Acetone and DMF did not seem to attack the carbon surface. 
Finally, DMF was chosen for the deposition of the carbon nanomaterials on the surface of the working electrode due to the better dispersion that provides against the other solvents [52].

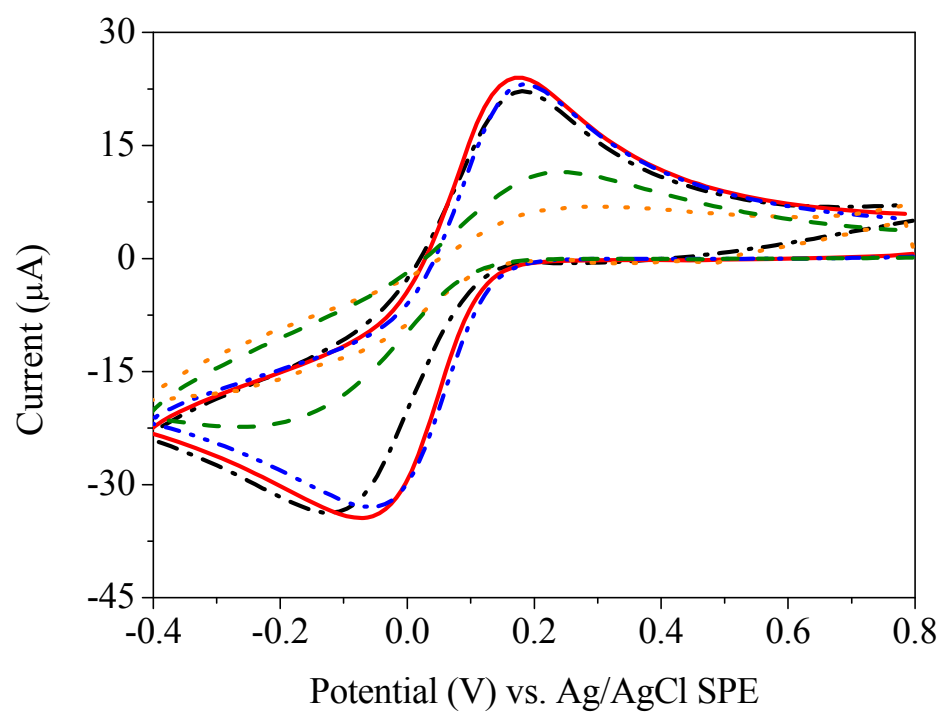

Figure 4.2.- Cyclic voltammograms of a $5.7 \mathrm{mM}$ ferricyanide solution in $100.0 \mathrm{mM} \mathrm{KNO}_{3}$, using a SPCE pretreated with $5 \mu L$ of different organic solvents: THF (...), chloroform (---), acetone (-..-..), DMF (—) and without treatment (-.-.).

\subsection{4.- INFLUENCE OF THE CONCENTRATION OF MWCNTS IN THE MODIFICATION OF SPCES}

The amount of carbon nanomaterial immobilised onto SPCEs also influences the recorded peak intensity. In this way, five different electrodes were modified with different concentrations of MWCNTs dispersions: $0.0,0.5,1.0,2.0,3.0$ and 4.0 $\mathrm{mg} / \mathrm{mL}$ MWCNTs in DMF. A volume of $5 \mu \mathrm{L}$ of each dispersion was dropped onto the corresponding working electrode and the devices were dried at room temperature.

Voltammetric and chronocoulometric measurements were made in order to evaluate the quality of the ferricyanide redox peaks and calculate the electroactive area of the electrodes. 
Chronocoulometry is an electrochemical technique that implies measurements of charge as a function of time. This technique is useful for the measurement of electrode surface area, diffusion coefficients, adsorption mechanisms, and kinetics of both heterogeneous electron transfer reactions and chemical reactions coupled to electron transfer [53]. The response to a potential step of this controlled-potential technique is a current due to the electrolysis of an electroactive species. The representation of current versus time is described by the Cottrell equation (Eq. 4.1), resulting its integrated form in the Anson equation (Eq. 4.2):

$$
\text { (Eq.4.1) } i=\frac{n F A C_{O} D_{O}^{1 / 2}}{\pi^{1 / 2}} t^{-1 / 2} \quad \text { (Eq.4.2) } Q=\frac{2 n F A C_{O} D_{O}^{1 / 2}}{\pi^{1 / 2}} t^{1 / 2}
$$

where $i$ is the current (A), $Q$ is the charge (C), $n$ is the number of electrons transferred per ion of molecule (eq/mol), $F$ is Faraday's constant $(96485 \mathrm{C} / \mathrm{eq}), A$ is the electrode surface area $\left(\mathrm{cm}^{2}\right), C_{O}$ is the concentration of the oxidised species $\left(\mathrm{mol} / \mathrm{cm}^{3}\right), D_{O}$ is the diffusion coefficient $\left(7.6 \times 10^{-6} \mathrm{~cm}^{2} / \mathrm{s}\left[\mathrm{Fe}(\mathrm{CN})_{6}\right]^{3-}\right)$ and $t$ is time $(\mathrm{s})$.

The results obtained with both electrochemical techniques showed a correlation between the intensity of the ferricyanide peaks in cyclic voltammetry with the electroactive area obtained in chronocoulometry (Figure 4.3). Besides, the higher the concentration of MWCNTs on the surface of the electrode was, the higher the peaks of ferricyanide and the electroactive area were (Figure 4.4). Thus, a 3.0 $\mathrm{mg} / \mathrm{mL}$ MWCNT dispersion was chosen as optimum, since higher concentrations were more difficult to manipulate and did not show much difference between their voltammetric signals.

The reproducibility of bare SPCE and SPCE modified with a dispersion of $3.0 \mathrm{mg} / \mathrm{mL}$ of MWCNTs (MWCNTs-SPCEs) was checked measuring the voltammetric peaks of a $5.7 \mathrm{mM}$ ferricyanide solution. The relative standard deviation $(\mathrm{RSD})$ was $7.3 \%(n=14)$ and $10.1 \%(n=14)$ for SPCEs and MWCNTsSPCEs, respectively. 


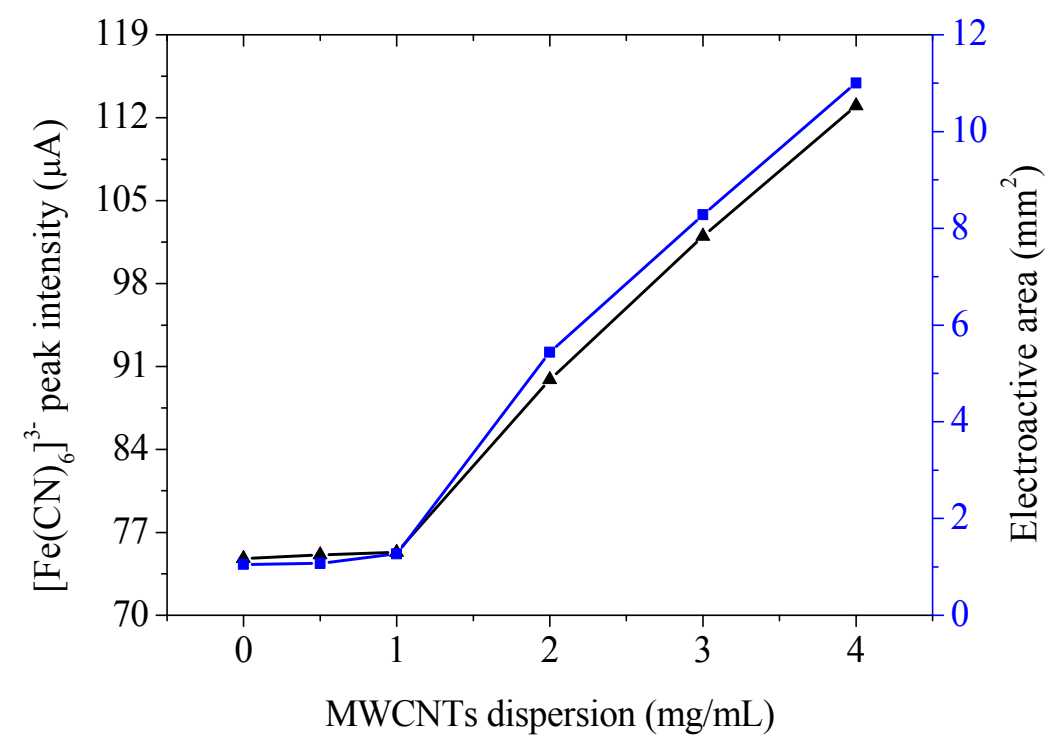

Figure 4.3.- Correlation between the ferricyanide peak intensity in cyclic voltammetry ( $\mathbf{\Delta})$ and the electroactive area of the SPE obtained through chronocoulometry

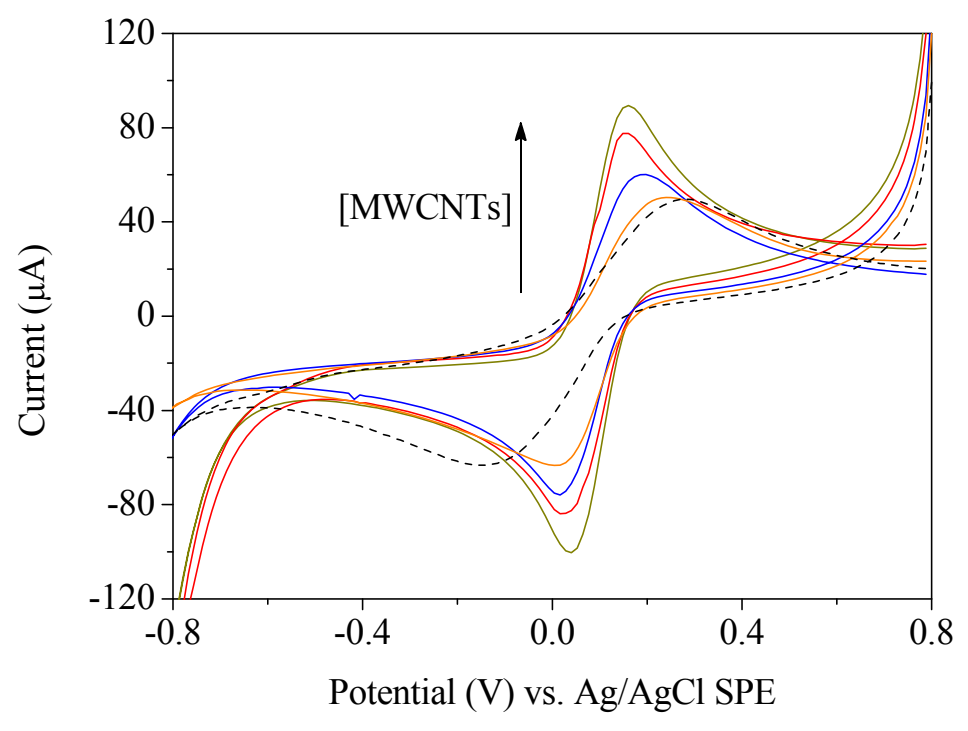

Figure 4.4.- Cyclic voltammograms of a $5.7 \mathrm{mM}$ ferricyanide solution in $100.0 \mathrm{mM} \mathrm{KNO}$, using SPCE modified with 0.0, 1.0, 2.0, 3.0 and $4.0 \mathrm{mg} / \mathrm{mL}$ of MWCNTs dispersions in DMF. 
In addition, a study of the MWCNTs-modified surface of the SPCEs was performed by scanning electron microscopy (SEM), in which a tangle of CNTs was observed (Figure 4.5).
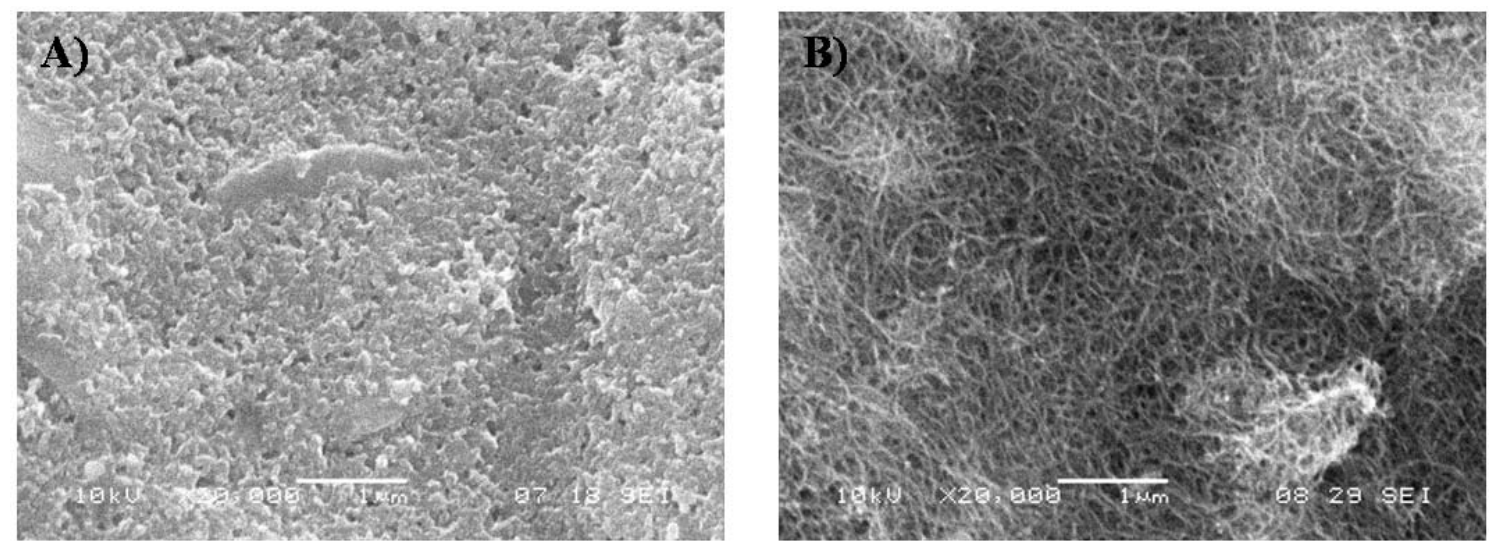

Figure 4.5.- SEM images of a SPCE surface (A) and a SPCE surface modified with 3.0 $m g / m L M W C N T s(B)$.

\subsection{5.- COCAINE DETECTION USING SPCES AND MWCNTS-SPCES BY SQUARE- WAVE VOLTAMMETRY}

\subsubsection{1.- Ordinary least squares regressions}

The purity of cocaine in real-life samples was evaluated through calibration curves of successive additions of a $5.0 \mathrm{mM}$ cocaine solution in $5 \mathrm{~mL}$ of supporting electrolyte in a calibration range from 10.0 to $155.0 \mu \mathrm{M}$, using SPCEs and MWCNTs-SPCEs. Two different confiscated street cocaine samples (sample 1 and 2) were analysed. An aliquot of sample 1 was dissolved in water without further pretreatment. However, sample 2 was slightly soluble in water due to the presence of cocaine base instead of cocaine hydrochloride, as it was confirmed by X-ray powder diffraction spectra (Figure. 4.6). Thus, an aliquot of sample 2 was completely dissolved in a $\mathrm{HCl}$ solution $\mathrm{pH} 3$ and neutralised with a diluted $\mathrm{NaOH}$ solution. 

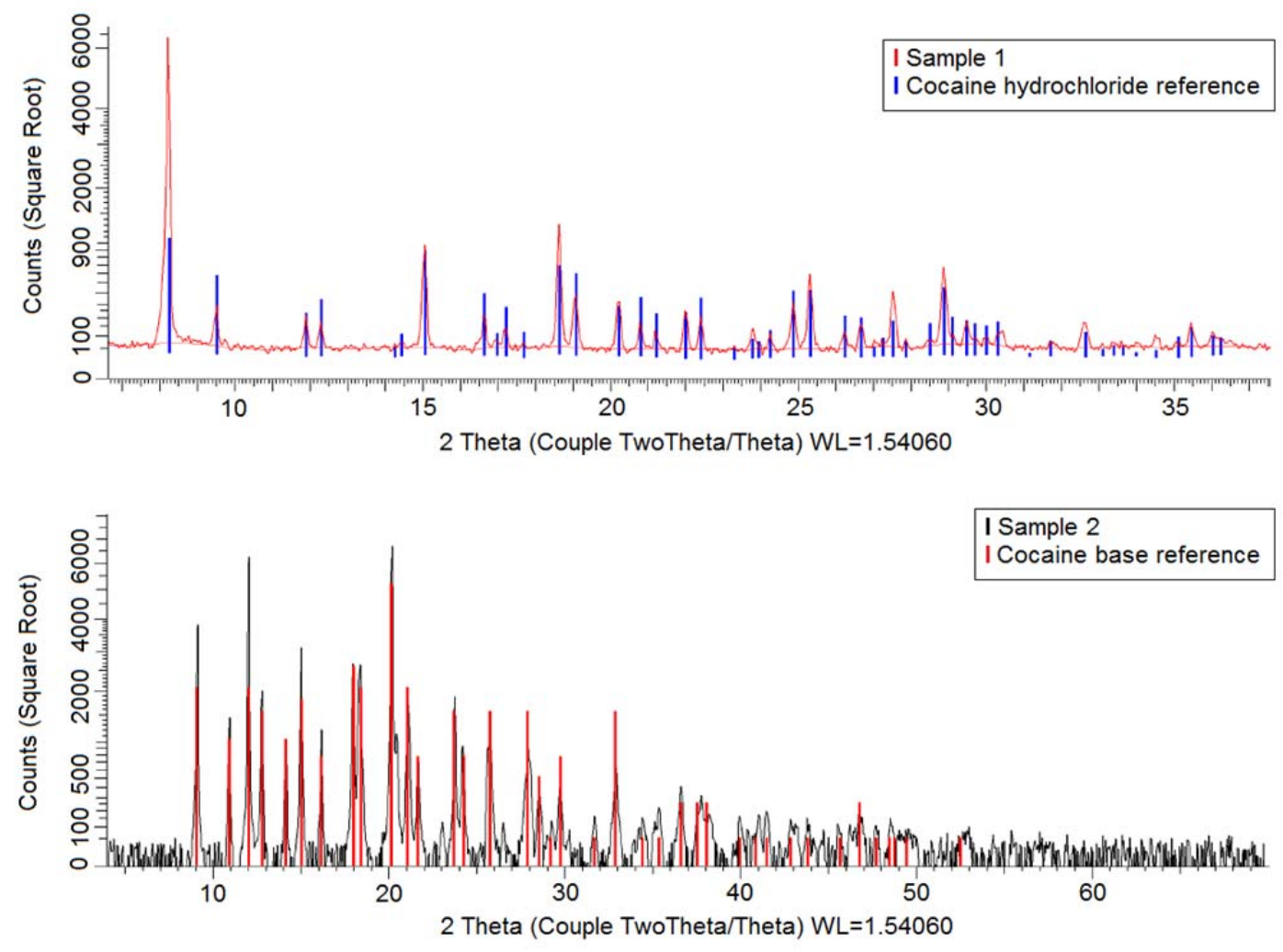

Figure 4.6.- X-ray powder diffraction spectra of two different cocaine street samples: sample 1, containing cocaine hydrochloride, and sample 2, containing cocaine base.

After the performance of the successive additions of cocaine to obtained a calibration curve, calibration parameters and standard deviation were optimally evaluated using the program PROGRESS [54]. This program evaluates the presence of anomalous points using a least median squares regression. Once these anomalous points are removed from the calibration set, a calibration line is built with the remaining points by OLS. This OLS regression provides a proper assessment of the slope (sensitivity) and the independent term of the calibration, both important parameters for judging the quality of the calibration and the analytical method.

Results of interpolating the voltammetric signal of the cocaine street samples solutions on the SPCEs calibration curves gave a purity higher than $100 \%$, due to the interference from other compounds in the sample. However, the interpolation of 
the results of the cocaine street samples on the MWCNTs-SPCEs calibration plots gave a concentration of [78.9 \pm 8.4$] \%(n=6, \alpha=0.05)$ and $[84.3 \pm 7.4] \%(n=4, \alpha$ $=0.05)$, which are in agreement with the purity value given by the supplier $(76.7 \%$ and $82.3 \%$, respectively) (Table 4.1 ).

Table 4.1.- Analytical characteristics in the detection of cocaine in street samples using MWCNTS-SPCES.

\begin{tabular}{ccccc}
\hline $\begin{array}{c}\text { Reference value } \\
(\%)\end{array}$ & $\begin{array}{c}\text { Cocaine } \\
\text { detected (\%) }\end{array}$ & $\begin{array}{c}\text { 95 \% confidence } \\
\text { interval for mean (\%) }\end{array}$ & Recovery (\%) & RSD (\%) \\
\hline 81.3 & & 106.0 & \\
& 86.9 & & 113.3 & \\
76.7 & 79.1 & {$[78.9 \pm 8.4]$} & 103.1 & 10.1 \\
& 66.7 & & 87.0 & \\
& 72.6 & 94.7 & \\
& 86.8 & & 113.2 & \\
& 84.0 & & 102.1 & \\
& 78.6 & 95.5 & 95.5 & \\
& 90.0 & & 109.4 & \\
& 84.8 & & 103.0 & \\
\hline
\end{tabular}

Cocaine street samples obviously contain adulterants, such as codeine, paracetamol and caffeine, whose oxidation peaks may overlap the cocaine one when using SPCEs (Figure 4.7.A). Nevertheless, the use of MWCNTs avoided this inconvenience (Figure 4.7.B), making the cocaine peak quantification easier. Moreover, an increase in sensitivity was observed when MWCNTs-SPCEs were used.

The precision of this simple procedure for the detection and quantification of cocaine using MWCNTs-SPCEs was characterised. 

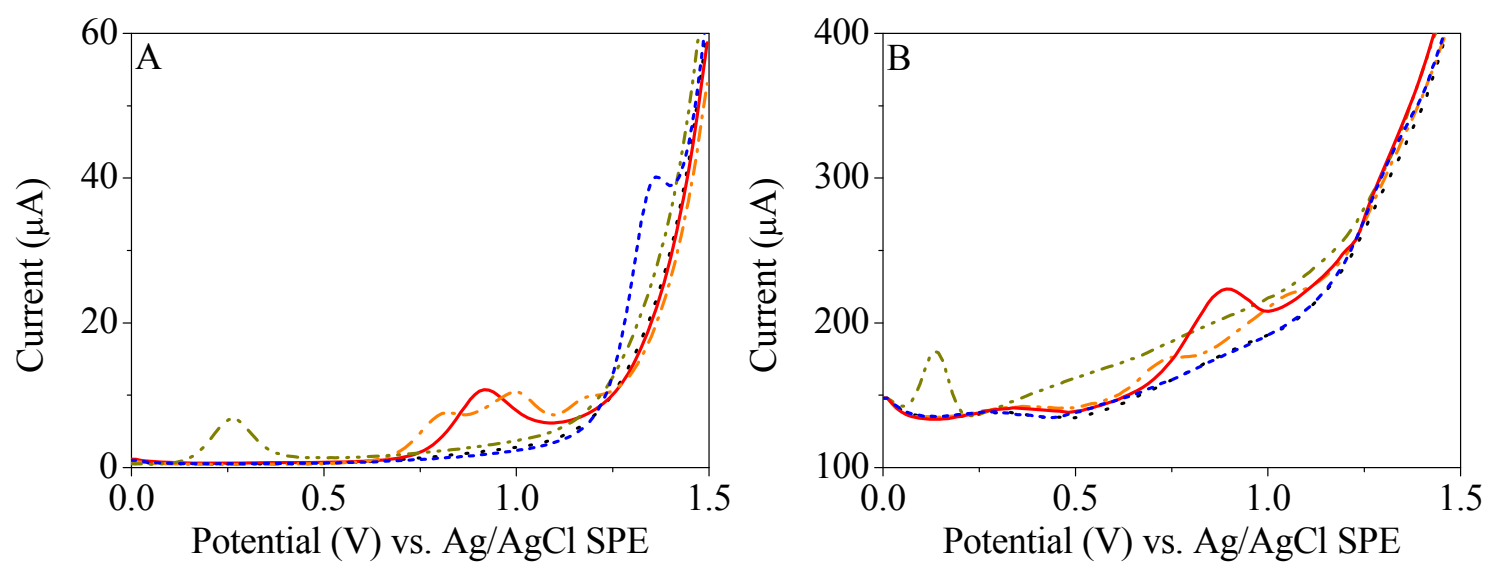

Figure 4.7.- Square-wave voltammograms of $5 \mathrm{~mL}$ of a supporting electrolyte solution $\mathrm{pH}$ 10 (....) containing $100 \mu \mathrm{L}$ of a $7.5 \mathrm{mM}$ caffeine solution (- - ), $5.0 \mathrm{mM}$ solutions of codeine (--.), paracetamol (-..-.) or cocaine (-) using a SPCE (A) and a MWCNTs$\operatorname{SPCE}(B)$.

Precision, which can be divided in reproducibility and repeatability, refers to the dispersion of a number of independent replicate measurements of a property about its central value. Reproducibility is the closeness of agreement between individual results obtained with the same method or identical test material, but under different conditions, in this case, different MWCNTs-SPCEs. On the other hand, repeatability is defined as the closeness of agreement between successive results obtained with the same method or identical test material and under the same conditions, which means performing the experiments with one single MWCNTsSPCE, in this case [55]. The RSD diminishes and stabilises at high concentrations, therefore, it is necessary to evaluate it at different levels in the concentration range in which it is applied. In this case, the precision is evaluated in the whole range of calibration taking into account the slope of the curves of calibration [56].

The reproducibility of MWCNTs-SPCEs in terms of RSD associated with the slopes of the calibration plots recorded in the cocaine concentration range from 10.0 to $155.0 \mu \mathrm{M}$ was estimated in $5.6 \%(n=7)$. 
Successive calibration curves were also performed with one single electrode to calculate the repeatability of the method. It was observed that the MWCNTsSPCEs kept the $60.2 \%$ of its initial sensitivity after the fourth calibration curve. Moreover, the consecutive measurement of cocaine sample 2 with the same electrode gives a repeatability of $7.4 \%(n=6)$.

\subsubsection{2.- Partial least squares regressions}

A multivariate analysis was suggested for the analysis of cocaine samples, when using SPCEs.

Methods that involve a soft calibration, such as PLS, have been demonstrated to be very useful in the resolution of overlapped signals [57-62]. The aim of soft modelling is to construct a good predictive model, in contrast to hard calibration methods where the goal is to obtain a model with high precision.

PLS calibration is achieved by constructing latent variables that are linear combinations of the original variables. Each latent variable will tend to pull the solutions towards directions of high variance and where the correlation with the response exists. Cross-validation is used to select the number of latent variables in the PLS model constructed [61].

The use of PLS implies three different stages. Firstly, the model is postulated and the regression coefficients are calculated, using the PARVUS program [63]. Then, this model is validated with test samples and finally, the postulated model is used to determine the concentration of real-life samples.

First, a calibration set, consisting of 7 synthetic samples containing cocaine between 10.0 and $155.0 \mu \mathrm{M}$, was studied. All the voltammograms were digitalised accounting for the intensity read at 105 potentials between $0.0 \mathrm{~V}$ and $+1.25 \mathrm{~V}$. 
Unfortunately, a purity higher than $100 \%$ was again obtained. This fact highlighted the importance of constructing the PLS model taking into account the presence of other compounds commonly found in cocaine street samples, such as codeine, paracetamol or caffeine. Therefore, different multivariate analyses were performed in order to determine the concentration of cocaine in real-life samples in the best conditions, using not only SPCEs, but also MWCNTs-SPCEs.

\section{Calibration stage}

Table 4.2 shows the calibration set used in the determination of cocaine in presence of codeine, paracetamol and caffeine, consisting of 25 synthetic samples containing different amounts of each drug. The design of concentrations correspond to a central composite design $2^{4}$ with a replicate at the central point, which allows analysing five levels of concentration for each of the four analytes. Square-wave voltammetric measurements were recorded accounting for the intensities read at 125 potentials between 0.0 and $+1.5 \mathrm{~V}$ vs. $\mathrm{Ag} / \mathrm{AgCl} \mathrm{SPEs}$, using SPCEs and MWCNTsSPCEs.

Different PLS calibration models were constructed using a single SPCE (Model A) and a single MWCNTs-SPCE (Model C) to perform the whole design, as well as using different SPCEs (Model B) and MWCNTs-SPCEs (Model D) for recording each voltammogram of the model. Data analysis was performed using the package PARVUS for the regression models [63].

Cross-validation is performed based on dividing the group of all objects into subgroups of equal size. Each of these groups will play the role of the evaluation set while the rest take part in the construction of a model. The obtained model will be evaluated through the calculation of the sum of squares in prediction (PRESS) [61].

$$
\operatorname{PRESS}(k)=\sum_{i=1}^{m}\left(c_{i}-\hat{c}_{k / i}\right)^{2}
$$


Table 4.2.- Set of calibration samples (C1-C25) and test samples (T1-T8) of paracetamol $(A P A P)$, codeine (COD), cocaine (COC) and caffeine (CAF).

\begin{tabular}{|c|c|c|c|c|}
\hline Sample & $\mathrm{C}_{\mathrm{APAP}}(\boldsymbol{\mu M})$ & $\mathrm{C}_{\mathrm{COD}}(\boldsymbol{\mu M})$ & $\mathrm{C}_{\mathrm{COC}}(\boldsymbol{\mu M})$ & $\mathrm{C}_{\mathrm{CAF}}(\mu \mathrm{M})$ \\
\hline $\mathrm{C} 1$ & 50.0 & 50.0 & 50.0 & 75.0 \\
\hline $\mathrm{C} 2$ & 100.0 & 50.0 & 50.0 & 75.0 \\
\hline $\mathrm{C} 3$ & 50.0 & 100.0 & 50.0 & 75.0 \\
\hline $\mathrm{C} 4$ & 100.0 & 100.0 & 50.0 & 75.0 \\
\hline $\mathrm{C} 5$ & 50.0 & 50.0 & 100.0 & 75.0 \\
\hline C6 & 100.0 & 50.0 & 100.0 & 75.0 \\
\hline C7 & 50.0 & 100.0 & 100.0 & 75.0 \\
\hline $\mathrm{C} 8$ & 100.0 & 100.0 & 100.0 & 75.0 \\
\hline C9 & 50.0 & 50.0 & 50.0 & 125.0 \\
\hline $\mathrm{C} 10$ & 100.0 & 50.0 & 50.0 & 125.0 \\
\hline $\mathrm{C} 11$ & 50.0 & 100.0 & 50.0 & 125.0 \\
\hline $\mathrm{C} 12$ & 100.0 & 100.0 & 50.0 & 125.0 \\
\hline C13 & 50.0 & 50.0 & 100.0 & 125.0 \\
\hline $\mathrm{C} 14$ & 100.0 & 50.0 & 100.0 & 125.0 \\
\hline C15 & 50.0 & 100.0 & 100.0 & 125.0 \\
\hline $\mathrm{C} 16$ & 100.0 & 100.0 & 100.0 & 125.0 \\
\hline $\mathrm{C} 17$ & 25.0 & 75.0 & 75.0 & 100.0 \\
\hline C18 & 125.0 & 75.0 & 75.0 & 100.0 \\
\hline C19 & 75.0 & 25.0 & 75.0 & 100.0 \\
\hline $\mathrm{C} 20$ & 75.0 & 125.0 & 75.0 & 100.0 \\
\hline $\mathrm{C} 21$ & 75.0 & 75.0 & 25.0 & 100.0 \\
\hline $\mathrm{C} 22$ & 75.0 & 75.0 & 125.0 & 100.0 \\
\hline $\mathrm{C} 23$ & 75.0 & 75.0 & 75.0 & 50.0 \\
\hline $\mathrm{C} 24$ & 75.0 & 75.0 & 75.0 & 150.0 \\
\hline $\mathrm{C} 25$ & 75.0 & 75.0 & 75.0 & 100.0 \\
\hline $\mathrm{T} 1$ & 50.0 & 75.0 & 75.0 & 100.0 \\
\hline $\mathrm{T} 2$ & 100.0 & 75.0 & 75.0 & 100.0 \\
\hline $\mathrm{T} 3$ & 75.0 & 50.0 & 75.0 & 100.0 \\
\hline $\mathrm{T} 4$ & 75.0 & 100.0 & 75.0 & 100.0 \\
\hline T5 & 75.0 & 75.0 & 50.0 & 100.0 \\
\hline T6 & 75.0 & 75.0 & 100.0 & 100.0 \\
\hline $\mathrm{T} 7$ & 75.0 & 75.0 & 75.0 & 75.0 \\
\hline T8 & 75.0 & 75.0 & 75.0 & 125.0 \\
\hline
\end{tabular}


In this way, the PRESS value of the four PLS models for cocaine was calculated with three cancelation groups. The PLS models were constructed in such a way that a maximum prediction ability was maintained [60]. That is to say, the models were constructed taking into account the number of latent variables that give the maximum cross-validate variance and, therefore, a minimum PRESS [61].

According to this criterion, five, seven, six and four latent variables were chosen for constructing Model A, B, C and D, respectively. In all the cases, the cross-validate variance exceeded $96.1 \%$, with an associated explained variance higher than $98.1 \%$ (Table 4.3.A and 4.3.B).

\section{Validation stage}

After the construction of the four models, they were validated for cocaine with the test samples in terms of [60],

- Accuracy of the predictions, evaluated by the mean square error of prediction $(M S E P)$ or the relative root MSEP (RRMSEP):

$$
\begin{gathered}
\operatorname{MSEP}(k)=\frac{\sum_{i=1}^{n}\left(\hat{c}_{i}(k)-c_{i}\right)^{2}}{n} \\
\operatorname{RRMSEP}(k)=\frac{100}{\bar{c}} \sqrt{M S E P}
\end{gathered}
$$

where $\hat{c}_{i}(k)$ is the concentration estimated by the PLS model with $k$ latent variables, $c_{i}$ is the real concentrations, $\bar{c}$ is the media of those concentrations and $n$ is the number of test samples. 

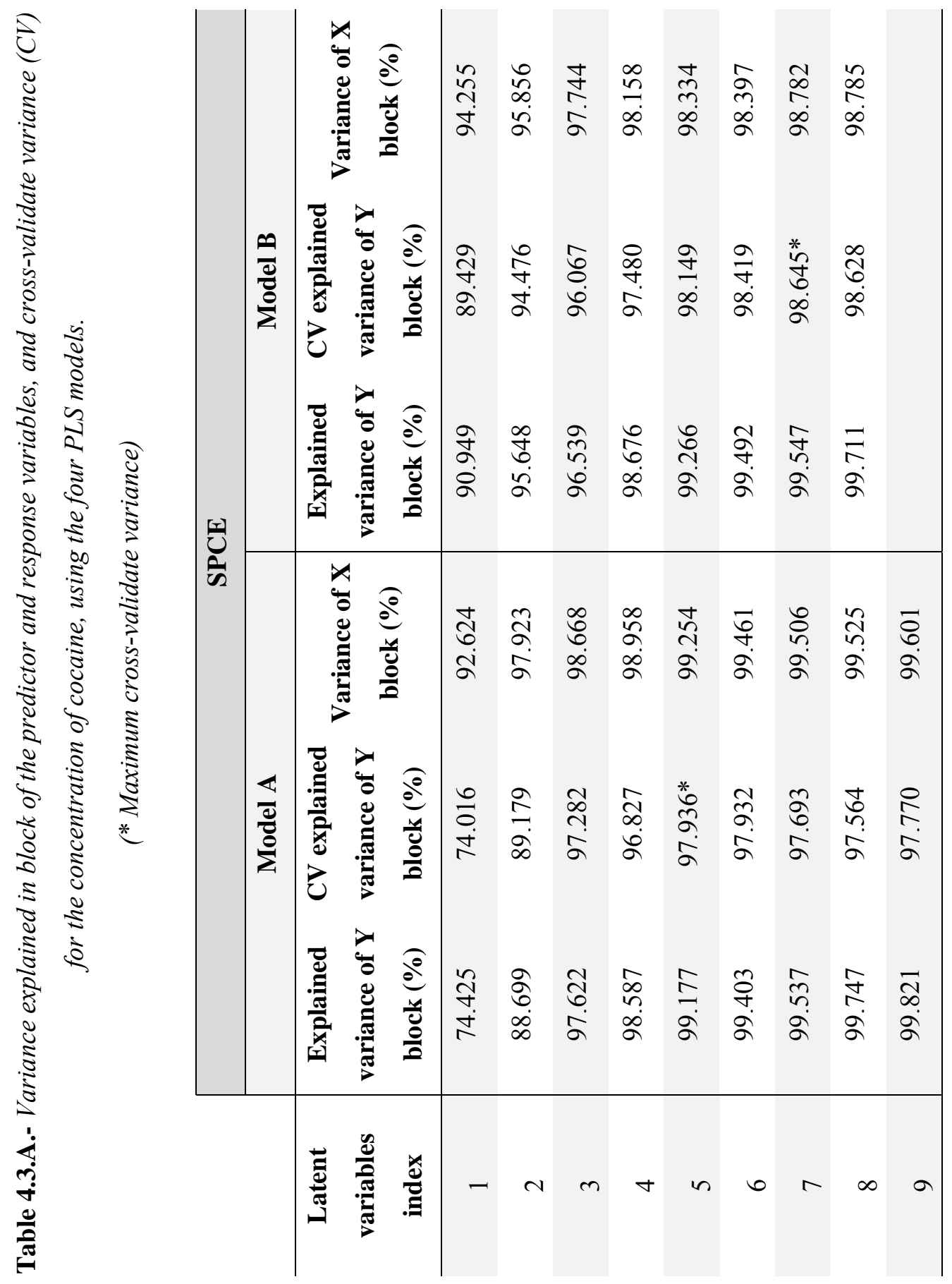

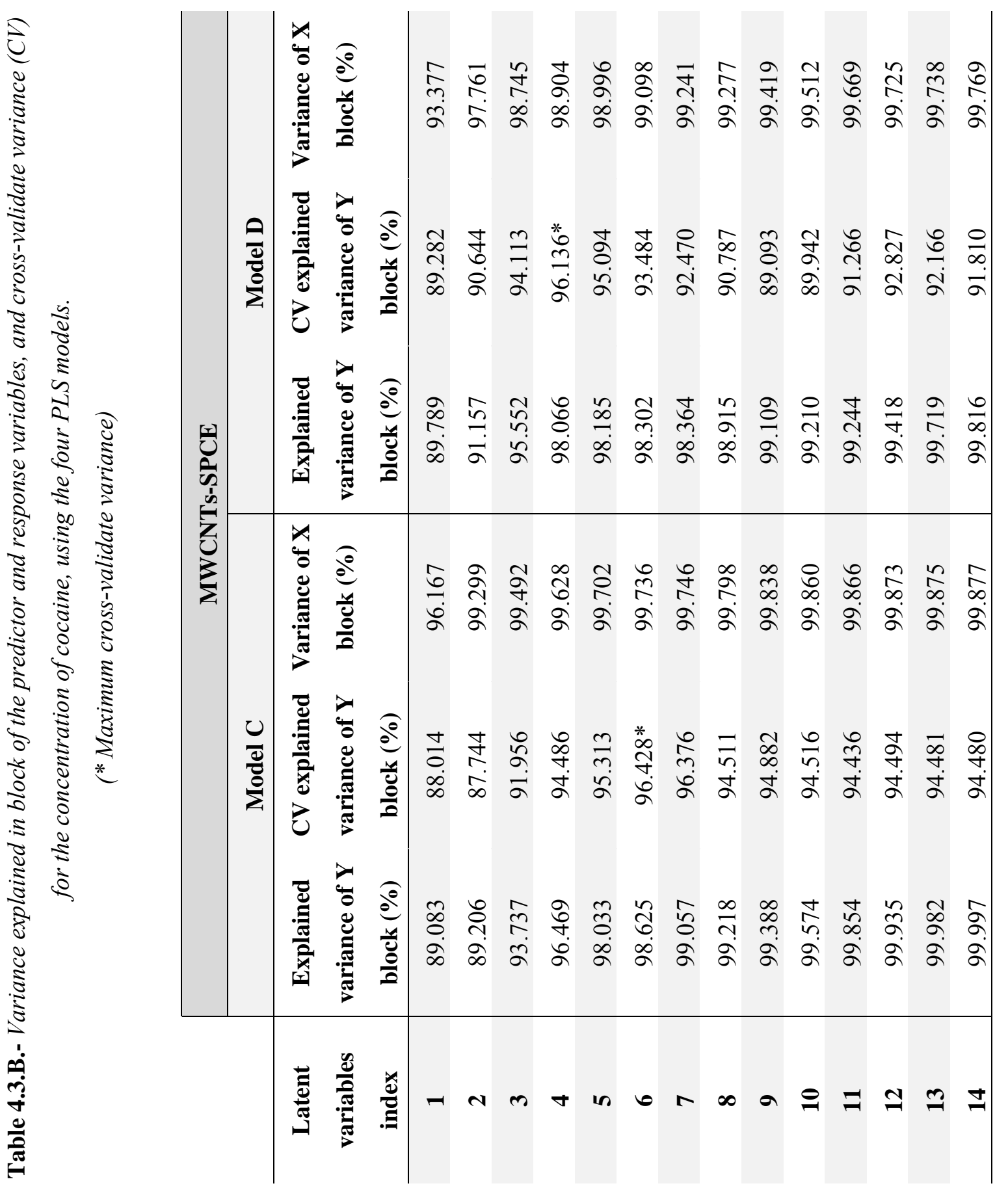
- Precision or variance in the prediction, evaluated by the estimation of the bias corrected MSEP (BCMSEP):

$$
\operatorname{BCMSEP}(k)=\frac{\sum_{i=1}^{n}\left(\hat{c}_{i}(k)-c_{i}\right)^{2}-\left[\left(\sum_{i=1}^{n}\left(\hat{c}_{i}(k)-c_{i}\right)\right)^{2} / n\right]}{n-1}
$$

- Trueness, verified by the joint confidence interval test (JCIT or $\left.F_{c a l}\right)$ of the slope and intercept of the real concentrations vs. predicted concentrations, where:

$H_{0}$ : The intercept is 0 and the slope is 1.

$H_{a}$ : The intercept is different from 0 and the slope is different from 1.

$$
\begin{gathered}
F_{c a l}=\frac{\left(0-b_{o}\right)^{2}+2 \bar{c}\left(0-b_{0}\right)\left(1-b_{1}\right)+\left(\sum c_{i}^{2} / n\right)\left(1-b_{1}\right)^{2}}{2\left(s_{y x}^{2} / n\right)} \\
\text { C.R. }=\left\{F_{c a l}>F_{\alpha, 2, n-2}\right\}
\end{gathered}
$$

where $b_{0}$ and $b_{1}$ are the intercept and the slope, respectively, and $s_{y x}$ is the standard deviation $\left(F_{0.05,2,6}=5.1\right)$.

As it can be seen in table 4.4, the best analytical results were obtained in the case of using different SPCEs to record each voltammogram of the model (Model B).

The models constructed with the voltammograms recorded using a single SPCE (Model A) or a single MWCNTs-SPCE (Model C) did not lead to satisfactory results, since the successive measurements and the application of high voltages damaged or modified the initial working surface.

The use of different MWCNTs-SPCEs (Model D) for recording each voltammogram slightly improved the quality of these figures of merit, but not as much as the use of different SPCEs (Model B). The manual MWCNTs-casting 
incorporates irreproducibility in the manufacture of the devices, which is avoided using bare SPCEs.

Table 4.4.- Predictions for the PLS models constructed for the determination of cocaine by square-wave voltammetry.

\begin{tabular}{c|cc|cc}
\cline { 2 - 5 } & \multicolumn{2}{|c|}{ SPCE } & \multicolumn{2}{c}{ MWCNTs-SPCE } \\
\cline { 2 - 5 } & Model A & Model B & Model C & Model D \\
\hline MSEP & 689.5 & 6.7 & 102.9 & 132.5 \\
SEP & 26.3 & 2.6 & 10.1 & 11.5 \\
RRMSEP & 35.0 & 3.4 & 13.5 & 15.3 \\
BCMSEP & 786.7 & 5.9 & 21.4 & 141.5 \\
JCIT (Fcal) & 0.0 & 0.8 & 3.0 & 0.5 \\
\hline
\end{tabular}

\section{Latent variables interpretation}

With the aim of explaining the different latent variables, the loadings of the potentials for the formation of each latent variable were studied (Figure 4.10).

The loadings of the first latent variable, with positive values, are analogous for the four analytes, reflecting the shape of a voltammogram mixture of the four drugs. The significance of this variable is linked to the size of the votammogram (total intensity) and, consequently, to the concentration of the analyte of interest. Thus, the first latent variable is interpreted as a size factor [61].

As it has been seen in figure 4.7, cocaine and codeine signals are overlapped. The PLS model has also depicted this effect, since it was necessary at least three latent variables to discriminate the voltammetric signals of both compounds (Figure 4.10). 

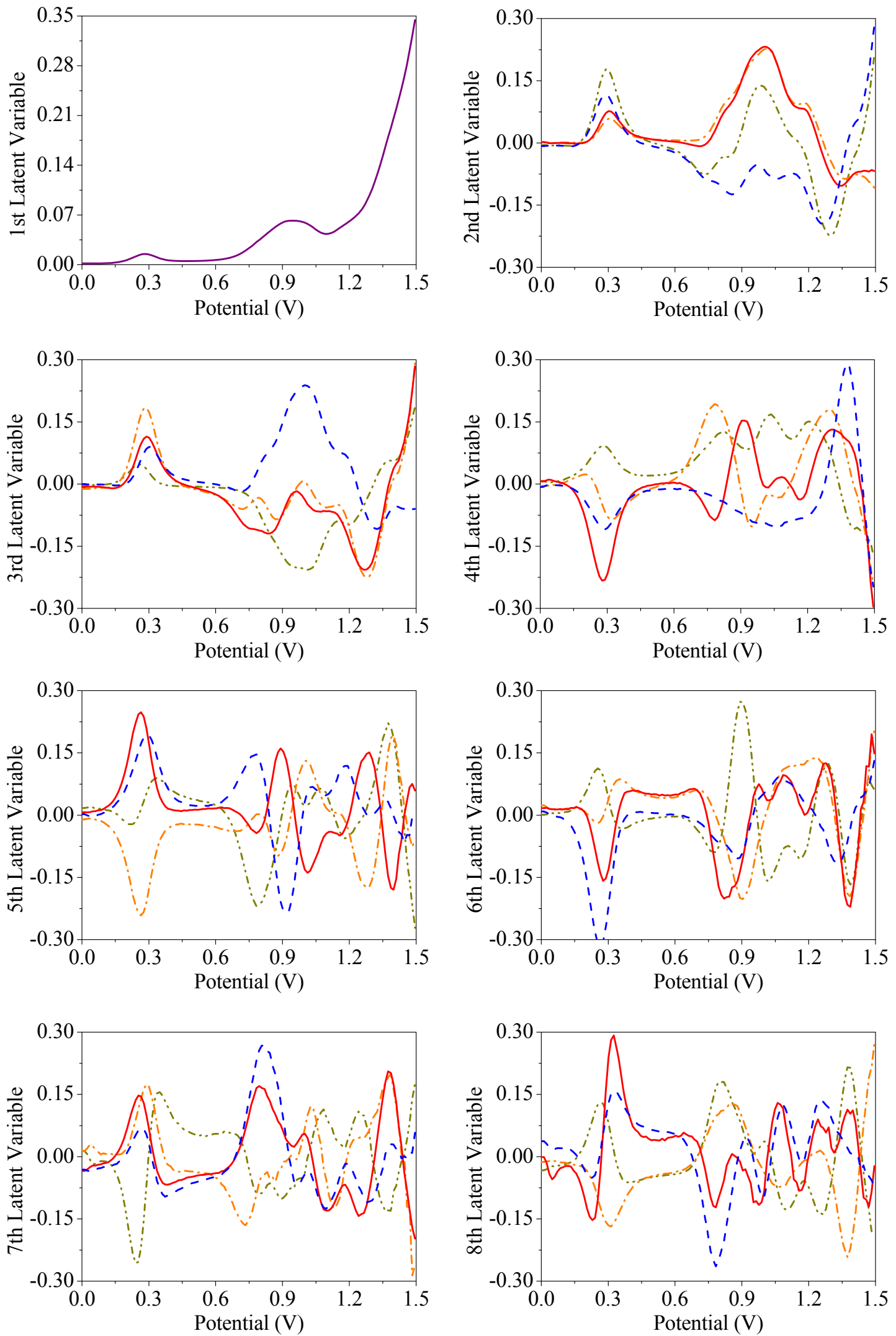

Figure 4.10.- Loadings of each latent variable of the PLS Model B for each drug: caffeine $(---)$, codeine (--.), paracetamol (-..-.) and cocaine $(-)$. 


\section{Prediction stage}

Finally, the PLS model constructed using different SPCEs to record each voltammogram (Model B) was used to determine the concentration of cocaine in street samples supplied by the local police. According to the PLS model, the purity of these samples were $[77.2 \pm 2.6] \%(n=6, \alpha=0.05)$ and $[80.5 \pm 3.0] \%(n=6, \alpha=$ $0.05)$, which agrees with the reference value $(76.7 \%$ and $82.3 \%$, respectively) (Table 4.5).

Table 4.5.- Analytical characteristics in the detection of cocaine in confiscated street samples using SPCEs and the optimum PLS model.

\begin{tabular}{ccccc}
\hline $\begin{array}{c}\text { Reference value } \\
(\%)\end{array}$ & $\begin{array}{c}\text { Cocaine } \\
\text { detected (\%) }\end{array}$ & $\begin{array}{c}\text { 95 \% confidence } \\
\text { interval for mean (\%) }\end{array}$ & Recovery (\%) & RSD (\%) \\
\hline 77.8 & & 101.4 & \\
79.9 & & 104.2 & \\
76.7 & 94.7 & 97.4 & 3.2 \\
& 79.3 & & 103.2 & \\
& 77.8 & & 101.4 & \\
& 73.7 & 96.1 & \\
& 77.5 & & 94.2 & \\
& 79.7 & & 96.8 & \\
& 81.0 & & 98.4 & \\
& 84.8 & & 103.1 & \\
& 82.6 & & 100.4 & \\
& 77.6 & & 94.3 &
\end{tabular}




\section{5.- CONCLUSIONS}

Although cocaine has a well-defined voltammetric peak when using SPCEs, the oxidation peaks of codeine, paracetamol and caffeine, which usually appear in real-life samples, can overlap this signal interfering in the analysis. The incorporation of a $3.0 \mathrm{mg} / \mathrm{mL}$ suspension of MWCNTs in DMF to the surface of carbon working electrodes permits a better separation between these peaks.

Moreover, the good reproducibility of the developed MWCNTs-SPCEs for cocaine detection, $\mathrm{RSD}=5.6 \%(n=7)$ in the concentration range from 10.0 to 155.0 $\mu \mathrm{M}$, allows the simple analysis of cocaine street samples using OLS regressions to build the calibration curves. The use of SPCEs without any modification involves the use of PLS regressions, taking into account different concentrations of cocaine, codeine, paracetamol and caffeine to build the regression models. PLS models with good analytical performance have been constructed, which have also led to the successful determination of cocaine in street samples.

\section{6.- REFERENCES}

1. UNODC, World Drug Report, (United Nations publication). 2012: Vienna.

2. Komorsky-Lovric, S., I. Galic, and R. Penovski, Voltammetric determination of cocaine microparticles. Electroanalysis 11, 1999, p. 120-123.

3. Volkow, N.D., Cocaine: Abuse and Addiction. National Institute on Drug Abuse, 2010.

4. Institóris, L., et al., The frequency of alcohol, illicit and licit drug consumption in the general driving population in South-East Hungary. Forensic Science International 224, 2013, p. 37-43.

5. Magalhães, E.J., et al., Evaluation of the composition of street cocaine seized in two regions of Brazil. Science and Justice 53, 2013, p. 425-432. 
6. Evrard, I., S. Legleye, and A. Cadet-Taïrou, Composition, purity and perceived quality of street cocaine in France. International Journal of Drug Policy 21, 2010, p. 399-406.

7. Bjørk, M.K., et al., Quantification of 31 illicit and medicinal drugs and metabolites in whole blood by fully automated solid-phase extraction and ultra-performance liquid chromatography-tandem mass spectrometry. Analytical and Bioanalytical Chemistry 405, 2013, p. 2607-2617.

8. Sergi, M., et al., Pressurized-liquid extraction for determination of illicit drugs in hair by LC-MS-MS. Analytical and Bioanalytical Chemistry 405, 2013, p. 725-735.

9. Zancanaro, I., et al., Prescription and illicit psychoactive drugs in oral fluidLC-MS/MS method development and analysis of samples from Brazilian drivers. Forensic Science International 223, 2012, p. 208-216.

10. Pascali, J.P., F. Bortolotti, and F. Tagliaro, Recent advances in the application of CE to forensic sciences, an update over years 2009-2011. Electrophoresis 33, 2012, p. 117-126.

11. Elnemma, E.M., M.A. Hamada, and S.S.M. Hassan, Liquid and poly (vinyl chloride) matrix membrane electrodes for the selective determination of cocaine in illicit powders. Talanta 39, 1992, p. 1329-1335.

12. Watanabe, K., et al., New cocaine-selective membrane electrode. Analytica Chimica Acta 316, 1995, p. 371-375.

13. Oiye, E.N., et al., Voltammetric determination of cocaine in confiscated samples using a cobalt hexacyanoferrate film-modified electrode. Forensic Science International 192, 2009, p. 94-97.

14. de Oliveira, L.S., et al., Voltammetric analysis of cocaine using platinum and glassy carbon electrodes chemically modified with Uranyl Schiff base films. Microchemical Journal 110, 2013, p. 374-378. 
15. de Oliveira, L.S., et al., Voltammetric determination of cocaine in confiscated samples using a carbon paste electrode modified with different [UO $\mathrm{UO}_{2}(\mathrm{X}$ MeOSalen) $\left.\left(\mathrm{H}_{2} \mathrm{O}\right)\right] \cdot \mathrm{H}_{2} \mathrm{O}$ complexes. Sensors (Switzerland) 13, 2013, p. 76687679.

16. Asturias-Arribas, L., et al., CYP450 biosensors based on screen-printed carbon electrodes for the determination of cocaine. Analytica Chimica Acta 685, 2011, p. 15-20.

17. Asturias-Arribas, L., et al., Electrochemical determination of cocaine using screen-printed cytochrome P450 $2 B 4$ based biosensors. Talanta 105, 2013, p. $131-134$.

18. Baker, B.R., et al., An electronic, aptamer-based small-molecule sensor for the rapid, label-free detection of cocaine in adulterated samples and biological fluids. Journal of the American Chemical Society 128, 2006, p. 3138-3139.

19. Freeman, R., et al., Self-assembly of supramolecular aptamer structures for optical or electrochemical sensing. Analyst 134, 2009, p. 653-656.

20. Golub, E., et al., Electrochemical, Photoelectrochemical, and Surface Plasmon Resonance Detection of Cocaine Using Supramolecular Aptamer Complexes and Metallic or Semiconductor Nanoparticles. Analytical Chemistry 81, 2009, p. 9291-9298.

21. Hua, M., et al., Quantum dots as immobilized substrate for electrochemical detection of cocaine based on conformational switching of aptamer. Journal of Electroanalytical Chemistry 662, 2011, p. 306-311.

22. Hua, M., et al., Label-free electrochemical cocaine aptasensor based on a target-inducing aptamer switching conformation. Analytical Sciences 26, 2010, p. 1265-1270. 
23. Swensen, J.S., et al., Continuous, real-time monitoring of cocaine in undiluted blood serum via a microfluidic, electrochemical aptamer-based sensor. Journal of the American Chemical Society 131, 2009, p. 4262-4266.

24. Wen, Y., et al., DNA nanostructure-decorated surfaces for enhanced aptamer-target binding and electrochemical cocaine sensors. Analytical chemistry 83, 2011, p. 7418-7423.

25. Zhang, D.W., et al., An electrochemical aptasensor based on enzyme linked aptamer assay. Biosensors and Bioelectronics 31, 2012, p. 363-368.

26. Suleiman, A.A. and Y. Xu, An amperometric immunosensor for cocaine. Electroanalysis 10, 1998, p. 240-243.

27. Zuo, X., Y. Xiao, and K.W. Plaxco, High specificity, electrochemical sandwich assays based on single aptamer sequences and suitable for the direct detection of small-molecule targets in blood and other complex matrices. Journal of the American Chemical Society 131, 2009, p. 69446945.

28. Du, Y., et al., Solid-state probe based electrochemical aptasensor for cocaine: A potentially convenient, sensitive, repeatable, and integrated sensing platform for drugs. Analytical Chemistry 82, 2010, p. 1556-1563.

29. He, J.L., et al., Electrochemical aptameric sensor based on the Klenow fragment polymerase reaction for cocaine detection. Biosensors and Bioelectronics 26, 2011, p. 4222-4226.

30. White, R.J., et al., Optimization of electrochemical aptamer-based sensors via optimization of probe packing density and surface chemistry. Langmuir 24, 2008, p. 10513-10518.

31. White, R.J. and K.W. Plaxco, Engineering new aptamer geometries for electrochemical aptamer-based sensors. Proceedings of SPIE - The International Society for Optical Engineering 7321, 2009, p. 732105. 
32. Zhang, H., et al., Aptamer/quantum dot-based simultaneous electrochemical detection of multiple small molecules. Analytica Chimica Acta 688, 2011, p. 99-103.

33. Wang, J., Nanomaterial-based electrochemical biosensors. Analyst 130, 2005, p. 421-426.

34. Trojanowicz, M., Analytical applications of carbon nanotubes: a review. TrAC - Trends in Analytical Chemistry 25, 2006, p. 480-489.

35. Albareda-Sirvent, M., A. Merkoçi, and S. Alegret, Configurations used in the design of screen-printed enzymatic biosensors. A review. Sensors and Actuators, B: Chemical 69, 2000, p. 153-163.

36. Alonso-Lomillo, M.A., O. Domínguez-Renedo, and M.J. Arcos-Martínez, Screen-printed biosensors in microbiology; A review. Talanta 82, 2010, p. 1629-1636.

37. Cooper, J. and T. Cass, Biosensors: A Practical Approach. 2nd ed. 2004, New York: Oxford University Press.

38. Domínguez-Renedo, O., M.A. Alonso-Lomillo, and M.J. Arcos-Martínez, Recent developments in the field of screen-printed electrodes and their related applications. Talanta 73, 2007, p. 202-219.

39. Alonso-Lomillo, M.A., et al., CYP450 2B4 covalently attached to carbon and gold screen printed electrodes by diazonium salt and thiols monolayers. Analytica Chimica Acta 633, 2009, p. 51-56.

40. del Torno-de Román, L., et al., Gluconic acid determination in wine by electrochemical biosensing. Sensors and Actuators B-Chemical 176, 2013, p. 858-862.

41. del Torno-de Román, L., et al., Fabrication and characterization of disposable sensors and biosensors for detection of formaldehyde. Talanta 86, 2011, p. 324-328. 
42. Abedul, M.T.F., et al., Voltammetric determination of cocaine in confiscated samples. Electroanalysis 3, 1991, p. 409-412.

43. Fernández-Abedul, M.T. and A. Costa-García, Flow injection analysis with amperometric detection of cocaine in confiscated samples. Analytica Chimica Acta 328, 1996, p. 67-71.

44. Garrido, J.M.P.J., et al., Spectroscopic and electrochemical studies of cocaine-opioid interactions. Analytical and Bioanalytical Chemistry 388, 2007, p. 1799-1808.

45. Freye, E. and J.V. Levy, Pharmacology and Abuse of Cocaine, Amphetamines, Ecstasy and Related Designer Drugs. 2009, NY: Springer.

46. Luo, H., et al., Investigation of the electrochemical and electrocatalytic behavior of single-wall carbon nanotube film on a glassy carbon electrode. Analytical Chemistry 73, 2001, p. 915-920.

47. Wang, J., et al., Direct electrochemistry of cytochrome c at a glassy carbon electrode modified with single-wall carbon nanotubes. Analytical Chemistry 74, 2002, p. 1993-1997.

48. Crevillen, A.G., et al., The preferential electrocatalytic behaviour of graphite and multiwalled carbon nanotubes on enediol groups and their analytical implications in real domains. Analyst 134, 2009, p. 657-662.

49. $\mathrm{Xu}, \mathrm{J} . \mathrm{Z}$., et al., An amperometric biosensor based on the coimmobilization of horseradish peroxidase and methylene blue on a carbon nanotubes modified electrode. Electroanalysis 15, 2003, p. 219-224.

50. Carrara, S., et al., Screen-printed electrodes based on carbon nanotubes and cytochrome P450scc for highly sensitive cholesterol biosensors. Biosensors and Bioelectronics 24, 2008, p. 148-150. 
51. Zhao, G.C., et al., Direct electrochemistry of cytochrome c on a multi-walled carbon nanotubes modified electrode and its electrocatalytic activity for the reduction of $\mathrm{H}_{2} \mathrm{O}_{2}$. Electrochemistry Communications 7, 2005, p. 256-260.

52. Inam, F., et al., Dimethylformamide: An effective dispersant for making ceramic-carbon nanotube composites. Nanotechnology 19, 2008.

53. Bott, A.W. and W.R. Heineman, Chronocoulometry. Current Separations 20, 2004, p. 121-126.

54. Rousseeuw, P.J. and A.M. Leroy, Robust Regression and Outlier Detection. 1989, New York: Wiley.

55. Massart, D.L., et al., Data Handling in Science and Technology 2. 2003, Amsterdam, The Netherlands: Elsevier.

56. Ríos Castro, Á., M.C. Moreno Bondi, and B.M. Simonet Suau, Técnicas espectroscópicas en química analítica. Aspectos básicos y espectrometría. Vol. I. 2012, Madrid, Spain: Síntesis.

57. Arcos, M.J., et al., Genetic-algorithm-based wavelength selection in multicomponent spectrometric determinations by PLS: Application on indomethacin and acemethacin mixture. Analytica Chimica Acta 339, 1997, p. 63-77.

58. Reguera, C., M. Julia Arcos, and M. Cruz Ortiz, An optimization procedure for determination of indomethacin and acemethacin by differential pulse adsorptive stripping voltammetry. Application on urine samples. Talanta 46, 1998, p. 1493-1505.

59. Reguera, C., M.C. Ortiz, and J. Arcos, Resolution of antiinflammatory drugs in quaternary mixtures by derivative spectrophotometry and partial least squares method (PLS). Quimica Analitica 18, 1999, p. 105-111.

60. Alonso-Lomillo, M.A., O. Domínguez-Renedo, and M.J. Arcos-Martínez, Resolution of ternary mixtures of rifampicin, isoniazid and pyrazinamide by 
differential pulse polarography and partial least squares method. Analytica Chimica Acta 449, 2001, p. 167-177.

61. Reguera, C., M.C. Ortiz, and M.J. Arcos, Differential pulse voltammetric simultaneous determination of four anti-inflammatory drugs by using soft modelling. Electroanalysis 14, 2002, p. 1699-1706.

62. Alonso-Lomillo, M.A., O. Domínguez-Renedo, and M.J. Arcos-Martínez, Resolution of binary mixtures of rifemycin $S V$ and rifampicin by UV/VIS spectroscopy and partial least-squares method (PLS). Chemistry \& Biodiversity 1, 2004, p. 1336-1343.

63. Forina, M., et al., PARVUS: An extendable package of programs for data explorative analysis, classification and regression analysis. Version 1.3, Istituto di Analisi e Tecnologie Farmaceutiche ed Alimentari, Universitá di Genova (available from the authors). 
CHAPTER 5:

CYP450 BIOSENSORS BASED ON SCREEN-PRINTED CARBON ELECTRODES FOR THE DETERMINATION OF COCAINE 

As it has been studied in the previous chapter, cocaine presents an oxidation peak at a high potential, $+1 \mathrm{~V}$ vs. $\mathrm{Ag} / \mathrm{AgCl} \mathrm{SPE}$, which could provoke the simultaneous oxidation of different analytes in chronoamperometric measurements. In order to improve this selectivity, several electrochemical immunosensors and aptasensors have been developed (Section 3.1.3.1). Thus, this chapter describes a valuable electrochemical approach for the selective and sensitive detection of cocaine using miniaturised chronoamperometric biosensors, based on the enzyme CYP2B4, which simplifies the previously reported measurement technologies.

In this way, CYP2B4 has been covalently attached to the working electrode surface of SPCEs, which has been previously functionalised with diazonium salts.

Experimental design methodology has been carried out to optimise the $\mathrm{pH}$ and the working potential, both variables that have an influence on the chronoamperometric determination of the drug. Under the optimum values of these experimental variables, calibration curves have been performed to evaluate the precision and the accuracy of the method.

Finally, the use of this kind of biosensors has been checked in the determination of cocaine in street samples, obtaining a good correlation between the electrochemical results and the reference value.

This work has been partially published in Analytica Chimica Acta 685, 2011, p.15-20, and presented at the fourth international workshop on Biosensors for food safety and environmental monitoring in Tangier, Morocco (October 2009), and at II International Workshop on Analytical Miniaturization ("lab-on-a-chip") in Oviedo, Spain (June 2010). Additionally, this work has been patented (ES 2370762 B1). 



\section{1.- INTRODUCTION}

The need for developing analytical procedures to sensitively detect addictive and dangerous drugs of abuse, such as cocaine, is well documented [1]. Although the trendiest analyses of cocaine are based on chromatography and immunoassays methods, electrochemical detection has been also reported. Cocaine has been electrochemically detected by voltammetry [2-7] and amperometry [8-10], reaching satisfactory results. Sensitive, accurate, fast response and low-cost methods can be easily developed by electrochemical techniques.

Advances in electronics have allowed electrochemical sensors to rival the most advanced optical protocols [11]. In this way, the simplicity and inherent miniaturisation afforded by screen-printing techniques can be mentioned as an illustration. Moreover, this technology has been introduced as a method for mass production of sensors and biosensors at low cost, which highlights the disposable nature of SPEs [12, 13].

Cocaine has been reported to be one of the preferred substrates of CYP2B4 [14]. The well-known mechanism of this enzyme involves the $\mathrm{N}$-demethylation of the tertiary amine in the cocaine moiety leading to the metabolite norcocaine [15]. As it has been depicted in figure 3.16, oxygen and electrons are necessary to metabolise the substrate, being the electron delivery provided by the SPCE in this case (Figure 5.1) [16-18]. Therefore, the cocaine concentration in a solution can be related to the registered chronoamperometric current.

In order to improve the selectivity of the electrochemical CYP2B4 biosensor to cocaine, experimental variables that strongly affect to the chronoamperometric response were evaluated by the experimental design methodology $[19,20]$. Thus, $\mathrm{pH}$ of the buffer solution and the working potential used to carry out the chronoamperometric analysis of cocaine were simultaneously optimised. The performance of the developed biosensor was checked in terms of reproducibility, 
repeatability, capability of detection and in the application to complex matrixes, such as cocaine street samples.

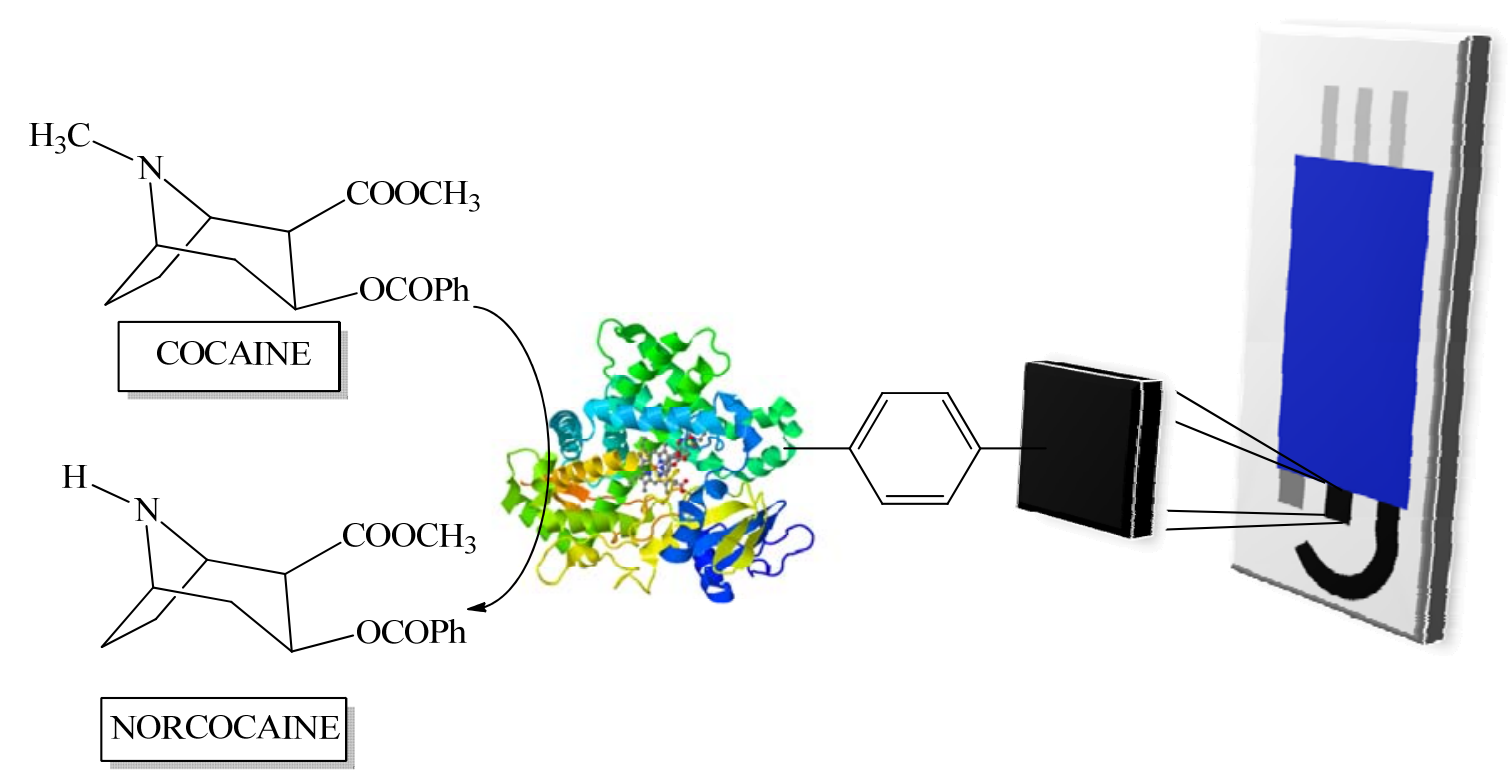

Figure 5.1.- Scheme of the developed CYP2B4 biosensor.

\section{2.-EXPERIMENTAL}

\subsection{1.- REAGENTS}

Several inks were used in the fabrication of SPEs, carbon ink named C10903P14 and platinised carbon ink C2050804D9 (Gwent Group, Torfaen, UK), $\mathrm{Ag} / \mathrm{AgCl}$ ink Electrodag $6037 \mathrm{SS}$ and silver ink Electrodag 418 (Acheson Colloiden, Scheemda, The Netherlands) and the dielectric inks 242-SB (ESL Europe, Agmet Ltd, Reading, UK), D2071120D1 (Gwent Electronic Materials, Torfaen, U.K) and Electrodag 452 SS (Acheson Colloiden, Scheemda, The Netherlands).

All solutions were prepared with water purified with a Milli-Q device that provided a resistivity of $18.2 \mathrm{M} \Omega \mathrm{cm}$. Nitrogen (99.9\%) was used to remove dissolved oxygen. 
A $100.0 \mathrm{mM} \mathrm{KNO}_{3}$ (Merck, Darmstadt, Germany) solution was used as supporting electrolyte to characterise the electrochemical behaviour of potassium ferricyanide (Merck, Darmstadt, Germany) solutions.

A $3.0 \mathrm{mM}$ solution of 4-nitrobenzenediazonium tetrafluoroborate $\left(\mathrm{N}_{2} \mathrm{C}_{6} \mathrm{H}_{4} \mathrm{NO}_{2} \quad \mathrm{BF}_{4}\right)$ (Sigma-Aldrich, Steinheim, Germany) was prepared in acetonitrile, containing $100.0 \mathrm{mM}$ tetrabutylammonium tetrafluoroborate $\left(\mathrm{NBu}_{4} \mathrm{BF}_{4}\right)$ (Sigma-Aldrich, Steinheim, Germany).

The enzyme CYP2B4 (C9095-15Y, US Biological, Swamscott, MA, USA) was used as received.

Solutions of $50.0 \mathrm{mM}$ pyrrole (Sigma-Aldrich, Steinheim, Germany) in 100.0 $\mathrm{mM} \mathrm{LiClO}_{4}$ (Panreac, Barcelona, Spain) were prepared by dissolving the adequate amount of each one in Milli-Q water.

Solutions of $40.0 \mathrm{mM} \quad N$-hydroxysuccinimide (NHS) (Sigma-Aldrich, Steinheim, Germany) and $\quad 80.0 \quad \mathrm{mM} \quad N$-(3-dimethylaminopropyl)- $N$ 'ethylcarbodiimide hydrochloride (EDC) (Fluka, Steinheim, Germany) were prepared in $10.0 \mathrm{mM}$ phosphate buffer $\mathrm{pH} 4$ and used for the covalent immobilisation procedure.

Stock standard solutions of cocaine were prepared by dissolving the adequate amount of cocaine hydrochloride (Sigma, Steinheim, Germany) in $50.0 \mathrm{mM}$ phosphate buffer $\mathrm{pH}$ 7. Subsequent standards were prepared by dilution in the same buffer.

A $50.0 \mathrm{mM}$ phosphate buffer $\left(\mathrm{NaH}_{2} \mathrm{PO}_{4} \cdot 2 \mathrm{H}_{2} \mathrm{O}\right.$, Panreac, Barcelona, Spain) and $100.0 \mathrm{mM} \mathrm{KCl}$ (Merck, Darmstadt, Germany) solution was used as supporting electrolyte. A NaOH (J.T. Baker, Deventer, The Netherlands) solution was used to adjust the $\mathrm{pH}$ value. 


\subsection{2.- APPARATUS}

SPEs were produced on a DEK 248 printing machine (DEK, Weymouth, UK).

Electrochemical measurements were made with a $\mu$ Autolab electrochemical system with GPES software (Eco Chemie, Utrecht, The Netherlands).

The $\mathrm{pH}$ of the solutions was measured with a Crison Model 2002 (Barcelona, Spain) $\mathrm{pH}$ meter.

\section{3.- METHODS}

\subsection{1.- SPES PREPARATION}

SPEs were manufactured using 4 screen polyester meshes with the patterns corresponding to conductive tracks, counter and working electrodes, reference electrode and dielectric (Figure 3.10). In order to design SPEs as much as sensitive as possible for the final determination of cocaine, the composition of the conductive tracks and the dielectric was modified, resulting in five different SPCEs. Table 5.1 shows the sequential layer deposition carried out on $0.5 \mathrm{~mm}$ thickness polyester films (HiFi Industrial Film, Dardilly, France), as well as the curing conditions for each type of electrode.

\subsection{2.- FUNCTIONALISATION OF SPCES}

\subsubsection{1.- Polypyrrole immobilisation}

Electrochemical polymerisation is a simple approach for the immobilisation of enzymes at electrode surfaces. As is has been said in section 3.2.3.2, this process 
involves the electrochemical synthesis and the consequent deposition of the conducting or non-conducting polymer on the surface of the electrode surface, while the bioelement is simultaneously trapped in the polymeric mesh [21, 22].

Table 5.1.- Composition and curing conditions of the different SPCEs manufactured by sequential layer deposition.

\begin{tabular}{c|ccccc|}
\cline { 2 - 6 } & Device I & Device II & Device III & Device IV & Device V \\
\hline 1. Conductive tracks & $\mathrm{Ag}$ & $\mathrm{Ag} / \mathrm{C}$ & $\mathrm{C}$ & $\mathrm{C}$ & $\mathrm{Ag}$ \\
$\mathrm{T}_{\text {cured }}\left({ }^{\circ} \mathrm{C}\right)$ & 120 & 60 & 60 & 60 & 120 \\
$\mathrm{t}_{\text {cured }}(\mathrm{min})$ & 20 & 30 & 30 & 30 & 20 \\
2. Reference electrode & $\mathrm{Ag} / \mathrm{AgCl}$ & $\mathrm{Ag} / \mathrm{AgCl}$ & $\mathrm{Ag} / \mathrm{AgCl}$ & $\mathrm{Ag} / \mathrm{AgCl}$ & $\mathrm{Ag} / \mathrm{AgCl}$ \\
$\mathrm{T}_{\text {cured }}\left({ }^{\circ} \mathrm{C}\right)$ & 120 & 120 & 120 & 120 & 120 \\
$\mathrm{t}_{\text {cured }}(\min )$ & 20 & 20 & 20 & 20 & 20 \\
3. Working electrode & $\mathrm{C}$ & $\mathrm{C}$ & $\mathrm{C}$ & $\mathrm{C}$ & $\mathrm{C}{ }_{\mathrm{Pt}}{ }^{* *}$ \\
$\mathrm{~T}_{\text {cured }}\left({ }^{\circ} \mathrm{C}\right)$ & 60 & 60 & 60 & 60 & 60 \\
$\mathrm{t}_{\text {cured }}($ min) & 30 & 30 & 30 & 30 & 30 \\
4. Counter electrode & $\mathrm{C}$ & $\mathrm{C}$ & $\mathrm{C}$ & $\mathrm{C}$ & $\mathrm{C}$ \\
$\mathrm{T}_{\text {cured }}\left({ }^{\circ} \mathrm{C}\right)$ & 60 & 60 & 60 & 60 & 60 \\
$\mathrm{t}_{\text {cured }}$ (min) & 30 & 30 & 30 & 30 & 30 \\
\hline 5. Dielectric material & $242-\mathrm{SB}$ & $242-\mathrm{SB}$ & $452 \mathrm{SS} *$ & $\mathrm{D} 2071120 \mathrm{D} 1$ & $242-\mathrm{SB}$ \\
$\mathrm{T}_{\text {cured }}\left({ }^{\circ} \mathrm{C}\right)$ & 120 & 120 & - & 80 & 120 \\
$\mathrm{t}_{\text {cured }}$ (min) & 60 & 60 & - & 30 & 60 \\
\hline
\end{tabular}

* UV oven cured //** $C_{P t}:$ platinised carbon

Among the conducting polymers (e.g. polyacetylene, polythiophene and polyaniline), polypyrrole and its derivatives play the leading role owing to their versatile applicability [23]. 
The deposition of a pyrrolic layer at platinum, gold or carbon surfaces has been previously carried out in aqueous solutions containing a salt such as $\mathrm{KCl}$ [24] or $\mathrm{LiClO}_{4}[18,25]$. These salts maintain the electroneutrality of the layer since the oxidised form of the polymer is positively charged [18]. The polymerisation sequence of this electropolymerisation is shown in figure 5.2 [24]. The oxidation of a monomer first produces a radical cation, which can then couple with a second radical cation or with another monomer to form a dimer. The dimer continues coupling with other pyrrole units, resulting in polymeric chains [26]. The $\pi$-conjugated system and the doping anions that are in the polymeric net produce the conductive characteristics of this polymer [27].

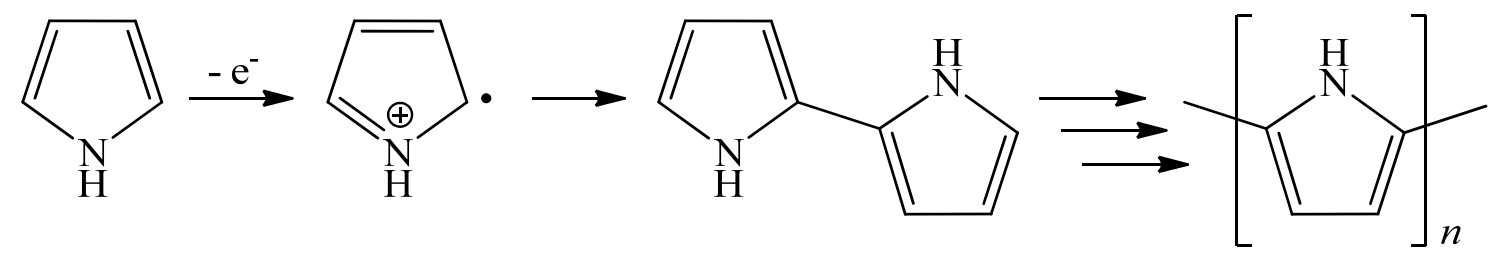

Figure 5.2.- Schematic representation of the electropolymerisation of pyrrole.

The performance of this immobilisation was carried out by depositing a prelayer of polypyrrole by scanning the potential between -100 and $+900 \mathrm{mV}$ vs. $\mathrm{Ag} / \mathrm{AgCl} \mathrm{SPE}$ at a scan rate of $10 \mathrm{mV} \mathrm{s}^{-1}$ for one complete cycle in a $50.0 \mathrm{mM}$ pyrrole and $100.0 \mathrm{mM} \mathrm{LiClO}_{4}$ solution (Figure 5.3) [18]. This polypyrrole prelayer was expected to offer a stronger biocatalytic film adhesion [28].

The polypyrrole-CYP2B4 film was subsequently grown onto the carbon working electrode. In order to carry out this electrodeposition, the electrode was

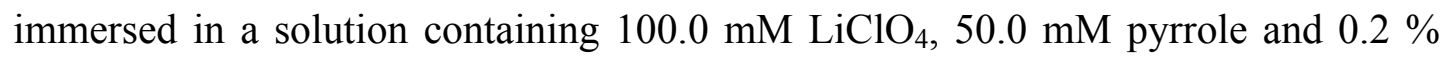
$(\mathrm{v} / \mathrm{v})$ of the CYP2B4 solution, and the potential was scanned twice between - 100 and $900 \mathrm{mV}$ vs. $\mathrm{Ag} / \mathrm{AgCl} \mathrm{SPE}$ at a scan rate of $10 \mathrm{mV} \mathrm{s}^{-1}$ [18]. The biomolecules present in the immediate vicinity of the electrode surface were thus incorporated into the growing polymer (Figure 5.4) [23]. 


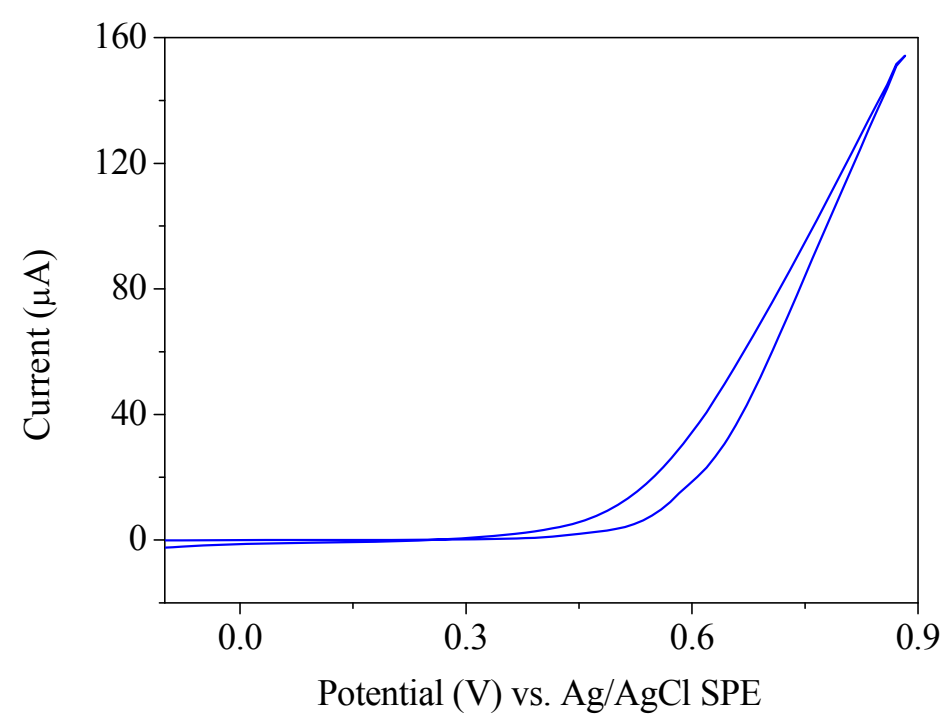

Figure 5.3.- Cyclic voltammogram of the electrodeposition of a layer of polypyrrole on the carbon working electrode.

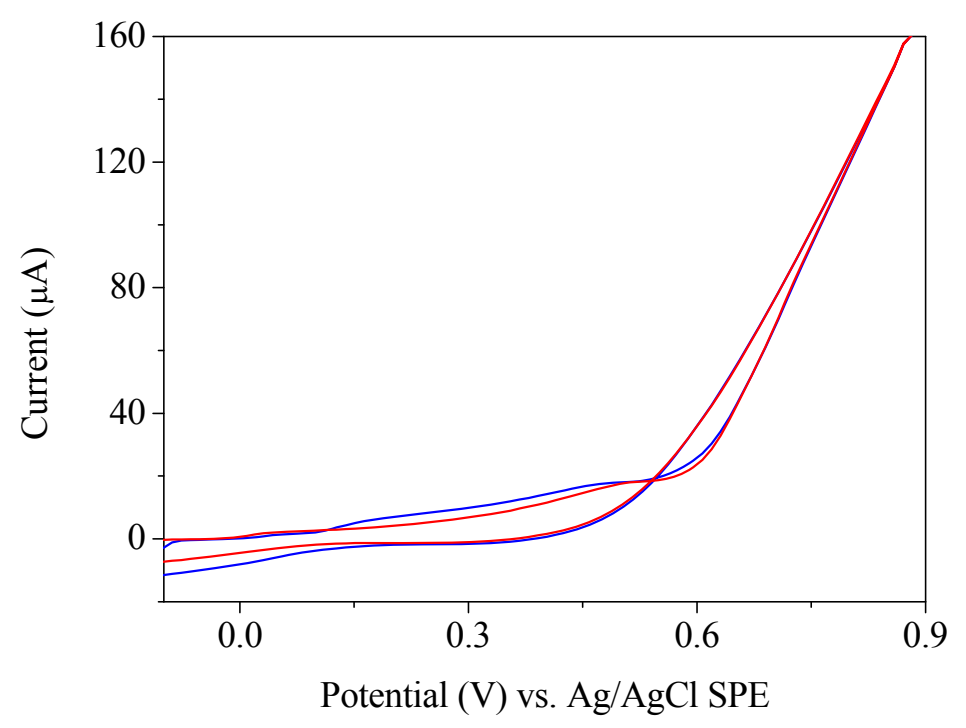

Figure 5.4.- Cyclic voltammogram of the electrodeposition of polypyrrole and CYP2B4 from a solution containing the monomer and the enzyme. 


\subsubsection{2.- Covalent-bond immobilisation}

Among all types of enzyme immobilisation (section 3.2.3.2), covalent bonding leads to more stable and reproducible biosensors due to the orientation and the strong attachment of the biological element to the transducer. This kind of immobilisation implies a functionalisation step of the working electrode before the attachment of the enzyme.

Electrografting is a versatile and a powerful technique to modify carbon, metallic and semiconductive surfaces [29]. In this way, in order to incorporate functional groups on the carbon working electrode (Figure 5.5), the transducer was immersed in a $3.0 \mathrm{mM}$ solution of $\mathrm{N}_{2} \mathrm{C}_{6} \mathrm{H}_{4} \mathrm{NO}_{2} \mathrm{BF}_{4}$. The grafting process was conducted by sweeping the potential between +800 and $-400 \mathrm{mV}$ vs. $\mathrm{Ag} / \mathrm{AgCl} \mathrm{SPE}$ at a scan rate of $200 \mathrm{mV} \mathrm{s}^{-1}[17,30]$. Two sequential scans were performed (Figure 5.6).
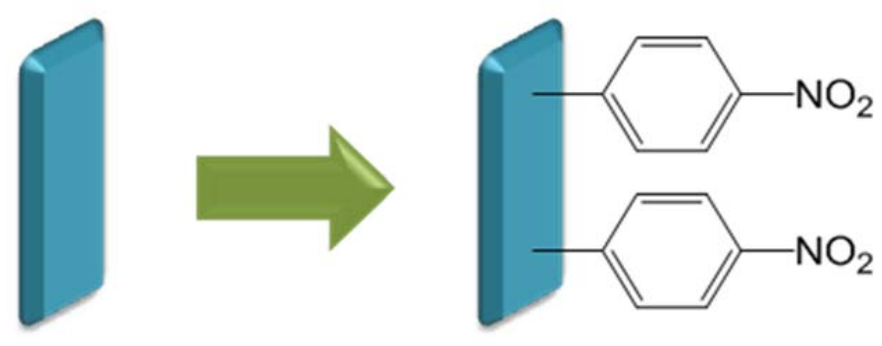

Figure 5.5.- Formation of a diazonium salt monolayer on the surface of the electrode.

Then, the aryl diazonium salt modified SPCE was immersed in a deoxygenated 9:1 water/ethanol solution, containing $100.0 \mathrm{mM} \mathrm{KCl}$. The potential was swept twice between 0.0 and $-1.7 \mathrm{~V}$ vs. $\mathrm{Ag} / \mathrm{AgCl} \mathrm{SPE}$ at a scan rate of $200 \mathrm{mV}$ $\mathrm{s}^{-1}$ (Figure 5.7) [17, 30]. A reduction peak was observed in the first voltammetric scan due to the reduction of the nitro groups into amino groups at a potential of -1.2 $\mathrm{V}$ vs. $\mathrm{Ag} / \mathrm{AgCl} \mathrm{SPE}$. In the second scan, the two reversible peaks were associated to 
the amine $\leftrightarrow$ hydroxylamine equilibrium. These amine groups provided a physical and electrical connection with the enzyme (Figure 5.8) [31].

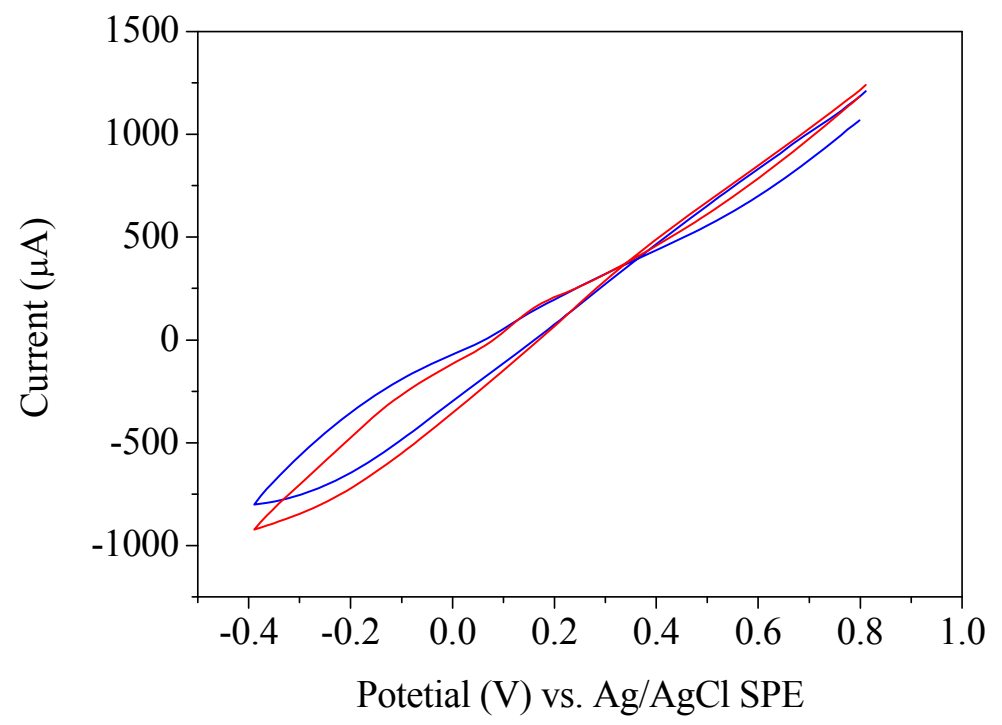

Figure 5.6.- Formation of the diazonium salt monolayer in the SPCE through two voltammetric scans in a acetonitrile solution containing $3 \mathrm{mM} \mathrm{N}_{2} \mathrm{C}_{6} \mathrm{H}_{4} \mathrm{NO}_{2} \mathrm{BF}_{4}$ and 100.0 $\mathrm{mMNBu}_{4} \mathrm{BF}_{4}$. Scan rate $200 \mathrm{mV} \mathrm{s}^{-1}$.

Nonetheless, $\mathrm{SPC}_{\mathrm{Pt}} \mathrm{Es}$ showed a different behaviour towards the electrografting of the diazonium salts. Platinum metal electrodes have been reported to form reducing phases upon its reduction in dry organic solvents, such as DMF. The electrochemical process involves an electron transfer coupled to the deposition of the electrolyte cation. As these platinum phases have been shown to exhibit strong reducing properties, this specific reactivity has been used for inducing the grafting of aryl groups onto platinum surfaces and the electroless reduction of diazonium salts [32].

In this way, the performance of the electrodeposition of the diazonium salts in the $\mathrm{SPC}_{\mathrm{Pt}} \mathrm{E}$ and the reduction of the nitro groups was carried out in a single step (Figure 5.9). As a consequence, the reduction peak of the nitro groups were not 
shown in the voltammogram registered in ethanol:water (Figure 5.10), although the equilibrium amine $\leftrightarrow$ hydroxylamine was observed (Figure 5.10. inset), giving evidence of the presence of the reduced diazonium salt in the surface of the platinised carbon electrode.

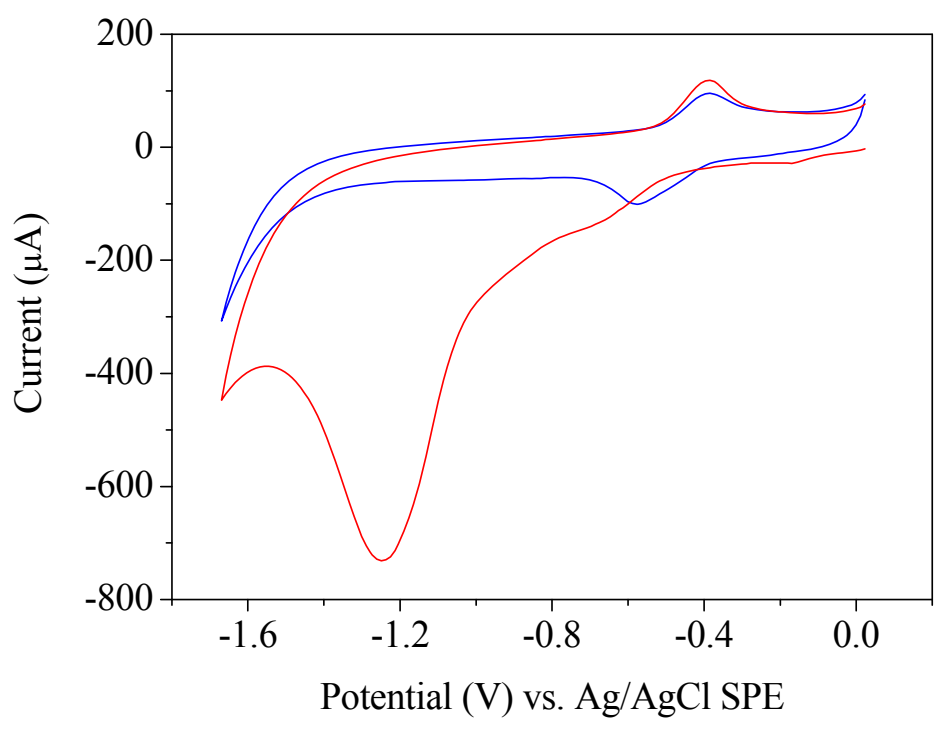

Figure 5.7.- Cyclic voltammogram of the reduction of the nitro groups from the diazonium salt in a deoxidised $100.0 \mathrm{mM} \mathrm{KCl}$ water:etanol (9:1) solution. Scan rate $200 \mathrm{mV} \mathrm{s}^{-1}$.
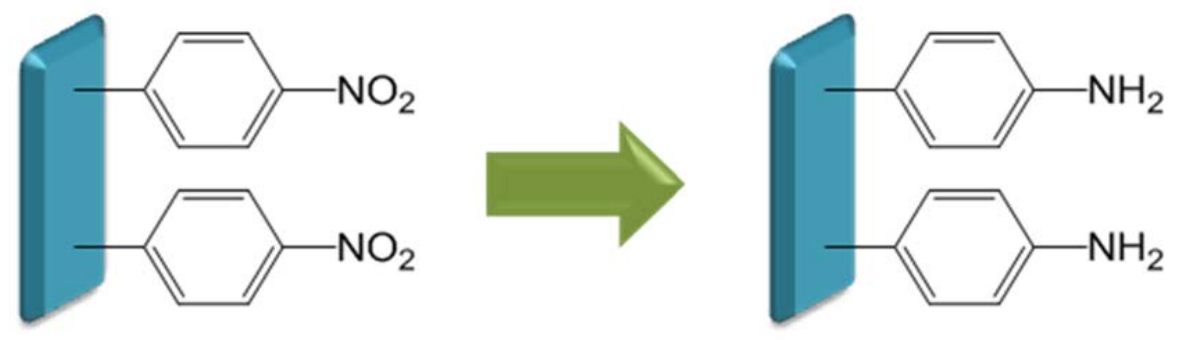

Figure 5.8.- Reduction of the nitro groups on the functionalised working electrode. 


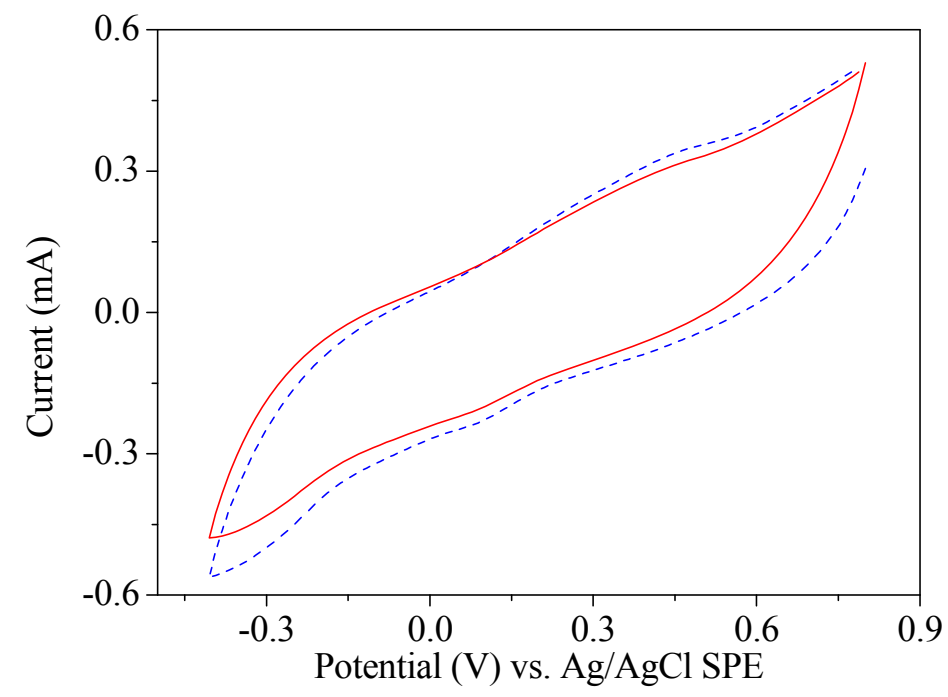

Figure 5.9.- Cyclic voltammograms of the grafting of the diazonium salt in the surface of the $S_{P} C_{P t} E$ through two scans in a $3.0 \mathrm{mM}$ diazonium salt solution in dry acetonitrile.

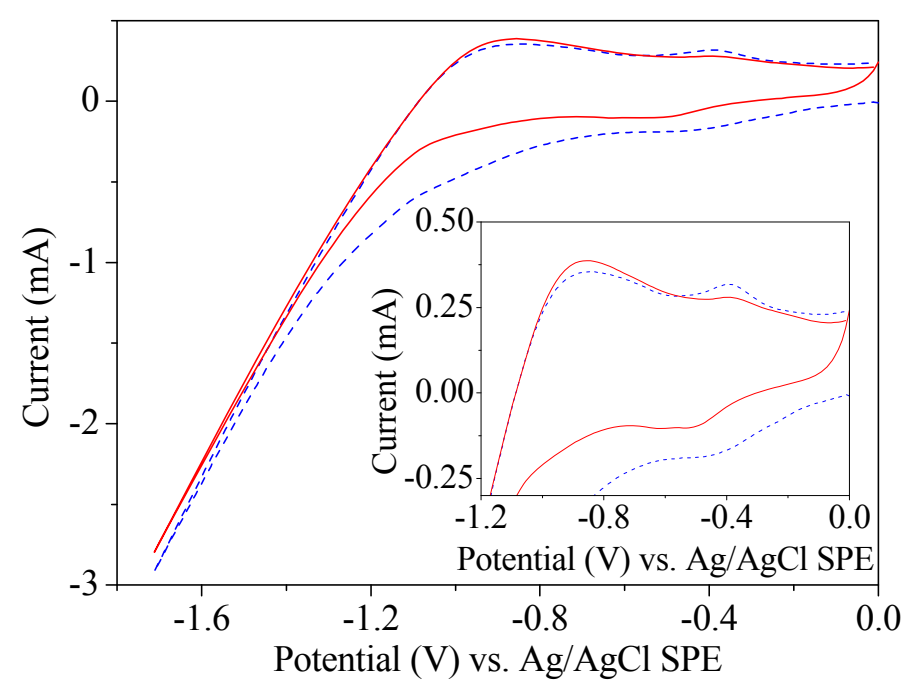

Figure 5.10.- Voltammetric behaviour of the diazonium salt modified $S P C_{P_{t}} E$ in a deoxygenated ethanol:water solution containing $100.0 \mathrm{mM} \mathrm{KCl}$. (inset: Amine $\leftrightarrow$ hydroxylamine equilibrium). 
The covalent immobilisation of CYP450 takes place thanks to the formation of amide bonds between the amino groups from the functionalised working electrode and the carboxylic groups from the enzyme, catalysed by EDC and NHS (Figure 5.11) $[17,33]$. In this way, EDC is used to form an active ester (o-acylisourea), which reacts so slowly with amines that can be hydrolysed in aqueous solutions. The addition of NHS to the reaction increases the stability of the active intermediate, facilitating the amide bond formation [34].

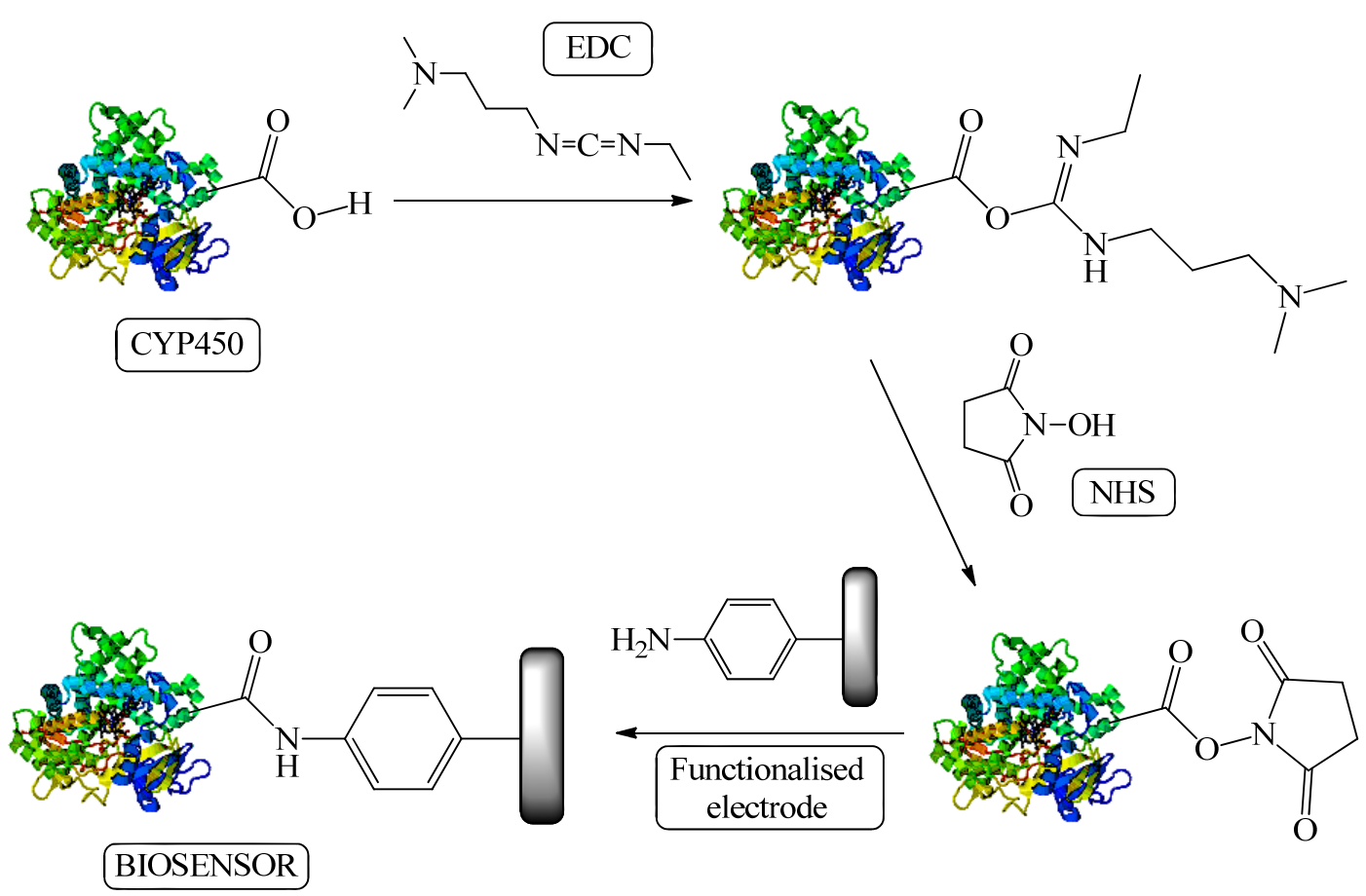

Figure 5.11.- Formation of a covalent bond between the enzyme and the transducer by means of the reaction between a carboxylic group from the enzyme and the aminofunctionalised surface of the working electrode mediated by EDC and NHS.

In order to perform this reaction on the amino-functionalised surface, the working electrode was washed using a $10.0 \mathrm{mM}$ phosphate buffer $\mathrm{pH}$. Then, $5 \mu \mathrm{L}$ of a CYP450 solution was dropped over it. Next, $2 \mu \mathrm{L}$ of a $40.0 \mathrm{mM}$ NHS solution and $2 \mu \mathrm{L}$ of an $80.0 \mathrm{mM}$ EDC solution in $10.0 \mathrm{mM}$ phosphate buffer $\mathrm{pH} 4$ were added (Figure 5.12). The mixture was left to react for $90 \mathrm{~min}$ at $4{ }^{\circ} \mathrm{C}$. 


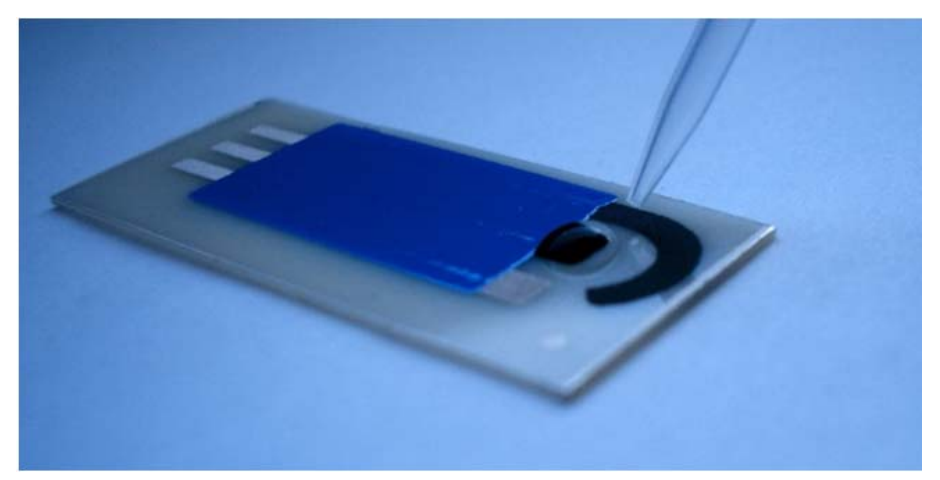

Figure 5.12.- Deposition of the enzyme, EDC and NHS solutions on the functionalised surface of the working electrode.

The biosensor was finally washed in a stirred solution containing $100.0 \mathrm{mM}$ $\mathrm{KCl}$ and $50.0 \mathrm{mM}$ phosphate buffer at $\mathrm{pH} 8.1$ for $1 \mathrm{~min}$, in order to eliminate the non-covalently attached enzyme. The biosensor was stored in a blank buffer solution at $4{ }^{\circ} \mathrm{C}$.

\subsection{3.- MEASURING PROCEDURE}

Electrochemical measurements were carried out in a batch system by voltammetry and chronoamperometry using the different SPCEs and CYP450 modified SPCEs, respectively.

Cyclic voltammetric measurements in $5.7 \mathrm{mM}$ ferricyanide solutions were made at room temperature in a cell containing $5 \mathrm{~mL}$ of a $100.0 \mathrm{mM} \mathrm{KNO}_{3}$ solution, scanning the potential between +800 and $-400 \mathrm{mV}$ vs. $\mathrm{Ag} / \mathrm{AgCl} \mathrm{SPE}$ at a scan rate of $100 \mathrm{mV} \mathrm{s}^{-1}$.

Chronoamperometric measurements were made at room temperature in a cell containing $5 \mathrm{~mL}$ of a $50.0 \mathrm{mM}$ phosphate buffer and $100.0 \mathrm{mM} \mathrm{KCl}$ solution, of the desired $\mathrm{pH}$, with constant stirring. The working electrode operated at $-250 \mathrm{mV}$ vs. $\mathrm{Ag} / \mathrm{AgCl} \mathrm{SPE}$, except for the experimental variables optimisation process. For the 
biosensor characterisation, identical volumes of a $1.0 \mu \mathrm{M}$ cocaine solution were added after reaching a stable baseline.

\subsection{4.- REAL SAMPLE PREPARATION}

Confiscated street cocaine samples were analysed. After sample homogenisation, an aliquot was dissolved in $50.0 \mathrm{mM}$ phosphate buffer $\mathrm{pH} 7$ and centrifuged at $+4{ }^{\circ} \mathrm{C}$ for $1 \mathrm{~min}$ at $13000 \mathrm{rpm}$. Then, a volume of $100 \mu \mathrm{L}$ from the supernatant was brought to $100 \mathrm{~mL}$ of $50.0 \mathrm{mM}$ phosphate buffer $\mathrm{pH} 7$.

\section{4.- RESULTS AND DISCUSSION}

\subsection{1.- SPCES CHARACTERISATION}

The definition of the different components of the SPCEs involved the employment of various inks, which significantly influence the sensitivity of the final device. Therefore, several cyclic voltammograms of a $5.7 \mathrm{mM}$ ferricyanide solution were recorded using the five developed SPCEs (Figure 5.13). The redox peak intensities of $\left[\mathrm{Fe}(\mathrm{CN})_{6}\right]^{4-} /\left[\mathrm{Fe}(\mathrm{CN})_{6}\right]^{3-}$ in a $100.0 \mathrm{mM}$ solution of $\mathrm{KNO}_{3}$ were used as sensitivity identification of the built SPCEs.

Device I, manufactured with silver conductive paths, carbon working electrode and 242-SB dielectric material, led to the optimum transducer to be covalently modified with CYP450 for the selective determination of cocaine.

Although devices III and IV presented voltammetric signals comparable to the device I, their dielectric material was degraded in the organic media required for the enzymatic immobilisation. 
In the case of devices II and V, which were built with the same insulating ink than the chosen device I, the ferricyanide peaks were not very well defined due to the high resistivity of the $\mathrm{C} / \mathrm{Ag}$ conductive tracks and the high capacitive current, respectively.
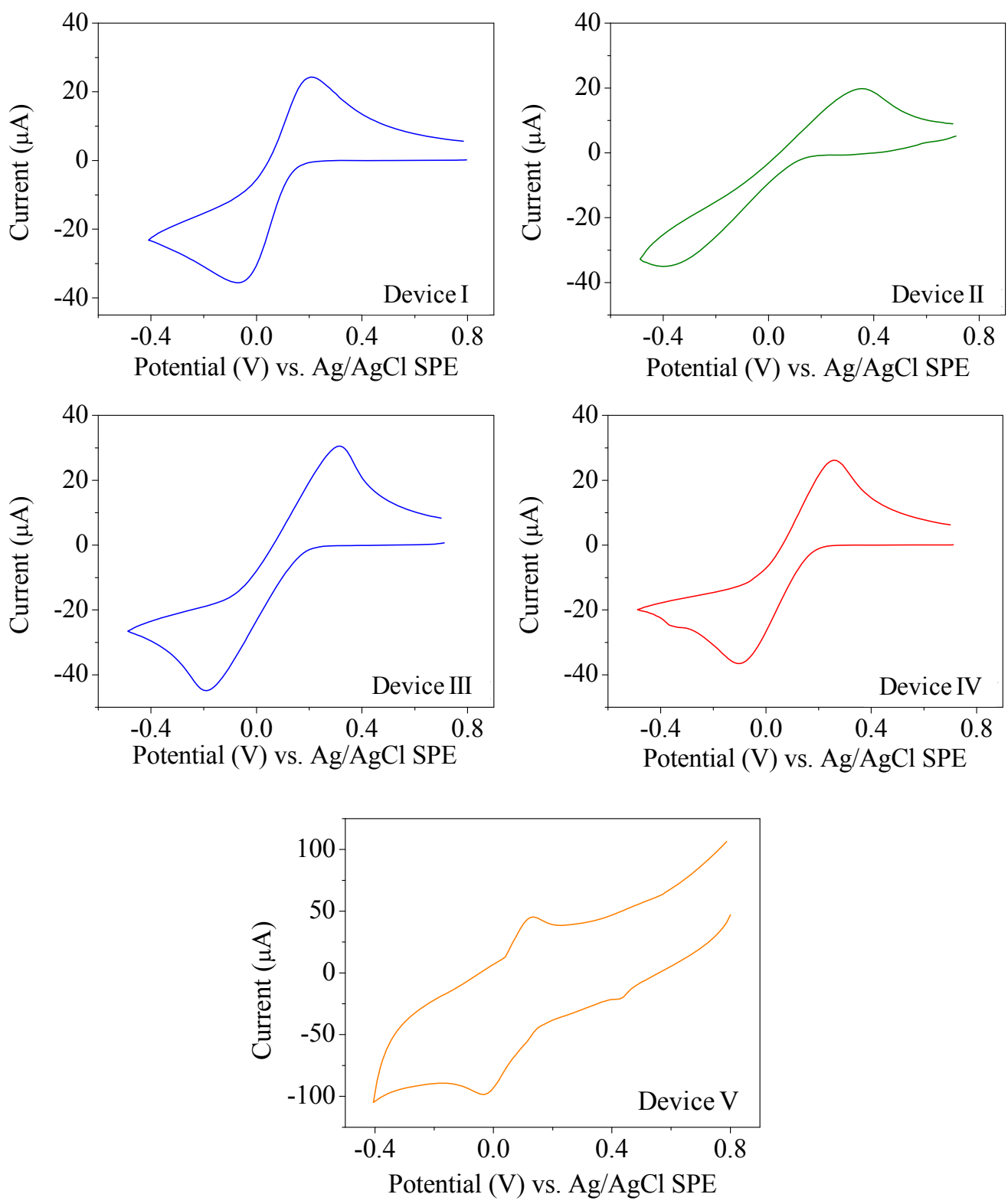

Figure 5.13.- Cyclic voltammograms of a $5.7 \mathrm{mM}$ ferricyanide solution recorded using the five types of SPCEs. 


\subsection{2.- OPTIMISATION OF THE INFLUENTIAL VARIABLES ON THE CHRONOAMPEROMETRIC MEASURES WITH THE CYP450-BIOSENSOR}

Even if cocaine is one of the preferred substrates of CYP450, it is a highly important issue to obtain the optimum conditions of the experimental variables that can influence the chronoamperometric response of cocaine, in order to develop a selective biosensor.

Optimisation of an analytical problem or an analytical device implies the study of a limited number of factors. Experimental designs are based on varying all factors simultaneously at a limited number of factor levels, allowing experiments to take place in the whole factor range. They reveal high precision at a minimum experimental effort and enable factor interactions to be detected [35]. Therefore, a $2^{2}$ central composite design was planned to optimise $\mathrm{pH}$ and working potential, selecting two levels for each factor (Figure 5.14) [35-37]:

$$
\begin{array}{cc}
\mathrm{pH}(-)=6 & \text { Working potential }(-)=-400 \mathrm{mV} \text { vs. } \mathrm{Ag} / \mathrm{AgCl} \\
\mathrm{pH}(0)=8 & \text { Working potential }(0)=-250 \mathrm{mV} \text { vs. } \mathrm{Ag} / \mathrm{AgCl} \\
\mathrm{pH}(+)=10 & \text { Working potential }(+)=-100 \mathrm{mV} \text { vs. } \mathrm{Ag} / \mathrm{AgCl}
\end{array}
$$

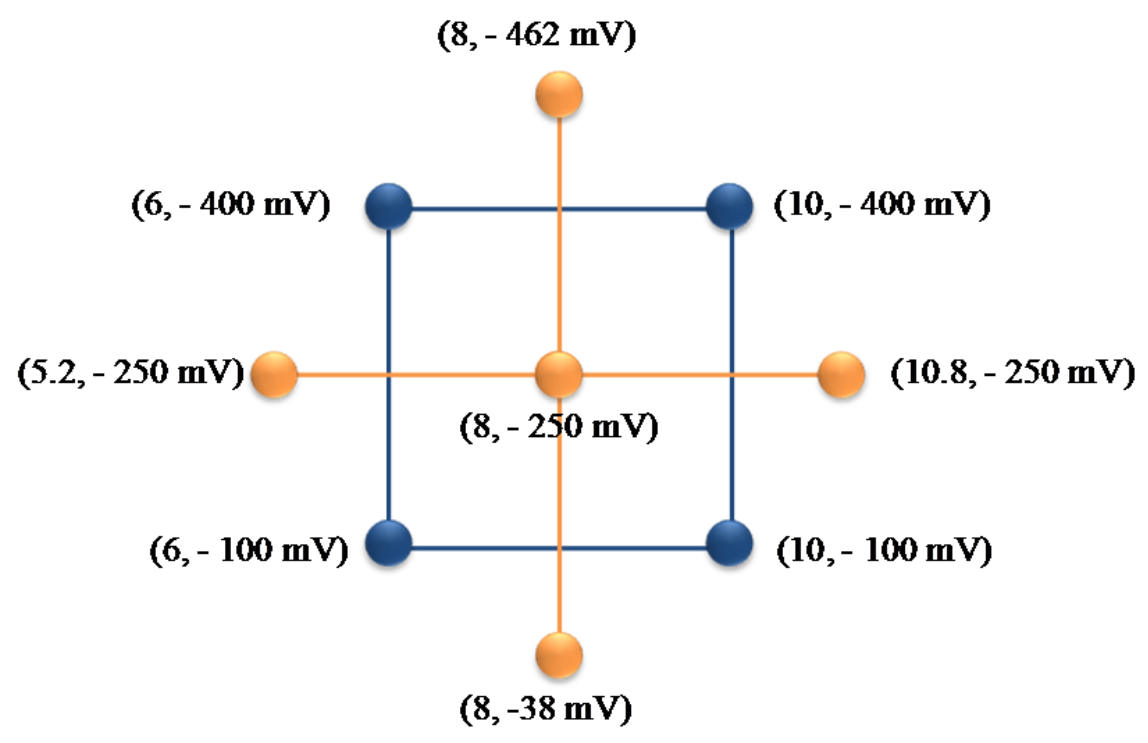

Figure 5.14.- Representation of the planned central composite design. 
The central point was three times replicated for the estimation of the residual error. The chronoamperometric reduction current related to a $19.6 \mu \mathrm{M}$ solution of cocaine was recorded as response variable, using CYP2B4 based biosensors built by entrapment and covalent immobilisation. The results of the eleven experiences of the design were evaluated using the STATGRAPHICS PLUS software package [38].

Figure 5.15 shows the chronoamperogram recorded under the optimum conditions of the experimental variables, $\mathrm{pH} 8.6$ and $-163 \mathrm{mV}$ vs. $\mathrm{Ag} / \mathrm{AgCl} \mathrm{SPE}$, using polypyrrole-modified CYP2B4 biosensors. A noisy reduction signal was registered, even in these optimum conditions, so a different immobilisation procedure was attempted.

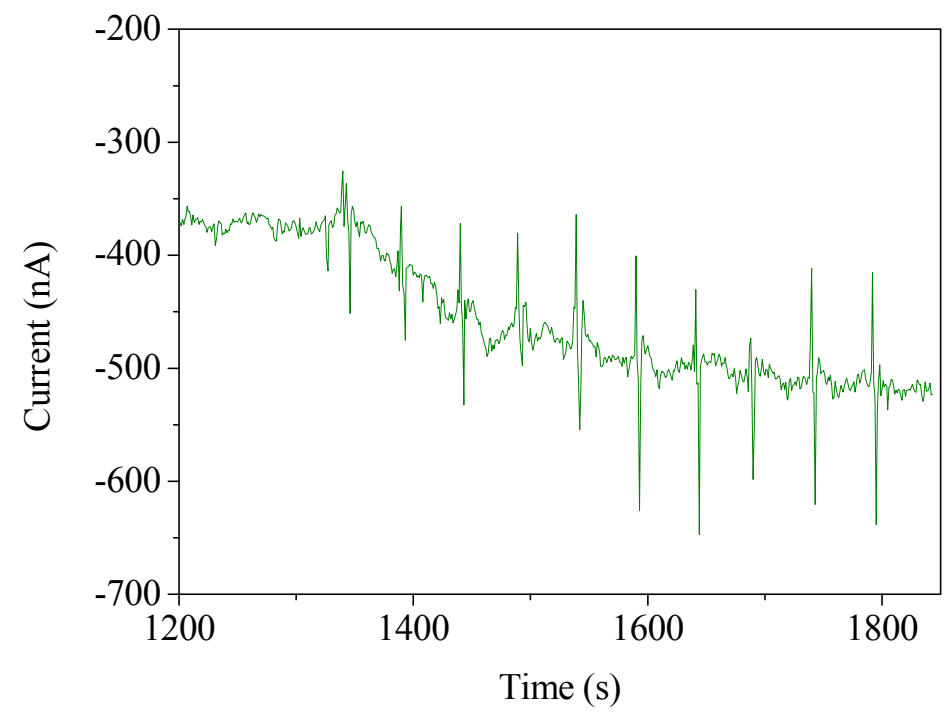

Figure 5.15.- Chronoamperometric signal of successive additions of cocaine in $5 \mathrm{~mL}$ of supporting electrolyte pH 8.6 at - $163 \mathrm{mV} v$. Ag/AgCl SPE, performed with a polypyrrolemodified CYP2B4 biosensor.

The same experimental design was carried out using the covalently-modified CYP2B4 biosensor. Table 5.2 shows the results for each of the individual experiments of the design. 
Table 5.2.- Results of a central composite design for the optimisation of the experimental parameters in the determination of cocaine.

\begin{tabular}{cccc}
\hline Experiment & $\mathbf{p H}$ & Working potential $(\mathbf{m V}) \mathbf{v s . ~ A g / A g C l ~ S P E}$ & Current (nA) \\
\hline $\mathbf{1}$ & 6.0 & -400.0 & 0.0 \\
$\mathbf{2}$ & 10.0 & -400.0 & 0.0 \\
$\mathbf{3}$ & 6.0 & -100.0 & 0.0 \\
$\mathbf{4}$ & 10.0 & -100.0 & 2.0 \\
$\mathbf{5}$ & 5.2 & -250.0 & 0.0 \\
$\mathbf{6}$ & 10.8 & -250.0 & 5.0 \\
$\mathbf{7}$ & 8.0 & -462.1 & 0.0 \\
$\mathbf{8}$ & 8.0 & -38.9 & 0.0 \\
$\mathbf{9}$ & 8.0 & -250.0 & 23.0 \\
$\mathbf{1 0}$ & 8.0 & -250.0 & 21.0 \\
$\mathbf{1 1}$ & 8.0 & -250.0 & 18.0 \\
\hline
\end{tabular}

The results in terms of ANOVA are shown in Table 5.3. It can be seen that a quadratic function was suitable for modelling these data, since the lack of fit was not significant at $95 \%$ confidence level [39].

The maximum cocaine reduction current in the response surface obtained from the experimental design was yielded at a working potential of $-250 \mathrm{mV}$ vs. $\mathrm{Ag} / \mathrm{AgCl} \mathrm{SPE}$ in supporting electrolyte $\mathrm{pH} 8.1$ (Figure 5.16).

The significant signal obtained in these conditions allowed recording calibration curves in the concentration range from 19.6 up to $166.7 \mathrm{nM}$, as it is showed in figure 5.17 .

Control experiments were performed under the optimum conditions, using bare electrodes and functionalised ones according to the procedure described in section 5.3.2.2 but without the enzyme. In the first case, no signal was detected and 
when using functionalised electrodes without enzyme, a chronoamperometric oxidation signal was recorded.

Table 5.3.- ANOVA from data shown in Table 5.2. (S.S: Sum of Squares; D.F: Degrees of Freedom; M.S: Mean Square; $F_{\text {ratio: }} M S_{\text {factor }} M S_{\text {error }}$; $P_{\text {level: }}$ probability level; *Significant factors at $\alpha=0.05$ ).

\begin{tabular}{llllll}
\hline \multicolumn{1}{c}{ EFFECT } & S.S. & D.F. & M.S. & F $_{\text {ratio }}$ & P $_{\text {level }}$ \\
\hline A: pH & 10.2 & 1 & 10.3 & 1.6 & 0.332 \\
B: Working potential & 0.5 & 1 & 0.5 & 0.1 & 0.806 \\
AA & 485.1 & 1 & 485.1 & 76.6 & $0.013^{*}$ \\
AB & 1.0 & 1 & 1.0 & 0.2 & 0.731 \\
BB & 624.5 & 1 & 624.5 & 98.6 & $0.010^{*}$ \\
Lack of fit & 4.8 & 3 & 1.6 & 0.25 & 0.855 \\
Pure error & 12.7 & 2 & 6.3 & & \\
Total (corr.) & 889.4 & & & & \\
\hline
\end{tabular}

$$
\mathrm{R}^{2}=0.98033
$$

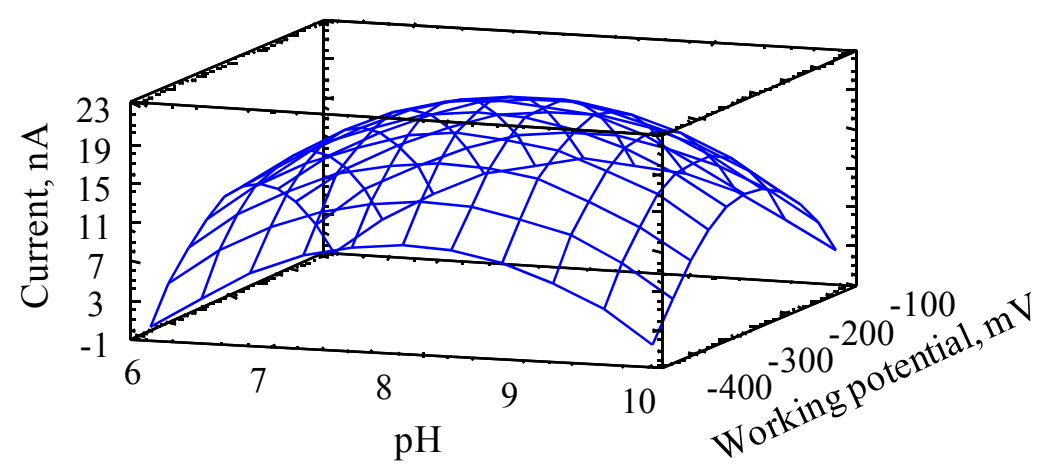

Figure 5.16.- Estimated response surface for the $2^{2}$ central composite design performed for the optimisation of the experimental variables in the chronoamperometric determination of cocaine, using covalently-modified CYP2B4 biosensors. 


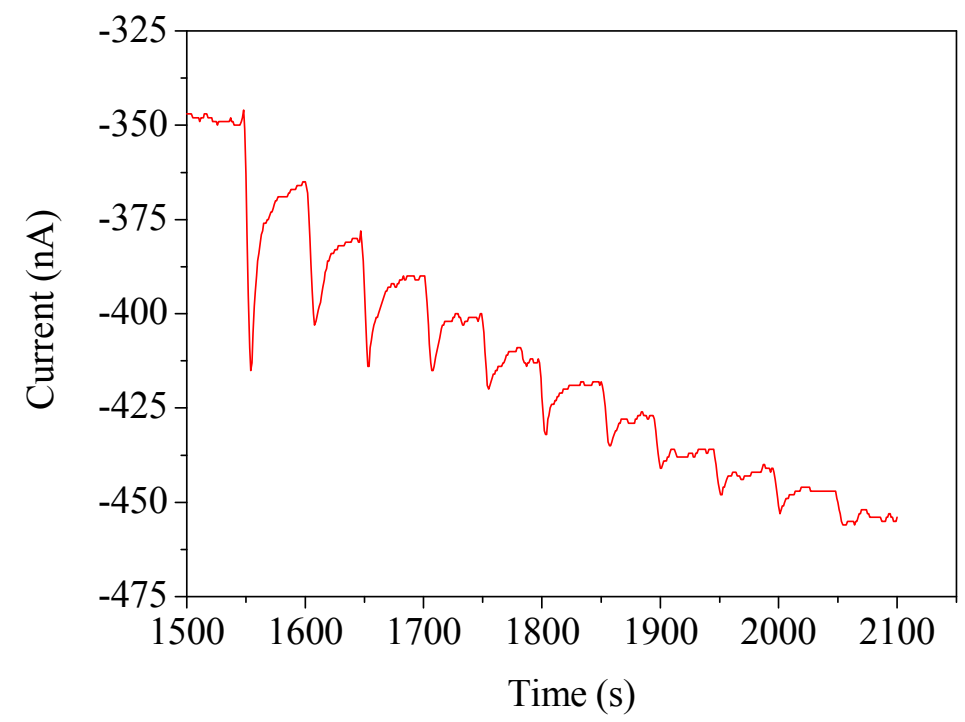

Figure 5.17.- Chronoamperometric signal of successive additions of $100 \mu \mathrm{L}$ of $1.0 \mu \mathrm{M}$ cocaine solution in $5 \mathrm{~mL}$ of supporting electrolyte $\mathrm{pH} 8.1$ at $-250 \mathrm{mV} v \mathrm{~s}$. $\mathrm{Ag} / \mathrm{AgCl} \mathrm{SPE}$.

\subsection{3.- BIOSENSOR VALIDATION}

Once an analytical method has been developed, it is of a great importance to validate it through the estimation of its precision, capability of detection and accuracy.

\subsubsection{1.- Precision}

The precision of the developed biosensor was checked in terms of reproducibility and repeatability. Calibration parameters and standard deviation were optimally evaluated using the program PROGRESS, as it has been stated in section 4.4.5.1 [40].

Table 5.4 shows the characteristic parameters of the calibration curves recorded, once the anomalous points were eliminated, using different CYP450 
modified SPCEs. The reproducibility achieved in terms of RSD associated with the slopes of the calibration curves registered in the concentration range from 19.6 up to $166.7 \mathrm{nM}$ was $3.6 \%(n=4)$ (Figure 5.18).

Table 5.4.- Calibration parameters, obtained through OLS regression without outliers, for the determination of cocaine using different CYP450 modified SPCEs under the optimum conditions to calculate the reproducibility of the biosensor.

\begin{tabular}{ccccc}
\hline Calibration & Slope (nA $\left.\mathbf{n M}^{-\mathbf{1}}\right)$ & Intercept (nA) & $\mathbf{S}_{\mathbf{y x}}$ & $\begin{array}{c}\text { Coefficient of } \\
\text { determination }\left(\mathbf{R}^{\mathbf{2}}\right)\end{array}$ \\
\hline I & 0.4 & 0.2 & 1.313 & 0.997 \\
II & 0.4 & 4.8 & 2.056 & 0.992 \\
III & 0.4 & 5.1 & 1.607 & 0.991 \\
IV & 0.4 & 10.3 & 1.901 & 0.992 \\
\hline
\end{tabular}

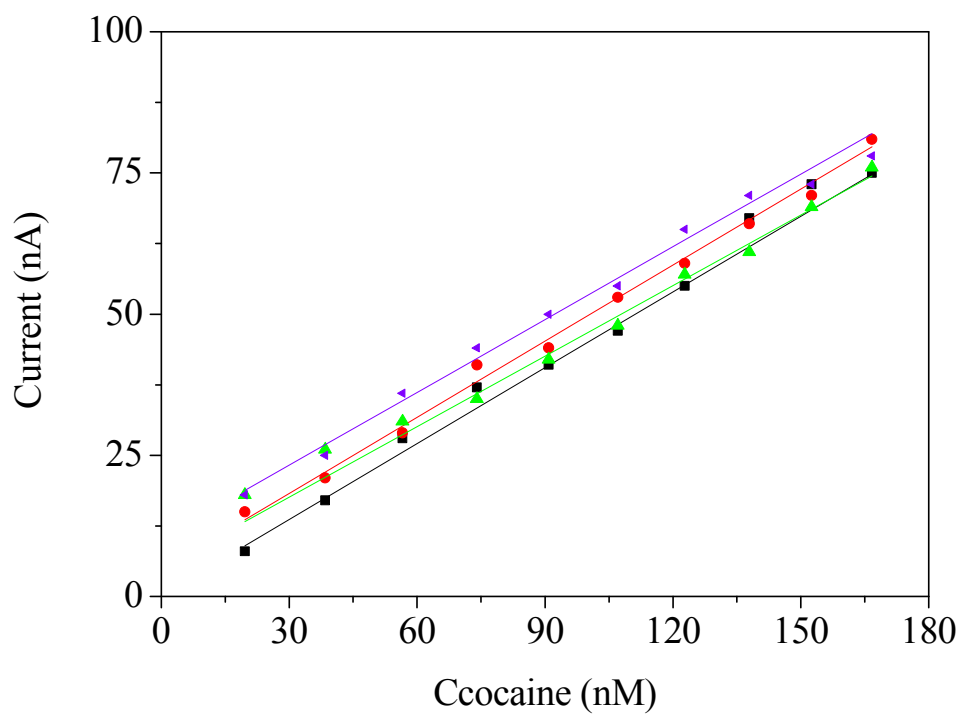

Figura 5.18.- Calibration curves for the determination of the reproducibility of the method. Consecutive additions of $100 \mu \mathrm{L}$ of a $1.0 \mu \mathrm{M}$ solution of cocaine in $5 \mathrm{~mL}$ of supporting electrolyte $\mathrm{pH}$ 8.1. 
Likewise, repeatability was estimated by recording successive calibration curves in the same calibration range, under the optimum operational conditions, by a single CYP450 based biosensor (Table 5.5). It can be seen in figure 5.19 that biosensor approximately kept a $40 \%$ of sensitivity after the fourth calibration curve.

Table 5.5.- Calibration parameters, obtained through OLS regression without outliers, for the determination of cocaine using one single CYP450 modified SPCEs under the optimum conditions in order to estimate the repeatability of the method.

\begin{tabular}{ccccc}
\hline Calibration & Slope $\left(\mathbf{n} \mathbf{A} \mathbf{n M}^{-\mathbf{1}}\right)$ & Intercept (nA) & $\mathbf{S}_{\mathbf{y x}}$ & $\begin{array}{c}\text { Coefficient of } \\
\text { determination }\left(\mathbf{R}^{2}\right)\end{array}$ \\
\hline I & 0.3 & 21.1 & 0.535 & 0.998 \\
II & 0.3 & 13.4 & 0.661 & 0.998 \\
III & 0.2 & 14.3 & 0.833 & 0.990 \\
IV & 0.1 & 11.9 & 0.275 & 0.995 \\
\hline
\end{tabular}
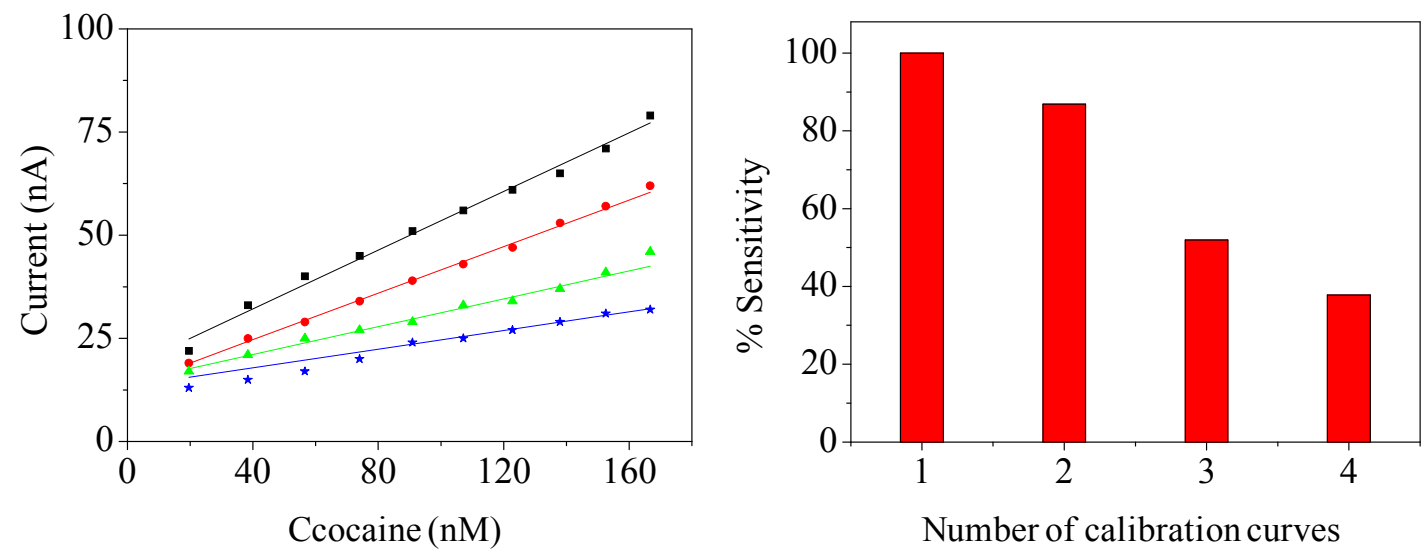

Figure 5.19.- Consecutive calibration curves performed with the same electrode. 
Taking into account the disposable nature of this kind of device, these figures of merit highlighted the high precision yielded in the manufacturing of CYP450 modified SPCEs for the determination of cocaine.

\subsubsection{2.- Capability of detection}

In addition, the capability of detection, that is, the minimum detectable (true) value of the appropriate chemical variable according to IUPAC [41], is essential to be determined in a new method.

Moreover, this discrimination between the blank and low-concentration solutions should be given for a probability of false positive $(\alpha)$ and negative $(\beta)[41$, 42]. $\alpha$ can be defined as the probability of erroneously detecting that there was analyte when there was not, while $\beta$ describes the probability of erroneously detecting that there was not analyte when there was $[41,43]$.

Several calibration curves were obtained in the concentration range from 19.6 up to $166.7 \mathrm{nM}$ under the optimum conditions. The parameters of the validated linear regressions between the concentration and the analytical signal, according to the procedure described above, were the required data to calculate the capability of detection. The average capability of detection was $[23.1 \pm 3.5] \mathrm{nM}(n=3, \alpha=\beta=$ $0.05)$.

\subsubsection{3.- Accuracy}

According to IUPAC definition, accuracy relates to the difference between a result (or mean) and the true value [44]. Different methodologies are performed for assessment of the accuracy of an analytical method in a single laboratory validation: analysis of a certified reference material or synthetic samples, comparison with the 
results from a recognised reference method or recovery of known quantities of a standard added to a representative sample matrix $[45,46]$.

In this work, biosensors based on CYP450 were used for the determination of cocaine in street samples. The selectivity towards the substrate, which characterises the biosensor, allowed the use of the device in complex analyses using a methodology as simple as the standard addition, which minimises sample matrix effects.

Street cocaine samples were prepared as it has been described in section 5.3.4. Then, chronoamperograms were recorded under the optimum conditions of the experimental parameters. Once a steady-state chronoamperometric current was recorded, a volume of $100 \mu \mathrm{L}$ of the problem sample solution was added into the electrochemical cell. Successive additions of $100 \mu \mathrm{L}$ of a $1.0 \mu \mathrm{M}$ cocaine solution were performed to obtain a curve of calibration (Figure 5.20).

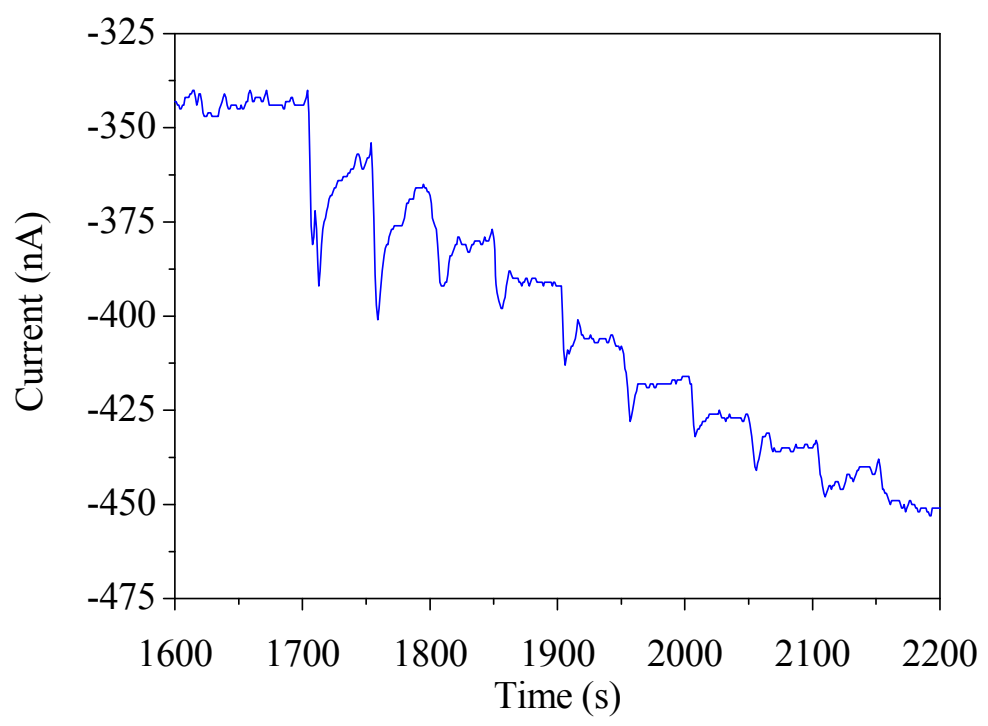

Figure 5.20.- Cocaine chronoamperogram obtained under the optimum conditions, $p H=$ 8.1 and $-250 \mathrm{mVvs} . \mathrm{Ag} / \mathrm{AgCl} \mathrm{SPE}$. The registered current at $1700 \mathrm{~s}$ corresponds to the addition of a solution of the street sample. Consecutive reduction signals correspond to additions of $100 \mu \mathrm{L}$ of a $1.0 \mu \mathrm{M}$ solution of cocaine. 
The concentration of cocaine in a confiscated street sample was found to be $[29.0 \pm 3.7] \% \mathrm{w} / \mathrm{w}(n=4, \alpha=0.05)$ (Table 5.6). This result was validated by comparison to HPLC as reference technique, $[28.0 \pm 2.0] \% \mathrm{w} / \mathrm{w}(n=4, \alpha=0.05)$, obtaining a good correlation between both methods.

Table 5.6.- Analytical characteristics in the analysis of cocaine street samples using covalently-modified CYP2B4 SPCEs.

\begin{tabular}{ccccc}
\hline $\begin{array}{c}\text { Reference value } \\
(\%)\end{array}$ & $\begin{array}{c}\text { Cocaine } \\
\text { detected (\%) }\end{array}$ & $\begin{array}{c}\text { 95 \% confidence } \\
\text { interval for mean (\%) }\end{array}$ & Recovery (\%) & RSD (\%) \\
\hline 31.2 & & 111.4 & \\
\hline $28.0 \pm 2.0]$ & 25.6 & {$[29.0 \pm 3.7]$} & 91.4 & 8.5 \\
& 28.8 & & 102.8 & \\
\hline
\end{tabular}

\section{5.- CONCLUSIONS}

Screen-printing technology has been used to fabricate biosensors based on the covalent bounding between the $-\mathrm{NH}_{2}$ functionalised working electrode and the enzyme CYP450 for the determination of cocaine.

The evaluation of the optimum conditions of chronoamperometric measurements through a $2^{2}$ central composite design leads to values of 8.1 for the $\mathrm{pH}$ and $-250 \mathrm{mV}$ vs. $\mathrm{Ag} / \mathrm{AgCl} \mathrm{SPE}$ for the working potential. Calibration curves performed under the optimum conditions can be used to characterise the reproducibility, repeatability and capability of detection of the method. In this way, the reproducibility in terms of the RSD of the slopes of the calibration curves is 3.6 $\%(n=4)$, and a capability of detection of [23.1 \pm 3.5$] \mathrm{nM}(n=3, \alpha=\beta=0.05)$ is obtained. The developed enzymatic biosensor has shown its viability in the determination of the drug in street samples. 


\section{6.- REFERENCES}

1. Goldstein, R.A., C. DesLauriers, and A.M. Burda, Cocaine: History, Social Implications, and Toxicity-A Review. Disease-a-Month 55, 2009, p. 6-38.

2. Oiye, E.N., et al., Voltammetric determination of cocaine in confiscated samples using a cobalt hexacyanoferrate film-modified electrode. Forensic Science International 192, 2009, p. 94-97.

3. Garrido, J.M.P.J., et al., Spectroscopic and electrochemical studies of cocaine-opioid interactions. Analytical and Bioanalytical Chemistry 388, 2007, p. 1799-1808.

4. Pavlova, V., et al., Studying electrode mechanism and analytical determination of cocaine and its metabolites at the mercury electrode using square-wave voltammetry. Analytica Chimica Acta 512, 2004, p. 49-56.

5. Komorsky-Lovric, S., I. Galic, and R. Penovski, Voltammetric determination of cocaine microparticles. Electroanalysis 11, 1999, p. 120-123.

6. Abedul, M.T.F., et al., Voltammetric determination of cocaine in confiscated samples. Electroanalysis 3, 1991, p. 409-412.

7. Du, Y., et al., Solid-state probe based electrochemical aptasensor for cocaine: A potentially convenient, sensitive, repeatable, and integrated sensing platform for drugs. Analytical Chemistry 82, 2010, p. 1556-1563.

8. Bauer, C.G., et al., Automated amplified flow immunoassay for cocaine. Analytical Chemistry 70, 1998, p. 4624-4630.

9. Suleiman, A.A. and Y. Xu, An amperometric immunosensor for cocaine. Electroanalysis 10, 1998, p. 240-243.

10. Teller, C., et al., Development of a bifunctional sensor using haptenized acetylcholinesterase and application for the detection of cocaine and organophosphates. Biosensors and Bioelectronics 24, 2008, p. 111-117. 
11. Sadik, O.A., S.K. Mwilu, and A. Aluoch, Smart electrochemical biosensors: From advanced materials to ultrasensitive devices. Electrochimica Acta 55, 2010, p. 4287-4295.

12. Cooper, J. and T. Cass, Biosensors: A Practical Approach. 2nd ed. 2004, New York: Oxford University Press.

13. Alonso-Lomillo, M.A., O. Domínguez Renedo, and M.J. Arcos-Martínez, Enzyme modified screen printed electrodes, in Biosensors: Properties, Materials and Applications, R. Comeaux and P. Novotny, Editors. 2009, Nova Publishers: Hauppauge NY. p. 1-52.

14. Lewis, D.F.V., Guide to Cytochromes P450: Structure and Function. 2001, Florida: CRC Press, Boca Ratón.

15. Testa, B., The metabolism of drugs and other xenobiotics. Biochemistry of redox reactions. 1995, London: Academic Press. p. 471.

16. Shumyantseva, V.V., et al., Direct electron transfer of cytochrome P450 2B4 at electrodes modified with nonionic detergent and colloidal clay nanoparticles. Analytical Chemistry 76, 2004, p. 6046-6052.

17. Alonso-Lomillo, M.A., et al., CYP450 2B4 covalently attached to carbon and gold screen printed electrodes by diazonium salt and thiols monolayers. Analytica Chimica Acta 633, 2009, p. 51-56.

18. Alonso-Lomillo, M.A., et al., CYP450 biosensors based on gold chips for antiepileptic drugs determination. Biosensors and Bioelectronics 23, 2008, p. 1733-1737.

19. Lewis, G.A., D. Mathieu, and R. Phan-Tan-Luu, Pharmaceutical experimental design. 1999, New York: Dekker.

20. Box, G.E.P., N.G. Hunter, and J.S. Hunter, Estadistica para investigadores. Introducción al diseño de experimentos. Análisis de datos y construcción del modelo. 1989, Barcelona: Reverté. 
21. Barlett, P.N. and J.M. Cooper, A review of the immobilization of enzymes in electropolymerized films. Journal of Electroanalytical Chemistry 362, 1993, p. 1-12.

22. Gerard, M., A. Chaubey, and B.D. Malhotra, Application of conducting polymers to biosensors. Biosensors and Bioelectronics 17, 2002, p. 345-359.

23. Cosnier, S., Biosensors based on immobilization of biomolecules by electrogenerated polymer films. Applied Biochemistry and Biotechnology Part A Enzyme Engineering and Biotechnology 89, 2000, p. 127-138.

24. Eggins, B.R., Chemical Sensors and Biosensors. 2004, UK: John Wiley \& Sons, LTD.

25. Alonso Lomillo, M.A., J.M. Kauffmann, and M.J. Arcos Martinez, HRPbased biosensor for monitoring rifampicin. Biosensors and Bioelectronics 18, 2003, p. 1165-1171.

26. Zhang, K., New conjugated polymers based on benzodifuranone and diketopyrrolopyrrole. 2012, Hamburg, Germany: disserta Verlag.

27. Gao, W., Z. Li, and N. Sammes, An introduction to electronic materials for engineers. 2nd ed. 2011, London, UK: World Scientific.

28. Serradilla Razola, S., et al., Hydrogen peroxide sensitive amperometric biosensor based on horseradish peroxidase entrapped in a polypyrrole electrode. Biosensors and Bioelectronics 17, 2002, p. 921-928.

29. Isbir-Turan, A.A., et al., Electrochemical and spectroscopic characterization of a Benzo[c]cinnoline electrografted platinum surface. Thin Solid Films 517, 2009, p. 2871-2877.

30. Alonso-Lomillo, M.A., et al., Horseradish peroxidase covalent grafting onto screen-printed carbon electrodes for levetiracetam chronoamperometric determination. Analytical Biochemistry 395, 2009, p. 86-90. 
31. Delamar, M., et al., Covalent modification of carbon surfaces by grafting of functionalized aryl radicals produced from electrochemical reduction of diazonium salts. Journal of the American Chemical Society 114, 1992, p. 5883-5884.

32. Ghilane, J., et al., Spectroscopic evidence of platinum negative oxidation states at electrochemically reduced surfaces. Journal of Physical Chemistry C 111, 2007, p. 5701-5707.

33. Dent, A.H., Conjugation methods, in The Immunoassay Handbook, D. Wild, Editor. 2006, Elsevier: London, UK. p. 246-264.

34. Hermanson, G.T., Bioconjugate Techniques. 2nd ed. 2008, USA: Academic Press Elsevier.

35. Kellner, R., et al., Analytical Chemistry. 2nd ed. A Modern Approach to Analytical Science. 2004, Germany: Wiley-VCH.

36. Massart, D.L., et al., Handbook of Chemometrics and Qualimetrics, Part A. 1997, Amsterdam: Elsevier.

37. Montgomery, D.C., Diseño y análisis de experimentos. 1991, México: Iberoamericana.

38. STATGRAPHICS, STATGRAPHICS PLUS for Windows. 1994-2001, Statistical Graphics Corp.

39. Bondell, H.D. and B.J. Reich, Simultaneous factor selection and collapsing levels in ANOVA. Biometrics 65, 2009, p. 169-177.

40. Rousseeuw, P.J. and A.M. Leroy, Robust Regression and Outlier Detection. 1989, New York: Wiley.

41. Inczédy, J., et al., Compendium of Analytical Nomenclature. 3rd ed. 2000, Baltimore: Port City Press Inc. 
42. ISO11843, Capability of Detection, Part I, 1997 and Part II, 2000. Genève, Switzerland.

43. Ortiz, M.C., L.A. Sarabia, and M.S. Sánchez, Tutorial on evaluation of type I and type II errors in chemical analyses: From the analytical detection to authentication of products and process control. Analytica Chimica Acta 674, 2010, p. 123-142.

44. IUPAC, Compendium of Analytical Nomenclature. 1978, Oxford: Pergamon Press.

45. Ríos Castro, Á., M.C. Moreno Bondi, and B.M. Simonet Suau, Técnicas espectroscópicas en química analítica. Aspectos básicos y espectrometría. Vol. I. 2012, Madrid, Spain: Síntesis.

46. Kay, J.F. and J. MacNeil, D., Method development and method validation, in Chemical analysis of antibiotic residues in food, J. Wang, J.D. MacNeil, and J.F. Kay, Editors. 2012, Wiley \& Sons: New Jersey, USA. 
CHAPTER 6:

ELECTROCHEMICAL DETERMINATION OF COCAINE USING SCREEN-PRINTED CYP2B4 BASED BIOSENSORS 

As it has been previously mentioned, the enzymatic immobilisation procedure is a key stage in the development of a biosensor, which can affect characteristic parameters such as lifetime, sensitivity or reproducibility (Section 3.2.3.2). Time consuming immobilisation stages are often necessary to set the contact between the enzyme and the transducer. Screen-printing technology has the advantage of simplifying this procedure, since the bioelement can be incorporated into the working electrode ink and screen-printed as an additional step in the SPE fabrication process.

This chapter describes the development of screen-printed CYP2B4 based biosensors $\left(\mathrm{SPC}_{\mathrm{CYP}} \mathrm{E}\right)$, from the fabrication of the device using screen-printing technology to its characterisation and application in the determination of cocaine street samples. Part of this work was carried out at the Free University of Brussels (ULB), under the supervision of Prof. Jean-Michel Kauffmann, during a 3-month academic visit.

The immobilisation of CYP2B4 by direct screen-printing has led to the semiautomatic fabrication of disposable biosensors, allowing mass production for the determination of cocaine. In order to prevent CYP2B4 denaturation, curing time and temperature has been controlled.

Voltammetric measurements have been first performed in order to study the electrochemical behaviour of the enzyme trapped in the structure of the working electrode, as well as its interaction with one of its substrates, cocaine. Then, chronoamperometric measurements have been carried out for the characterisation of the biosensor. Calibration curves under optimum conditions of the experimental variables have been used for establishing the reproducibility, the repeatability and the capability of detection of the described method. Additionally, the enzymatically formation of formaldehyde, as subproduct of the electrochemical biotransformation of the cocaine (Figure 3.16), has been checked by spectrophotometry after its 
reaction with the Nash reagent. Finally, the performance of the developed biosensors has been successfully proved by the analysis of the purity of cocaine street samples.

This work has been partially published in Talanta 105, 2013, p. 131-134, and presented at XXXIII Reunión del Grupo de Electroquímica de la Real Sociedad Española in Miraflores de la Sierra, Madrid, Spain (July 2012). 


\section{1.- INTRODUCTION}

Cocaine is one of the most trafficked and used illicit drugs. It is an alkaloid that acts as analgesic and local anaesthetic. It also stimulates the modulation of dopamine, producing a sensation of euphoria, which provokes addiction [1].

Two pathways for cocaine metabolism have been described (Figure 3.2) [2] The first one, and the mayor route, is mediated by hydrolytic reactions, which lead to inactive pharmacological metabolites. The second one leads to the $N$-demethylation of the drug producing norcocaine and formaldehyde as subproduct of the metabolism [2]. This last transformation is catalysed by the well-known enzyme CYP450 (Figure 3.17) [3].

Since cocaine is a substance of abuse, its determination has been of a great importance. Different methodologies have been used for this purpose, such as gas chromatography [4-6], liquid chromatography [7-9] and electroanalytical techniques [10-12]. This last one has been evolved in the last few years in aspects related not only with the specificity of the sensors, thanks to bioelements such as enzymes or biological receptors, but also with the miniaturisation of the electrodes.

Screen-printing technology has made possible the miniaturisation of these devices, providing a sensitivity as good as the conventional macroelectrodes, by giving advantages such as flexibility in the design, automation of its manufacture, good reproducibility and a wide choice of materials to fabricate the transducer [13]. Additionally, these devices can be modified with bioelements in order to make them more selective to the analyte. In this way, bioelements, such as enzymes, can be incorporated into the ink to form a sensing paste, which can be screen-printed in one single step, giving as a result a screen-printed biosensor. Consequently, fabrication time is considerably reduced and automation becomes possible [14]. 
In this work, CYP2B4 was mixed with a commercial carbon ink to be screenprinted as the working electrode to complete a three-electrode disposable device for chronoamperometric measurements. Being one of the preferred substrates of the enzyme, cocaine was used for the characterisation of the manufactured biosensor (Figure 6.1) [3, 15].

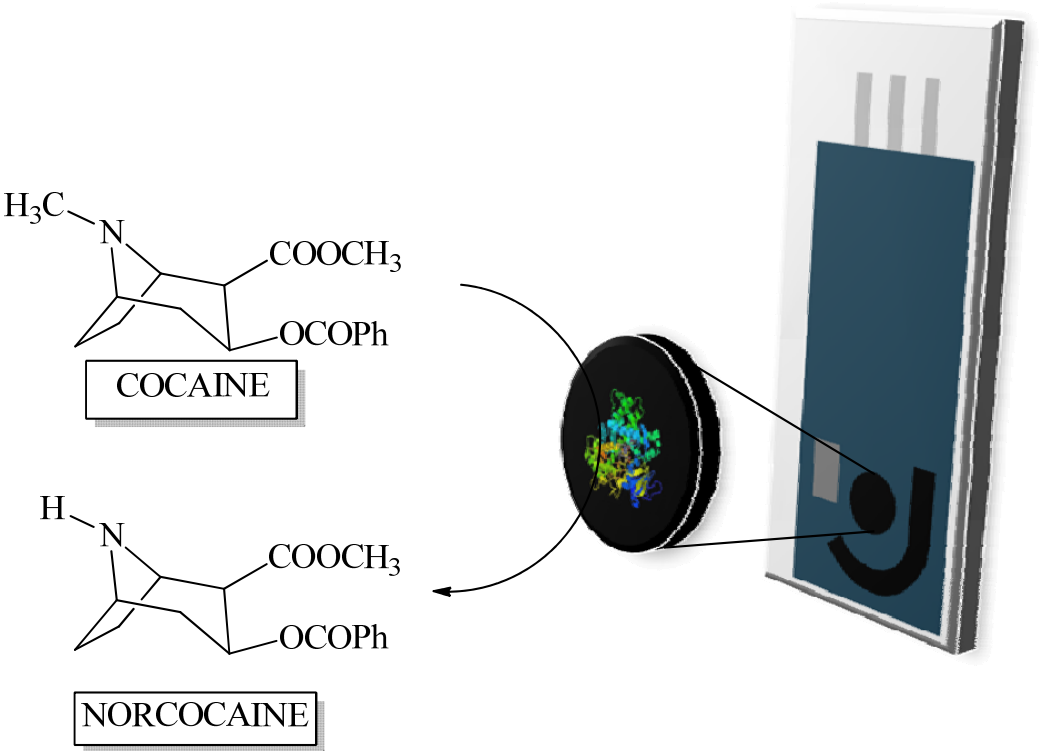

Figure 6.1.- Scheme of the developed $S P C_{C Y P} E$ biosensor.

Chronoamperometric measurements were performed with these biosensors at the optimum conditions of $\mathrm{pH}$ and working potential, obtaining a reduction current as consequence of the enzymatic mechanism [3, 15]. Taking into account that the reaction between this enzyme and cocaine produces formaldehyde, this subproduct was used to check the success of the enzymatic metabolism, after its reaction with the Nash reagent, by spectrophotometry [16]. Furthermore, cocaine street samples were used to highlight the performance of the developed procedure. 


\section{2.- EXPERIMENTAL}

\subsection{1.- REAGENTS}

Different commercial inks were used in the fabrication of different parts of the transducer, namely carbon ink C10903P14 and dielectric ink D2071120D1 supplied by Gwent Electronic Materials (Torfaen, U.K), $\mathrm{Ag} / \mathrm{AgCl}$ ink Electrodag 6037 SS and Ag ink Electrodag 418 supplied by Acheson Colloiden (Scheemda, The Netherlands).

Analytical grade chemicals with no further purification were used. All solutions were prepared in Milli-Q water.

The enzyme CYP2B4 purchased from US Biological (C9095-15Y, Swamscott, MA, USA) was used as received.

A $100.0 \mathrm{mM}$ phosphate buffer $\left(\mathrm{NaH}_{2} \mathrm{PO}_{4} \cdot 2 \mathrm{H}_{2} \mathrm{O}\right.$, Merck, Darmstadt, Germany) and $100.0 \mathrm{mM} \mathrm{KCl} \mathrm{(Merck,} \mathrm{Darmstadt,} \mathrm{Germany)} \mathrm{solution} \mathrm{were} \mathrm{used} \mathrm{as}$ supporting electrolyte. A NaOH (J.T. Baker, Deventer, The Netherlands) solution was used to adjust the $\mathrm{pH}$ value.

Stock standard solutions of cocaine were prepared by dissolving the adequate amount of cocaine hydrochloride (Sigma, Steinheim, Germany) in supporting electrolyte.

The Nash reagent was prepared by mixing solutions of $3.9 \mathrm{M}$ of ammonium acetate (Panreac, Barcelona, Spain), $100.0 \mathrm{mM}$ of glacial acetic acid (Merck, Darmstadt, Germany) and 39.0 mM of acetyl acetone (Merck, Darmstadt, Germany). 


\subsection{2.- APPARATUS}

SPEs were manufactured on a DEK 248 printing machine (DEK, Weymouth, UK).

Electrochemical measurements were made with a $\mu$ Autolab electrochemical system with GPES software (Eco Chemie, Utrecht, The Netherlands).

The $\mathrm{pH}$ of the solutions was measured with a $\mathrm{pH}$ meter from HANNA instruments Model HI221 (USA).

Spectrophotometric measurements were carried out with a spectrophotometer Spectronic 20 Genesys from Spectronic Instruments (Rochester, NY, USA).

\section{3.- METHODS}

\subsection{1.- CYP2B4 BASED SPCES FABRICATION}

The biosensors were produced by the so called screen-printing technology according to the procedure described in Section 3.2.1 [14]. The sequential deposition of the inks, which define the conductive silver tracks, the $\mathrm{Ag} / \mathrm{AgCl}$ reference electrode, the carbon counter electrode and the dielectric layer, was performed on polyester films (HiFi Industrial Film, Dardilly, France). The inks were cured according to the manufacturer's specifications.

The immobilisation of the bioelement in the fabrication of a biosensor involves sometimes a sequence of tedious steps. In this work, the enzyme was incorporate in the carbon matrix of the working electrode.

The working electrode ink was prepared by thoroughly mixing the carbon ink with CYP2B4 $(7 \% \mathrm{v} / \mathrm{w})$ and immediately screen-printing it. Curing time and 
temperature were controlled in order to avoid the enzyme denaturation, which has been reported to take place at temperatures higher than $58^{\circ} \mathrm{C}$ [17]. However, it has been also described that a fast denaturation process is observed when the enzyme is heated at $45^{\circ} \mathrm{C}$ for more than $15 \mathrm{~min}$ [17]. Therefore, the developed biosensor was cured at $30{ }^{\circ} \mathrm{C}$ during $1 \mathrm{~h}$ and then kept at $4{ }^{\circ} \mathrm{C}$ when not in use. No additional treatment was required to be used after its fabrication.

\subsection{2.- MEASURING PROCEDURE}

Cyclic voltammetric measurements were made at room temperature in a drop containing $100 \mu \mathrm{L}$ of supporting electrolyte $\mathrm{pH} \mathrm{7,} \mathrm{and} \mathrm{scanning} \mathrm{the} \mathrm{potential}$ between 0 and $-800 \mathrm{mV}$ vs. $\mathrm{Ag} / \mathrm{AgCl} \mathrm{SPE}$ at a scan rate of $50 \mathrm{mV} \mathrm{s}^{-1}$ (Figure 6.2).

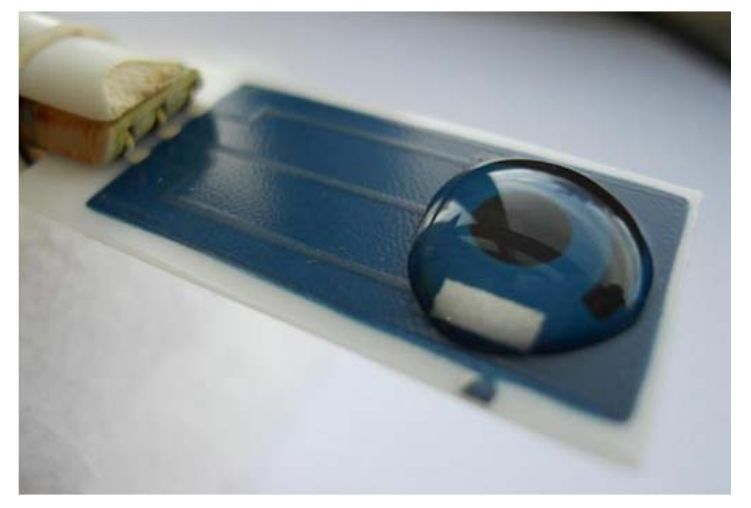

Figure 6.2.- Image of a $S P C_{C Y P} E$ connected to the potentiostat to carry out cyclic voltammetric measurements in a $100 \mu \mathrm{L}$ drop of supporting electrolyte $\mathrm{pH} 7$.

Chronoamperometric measurements were made at room temperature in a cell containing $5 \mathrm{~mL}$ of $100.0 \mathrm{mM}$ phosphate buffer and $100.0 \mathrm{mM} \mathrm{KCl}$ solution, of the desired $\mathrm{pH}$, under constant mechanical stirring. The working electrode operated at $250 \mathrm{mV}$ vs. $\mathrm{Ag} / \mathrm{AgCl} \mathrm{SPE}$, except for the experimental variables optimisation process. 
Spectrophotometric measurements were made at room temperature in a $1 \mathrm{~cm}$ quartz cell at $412 \mathrm{~nm}$.

\section{4.- RESULTS AND DISCUSSION}

\subsection{1.- CHARACTERISATION OF THE BIOSENSOR}

The use of screen-printing technology to fabricate biosensors not only reduces the time on the production, but also improves the electron transfer between the biological system and the electrode due to the proximity of both components. This closeness made possible the visualisation of the redox peaks from the screenprinted enzyme, which highlighted the success of the immobilisation procedure (Figure 6.3).

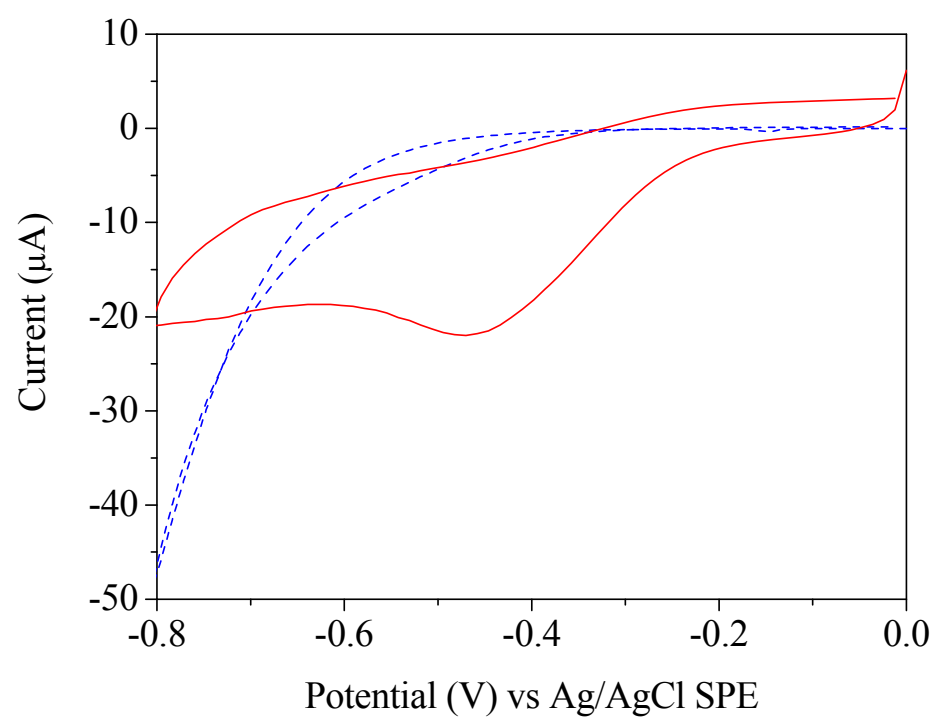

Figure 6.3.- Cyclic voltammogram of a SPCE (dash line) and a $S P C_{C Y P E}$ (solid line) in a $100 \mu \mathrm{L}$ drop of supporting electrolyte $\mathrm{pH}$ 7. Scan rate: $50 \mathrm{mV} \mathrm{s}^{-1}$. 
According to the scheme proposed by Shumyantseva et al. and Krishnan et al. (Figure 6.4) [18, 19], this single reduction peak appears due to the tight and irreversible bond between the enzyme and the dissolved oxygen. The $\mathrm{H}_{2} \mathrm{O}_{2}$ electrochemically formed interacts with $\mathrm{Fe}^{\mathrm{III}}$, giving as result the active specie $\left[\mathrm{Fe}^{I V}=\mathrm{O}\right]^{++}$that is reduced to the ferric state at $-450 \mathrm{mV}$ vs. $\mathrm{Ag} / \mathrm{AgCl} \mathrm{SPE}$. Consequently, when the potential is swept towards positive values, no oxidation peak is shown since the predominant species is already $F e^{I I I}$ (Figure 6.3).

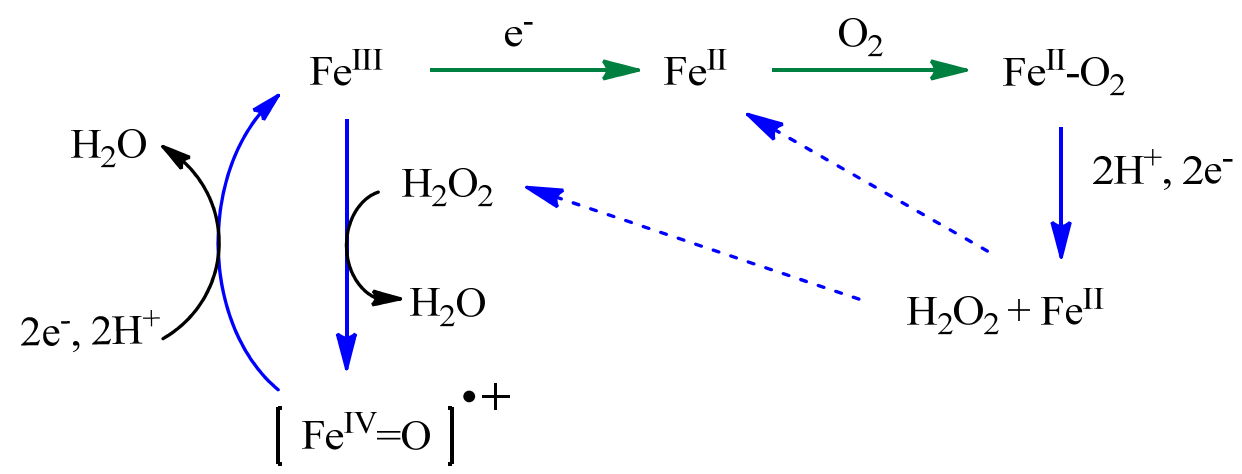

Figure 6.4.- Schematic representation of the reaction that takes place in the working surface of a $S P C_{C Y P} E$ in absence of substrate.

This fact was also confirmed by the consumption of the oxygen in the drop as it is transformed into water by the CYP450. Therefore, CYP450 peak decreases when consecutive voltammetric cycles are performed (Figure 6.5). Once the electrolyte solution is again oxygenated, the CYP450 peak gives a response like the initial one.

In presence of cocaine, two different paths can be performed in the surface of the $\mathrm{SPC}_{\mathrm{CYP}} \mathrm{E}$ (Figure 6.6). The lower cycle path is related to the enzymatic behaviour of the $\mathrm{SPC}_{\mathrm{CYP}} \mathrm{E}$ in presence of oxygen but in absence of cocaine. When cocaine is present in the media, the upper cycle route takes place to obtain norcocaine and 
regenerate $\mathrm{Fe}^{\mathrm{III}}$ (Figure 3.16), leading to the formation of the species $\left[\mathrm{Fe}^{I V}=\mathrm{O}\right]^{++}$, which is reflected in an increment of the reduction current. This catalytic effect was monitored in a solution of $1.7 \mathrm{mM}$ of cocaine (Figure 6.7).

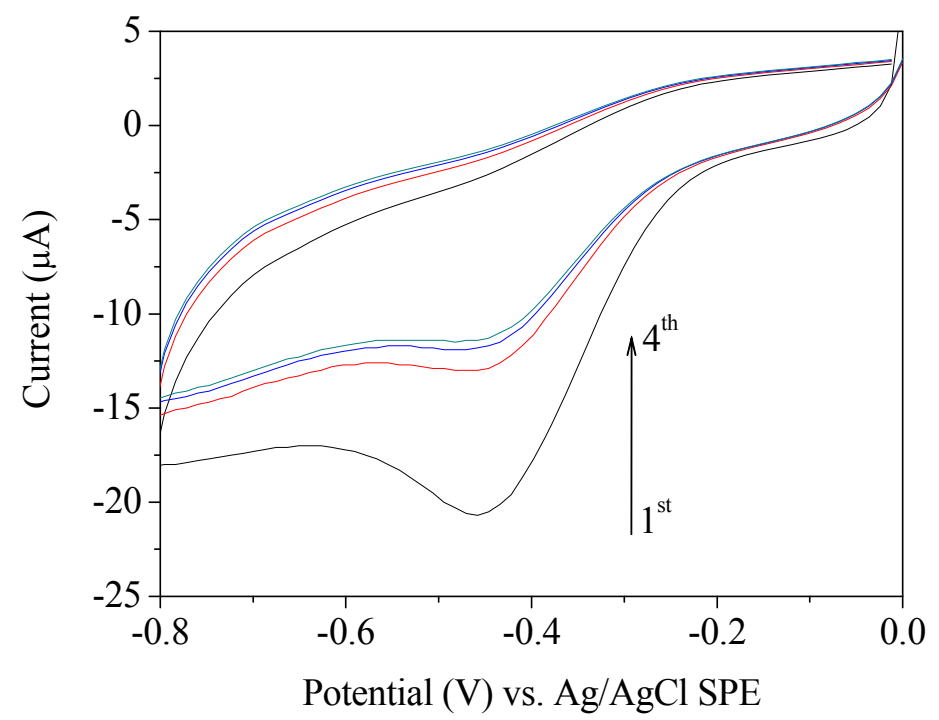

Figure 6.5.- $C Y P 2 B 4$ peak variation influenced by the oxygen consumption from the media. Four consecutive cyclic voltammograms performed in a $100 \mu \mathrm{L}$ drop of supporting electrolyte $\mathrm{pH}$ 7. Scan rate: $50 \mathrm{mV} \mathrm{s}^{-1}$.

\subsection{2.- OPTIMISATION OF THE CHRONOAMPEROMETRIC VARIABLES}

The developed biosensor was thus used for the determination of cocaine by chronoamperometry, since cocaine concentration in a solution can be related to the chronoamperometric current registered. It is well-known that chronoamperometric measurements are influenced by different factors, such as $\mathrm{pH}$ of the media and working potential, among others, depending on the studied system. In order to obtain the best current response related to a $200 \mu \mathrm{M}$ solution of cocaine, experiments performed at different $\mathrm{pH}$ and working potential were carried out. The maximum cocaine reduction current was obtained at $\mathrm{pH} 8$ and $-250 \mathrm{mV}$ vs. $\mathrm{Ag} / \mathrm{AgCl} \mathrm{SPE}$ (Figure 6.8). 


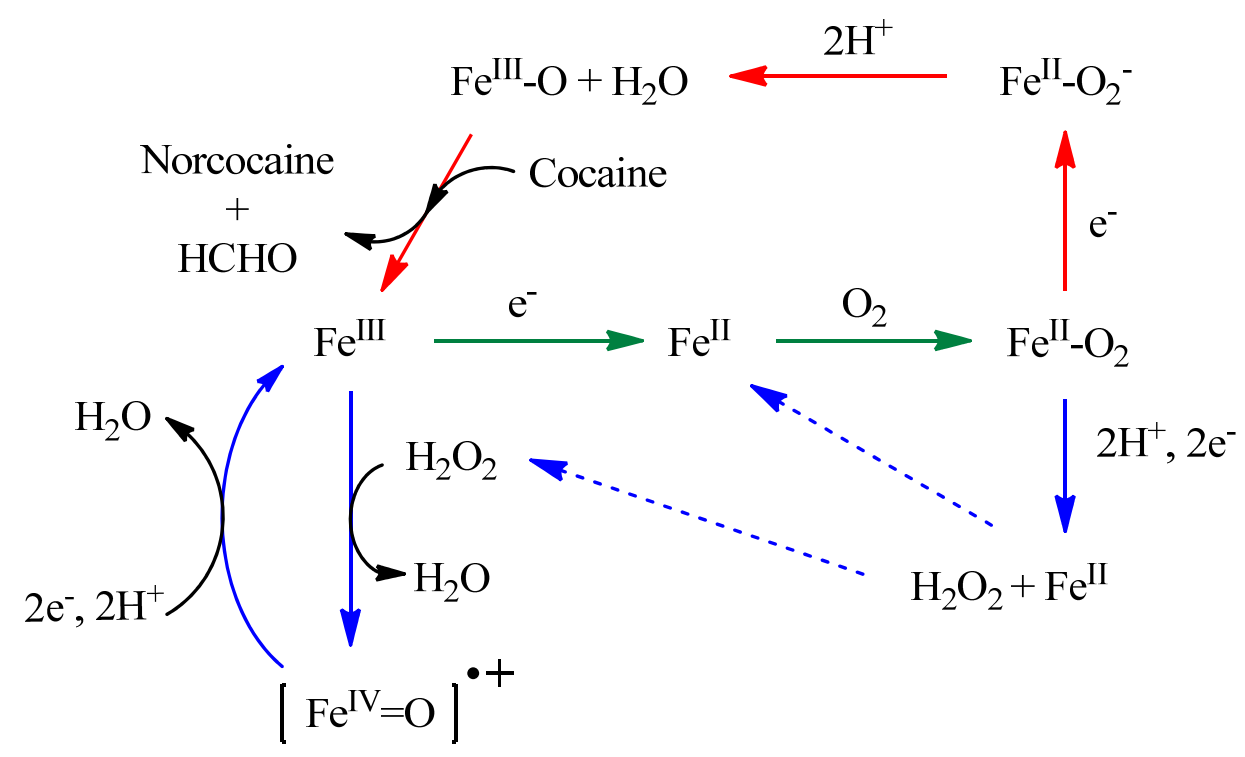

Figure 6.6.- Schematic representation of the reactions that take place at the working surface of a $S P C_{C Y P} E$ in presence of cocaine.

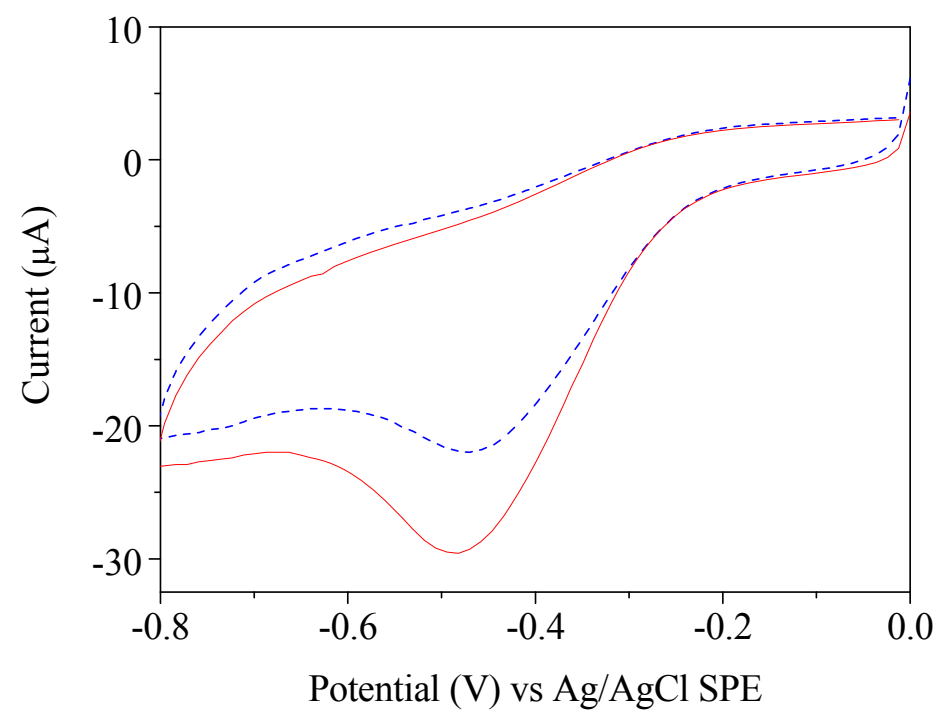

Figure 6.7.- Cyclic voltammogram of a $S P C_{C Y P} E$ in a $100 \mu \mathrm{L}$ drop of supporting electrolyte pH 7 (dash line) and in a $1.7 \mathrm{mM}$ solution of cocaine (solid line). Scan rate: $50 \mathrm{mV} \mathrm{s}{ }^{-1}$. 


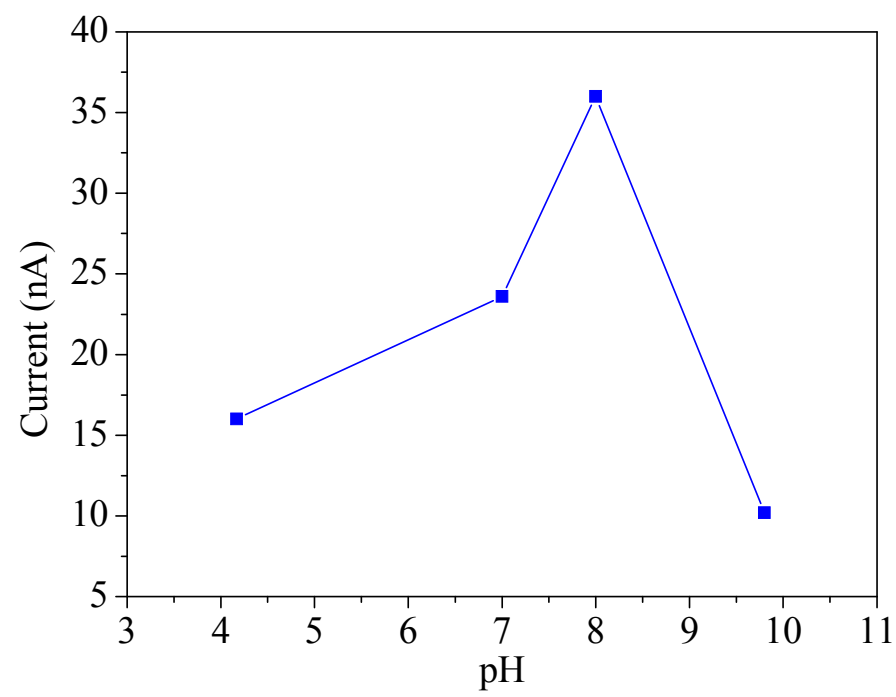

Figure 6.8.- $p H$ effect on the cocaine reduction current registered using $S P C_{C Y P} E s$. Working potential, - $250 \mathrm{mV} v \mathrm{~s} . \mathrm{Ag} / \mathrm{AgCl} \mathrm{SPE}$.

Control experiments were also carried out under these optimum conditions, using SPCEs without enzyme. Analytical signal was not obtained, which emphasises the fact that the chronoamperometric current registered as a consequence of the enzymatic process can be directly related to the cocaine concentration into the electrochemical cell (Figure 6.9).

\subsection{3.- SPECTROPHOTOMETRIC STUDY OF CYP2B4 BASED BIOSENSOR}

Furthermore, the success of the enzymatic transformation of cocaine was also checked by spectrophotometry taking into account that formaldehyde, which is obtained as subproduct of the enzymatic reaction, can react with the Nash reagent by means of the Hantzsch reaction [16]. 


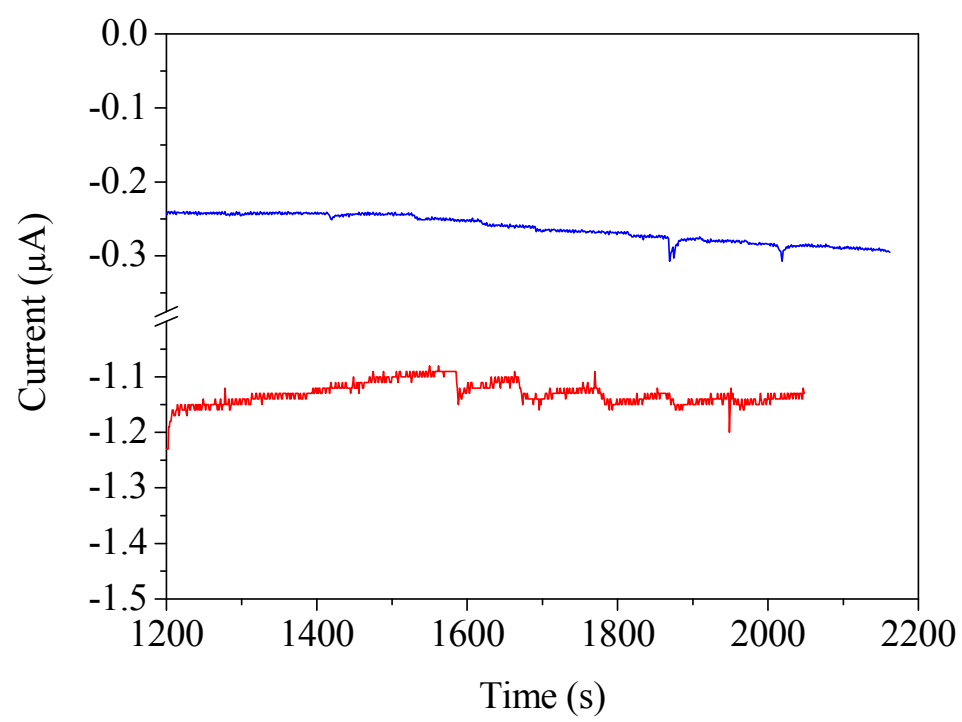

Figure 6.9.- Chronoamperometric signal from the biosensor (lower chronoamperogram) and the SPCE without enzyme (upper signal) at the optimum values of $\mathrm{pH} 8$ and $-250 \mathrm{mV}$ vs. $\mathrm{Ag} / \mathrm{AgCl} \mathrm{SPE}$.

In this way, $1 \mathrm{~mL}$ of a $5.0 \mathrm{mM}$ cocaine solution in supporting electrolyte $\mathrm{pH} 8$ was placed on top of the biosensor and a potential of $-250 \mathrm{mV}$ vs. $\mathrm{Ag} / \mathrm{AgCl} \mathrm{SPE}$ was applied for 1 hour, leading to the formation of formaldehyde and norcocaine.

Likewise, the experiment was performed with $1 \mathrm{~mL}$ of supporting electrolyte $\mathrm{pH} 8$, taking this solution as blank.

Next, the remaining solutions were mixed with $1 \mathrm{~mL}$ of the Nash solution and heated in a water bath for $30 \mathrm{~min}$ at $60^{\circ} \mathrm{C}$. A colourless solution and a yellow one, corresponding to the compound 3,5-diacetyl-1,4-dihydrolutidine formed between the formaldehyde and the acetyl acetone (Figure 6.10), were obtained for the blank and the cocaine solutions, respectively $[20,21]$. The solutions were left to cool and measured spectrophotometrically at $412 \mathrm{~nm}$, characteristic wavelength of the yellow compound, confirming the enzymatic activity of CYP2B4 towards cocaine. 


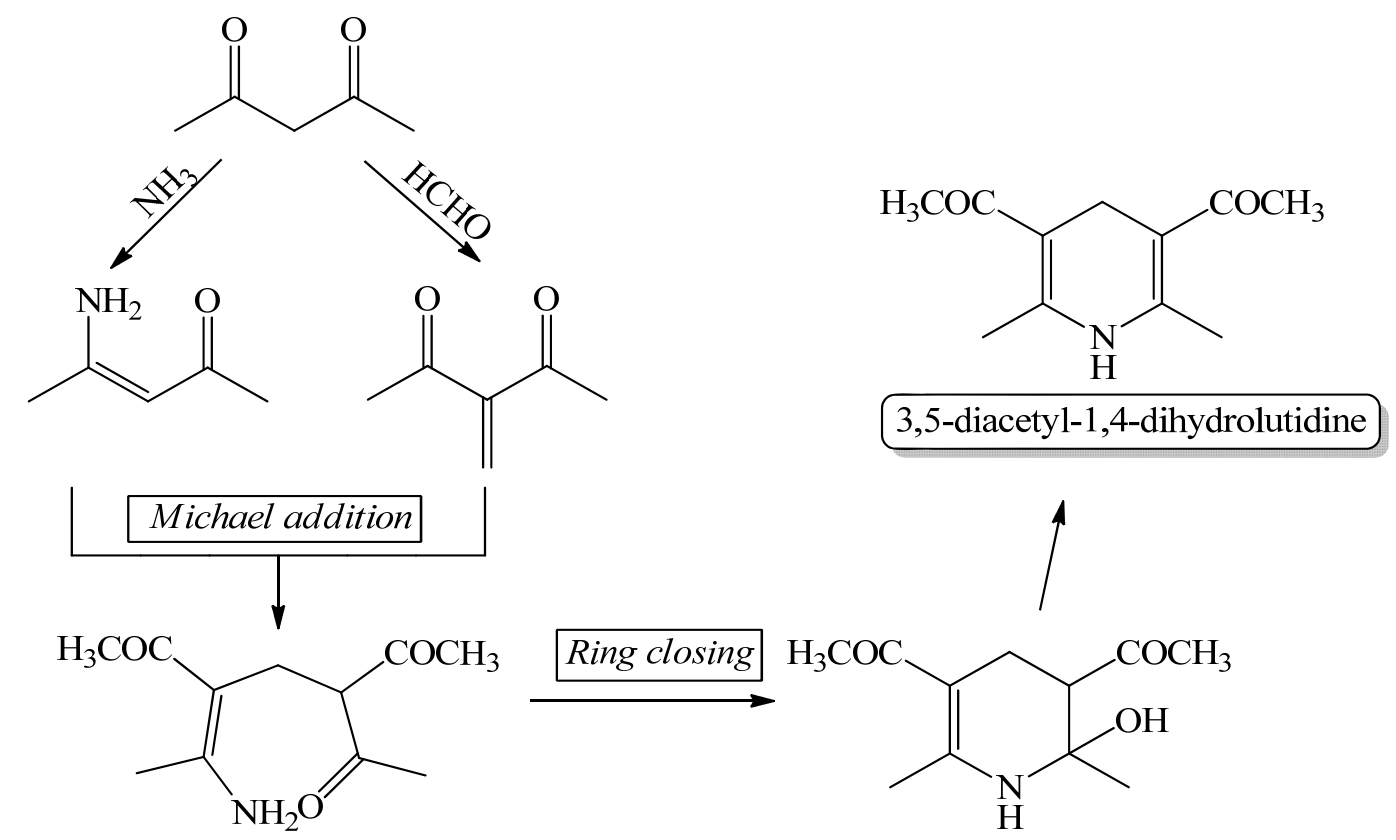

Figure 6.10.- Hantzsch reaction.

\subsection{4.- BIOSENSOR VALIDATION}

\subsubsection{1.- Precision}

In order to characterise an analytical method, it is important to establish its precision in terms of reproducibility and repeatability (Section 4.4.5.1). The first one was calculated taking into account calibration curves registered using different biosensors, and the second one with one single biosensor.

In this way, several calibration curves were performed in the cocaine concentration range from 0.2 to $1.2 \mathrm{mM}$ at the optimum conditions of the experimental variables.

Both figures of merit were calculated by the RSD of the slopes of different calibration curves. For that reason, anomalous points that would alter intercept and slope values of the calibration curves, leading to wrong conclusions, were first detected and eliminated using the PROGRESS program (Section 4.4.5.1) [22]. 
Table 6.1 shows the validated parameters of the calibration curves registered using different biosensors. The reproducibility associated to the slopes of these calibration curves in terms of RSD was $5.9 \%(n=5)$ (Figure 6.11).

Table 6.1.- Calibration parameters obtained through OLS regressions without outliers to estimate the reproducibility of the method in the determination of codeine using different $S P C_{C Y P}$ under the optimum conditions.

\begin{tabular}{ccccc}
\hline Calibration & Slope (nA $\left.\mathbf{~ m M}^{-\mathbf{1}}\right)$ & Intercept (nA) & $\mathbf{S}_{\mathbf{y x}}$ & $\begin{array}{c}\text { Coef. of } \\
\text { determination }\left(\mathbf{R}^{\mathbf{2}}\right)\end{array}$ \\
\hline I & 138.9 & 45.9 & 1.853 & 0.998 \\
II & 147.1 & 6.4 & 2.591 & 0.997 \\
III & 155.2 & 43.0 & 1.847 & 0.999 \\
IV & 133.0 & 36.4 & 1.814 & 0.998 \\
V & 147.5 & 22.0 & 2.161 & 0.998 \\
\hline
\end{tabular}

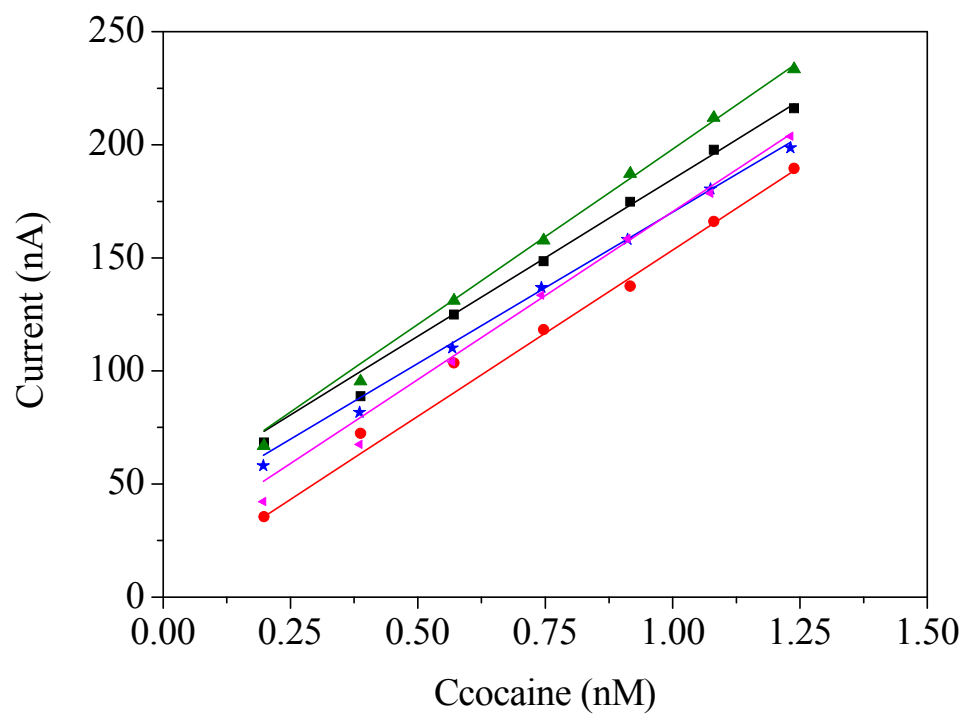

Figura 6.11.- Calibration curves for the estimation of the reproducibility of the method. Consecutive additions of $100 \mu \mathrm{L}$ from a $10.0 \mathrm{mM}$ solution of cocaine in $5 \mathrm{~mL}$ of supporting electrolyte $\mathrm{pH} 8$. 
It was similarly proceeded for the determination of the repeatability using a single $\mathrm{SPC}_{\mathrm{CYP}} \mathrm{E}$, obtaining a value of $10.4 \%(n=3)$ in terms of RSD (Table 6.2). It can be seen in figure 6.12 that the biosensors kept the $80 \%$ of its initial sensitivity after the third calibration curve.

Table 6.2.- Calibration parameters of OLS regression without outliers to evaluate the repeatability of the developed biosensor, using different $S P C_{C Y P} E S$ under the optimum conditions.

\begin{tabular}{ccccc}
\hline Calibration & Slope (nA $\mathbf{~ M M}^{-\mathbf{1}}$ ) & Intercept (nA) & $\mathbf{S}_{\mathbf{y x}}$ & $\begin{array}{c}\text { Coef. of } \\
\left.\text { determination } \mathbf{( R}^{\mathbf{2}}\right)\end{array}$ \\
\hline I & 151.0 & 1.7 & 2.952 & 0.997 \\
II & 139.9 & 30.9 & 1.148 & 0.999 \\
III & 122.4 & 52.5 & 1.770 & 0.998 \\
\hline
\end{tabular}

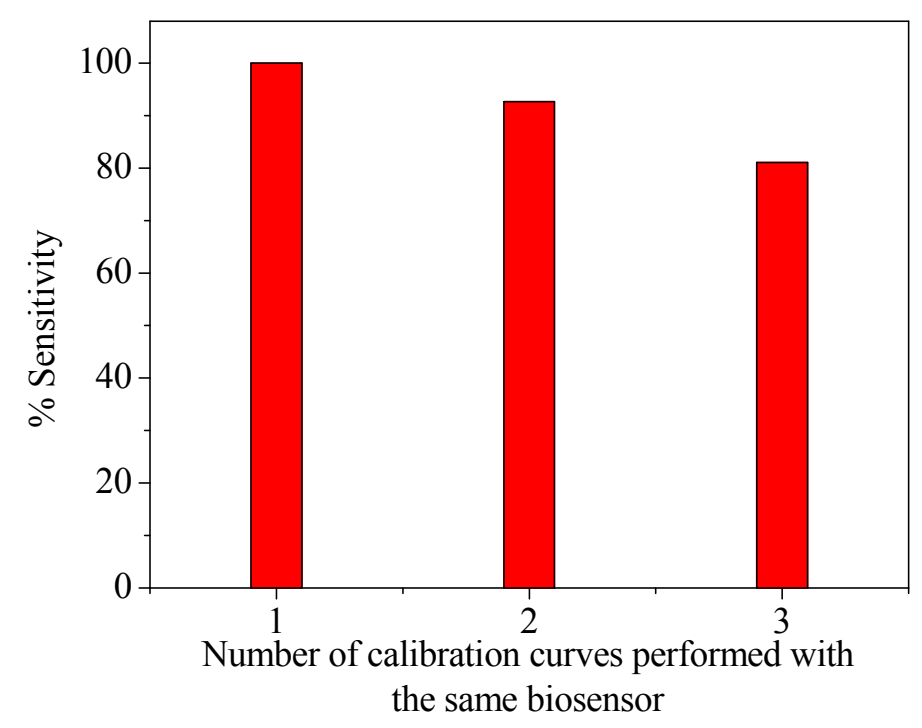

Figure 6.12.- Repeatability of the biosensor in terms of sensitivity. 


\subsubsection{2.- Capability of detection}

Additionally, it is important to calculate the capability of detection of the proposed analytical method. Calibration curves were obtained and validated in the same conditions as for the precision.

The parameters of the validated linear regressions were used to estimate the capability of detection of these biosensors for a given probability of false positive $(\alpha)$ and negative $(\beta)$ (Section 5.4.3.2) [23, 24]. The minimum detectable net concentration found was $[121.2 \pm 11.3] \mu \mathrm{M}(n=5, \alpha=\beta=0.05)$, which was slightly lower than the first concentration of the standards used to build the calibration curves, $200.0 \mu \mathrm{M}$. Therefore, from an analytical point of view, the latter was taken as the capability of detection of this method $[25,26]$.

Taking into account these results, it can be summarised that even if the capability of detection of these CYP2B4 biosensors is not as low as for those in which CYP2B4 was immobilised onto SPCEs by covalent bonds (Section 5.4.3.2), this methodology allows the semi-automatic fabrication of the biosensors, which is a clear advantage for their mass production.

\subsubsection{3.- Accuracy}

The accuracy of the developed CYP450 biosensor was evaluated by the analysis of the purity of cocaine street samples supplied by the local police (Section 5.4.3.3). The standard addition methodology, which minimises sample matrix effects, was used to carry out this assay.

Consequently, an aliquot of a homogenised confiscated cocaine street sample, supplied by police authorities, was dissolved in supporting electrolyte and centrifuged at $+4{ }^{\circ} \mathrm{C}$ for $1 \mathrm{~min}$ at $13000 \mathrm{rpm}$. Then, chronoamperometric measurements were performed at $\mathrm{pH} 8$ and $-250 \mathrm{mV}$ vs. $\mathrm{Ag} / \mathrm{AgCl} \mathrm{SPE}$. After 
reaching a stable baseline, a volume of $50 \mu \mathrm{L}$ of the problem-sample solution was added into the electrochemical system and successive additions of $50 \mu \mathrm{L}$ of a 10.0 $\mathrm{mM}$ cocaine solution were made. The purity of the cocaine street sample was found to be $[84.4 \pm 7.8] \% \mathrm{w} / \mathrm{w}(n=4, \alpha=0.05)$. This result agrees with the value of purity given for this sample by the local police (76.7\%) (Table 6.3).

Table 6.3.- Analytical characteristics in the detection of cocaine in a cocaine street sample using $S P C_{C Y P} E s$.

\begin{tabular}{ccccc}
\hline $\begin{array}{c}\text { Reference value } \\
(\%)\end{array}$ & $\begin{array}{c}\text { Cocaine } \\
\text { detected (\%) }\end{array}$ & $\begin{array}{c}\text { 95 \% confidence } \\
\text { interval for mean (\%) }\end{array}$ & Recovery (\%) & RSD (\%) \\
\hline 76.7 & & 111.1 & \\
\multirow{2}{*}{76.7} & 90.9 & {$[84.4 \pm 7.8]$} & 118.5 & 5.8 \\
& 81.8 & & 106.6 & \\
& 79.7 & & 103.9 & \\
\hline
\end{tabular}

\section{5.- CONCLUSIONS}

The immobilisation of CYP2B4 by directly screen-printing has led to the semi-automatic fabrication of disposable biosensors, allowing mass production for the determination of cocaine. In order to prevent CYP2B4 denaturation, the curing process has been performed at $30{ }^{\circ} \mathrm{C}$ during $1 \mathrm{~h}$. The success in the immobilisation procedure has been verified through the visualisation of the enzyme redox peaks by cyclic voltammetry in a supporting electrolyte solution $\mathrm{pH}$ 7. A reduction current has been registered by chronoamperometry as consequence of the enzymatic mechanism, in which cocaine is metabolised to norcaine, obtaining formaldehyde as subproduct. This fact has been proved by analysing the enzymatically generated formaldehyde by spectrophotometry after its reaction with the Nash reagent. Calibration curves recorded under the optimum conditions, $\mathrm{pH} 8$ and working potential of $-250 \mathrm{mV}$ vs. $\mathrm{Ag} / \mathrm{AgCl} \mathrm{SPE}$, have been used to calculate the values of reproducibility $(5.9 \%, n=$ 
$5)$, repeatability $(10.5 \%, n=3)$ and capability of detection $(200.0 \mu \mathrm{M}, \alpha=\beta=0.05)$ of the described method in the calibration range from 0.2 to $1.2 \mathrm{mM}$. The developed enzymatic biosensor has proved its viability in the determination of cocaine in adulterated samples.

\section{6.- REFERENCES}

1. Komorsky-Lovric, S., I. Galic, and R. Penovski, Voltammetric determination of cocaine microparticles. Electroanalysis 11, 1999, p. 120-123.

2. Kloss, M.W., G.M. Rosen, and E.J. Rauckman, Cocaine-mediated hepatotoxicity. A critical review. Biochemical Pharmacology 33, 1984, p. 169-173.

3. Lewis, D.F.V., Guide to Cytochromes P450: Structure and Function. 2001, Florida: CRC Press, Boca Ratón.

4. Colucci, A.P., et al., Validation of an extraction and gas chromatographymass spectrometry quantification method for cocaine, methadone, and morphine in postmortem adipose tissue. Journal of Analytical Toxicology 34, 2010, p. 342-346.

5. Del Rosario Brunetto, M., et al., Analysis of cocaine and benzoylecgonine in urine by using multisyringe flow injection analysis-gas chromatography-mass spectrometry system. Journal of Separation Science 33, 2010, p. 1779-1786.

6. Valente, M.J., et al., Development and validation of a gas chromatography/ion trap-mass spectrometry method for simultaneous quantification of cocaine and its metabolites benzoylecgonine and norcocaine: Application to the study of cocaine metabolism in human primary cultured renal cells. Journal of Chromatography B: Analytical Technologies in the Biomedical and Life Sciences 878, 2010, p. 3083-3088. 
7. Mercolini, L., et al., Analysis of cocaine and two metabolites in dried blood spots by liquid chromatography with fluorescence detection: A novel test for cocaine and alcohol intake. Journal of Chromatography A 1217, 2010, p. $7242-7248$.

8. Concheiro, M., D.M. Shakleya, and M.A. Huestis, Simultaneous analysis of buprenorphine, methadone, cocaine, opiates and nicotine metabolites in sweat by liquid chromatography tandem mass spectrometry. Analytical and Bioanalytical Chemistry 400, 2011, p. 69-78.

9. Favretto, D., et al., High performance liquid chromatography-high resolution mass spectrometry and micropulverized extraction for the quantification of amphetamines, cocaine, opioids, benzodiazepines, antidepressants and hallucinogens in 2.5mg hair samples. Journal of Chromatography A 1218, 2011, p. 6583-6595.

10. Jiang, B., et al., Highly sensitive electrochemical detection of cocaine on graphene/AuNP modified electrode via catalytic redox-recycling amplification. Biosensors and Bioelectronics 32, 2012, p. 305-308.

11. Wen, Y., et al., DNA nanostructure-decorated surfaces for enhanced aptamer-target binding and electrochemical cocaine sensors. Analytical chemistry 83, 2011, p. 7418-7423.

12. Oiye, E.N., et al., Voltammetric determination of cocaine in confiscated samples using a cobalt hexacyanoferrate film-modified electrode. Forensic Science International 192, 2009, p. 94-97.

13. Alonso-Lomillo, M.A., et al., CYP450 2B4 covalently attached to carbon and gold screen printed electrodes by diazonium salt and thiols monolayers. Analytica Chimica Acta 633, 2009, p. 51-56.

14. Alonso-Lomillo, M.A., et al., Horseradish peroxidase-screen printed biosensors for determination of Ochratoxin A. Analytica Chimica Acta 688, 2011, p. 49-53. 
15. Asturias-Arribas, L., et al., CYP450 biosensors based on screen-printed carbon electrodes for the determination of cocaine. Analytica Chimica Acta 685, 2011, p. 15-20.

16. Kleeberg, U. and W. Klinger, Sensitive formaldehyde determination with Nash's reagent and a 'tryptophan reaction'. Journal of Pharmacological Methods 8, 1982, p. 19-31.

17. Talakad, J.C., et al., Rational engineering of cytochromes P450 2 B6 and 2 B11 for enhanced stability: Insights into structural importance of residue 334. Archives of Biochemistry and Biophysics 494, 2010, p. 151-158.

18. Shumyantseva, V.V., et al., A new format of electrodes for the electrochemical reduction of cytochromes P450. Journal of Inorganic Biochemistry 100, 2006, p. 1353-1357.

19. Krishnan, S., J.B. Schenkman, and J.F. Rusling, Bioelectronic delivery of electrons to cytochrome P450 enzymes. Journal of Physical Chemistry B 115, 2011, p. 8371-8380.

20. Nash, T., The colorimetric estimation of formaldehyde by means of the Hantzsch reaction. The Biochemical journal 55, 1953, p. 416-421.

21. Katritzky, A.R., D.L. Ostercamp, and T.I. Yousaf, The mechanism of the hantzsch pyridine synthesis: A study by $15 N$ and $13 C$ NMR spectroscopy. Tetrahedron 42, 1986, p. 5729-5738.

22. Rousseeuw, P.J. and A.M. Leroy, Robust Regression and Outlier Detection. 1989, New York: Wiley.

23. Inczédy, J., et al., Compendium of Analytical Nomenclature. 3rd ed. 2000, Baltimore: Port City Press Inc.

24. ISO11843, Capability of Detection, Part I, 1997 and Part II, 2000. Genève, Switzerland. 
25. Ortiz, M.C., et al., Capability of detection of an analytical method evaluating false positive and false negative (ISO 11843) with partial least squares. Chemometrics and Intelligent Laboratory Systems 69, 2003, p. 21-33.

26. Alonso-Lomillo, M.A., et al., Sensitive enzyme-biosensor based on screenprinted electrodes for Ochratoxin A. Biosensors \& Bioelectronics 25, 2010, p. 1333-1337. 
CHAPTER 7:

SCREEN-PRINTED BIOSENSOR BASED ON THE INHIBITION OF THE ACETYLCHOLINESTERASE ACTIVITY FOR THE DETERMINATION OF CODEINE 

Codeine is an alkaloid mainly used in the treatment of moderate pain. It has been determined by immunosensors and enzymatic sensors, based on the enzyme morphine dehydrogenase (Section 3.1.3.1). The use of NADPH as cofactor can decrease the electrochemical activity of the sensor, since its oxidised form can dimerise, being adsorbed at the electrode surface and, thus, blocking it ${ }^{1-3}$.

Being codeine a cholinesterase inhibitor, AChE based biosensors can be introduced as an alternative to the biosensing detection of codeine (Section 3.1.3.1). The current chapter presents the chronoamperometric determination of codeine using SPCEs that incorporate the mediator tetrathiafulvalene (TTF) in the matrix of the working electrode and cross-linked AChE. The redox mediator TTF allows monitoring the enzymatic activity at a lower working potential than the rather high potentials usually required for the oxidation of acetylthiocholine iodide (ATI). The application of $+250 \mathrm{mV}$ vs. $\mathrm{Ag} / \mathrm{AgCl} \mathrm{SPE}$ in a $1.0 \mathrm{mM}$ solution of ATI in an electrolyte solution $\mathrm{pH} 7$ gives an oxidation signal due to the dimerisation of such metabolite after the reaction with the enzyme. This electrochemical signal is decreased by consecutive additions of a solution of codeine, which allows building calibration curves for the validation of this electrochemical method. This type of inhibition has been studied by means of a Lineweaver-Burk plot. Additionally, the developed biosensor has been used for the determination of the quantity of codeine in pharmaceutical commercial tablets and urine spiked samples.

This work has been partially published in Talanta 111,2013 , p. 8-12, and presented at XXXIV Reunión del Grupo de Electroquímica de la Real Sociedad Española y XV Encontro Ibérico de Electroquímica in Valencia, Spain (July 2013).

1. Bareket, L, et al, Carbon nanotubes based electrochemical biosensor for detection of formaldehyde released from a cancer cell line treated with formaldehyde-releasing anticancer prodrugs. Bioelectrochemistry 77, 2010, p. 94-99

2. Ragg, E, et al, ${ }^{1} H-N M R$ study and structure determination of 4,4- and 4,6-dimers from electrochemical reduction of $N A D P^{+}$, Biochimica et Biophysica Acta 1076, 1991, p. 37-48

3. Braden Ohlsen and Shelley D. Minteer, NADH regeneration for use in bioelectrofuels production, $224^{\text {th }}$ ECS Meeting, 2013 The electrochemical society. 



\section{1.- INTRODUCTION}

Codeine, or methylmorphine, is an alkaloid that is extracted from opium and one of the most common used antitussive drugs, being also used as analgesic and antidiarrheal $[1,2]$. Although it belongs to the same opium family as morphine and heroin, codeine is used for the treatment of moderated pain and induces less euphoria and sedation than the first two, but it can also produce addiction [3]. Even though codeine does not produce as strong effects as heroin, it is also considered a drug of abuse.

This drug has been determined in diverse matrixes by different methodologies such as gas chromatography [4, 5], liquid chromatography [5], electrophoresis [6], chemiluminescence [7] or electrochemistry [3, 8-19]. Although electrochemical methods have given good results, rather high potentials must be applied for the direct oxidation of this analyte, which carries possible interferences. This problem can be sometimes solved by the incorporation of a biorecognition element, giving a specific biosensor. In this way, two enzymatic procedures based on the immobilisation of morphine dehydrogenase [20,21] and two aptamer based methods [22, 23] have been developed to quantify codeine (Section 3.1.3.1).

In this chapter, the detection of codeine has been attempted using $\mathrm{AChE}$ based SPCEs, taking into account the reversible inhibition of the enzyme activity in presence of this drug [24].

ATI acts as substrate for AChE [25, 26], generating thiocholine and acetic acid (Section 3.3.2.1). The enzymatically-generated thiocholine can be electrochemically detected at slightly high potentials using SPCEs [27, 28], which could provoke the interference of other substances in the media or even the direct oxidation of the analyte [3]. In order to reduce this potential, chemical mediators such as cobalt phthalocyanine (CoPC) [29-34], Prussian Blue [35, 36], 7,7,8,8tetracyanoquinodimethane [37-39] or poly(3,4-ethylenedioxythiophene) (PEDOT) [40] have been added in solution. Moreover, the use of SPCEs allows the 
incorporation of mediators into the working electrode in the screen-printing fabrication, which undoubtedly simplifies the chronoamperometric measurement procedure. In this way, CoPC [41] and PEDOT [42] have been screen-printed for the detection of the enzymatically-generated thiocholine. TTF seems to be an optimum mediator in order to be screen-printed, since its non-solubility in water avoids risks of dissolution when working in aqueous solutions. Thus, TTF based SPCEs $\left(\mathrm{SPC}_{\mathrm{TTF}} \mathrm{Es}\right)$ have been built by screen-printing a mixture of mediator and carbon paste. In the next step, $\mathrm{AChE}$ has been cross-linked to the $\mathrm{SPC}_{\mathrm{TTF}} \mathrm{Es}$ with $\mathrm{GA}$ and BSA to obtain a biosensor for codeine detection.

According to figure 7.1, two molecules of the enzymatically-generated thiocholine dimerise thanks to the mediator, which is converted in its reduced form. The mediator is then reoxidised on the electrode giving an oxidation signal, which can be related to the substrate. When codeine is added to the solution, the transformation of acetylthiocholine in thiocholine is avoided and consequently, the decrease in the oxidation signal can be related to the concentration of the drug in solution.

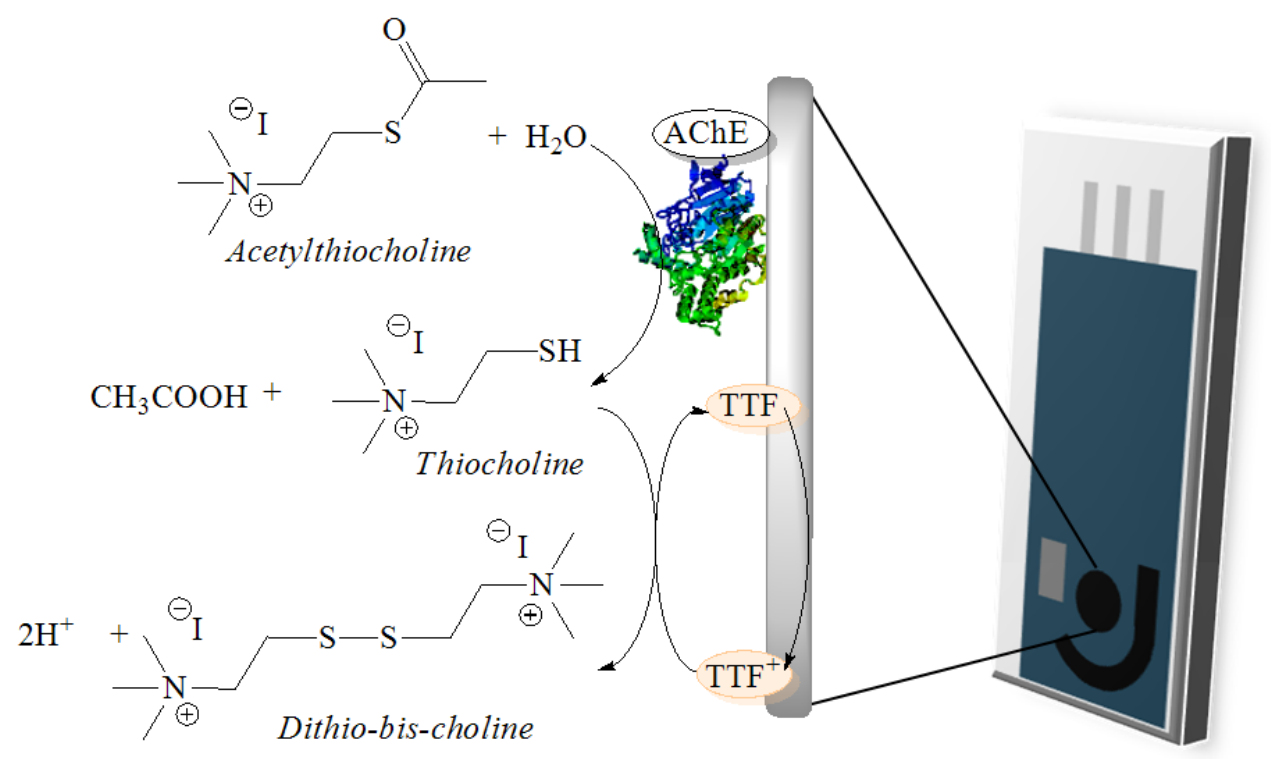

Figure 7.1.- Enzymatic reaction involved in the codeine chronoamperometric determination. 
The performance of the developed biosensor has been checked in terms of precision, capability of detection and accuracy by its application to pharmaceutical samples.

\section{2.- EXPERIMENTAL}

\subsection{1.- REAGENTS}

Screen-printed transducers were fabricated by sequential deposition of different commercial inks that define the different parts of the three-electrode system, namely carbon ink (C10903P14, Gwent Electronic Materials, Torfaen, U.K), dielectric ink (D2071120D1, Gwent Electronic Materials, Torfaen, U.K), Ag/AgCl ink (Electrodag 6037 SS, Acheson Colloiden, Scheemda, The Netherlands) and Ag ink (Electrodag 418, Acheson Colloiden, Scheemda, The Netherlands).

Analytical grade chemicals with no further purification were used. All solutions were prepared in Milli-Q water.

TTF was purchased from Acros Organics (Geel, Belgium).

GA and BSA were obtained from Sigma (Steinheim, Germany), as well as the enzyme AChE from Electrophorus electricus (Type IV-S, 410 units/mg protein).

A $100.0 \mathrm{mM} \mathrm{NaH} \mathrm{PO}_{4}$ (Merck, Darmstadt, Germany) and $\mathrm{NaOH}$ (J.T. Baker, Deventer, The Netherlands) buffer, containing $100.0 \mathrm{mM}$ of $\mathrm{KCl}$ (Merck, Darmstadt, Germany), was used as supporting electrolyte.

ATI was supplied by Fluka Analytical (Steinheim, Germany). Stock solutions were daily made in supporting electrolyte and stored at $4{ }^{\circ} \mathrm{C}$ when not in use. Stock standard solutions of codeine were prepared by dissolving the adequate amount of codeine hydrochloride (Alcaliber S.A., Madrid, Spain) in supporting electrolyte. 


\subsection{2.- APPARATUS}

A DEK 248 printing machine (DEK, Weymouth, UK) was used for the manufacture of the SPEs.

A $\mu$ Autolab electrochemical system with GPES software (Eco Chemie, Utrecht, The Netherlands) was utilised to carry out electrochemical measurements.

The $\mathrm{pH}$ of the solutions was adjusted with a $\mathrm{pH}$ meter from HANNA instruments Model HI221 (USA).

\section{3.- METHODS}

\subsection{1.- FABRICATION OF SPC TTFES}

Each different component from the electrochemical transducer, that is conductive silver tracks, $\mathrm{Ag} / \mathrm{AgCl}$ reference electrode, carbon counter electrode and dielectric layer, was defined by sequential deposition of the different inks on polyester films (HiFi Industrial Film, Dardilly, France) and its subsequent curing, according to the manufacturer's specifications (Section 3.2.1).

The working electrode ink was prepared by thoroughly mixing the carbon ink with TTF (5\% w/w) and immediately screen-printed.

\subsection{2.- IMMOBILISATION OF THE ENZYME ACHE ONTO SPC TTFES}

Cross-linking is a type of immobilisation that combines features of covalent bonding and entrapment immobilisation. As it has been mentioned in section 3.2.3.2, cross-linking agents, such as GA, are used to polymerise a base layer and anchor the 
entrapped bioelement in the layer by forming intermolecular linkages between the binding agent and the biomolecule [43].

GA is a bifunctional aldehyde and a widely used cross-linking agent. Crosslinking reactions occur between the free amino groups of lysine residues on the enzyme or protein molecule and the carbonyl group of GA, resulting in a Schiff base formation (Figure 7.2) [44].

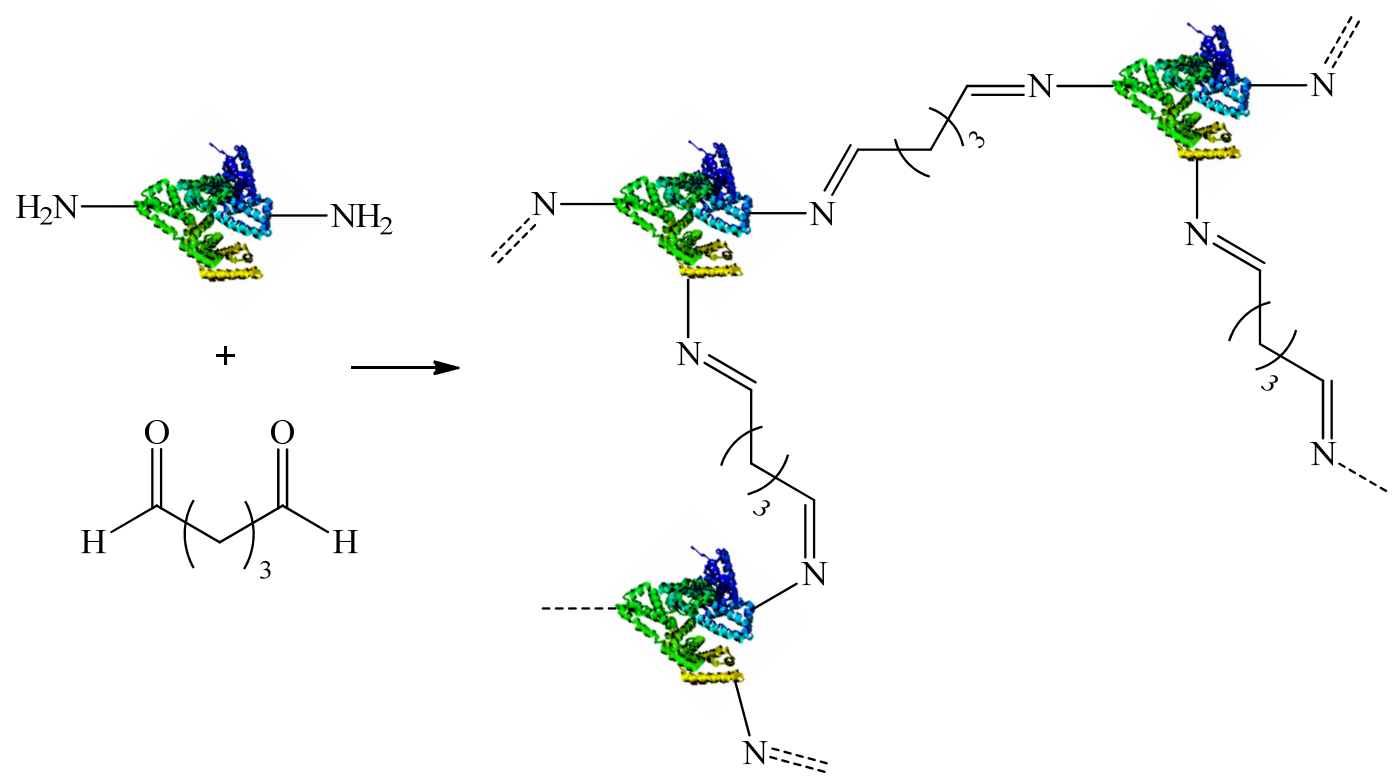

Figure 7.2.- Cross-linking reaction between the amino groups of lysine residues of an enzyme and the carbonyl groups of GA.

In the cross-linking process, GA can denature proteins. This undesirable effect is counteracted by adding a non-active protein, such as BSA [45, 46]. Bearing this in mind, cross-linking immobilisation through GA and BSA was used in order to attach AChE to the carbon surface of the working electrode. $2.5 \mu \mathrm{L}$ of a $0.1 \% \mathrm{w} / \mathrm{v}$ AChE solution in $10.0 \mathrm{mM}$ phosphate $\mathrm{pH} 6,1.25 \mu \mathrm{L}$ of a $6.0 \% \mathrm{w} / \mathrm{v}$ BSA solution in $10.0 \mathrm{mM}$ phosphate $\mathrm{pH} 6$ and $1.25 \mu \mathrm{L}$ of a $2.5 \% \mathrm{v} / \mathrm{v}$ GA solution in water were mixed and deposited onto the working electrode. After 120 minutes under $4{ }^{\circ} \mathrm{C}$, the biosensor was ready to be used. 


\subsection{3.- MEASURING PROCEDURE}

Cyclic voltammetric measurements were obtained at room temperature in a $100 \mu \mathrm{L}$ drop of $100.0 \mathrm{mM} \mathrm{KCl}$, scanning the potential between -300 and $+800 \mathrm{mV}$ vs. $\mathrm{Ag} / \mathrm{AgCl} \mathrm{SPE}$, at a scan rate of $50 \mathrm{mV} \mathrm{s}^{-1}$.

Differential pulse voltammetric measurements were performed at room temperature in $5 \mathrm{~mL}$ supporting electrolyte solution, scanning the potential between +0.5 and $+1.4 \mathrm{~V}$ vs. $\mathrm{Ag} / \mathrm{AgCl} \mathrm{SPE}$, at a scan rate of $5 \mathrm{mV} \mathrm{s}^{-1}$.

Chronoamperometric measurements were made at room temperature in a cell containing $5 \mathrm{~mL}$ of supporting electrolyte, of the desired $\mathrm{pH}$, under constant mechanical stirring. Experimental measurements were performed applying a fixed potential of $+250 \mathrm{mV}$ vs. $\mathrm{Ag} / \mathrm{AgCl} \mathrm{SPE}$. After reaching a stable baseline, a volume of a solution of ATI was added into the electrochemical system to a final concentration of $1.0 \mathrm{mM}$, except for the optimisation process. After the stabilisation of the signal, successive additions of $10 \mu \mathrm{L}$ of a $10.0 \mathrm{mM}$ codeine solution were made.

\section{4.- RESULTS AND DISCUSSION}

\subsection{1.- ELECTROCHEMICAL BEHAVIOUR OF CODEINE IN SPCES}

As it has been already mentioned, codeine presents a different electrochemical behaviour depending on the $\mathrm{pH}$ of the media (Section 3.1.3.1). This behaviour is shown in figure 7.3.

According to Garrido et al [3], the electroactive groups of codeine can be oxidised at different $\mathrm{pH}$. In this way, only one peak was shown at $\mathrm{pH} 2.1$, corresponding to the overlapped signals of the hydroxyl and tertiary amine groups (Figure 7.3.A). These two overlapped signals got separated as the $\mathrm{pH}$ of the media 
was increased (Figure 7.3.B). It was also depicted that both hydroxyl (+ $980 \mathrm{mV}$ vs. $\mathrm{Ag} / \mathrm{AgCl} \mathrm{SPE})$ and tertiary amine groups (+ $850 \mathrm{mV}$ vs. $\mathrm{Ag} / \mathrm{AgCl} \mathrm{SPE})$ shifted their maximum potential peaks depending on the $\mathrm{pH}$ (Figure 7.3.C). At $\mathrm{pH}$ 8, three peaks were observed (Figure 7.3.D). The additional peak at 1.1 V vs. Ag/AgCl SPE could be attributed to the oxidation of the methoxy group.
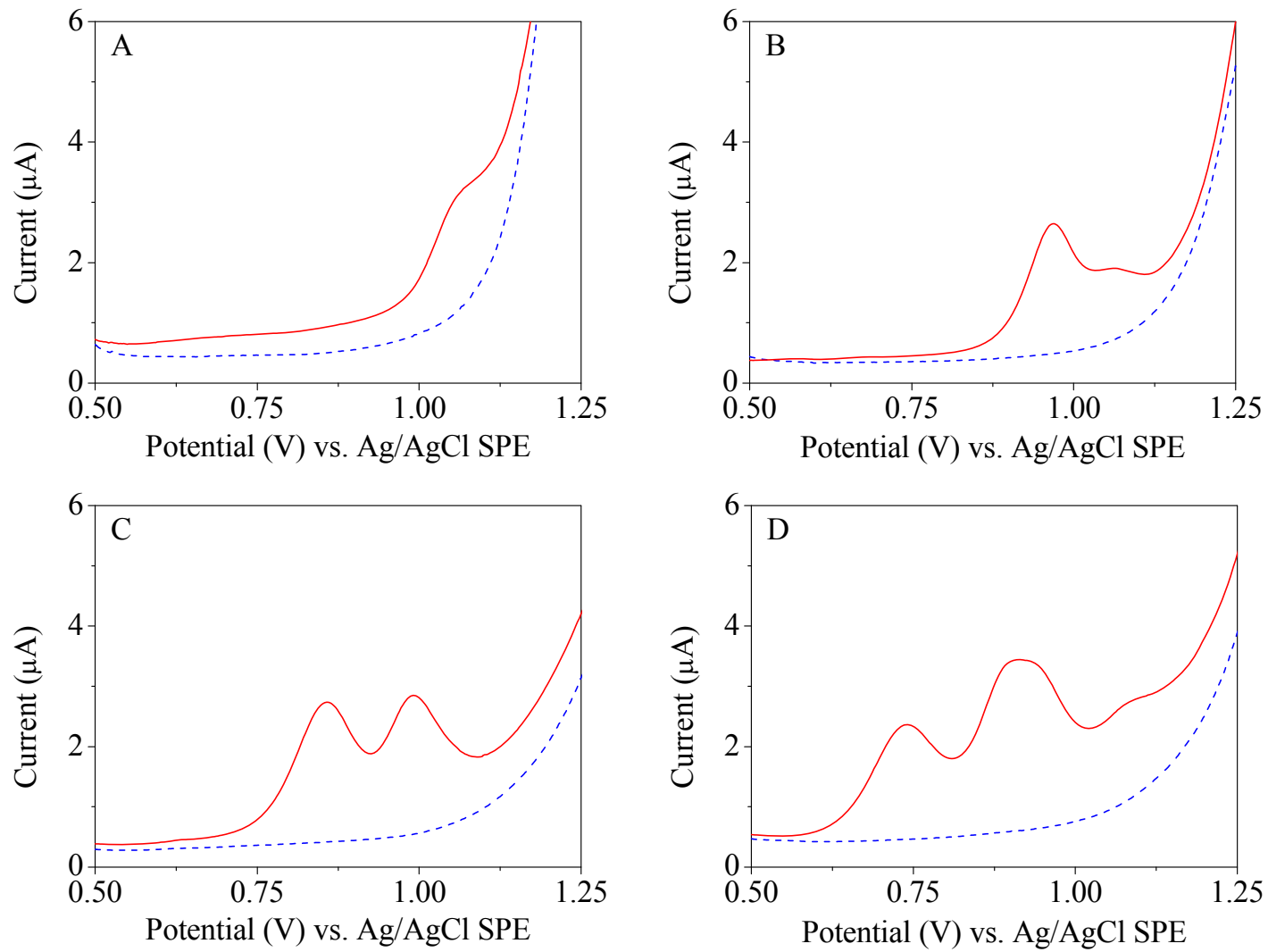

Figure 7.3.- Differential pulse voltammograms of a $100 \mu \mathrm{M}$ codeine solution (solid line) in 5 $m L$ of supporting electrolyte (dashed line) pH 2.1 (A), 4.4 (B), 6.0 (C) and 8.0 (D).

\subsection{2.- CHARACTERISATION OF SPC TTFES}

The use of screen-printing technology allows the fabrication of electrodes with different characteristics. In this case, the screen-printed mediator led to the reduction of the usual high working potential needed in chronoamperometric measurements using AChE based SPCEs [27, 28]. 
The TTF (Figure 7.4) incorporation in the carbon matrix of the working electrode was checked by cyclic voltammetry. As it can be observed in figure 7.5, TTF was oxidised to $\mathrm{TTF}^{+}$at a potential of $+250 \mathrm{mV}$ vs. $\mathrm{Ag} / \mathrm{AgCl} \mathrm{SPE}$, which was the chosen potential for the chronoamperometric measurements since the oxidised species is required for the development of the enzymatic system (Figure 7.1) [47].

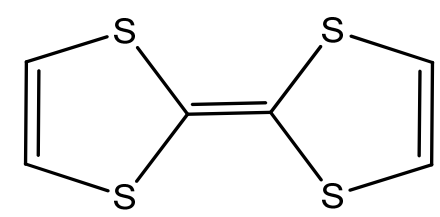

Figure 7.4.- TTF structure.

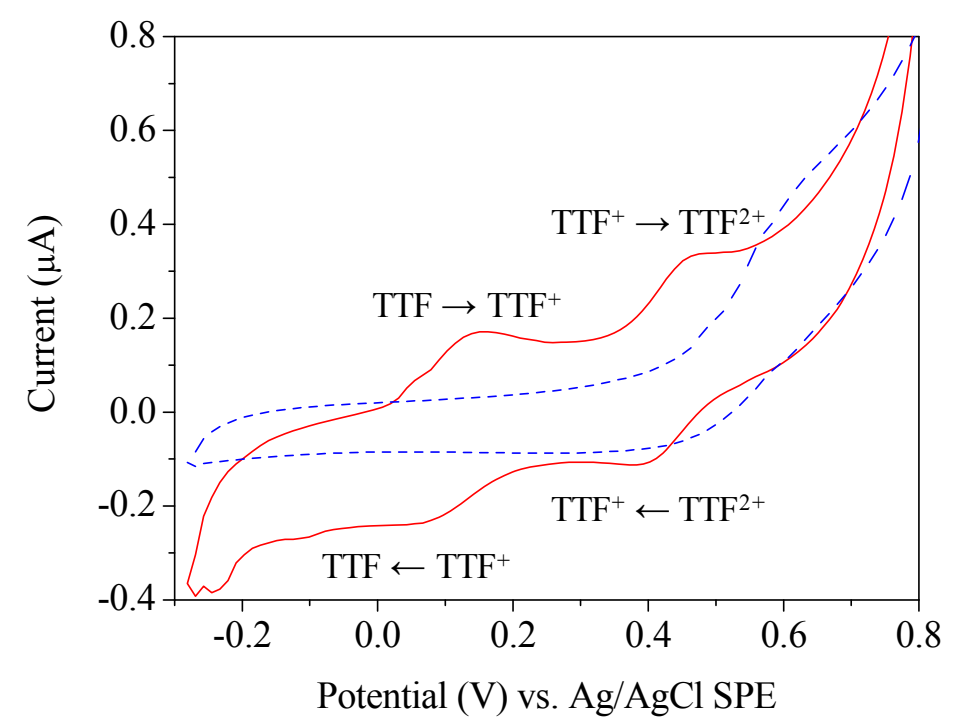

Figure 7.5.- Cyclic voltammogram of a SPCE (dashed line) and a $S P C_{T T F} E$ (solid line) in a $100 \mu \mathrm{L}$ drop of a $100.0 \mathrm{mM} \mathrm{KCl}$ solution. Scan rate, $100 \mathrm{mV} \mathrm{s}^{-1}$ vs. $\mathrm{Ag} / \mathrm{AgCl} \mathrm{SPE}$.

\subsection{3.- OPTIMISATION OF THE ENZYMATIC IMMOBILISATION STAGE}

As it has been previously said, cross-linking immobilisation through GA can provoke the denaturation of proteins (Section 7.3.2). For that reason, volume and 
concentration of AChE, GA and BSA were optimised, not only to avoid the denaturation of the enzyme but also to obtain the highest analytical response for the inhibition with codeine (Table 7.1). The optimum immobilisation conditions obtained for the development of this biosensor were $2.5 \mu \mathrm{L}$ of a $0.1 \% \mathrm{w} / \mathrm{v}$ AChE solution in $10.0 \mathrm{mM}$ phosphate $\mathrm{pH} 6,1.25 \mu \mathrm{L}$ of a $6.0 \% \mathrm{w} / \mathrm{v}$ BSA solution in 10.0 $\mathrm{mM}$ phosphate $\mathrm{pH} 6$ and $1.25 \mu \mathrm{L}$ of a $2.5 \% \mathrm{v} / \mathrm{v}$ GA solution in water.

Table 7.1.- Influence of the amount of the cross-linking reagents used for AChE immobilisation onto $S P C_{T T F}$ Es in the chronoamperometric current registered for codeine $(\mathrm{pH} 7$, ATI concentration $=1.0 \mathrm{mM}$, working potential $=+250 \mathrm{mV} v \mathrm{~s} . \mathrm{Ag} / \mathrm{AgCl} S P E)$.

\begin{tabular}{cccc}
\hline VAChE 0.1 \% $(\boldsymbol{\mu L})$ & VBSA 6.0 \% $(\boldsymbol{\mu L})$ & VGA $2.5 \%(\mu \mathrm{L})$ & Current $(\mathbf{n A})$ \\
\hline 2.5 & 0.0 & 2.0 & 59.0 \\
2.5 & 0.5 & 1.5 & 86.0 \\
2.5 & 1.0 & 1.0 & 89.0 \\
2.5 & 1.25 & 1.25 & 105.0 \\
2.5 & 1.5 & 0.5 & 81.0 \\
2.5 & 2.0 & 0.0 & 46.0 \\
\hline
\end{tabular}

\subsection{4.- OPTIMISATION OF THE CHRONOAMPEROMETRIC VARIABLES}

After the immobilisation of $\mathrm{AChE}$ by cross-linking on the $\mathrm{SPC}_{\mathrm{TTF}} \mathrm{Es}$, the developed biosensor was used for the determination of codeine by chronoamperometry.

For the study of this system, experimental factors such as $\mathrm{pH}$ of the media (from 3 to 11) and the concentration of ATI in solution (from 0.6 to $3.2 \mathrm{mM}$ ) were optimised, applying a potential of $+250 \mathrm{mV}$ vs. $\mathrm{Ag} / \mathrm{AgCl} \mathrm{SPE}$, to obtain the best current response related to a $0.2 \mathrm{mM}$ codeine solution. The optimum values for these 
experimental variables were $\mathrm{pH} 7$ for the supporting electrolyte and $1.0 \mathrm{mM}$ for concentration of ATI.

$\mathrm{SPC}_{\mathrm{TTF}}$ Es without further modification and $\mathrm{SPC}_{\mathrm{TTF}}$ Es modified with BSA and GA were used to carry out control experiments under these optimum conditions (Figure 7.7). The addition of codeine to the electrochemical cell, after the addition of ATI, did not alter in any case the registered chronoamperometric current, which points out the successful interaction between AChE and codeine that allowed the quantification of this drug (Figure 7.8).

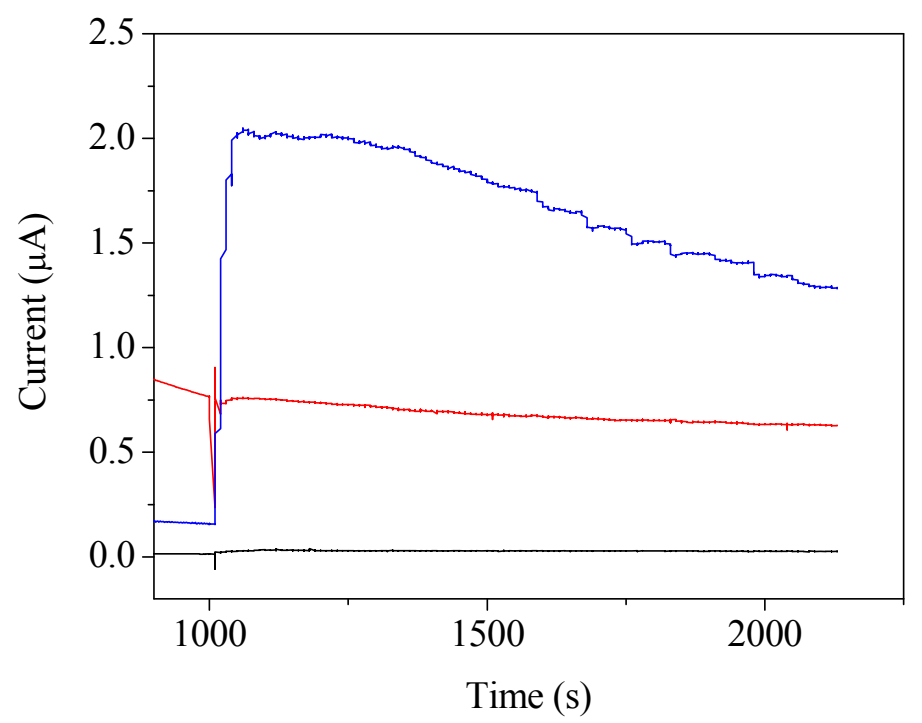

Figure 7.7.- Chronoamperometric signal from the biosensor (blue upper signal) and the negative controls (red and black lines) under the optimum conditions of pH 7 and working potential of $+250 \mathrm{mV} v \mathrm{~s} . \mathrm{Ag} / \mathrm{AgCl} \mathrm{SPE}$.

\subsection{5.- STUDY OF THE TYPE OF INHIBITION}

The type of inhibition between AChE and codeine was also studied. Chronoamperometric measurements were carried out, in presence and absence of 
codeine, by subsequent additions of a $50.0 \mathrm{mM}$ ATI solution into $5 \mathrm{~mL}$ of supporting electrolyte $\mathrm{pH} 7$ [27].

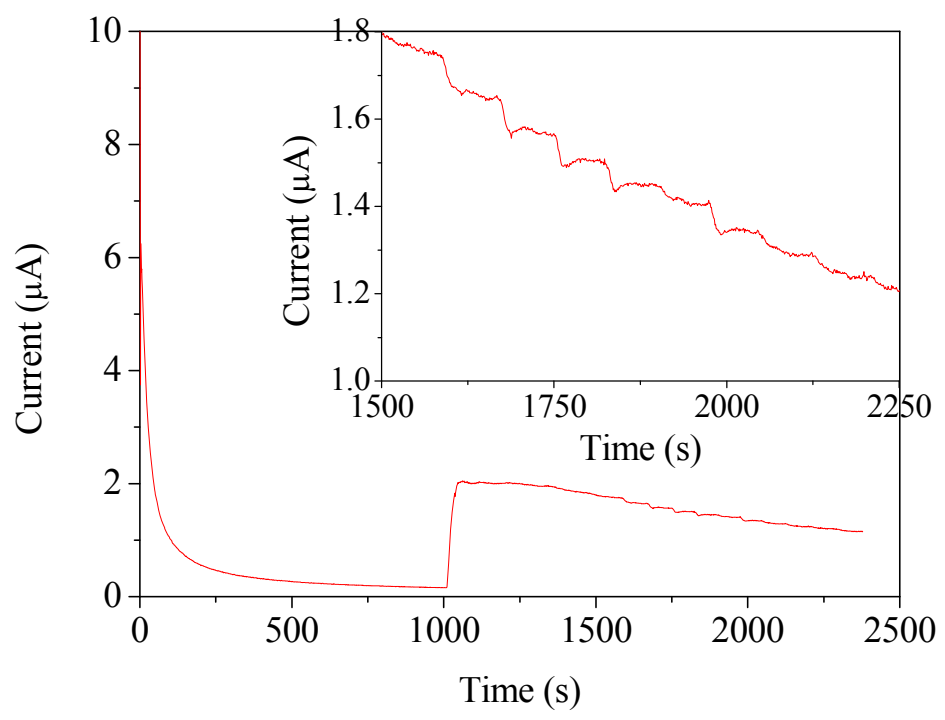

Figure 7.8.- Chronoamperometric signal of the AChE based $S P C_{T T F} E$ when $50 \mu \mathrm{L}$ of a 100.0 mM ATI solution (oxidation signal) and consecutive additions of codeine (inhibition signal) were performed under the optimum conditions of $\mathrm{pH} 7$ and working potential of $+250 \mathrm{mV}$ vs. Ag/AgCl SPE. Inset: consecutive additions of $10 \mu \mathrm{L}$ of a $10.0 \mathrm{mM}$ codeine solution at the developed biosensor.

The inhibitory effect of codeine was studied by means of the LineweaverBurk plot (Figure 7.9), which in presence of codeine showed a constant maximum reaction rate, $v_{\max }$, and an increase in the apparent Michaelis-Menten constant, $K_{m}$, suggesting a competitive inhibition (Section 3.3.2.3.1) [48]. In addition, it was observed that the excess of substrate also inhibited the activity of this enzyme (Figure 7.10) [24]. 


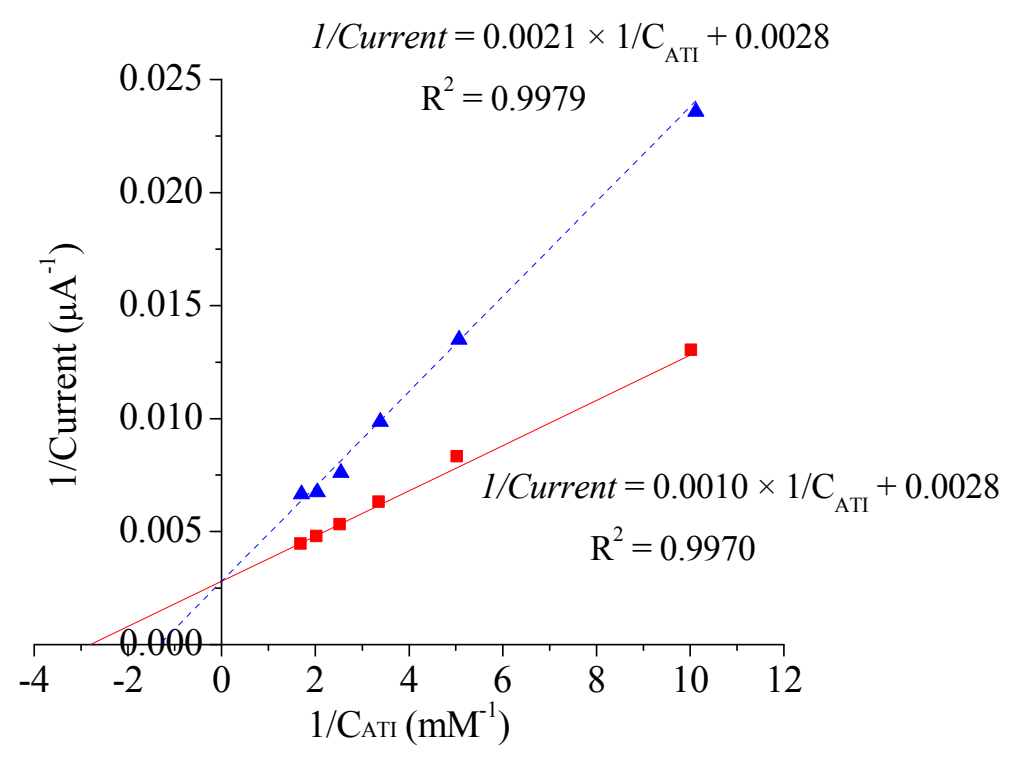

Figure 7.9.- Lineweaver-Burk plot for the study of the type of inhibition between AChE and codeine. Calibration curves recorded at $\mathrm{pH} 7$ and $+250 \mathrm{mV} v \mathrm{~s}$. $\mathrm{Ag} / \mathrm{AgCl}$ SPE by consecutive additions of ATI in presence (dashed line) and absence (solid line) of a $0.2 \mathrm{mM}$ solution of codeine.

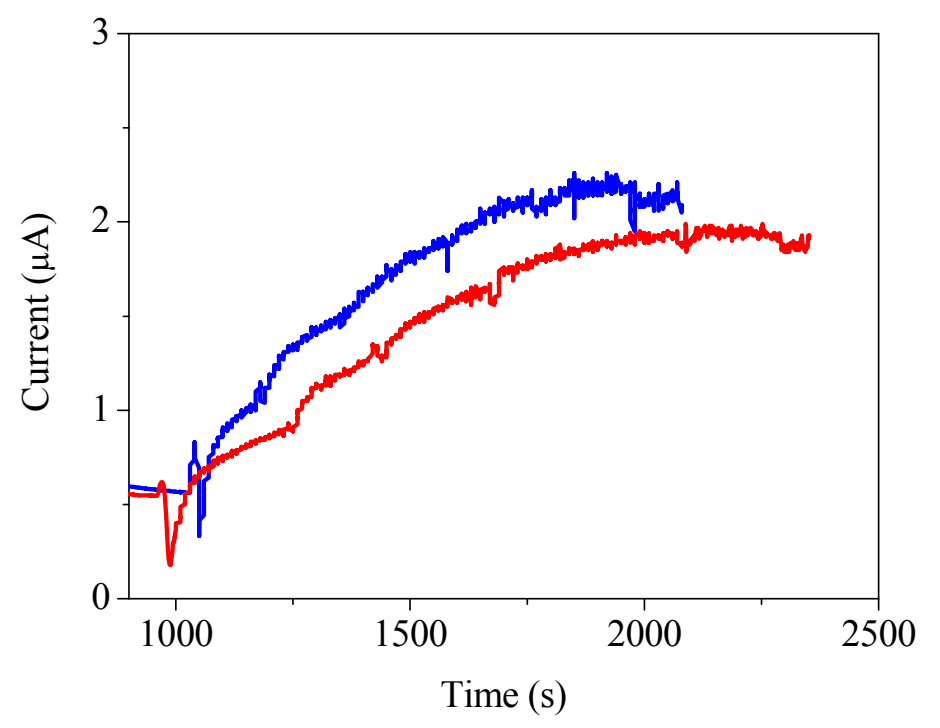

Figure 7.10.- Chronoamperogram of successive additions of ATI in presence of $0.2 \mathrm{mM}$ of codeine (lower red line) and absence (upper blue line) under the optimum conditions of $\mathrm{pH} 7$ and $+250 \mathrm{mV}$ vs. $\mathrm{Ag} / \mathrm{AgCl} \mathrm{SPE}$. 


\subsection{6.-VALIDATION OF THE METHOD}

The validation of an analytical method is performed to guarantee its quality. This justification is established in terms of precision, studying the reproducibility and the repeatability, as well as its capability of detection and accuracy.

\subsubsection{1.- Precision}

Calibration curves were performed with different biosensors in order to obtain the reproducibility of the method in terms of RSD associated to the slopes of these curves.

Each biosensor was used to carry out a calibration curve at the optimum conditions in the range from 20.0 to $200.0 \mu \mathrm{M}$ of codeine. The anomalous points of these calibration curves were detected and eliminated using PROGRESS program (Section 4.4.5.1) [49]. Table 7.2 and figure 7.11 show the validated data of these curves. The reproducibility of the method was estimated to be $3.3 \%(n=6)$.

Table 7.2.- Calibration parameters obtained through OLS regressions without outliers to estimate the reproducibility of the method in the determination of codeine using different AChE based SPCE under the optimum conditions.

\begin{tabular}{ccccc}
\hline Calibration & Slope $\left(\mathbf{n} \mathbf{A} \mathbf{~ M}^{-\mathbf{1}}\right)$ & Intercept (nA) & Syx & $\begin{array}{c}\text { Coef. of } \\
\text { determination }\left(\mathbf{R}^{2}\right)\end{array}$ \\
\hline I & 3.6 & -2.3 & 4.885 & 0.999 \\
II & 3.4 & 6.0 & 5.151 & 0.999 \\
III & 3.7 & 71.2 & 10.464 & 0.998 \\
IV & 3.5 & -40.5 & 10.341 & 0.997 \\
V & 3.6 & 1.8 & 4.581 & 0.999 \\
VI & 3.7 & 59.7 & 1.601 & 0.999 \\
\hline
\end{tabular}




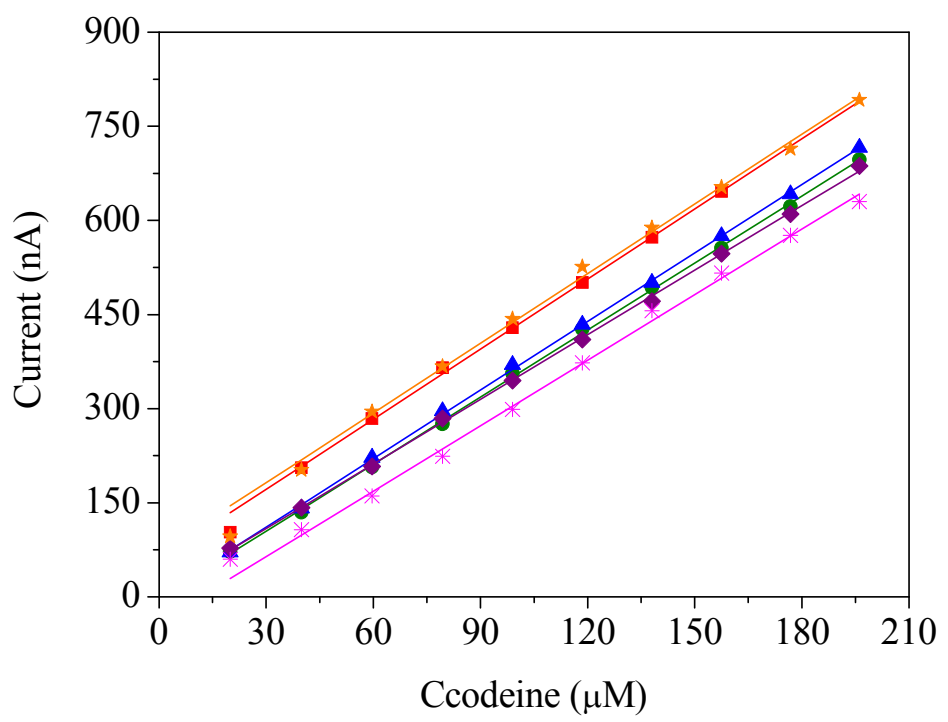

Figure 7.11.- Experimental points and OLS regressions for the different calibration curves carried out to evaluate the reproducibility of $A C h E$ based $S P C_{T T F} E$ s in the determination of codeine.

The same procedure was carried out to calculate the repeatability of this method. However, it was observed that it was not possible to performed more than one calibration curve with the same electrode. This fact is not really significant due to the disposable nature of the biosensor and its good reproducibility.

\subsubsection{2.- Capability of detection}

The calculation of the capability of detection of the electroanalytical method was obtained from different calibration curves. The validated parameters of these linear regressions, in the same conditions as for the precision, were used to estimate the capability of detection of these biosensors for a given probability of false positive $(\alpha)$ and negative $(\beta)$ (Section 5.4.3.2) $[50,51]$. The minimum detectable concentration was lower than the concentration of the first standard used to build the calibration curves, $20.0 \mu \mathrm{M}$. Therefore, from an analytical point of view, the first 
point of the calibration curve has been taken as the capability of detection of this method [52].

Capability of detection and reproducibility values confirm the good performance of the developed procedure for the chronoamperometric determination of codeine, in relation with the previously reported chronoamperometric biosensor (Table 7.3).

\subsubsection{3.- Accuracy}

The developed biosensor was used for the determination of codeine in complex matrixes, such as Codeisan, with codeine phosphate $1 / 2 \mathrm{H}_{2} \mathrm{O}$ as active principle (28.7 mg per tablet), and urine samples.

A tablet of Codeisan was homogeneously crushed and an aliquot was weight and dissolved in $1 \mathrm{~mL}$ of a $100.0 \mathrm{mM}$ phosphate buffer solution, $\mathrm{pH} \mathrm{7.} \mathrm{After}$ centrifuging this suspension at $4{ }^{\circ} \mathrm{C}$ for $1 \mathrm{~min}$ at $13000 \mathrm{rpm}$, the supernatant was pipetted and used as studied solution. Urine samples, collected from a healthy person, were spiked with codeine to a final concentration of $10.7 \mathrm{mM}$. Standard addition methodology was used to minimise the possible sample matrix effects.

Chronoamperometric measurements were performed at the optimised experimental conditions. After adding the substrate of the AChE and obtaining a stable baseline, a volume of $10 \mu \mathrm{L}$ of the studied solution was added into the electrochemical cell and successive additions of $10 \mu \mathrm{L}$ from the $10.0 \mathrm{mM}$ codeine solution were made (Figure 7.12). The value of the concentration of codeine found in the tablet was $[29.4 \pm 3.1] \mathrm{mg} /$ tablet $(n=5, \alpha=0.05)$ (Table 7.4). This result agrees with the values shown in the patient information leaflet $(28.7 \mathrm{mg})$. In the case of spiked urine samples, the codeine concentration found was [10.8 \pm 2.5$](n=3, \alpha=$ 0.05) (Table 7.4). 


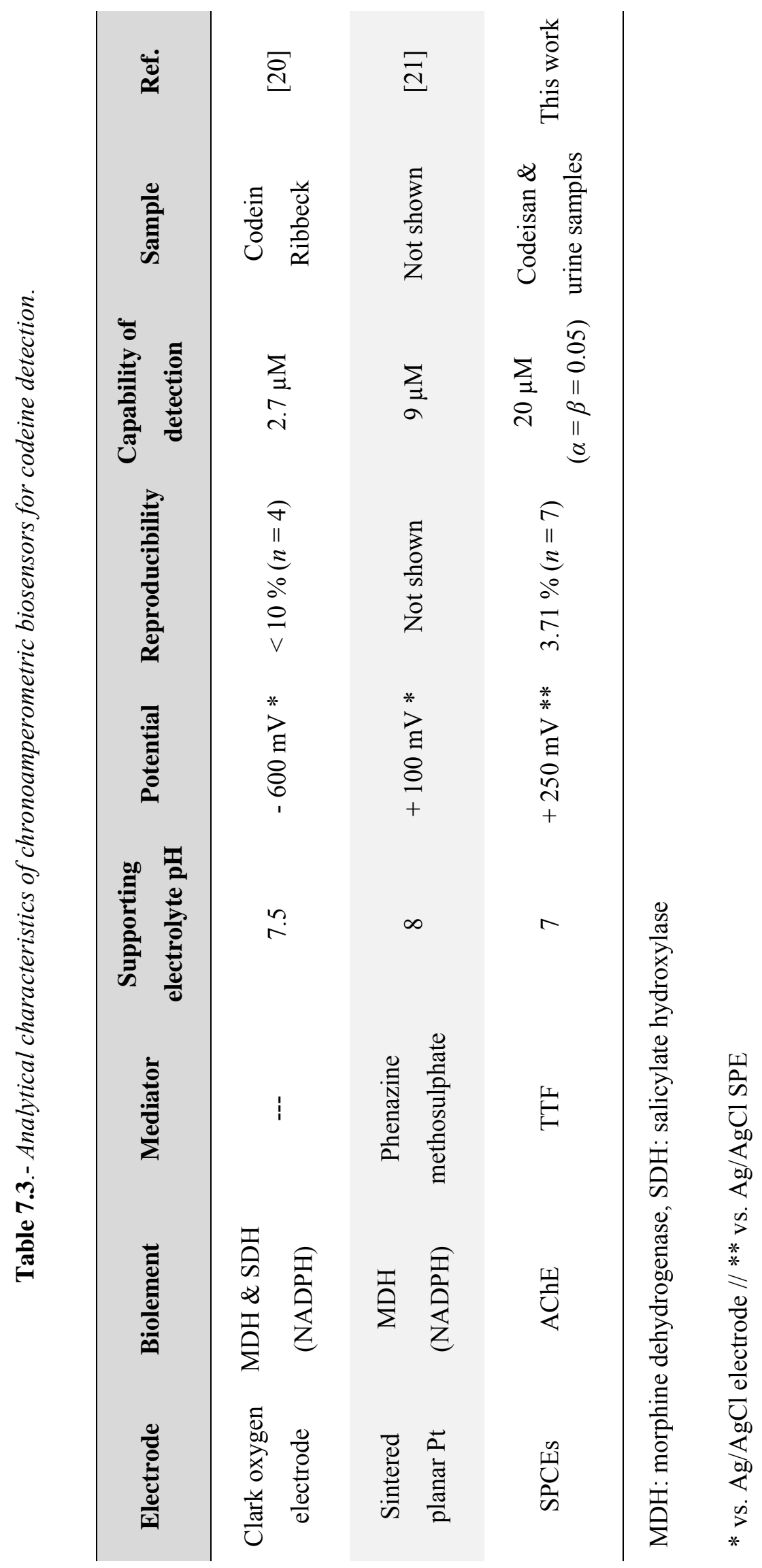



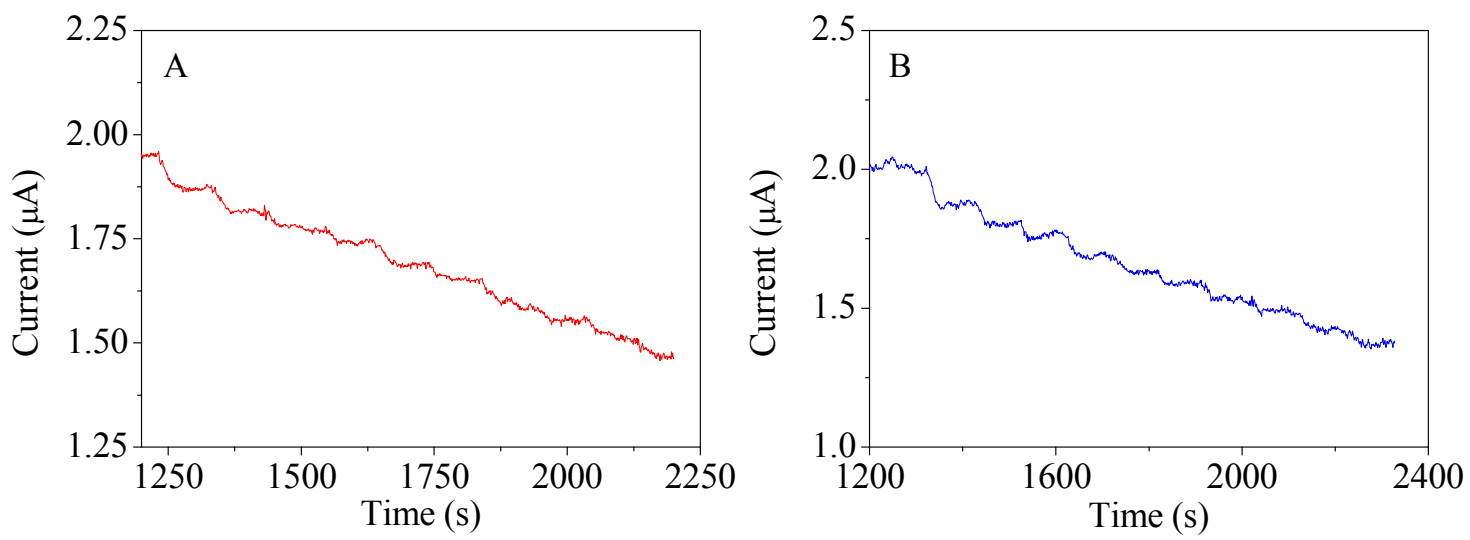

Figure 7.12.- Cronoamperometric signal of curves of calibration performed to calculate the concentration of codeine in Codeisan (A) and spiked urine (B) using the standard addition methodology. The first addition belongs to $10 \mu \mathrm{L}$ of the studied sample and consecutive additions of $10 \mu \mathrm{L}$ from the $10.0 \mathrm{mM}$ codeine solution were made.

Table 7.4.- Analytical characteristics in the detection of codeine in pharmaceutical and spiked urine samples using $A C h E$ based $S P C_{T T F} E s$.

\begin{tabular}{|c|c|c|c|c|c|}
\hline & $\begin{array}{c}\text { Reference } \\
\text { value }\end{array}$ & $\begin{array}{l}\text { Codeine } \\
\text { detected }\end{array}$ & $\begin{array}{l}95 \% \text { confidence } \\
\text { interval for mean }\end{array}$ & $\begin{array}{c}\text { Recovery } \\
\text { (\%) }\end{array}$ & RSD (\%) \\
\hline & $28.7 \mathrm{mg} /$ tablet & $\begin{array}{l}27.6 \\
26.9 \\
28.5 \\
32.9 \\
31.0\end{array}$ & $\begin{array}{c}{[29.4 \pm 3.1]} \\
\mathrm{mg} / \text { tablet }\end{array}$ & $\begin{array}{r}96.2 \\
93.7 \\
99.3 \\
114.6 \\
108.0\end{array}$ & 8.5 \\
\hline 总 & $10.7 \mathrm{mM}$ & $\begin{array}{c}11.5 \\
11.2 \\
9.6\end{array}$ & {$[10.8 \pm 2.5] \mathrm{mM}$} & $\begin{array}{c}107.5 \\
104.7 \\
89.7\end{array}$ & 9.5 \\
\hline
\end{tabular}

Additionally, the interference of urea, second main component in urine after water, was checked with the developed biosensor. In this way, $10 \mu \mathrm{L}$ of a $10.0 \mathrm{mM}$ 
urea solution were added to the electrochemical cell, but no signal was observed due to this compound.

\section{5.- CONCLUSIONS}

AChE based SPC $_{\text {TTF }}$ Es have been developed in order to determine codeine. Taking advantage of the screen-printing technology, $\mathrm{SPC}_{\mathrm{TTF}}$ Es have been fabricated. The use of TTF as a mediator, in this case, allows the application of a low potential and, consequently, the avoidance of possible influences from different substances and the direct electrochemical oxidation of codeine in the carbon electrode.

The interaction between codeine and $\mathrm{AChE}$ allows the determination of this drug through the monitoring of the chronoamperometric signal of the dimer formed from the thiocoline, the metabolite obtained from the reaction between AChE and ATI. The capability of the enzyme to metabolise the substrate is competitively inhibited by codeine and thus, the chronoamperometric response related to the ATI oxidation signal decreases. Taking this into account, curves of calibration have been carried out to estimate the precision of the method (Reproducibility, $3.3 \%, n=6$ ), as well as its capability of detection $(20.0 \mu \mathrm{M}, \alpha=\beta=0.05)$ under the optimum conditions (supporting electrolyte $\mathrm{pH} 7$ and working potential of $+250 \mathrm{mV}$ vs. $\mathrm{Ag} / \mathrm{AgCl} \mathrm{SPE})$. Moreover, this biosensor has been successfully applied in the quantification of codeine in pharmaceutical tablets and urine samples, which highlights its good performance in relation with the previously reported chronoamperometric based biosensors.

\section{6.- REFERENCES}

1. Velázquez, B.L., et al., Farmacología Básica y Clínica. 18th ed. 2008, Madrid: Médica Panamericana. 
2. López Castellano, A.C., L. Moreno Royo, and V. Villagrasa Sebastián, Manual de Farmacología: Guía para el uso racional del medicamento. 2006, Madrid: Elsevier.

3. Garrido, J.M.P.J., et al., Voltammetric oxidation of drugs of abuse: II. Codeine and metabolites. Electroanalysis 16, 2004, p. 1427-1433.

4. Wasels, R. and F. Belleville, Gas chromatographic-mass spectrometric procedures used for the identification and determination of morphine, codeine and 6- monoacetylmorphine. Journal of Chromatography A 674, 1994, p. 225-234.

5. Bosch, M.E., et al., Morphine and its metabolites: Analytical methodologies for its determination. Journal of Pharmaceutical and Biomedical Analysis 43, 2007, p. 799-815.

6. Cruces-Blanco, C. and A.M. García-Campaña, Capillary electrophoresis for the analysis of drugs of abuse in biological specimens of forensic interest. TrAC - Trends in Analytical Chemistry 31, 2012, p. 85-95.

7. $\quad$ Francis, P.S., et al., Chemiluminescence detection of opium poppy (Papaver somniferum) alkaloids. Journal of Pharmaceutical and Biomedical Analysis 48, 2008, p. 508-518.

8. Campean, A., M. Tertis, and R. Sandulescu, Voltammetric determination of some alkaloids and other compounds in pharmaceuticals and urine using an electrochemically activated glassy carbon electrode. Central European Journal of Chemistry 9, 2011, p. 688-700.

9. Pournaghi-Azar, M.H., S. Kheradmandi, and A. Saadatirad, Simultaneous voltammetry of paracetamol, ascorbic acid, and codeine on a palladiumplated aluminum electrode: Oxidation pathway and kinetics. Journal of Solid State Electrochemistry 14, 2010, p. 1689-1695. 
10. Bishop, E. and W. Hussein, Anodic voltammetry of codeine and dihydrocodeine at rotating disc electrodes of platinum and gold. Analyst 109, 1984, p. 143-145.

11. Garrido, J.M.P.J., et al., Electroanalytical determination of codeine in pharmaceutical preparations. Analytical Letters 35, 2002, p. 2487-2498.

12. Kauffmann, J.M., et al., Voltammetry of pharmaceuticals using different types of modified electrodes. Fresenius Zeitschrift für Analytische Chemie 321, 1985, p. 172-176.

13. Komorsky-Lovric, S., N. Vukasinovic, and R. Penovski, Voltammetric determination of microparticles of some local anesthetics and antithusics immobilized on the graphite electrode. Electroanalysis 15, 2003, p. 544-547.

14. Li, F., et al., Simple and rapid voltammetric determination of morphine at electrochemically pretreated glassy carbon electrodes. Talanta 79, 2009, p. 845-850.

15. Pournaghi-Azar, M.H. and A. Saadatirad, Simultaneous voltammetric and amperometric determination of morphine and codeine using a chemically modified-palladized aluminum electrode. Journal of Electroanalytical Chemistry 624, 2008, p. 293-298.

16. Pournaghi-Azar, M.H. and A. Saadatirad, Simultaneous determination of paracetamol, ascorbic acid and codeine by differential pulse voltammetry on the aluminum electrode modified by thin layer of palladium. Electroanalysis 22, 2010, p. 1592-1598.

17. Shih, Y., J.M. Zen, and H.H. Yang, Determination of codeine in urine and drug formulations using a clay-modified screen-printed carbon electrode. Journal of Pharmaceutical and Biomedical Analysis 29, 2002, p. 827-833.

18. Zen, J.M., et al., Determination of Codeine in Human Plasma and Drug Formulation Using a Chemically Modified Electrode. Electroanalysis 10, 1998, p. 536-540. 
19. Garrido, J.M.P.J., et al., Electrochemical Analysis of Opiates - An Overview. Analytical Letters 37, 2004, p. 831-844.

20. Bauer, C.G., et al., New enzyme sensors for morphine and codeine based on morphine dehydrogenase and laccase. Fresenius' Journal of Analytical Chemistry 364, 1999, p. 179-183.

21. Holt, P.J., et al., An amperometric opiate assay. Biosensors \& Bioelectronics 10, 1995, p. 517-526.

22. Saberian, M., et al., Aptamer-based Nanosensors: Juglone as an AttachedRedox Molecule for Detection of Small Molecules. BioImpacts 1, 2011, p. 3136.

23. Huang, L., et al., A label-free electrochemical biosensor based on a DNA aptamer against codeine. Analytica Chimica Acta 787, 2013, p. 203-210.

24. Repetto, M., Toxicología avanzada. 1995, Madrid: Diaz de Santos.

25. Hassanein, H.M.A., Acetylcholinesterase Inhibition, in Recent Trends in the Acetylcholinesterase System, M. Parveen and S. Kumar, Editors. 2005, IOS Press: Amsterdam, The Netherlands.

26. Pandey, P.C., et al., Acetylthiocholine/acetylcholine and thiocholine/choline electrochemical biosensors/sensors based on an organically modified sol-gel glass enzyme reactor and graphite paste electrode. Sensors and Actuators BChemical 62, 2000, p. 109-116.

27. Domínguez-Renedo, O., et al., Screen-printed acetylcholinesterase-based biosensors for inhibitive determination of permethrin. Science of the Total Environment 426, 2012, p. 346-350.

28. Sanllorente-Méndez, S., O. Domínguez-Renedo, and M.J. Arcos-Martínez, Immobilization of acetylcholinesterase on screen-printed electrodes. Application to the determination of arsenic(III). Sensors 10, 2010, p. 21192128. 
29. Ben Oujji, N., et al., Sol-gel immobilization of acetylcholinesterase for the determination of organophosphate pesticides in olive oil with biosensors. Food Control 30, 2013, p. 657-661.

30. Evtugyn, G.A., et al., Cholinesterase Biosensors Based on Screen-Printed Electrodes Modified with Co-Phtalocyanine and Polycarboxylated Thiacalixarenes. Electroanalysis 24, 2011, p. 554-562.

31. Ivanov, A.N., et al., Acetylcholinesterase biosensor based on single-walled carbon nanotubes - Co phtalocyanine for organophosphorus pesticides detection. Talanta 85, 2011, p. 216-221.

32. Mishra, R.K., et al., A novel automated flow-based biosensor for the determination of organophosphate pesticides in milk. Biosensors and Bioelectronics 32, 2012, p. 56-61.

33. Pchelintsev, N.A. and P.A. Millner, A novel procedure for rapid surface functionalisation and mediator loading of screen-printed carbon electrodes. Analytica Chimica Acta 612, 2008, p. 190-197.

34. Valdés-Ramírez, G., et al., Sensitive amperometric biosensor for dichlorovos quantification: Application to detection of residues on apple skin. Talanta 74, 2008, p. 741-746.

35. Ben Rejeb, I., et al., Development of a bio-electrochemical assay for AFB 1 detection in olive oil. Biosensors and Bioelectronics 24, 2009, p. 1962-1968.

36. Gan, N., et al., A disposable organophosphorus pesticides enzyme biosensor based on magnetic composite nano-particles modified screen printed carbon electrode. Sensors 10, 2010, p. 625-638.

37. Hildebrandt, A., et al., Performance of a portable biosensor for the analysis of organophosphorus and carbamate insecticides in water and food. Sensors and Actuators, B: Chemical 133, 2008, p. 195-201. 
38. Hildebrandt, A., et al., Development of a portable biosensor for screening neurotoxic agents in water samples. Talanta 75, 2008, p. 1208-1213.

39. Rotariu, L., L.G. Zamfir, and C. Bala, A rational design of the multiwalled carbon nanotube-7,7,8,8-tetracyanoquinodimethan sensor for sensitive detection of acetylcholinesterase inhibitors. Analytica Chimica Acta 748, 2012, p. 81-88.

40. Noguer, T., et al., Highly sensitive detection of organophosphate insecticides using biosensors based on genetically engineered acetylcholinesterase and poly(3,4- ethylenedioxythiophene). Journal of Sensors 2011, 2011.

41. Crew, A., et al., A screen-printed, amperometric biosensor array incorporated into a novel automated system for the simultaneous determination of organophosphate pesticides. Biosensors and Bioelectronics 26, 2011, p. 2847-2851.

42. Istamboulie, G., et al., Screen-printed poly(3,4-ethylenedioxythiophene) (PEDOT): A new electrochemical mediator for acetylcholinesterase-based biosensors. Talanta 82, 2010, p. 957-961.

43. Taylor, R.F., Immobilization methods, in Handbook of chemical and biological sensors, R.F. Taylor and J.S. Schultz, Editors. 2003, Ed. IOP: UK.

44. Tükel, S.S., et al., Preparation of crosslinked enzyme aggregates (CLEA) of catalase and its characterization. Journal of Molecular Catalysis B: Enzymatic 97, 2013, p. 252-257.

45. del Torno-de Román, L., et al., Gluconic acid determination in wine by electrochemical biosensing. Sensors and Actuators B-Chemical 176, 2013, p. 858-862.

46. Alonso-Lomillo, M.A., O. Domínguez Renedo, and M.J. Arcos-Martínez, Enzyme modified screen printed electrodes, in Biosensors: Properties, Materials and Applications, R. Comeaux and P. Novotny, Editors. 2009, Nova Publishers: Hauppauge NY. p. 1-52. 
47. Kaminska, I., et al., Preparation of graphene/tetrathiafulvalene nanocomposite switchable surfaces. Chemical Communications 48, 2012, p. 1221-1223.

48. Turdean, G.L., Design and Development of Biosensors for the Detection of Heavy Metal Toxicity. International Journal of Electrochemistry 2011, 2011, p. 1-15.

49. Rousseeuw, P.J. and A.M. Leroy, Robust Regression and Outlier Detection. 1989, New York: Wiley.

50. ISO11843, Capability of Detection, Part I, 1997 and Part II, 2000. Genève, Switzerland.

51. Inczédy, J., et al., Compendium of Analytical Nomenclature. 3rd ed. 2000, Baltimore: Port City Press Inc.

52. Alonso-Lomillo, M.A., et al., Sensitive enzyme-biosensor based on screenprinted electrodes for Ochratoxin A. Biosensors \& Bioelectronics 25, 2010, p. 1333-1337. 
CHAPTER 8:

CYTOCHROME P450 2D6 BASED ELECTROCHEMICAL SENSOR FOR THE DETERMINATION OF CODEINE 

As it has been previously mentioned, biosensors for the detection of codeine are usually based on the incorporation of a mediator or a second enzyme to diminish the working potential (Section 3.1.3.1). This chapter describes the development of a non-redox mediated CYP2D6 based biosensor for the detection of codeine. In this way, the electrochemical biotransformation takes place by direct electron transference between the enzyme and the electrode at low potential.

Home-made SPCEs have been used as electrochemical transducers of the biosensor, in which the enzyme has been covalently attached to the carbon surface of the working electrode, being this type of modification the most suitable for the immobilisation of the biological element.

Chronoamperometric measurements have been carried out under optimum conditions of $\mathrm{pH}$ and working potential, $\mathrm{pH} 7$ and $+200 \mathrm{mV}$ vs. $\mathrm{Ag} / \mathrm{AgCl} \mathrm{SPE}$, giving a reduction signal related to the concentration of codeine in solution.

Consecutive additions of a solution of codeine have been performed to obtain calibration curves in order to validate the electrochemical method, in terms of precision, and calculate its capability of detection.

These biosensors have been used for the determination of codeine in urine and commercial pharmaceutical samples.

Part of this work has been submitted for publication and is going to be presented at XXXV Reunión del Grupo de Electroquímica de la RSEQ \& $1^{\text {er }}$ simposio E3 del Mediterráneo: Electroquímica para la Energía y el Medioambiente, Burgos, Spain (July 2014). 



\section{1.- INTRODUCTION}

Codeine is widely used in medical treatment of light to moderate pain, cough, constipation, etc. Although it belongs to the same opioid family as morphine, codeine produces less analgesia, sedation and respiratory depression than the latter.

Codeine is primarily metabolised in the liver. Opioid metabolism involves demethylation and glucuronidation stages, with the latter being the main route of metabolism [1]. The demethylation pathway is performed by two CYP450 isoforms, which are part of a wide group of heme-enzymes characterised by their Soret band at $450 \mathrm{~nm}$ when interacting with carbon monoxide [2]. On one hand, CYP450 3A4 isoform is responsible for the transformation of codeine into norcodeine through the $\mathrm{N}$-demethylation of the tertiary amine group. On the other hand, the isoform CYP2D6 carries out the $O$-demethylation of the methoxy group in the third position, giving morphine as a product of the biotransformation (Figure 3.4) [3]. Unfortunately, not all the population has functional CYP2D6 enzymes, due to a genetic polymorphism, that is, not everybody is capable of transforming codeine to morphine for pain relief [4].

Although codeine is commonly used as a pharmaceutical drug, it is sometimes improperly consumed due to the subsequent euphoric effects. As drug abuse is a world-wide problem, the development of methods for determining and quantifying these substances is essential.

Different analytical techniques have been reported for its determination such as chromatographic [5, 6], chemiluminescent [7], electrophoretic [8] and electrochemical methods [9-23]. Good results in the determination of codeine have been obtained by electrochemical methods, but chronoamperometric analyses require the application of high potentials that can provoke the simultaneous oxidation of codeine and other interferences $[10,14]$. Nevertheless, this inconvenience has been solved by the incorporation of different enzymes to the electrochemical system, using mediators such as phenazine methosulphate and TTF [24, 25]. 
In this work, the selective determination of codeine has been attempted using a non-mediated electrochemical biosensor based on the enzyme CYP2D6 [26]. The well-known mechanism of CYP450 involves the combination of oxygen with codeine to produce morphine and formaldehyde (Figure 3.18), being the electron delivery provided by the SPCE in this case (Figure 8.1) [27-32]. Consequently, the recorded reduction current can be related to the concentration of codeine in the electrochemical cell.

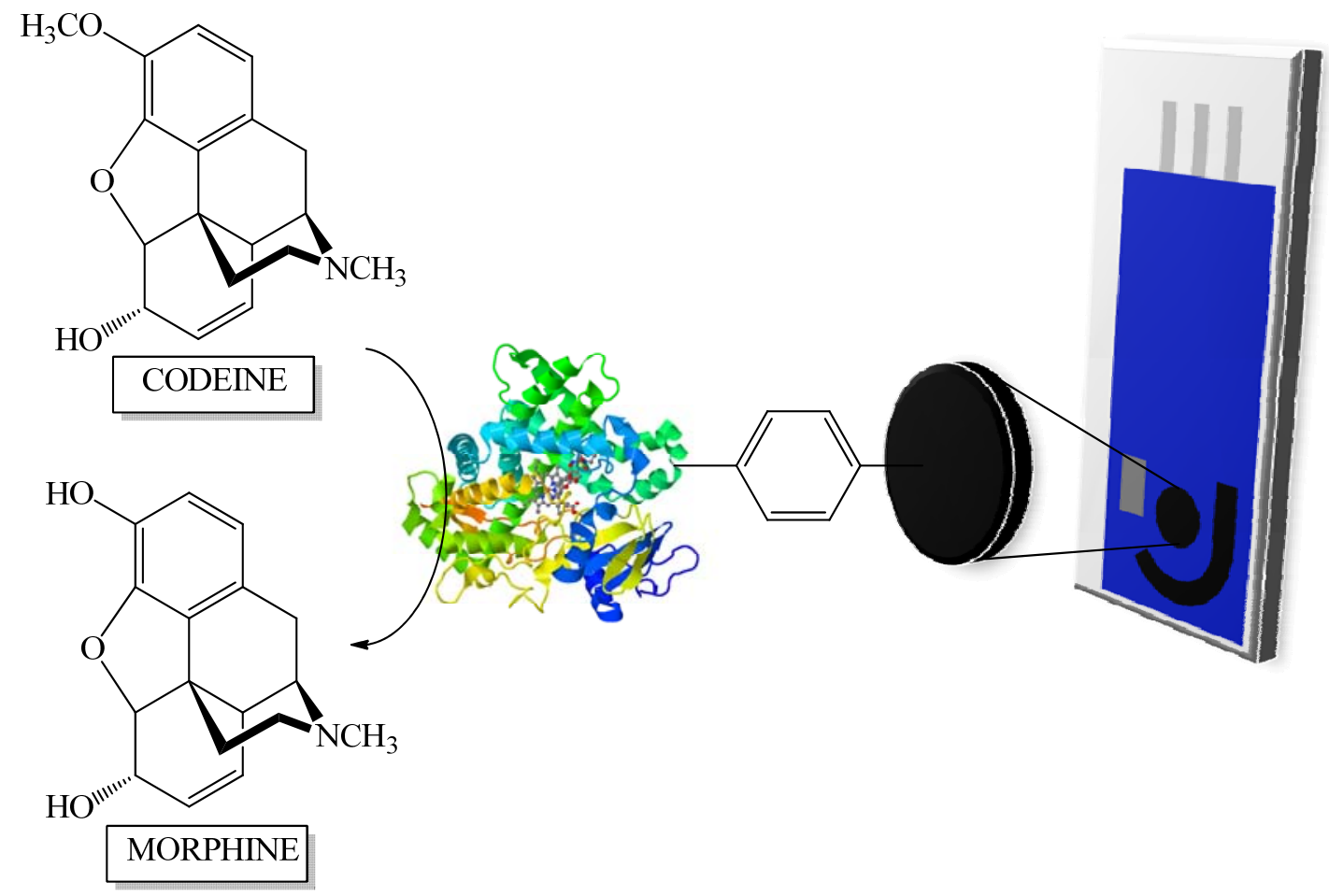

Figure 8.1.- Biotransformation of codeine into morphine catalysed by the enzyme CYP2D6.

Home-made SPCEs have been modified with this enzyme through three different types of immobilisation, namely covalent attachment, cross-linking immobilisation and simple adsorption on the working electrode surface. The best conditions of $\mathrm{pH}$ and working potential to carry out chronoamperometric measurements have been optimised using an experimental design methodology. Furthermore, the developed method has been characterised in terms of precision and 
capability of detection and applied to the determination of codeine in pharmaceutical drugs and urine.

\section{2.- EXPERIMENTAL}

\subsection{1.- REAGENTS}

Home-made screen-printed devices were fabricated using the following commercial inks: carbon ink C10903P14 (Gwent Group, Torfaen, UK), silver ink Electrodag 418 and $\mathrm{Ag} / \mathrm{AgCl}$ ink Electrodag $6037 \mathrm{SS}$ (Acheson Colloiden, Scheemda, The Netherlands), and dielectric ink 242-SB (ESL Europe, Agmet Ltd, Reading, UK).

Analytical grade reagents including CYP2D6 (C9095-15K2, US Biological, Swampscott, MA, USA, $1.0 \mathrm{mg} \mathrm{mL}^{-1}$ ), GA and BSA (Sigma-Aldrich, Steinheim, Germany) were used as received. All solutions were prepared with Milli-Q water.

A solution of $3.0 \mathrm{mM}$ of 4-nitrobenzenediazonium tetrafluoroborate $\left(\mathrm{N}_{2} \mathrm{C}_{6} \mathrm{H}_{4} \mathrm{NO}_{2} \mathrm{BF}_{4}\right.$, Sigma-Aldrich, Steinheim, Germany) was prepared in acetonitrile, containing $100.0 \mathrm{mM}$ of tetrabutylammonium tetrafluoroborate $\left(\mathrm{NBu}_{4} \mathrm{BF}_{4}\right.$, SigmaAldrich, Steinheim, Germany). Additionally, a solution of water:ethanol (9:1 v/v) (VWR Prolabo, Fontenay-sous-Bois, France) containing $100.0 \mathrm{mM}$ of $\mathrm{KCl}$ (Merck, Darmstadt, Germany) was prepared for the reduction of the diazonium salt.

Solutions of $40.0 \mathrm{mM}$ of NHS (Sigma-Aldrich, Steinheim, Germany) and $80.0 \mathrm{mM}$ of EDC (Fluka, Steinheim, Germany) were prepared in $10.0 \mathrm{mM}$ phosphate buffer $\mathrm{pH} 4$.

Stock standard solutions of codeine were daily prepared by dissolving the adequate amount of codeine hydrochloride (Alcaliber S.A., Madrid, Spain) in 100.0 $\mathrm{mM}$ phosphate buffer $\mathrm{pH}$ 7. In this work, a $100.0 \mathrm{mM}$ phosphate buffer 
$\left(\mathrm{NaH}_{2} \mathrm{PO}_{4} \cdot 2 \mathrm{H}_{2} \mathrm{O}\right.$, Merck, Darmstadt, Germany) solution was used as supporting electrolyte and adjusted to the desired $\mathrm{pH}$ value with a $1.0 \mathrm{M} \mathrm{NaOH}$ (J.T. Baker, Deventer, The Netherlands) solution.

\subsection{2.- APPARATUS}

A DEK 248 printing device (DEK, Weymouth, UK) was used for the fabrication of the screen-printed transducers.

Electrochemical measurements were made with a PalmSens Sensor Interface (PalmSens BV, Utrecht, The Netherlands) with PalmSens PC software.

The $\mathrm{pH}$ of the solutions was measured with a $\mathrm{pH}$ meter HANNA instruments Model HI221 (USA).

\section{3.- METHODS}

\subsection{1.- HOME-MADE SPCES FABRICATION}

SPCEs were manufactured by sequential deposition of different commercial inks, followed by their curing process. Four polyester meshes with different patterns were used to print each of the parts of the electrochemical setup on the surface of a polyester substrate (Section 3.2.1).

The electrochemical system consisted of three silver conductive tracks, a carbon counter electrode, a carbon working electrode (Area, $12.6 \mathrm{~mm}^{2}$ ), a $\mathrm{Ag} / \mathrm{AgCl}$ reference electrode and an insulating film utilised to cover the silver tracks and to define the final geometry of the three electrodes. 


\subsection{2.- FUNCTIONALISATION OF SPCES}

Three different types of enzymatic immobilisation were attempted to obtain the best CYP2D6 based biosensor to determine codeine.

\subsubsection{1.- Covalent immobilisation}

CYP2D6 was covalently attached to functionalised carbon working electrode surfaces (Section 5.3.2.2). This procedure implies the electrografting of a diazonium salt, which provides the $-\mathrm{NH}_{2}$ groups necessary to link the enzyme on a second step.

The modification of the working surface was carried out placing a drop of 50 $\mu \mathrm{L}$ of a $3.0 \mathrm{mM}$ solution of $\mathrm{N}_{2} \mathrm{C}_{6} \mathrm{H}_{4} \mathrm{NO}_{2} \mathrm{BF}_{4}$ on the electrochemical system. and sweeping the potential between +800 and $-400 \mathrm{mV}$ vs. $\mathrm{Ag} / \mathrm{AgCl} \mathrm{SPE}$ at a scan rate of $200 \mathrm{mV} \mathrm{s}^{-1}$ [31]. Two consecutive scans were performed (Figure 5.6).

Then, a drop of $100 \mu \mathrm{L}$ of a solution of water:ethanol $(9: 1 \mathrm{v} / \mathrm{v})$, containing $100.0 \mathrm{mM}$ of $\mathrm{KCl}$, was placed on top of the aryl diazonium salt-modified SPCE. Two scans were recorded between $0.0 \mathrm{~V}$ and $-1.7 \mathrm{~V}$ vs. $\mathrm{Ag} / \mathrm{AgCl} \mathrm{SPE}$ at a scan rate of $200 \mathrm{mV} \mathrm{s}^{-1}$ (Figure 5.7) [31]. CYP2D6 was covalently attached to the working electrode using the procedure described in section 5.3.2.2 [30]. Briefly, once the working electrode was washed using $10.0 \mathrm{mM}$ phosphate buffer $\mathrm{pH} 4,0.5 \mu \mathrm{L}$ of a CYP2D6 solution was applied, followed by $2 \mu \mathrm{L}$ of a $40.0 \mathrm{mM}$ NHS solution and 2 $\mu \mathrm{L}$ of an $80.0 \mathrm{mM}$ EDC solution. After $90 \mathrm{~min}$ at $4{ }^{\circ} \mathrm{C}$, the biosensor was washed to eliminate the non-covalently attached enzyme and stored at $4{ }^{\circ} \mathrm{C}$ until its use.

\subsubsection{2.- Cross-linking immobilisation}

Cross-linking immobilisation involves the formation of chemical links between the enzyme and a bifunctional linker, such as GA (Section 3.2.3.2). 
This immobilisation was accomplished by the sequential deposition onto the carbon working electrode of $0.5 \mu \mathrm{L}$ of CYP2D6, followed by $2 \mu \mathrm{L}$ of a $6 \% \mathrm{w} / \mathrm{v}$ BSA solution in $10.0 \mathrm{mM}$ phosphate $\mathrm{pH} 6$ and $1 \mu \mathrm{L}$ of a $2.5 \% \mathrm{v} / \mathrm{v}$ GA solution in water. This mixture was left to dry at $4{ }^{\circ} \mathrm{C}$.

\subsubsection{3.- Adsorption immobilisation}

As it has been previously mentioned, adsorption immobilisation is one of the simplest procedures to biologically modify the surface of the working electrode, providing a high retention of activity because there is no chemical modifications (Section 3.2.3.2) [33]. This type of immobilisation was carried out by casting $0.5 \mu \mathrm{L}$ of the enzyme on the surface of the working electrode and letting it dry at $4{ }^{\circ} \mathrm{C}$.

\subsection{3.- ELECTROCHEMICAL MEASUREMENTS}

Chronoamperometric measurements were carried out at room temperature under constant magnetic stirring in a cell containing $5 \mathrm{~mL}$ of a $100.0 \mathrm{mM}$ phosphate buffer solution of the selected $\mathrm{pH}$. A potential of $+200 \mathrm{mV}$ vs. $\mathrm{Ag} / \mathrm{AgCl} \mathrm{SPE}$ was applied, except for the experimental variables optimisation process.

\subsection{4.- REAL SAMPLE PREPARATION}

A commercial pharmaceutical drug, named Codeisan, was used to test the viability of the developed biosensor in complex matrixes. Different pills were homogenously crushed and an aliquot from each of them was dissolved in the supporting electrolyte solution. Then, the suspension was centrifuged at $10{ }^{\circ} \mathrm{C}$ for 1 min. at $13000 \mathrm{rpm}$ and the supernatant was transferred to a vial, where it was kept until its use. 
Additionally, codeine was determined in spiked diluted urine samples. The urine sample was centrifuged to eliminate solids in suspension and spiked with codeine to a final concentration of $10.0 \mathrm{mM}$.

\section{4.- RESULTS AND DISCUSSION}

\subsection{1.- OPTIMISATION OF THE IMMOBILISATION STAGE}

EDC is the most popular carbodiimide used for conjugating biological substances containing carboxylates and amines. Its application along with NHS makes it the most common bioconjugation reagent in use today (Figure 5.11). Carboxylate activation occurs most effectively with EDC at $\mathrm{pH} 3.5$ to 4.5, while amide bond formation occurs with highest yield in the range of $\mathrm{pH} 4$ to 6 [34]. Thus, $\mathrm{pH}$ was firstly studied in order to choose the best conditions to carry out the covalent enzymatic immobilisation stage. $10 \mathrm{mM}$ phosphate solutions with different $\mathrm{pH}$ values were used to immobilise CYP2D6 on diazonium salt-modified SPCEs. The performance of the three devices was checked recording chronoamperograms at $\mathrm{pH} 7$ and $+200 \mathrm{mV}$ vs. $\mathrm{Ag} / \mathrm{AgCl}$ (Figure 8.2). The reduction current recorded due to the addition of a codeine solution was taken as analytical response. There were no huge differences between $\mathrm{pH} 4$ and 6 . However, $\mathrm{pH} 4$ was the chosen buffer to carry out the enzymatic immobilisation since the response of the biosensor is less noisy.

\subsection{2.- OPTIMISATION OF THE CHRONOAMPEROMETRIC EXPERIMENTAL VARIABLES}

Chronoamperometric measurements are influenced by different factors that mainly depend on the enzyme used as biorecognition element of the biosensor. Two main variables are known to influence the electrochemical response, $\mathrm{pH}$ of the buffer solution and working potential. 


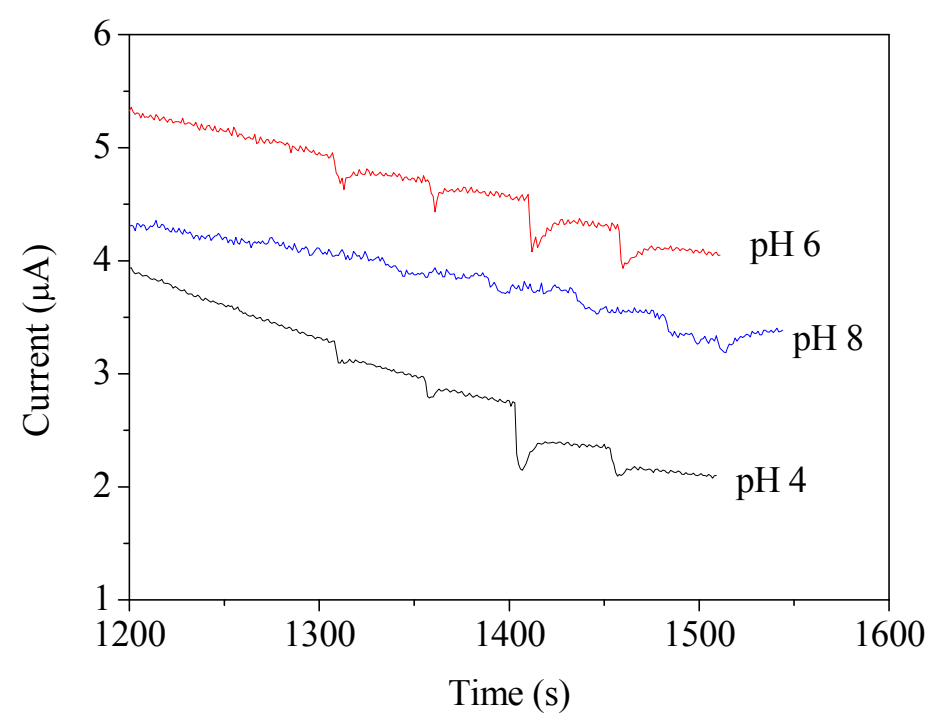

Figure 8.2.- Chronoamperometric signals of CYP2D6 based biosensors manufactured using different $p H$ values in the immobilisation step. Experimental conditions: $p H 7$ and $+200 \mathrm{mV}$ vs. $\mathrm{Ag} / \mathrm{AgCl} \mathrm{SPE}$.

These two variables were studied through a $2^{2}$ central composite design, taking as response variable the chronoamperometric reduction current of a $0.2 \mathrm{mM}$ solution of codeine $[35,36]$. According to the experimental design, a total of 11 experiences were performed with the covalently-immobilised CYP2D6 biosensor and then, the results were evaluated using the STATGRAPHICS PLUS software package [37]. The values of $\mathrm{pH} 7$ and $+200 \mathrm{mV}$ vs. $\mathrm{Ag} / \mathrm{AgCl} \mathrm{SPE}$ were obtained as the best conditions to achieve the maximum response (Figure 8.3).

In order to ascertain that the recorded chronoamperometric current was due to the interaction codeine-CYP2D6, control experiments were performed under the optimum conditions using bare and aryl diazonium salt-functionalised electrodes without the enzyme. No electrochemical signal was obtained with these control electrodes (Figure 8.4). 


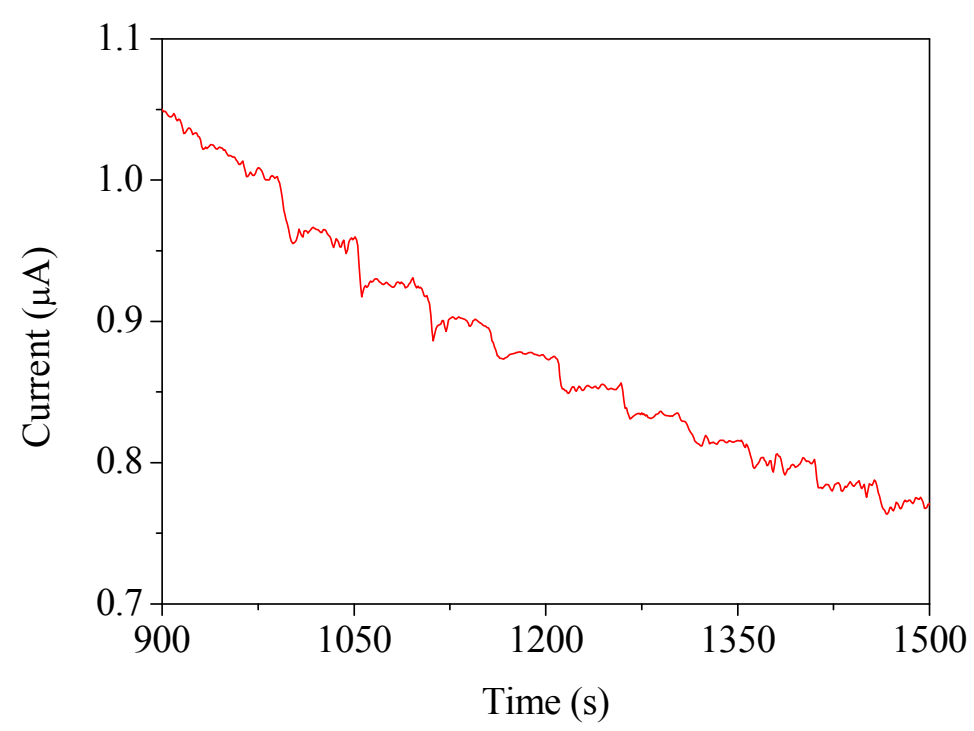

Figure 8.3.- Chronoamperometric signal of successive additions of $50 \mu \mathrm{L}$ of a $0.5 \mathrm{mM}$ codeine solution in $5 \mathrm{~mL}$ of supporting electrolyte $\mathrm{pH} 7$, under a working potential of +200 $m V$ vs. Ag/AgCl SPE.

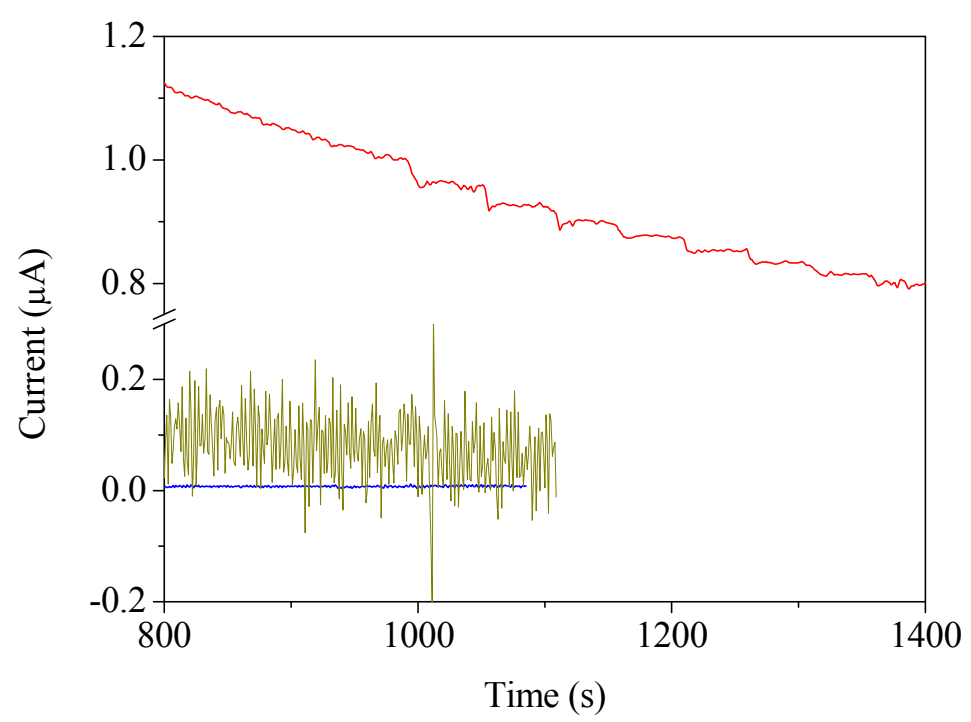

Figure 8.4.- Chronoamperometric measurements with SPCE (blue line), SPCE/diazonium salt (green line), and CYP2D6 based SPCE (red line). Experimental conditions: supporting electrolyte $\mathrm{pH} 7$; working potential, $+200 \mathrm{mV} v \mathrm{~s} . \mathrm{Ag} / \mathrm{AgCl}$ SPE. 
Additionally, different kinds of immobilisation were tested to evaluate the quality of the chronoamperometric reduction signal under these optimum conditions. Figure 8.5 shows the comparison of the chronoamperometric signal of the three biosensors under the optimum $\mathrm{pH}$ and working potential conditions. The extraordinary simplicity of the adsorption method makes its application very attractive; however, random orientation and possible desorption led to poor signal and reproducibility $[33,38]$. The additional enzyme stabilisation achieved by its entrapment with GA did not lead to satisfactory results either. However, the quality of the chronoamperometric signals improved by using the covalently-modified biosensor: a better definition of the registered current for each concentration of codeine was observed, since a lower background current was recorded. This fact can be attributed to the strong link of the enzyme onto the electrode, which prevents its leakage in the stirred solution, leading to more reproducible devices.

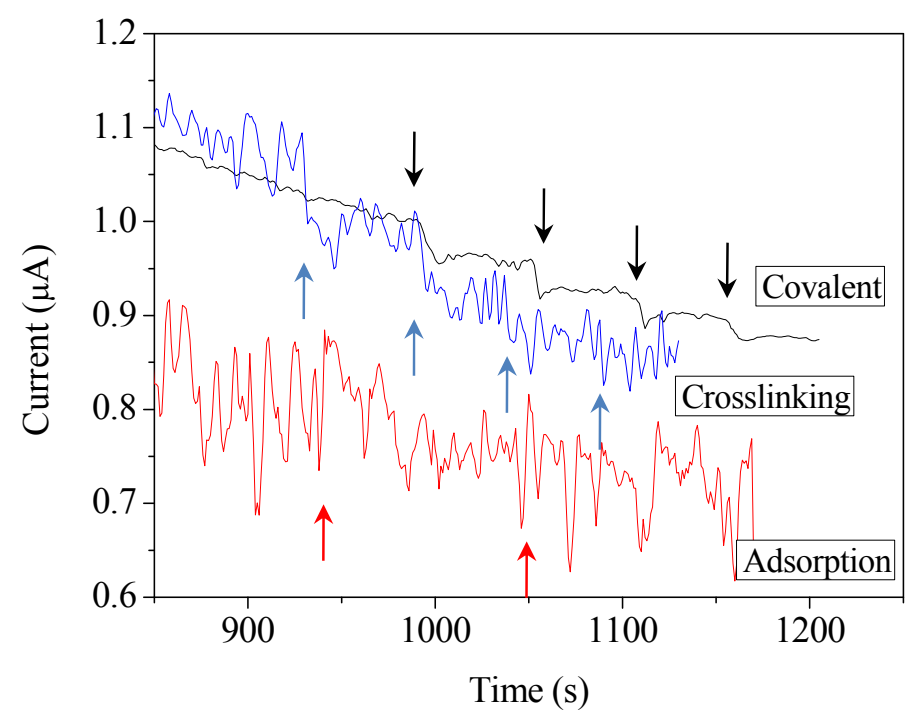

Figure 8.5.- Chronoamperograms recorded by successive additions of $50 \mu \mathrm{L}$ of a $0.5 \mathrm{mM}$ solution of codeine, pointed by arrows, in $5 \mathrm{~mL}$ of supporting electrolyte under the optimum conditions using CYP2D6 based biosensors built by covalent, adsorption and cross-linking procedures. 


\subsection{3.- METHOD VALIDATION}

The developed analytical procedure was characterised by establishing its precision in terms of reproducibility and repeatability. Additionally, the capability of detection was calculated to get information about the sensitivity of the method, as well as its accuracy.

\subsubsection{1.- Precision}

In order to estimate the reproducibility of the biosensor built through the covalent immobilisation procedure, calibration curves with different CYP2D6 based SPCEs were performed under the optimum conditions in the calibration range from 4.9 to $45.4 \mu \mathrm{M}$.

Furthermore, several calibration curves were recorded using a single CYP2D6 based SPCE, under the same conditions as for the reproducibility, to obtain the repeatability of the electrochemical system.

The calibration parameters and the standard deviation of all calibration curves were properly evaluated using the PROGRESS program (Section 4.4.5.1) [39]. Both reproducibility and repeatability were calculated in terms of RSD associated with the slopes of the different calibration curves.

The reproducibility of the developed covalently modified CYP2D6 SPCE was estimated to be $8.9 \%(n=6)$ (Table 8.1 and Figure 8.6). It was also observed that the biosensor kept around the $31 \%$ of sensitivity after the third calibration curve using the same CYP2D6 based SPCE (Table 8.2 and Figure 8.7). 
Table 8.1.- Calibration parameters obtained through OLS regressions without outliers to estimate the reproducibility of the method in the determination of codeine using different CYP2D6 based SPCE under the optimum conditions.

\begin{tabular}{ccccc}
\hline Calibration & Slope $\left(\mathbf{n} \mathbf{A} \mathbf{~ M}^{-\mathbf{1}}\right)$ & Intercept (nA) & $\mathbf{S}_{\mathbf{y x}}$ & $\begin{array}{c}\text { Coefficient of } \\
\left.\text { determination } \mathbf{( R}^{\mathbf{2}}\right)\end{array}$ \\
\hline I & 3.5 & 30.2 & 2.876 & 0.996 \\
II & 3.8 & -0.7 & 2.447 & 0.998 \\
III & 3.2 & 9.7 & 2.801 & 0.995 \\
IV & 3.8 & 10.9 & 3.891 & 0.995 \\
V & 3.3 & 11.2 & 0.814 & 0.999 \\
VI & 4.0 & 2.0 & 0.837 & 0.999 \\
\hline
\end{tabular}

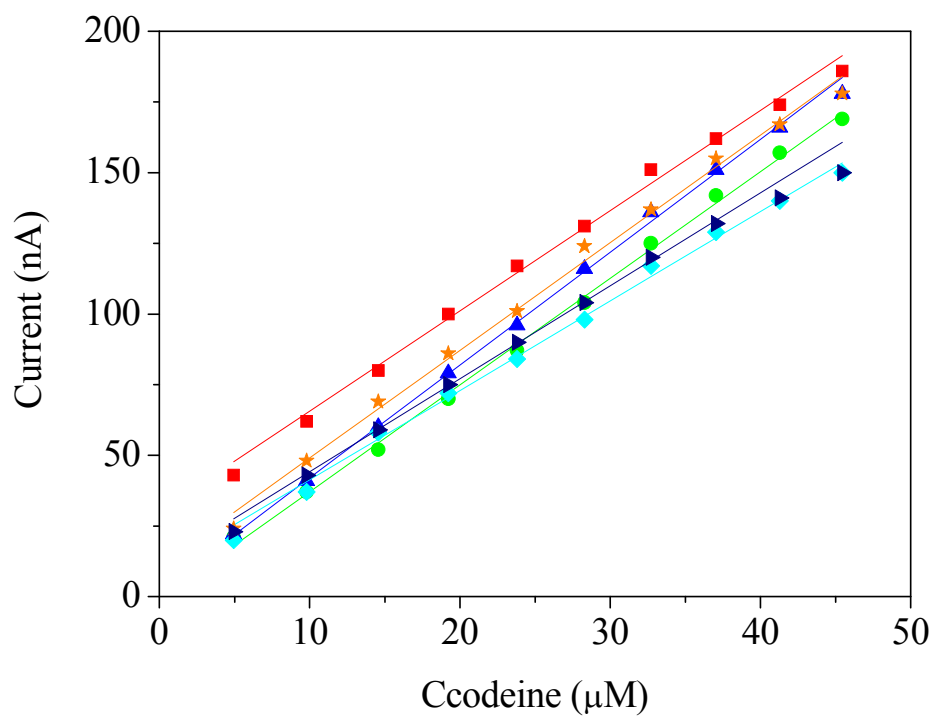

Figure 8.6.- Experimental points and OLS regressions for the different calibration curves carried out to evaluate the reproducibility of CYP2D6 based SPCEs in the determination of codeine. 
Table 8.2.- Calibration parameters obtained through OLS regressions without outliers to evaluate the repeatability of the developed CYP2D6 based SPCE under the optimum conditions.

\begin{tabular}{ccccc}
\hline Calibration & Slope $\left(\mathbf{n} \mathbf{A} \mathbf{\mu M}^{-\mathbf{1}}\right)$ & Intercept (nA) & $\mathbf{S}_{\mathbf{y x}}$ & $\begin{array}{c}\text { Coefficient of } \\
\left.\text { determination } \mathbf{( R}^{2}\right)\end{array}$ \\
\hline I & 3.5 & 30.2 & 2.876 & 0.996 \\
II & 1.5 & 22.2 & 1.370 & 0.995 \\
III & 1.1 & 9.6 & 0.537 & 0.997 \\
\hline
\end{tabular}
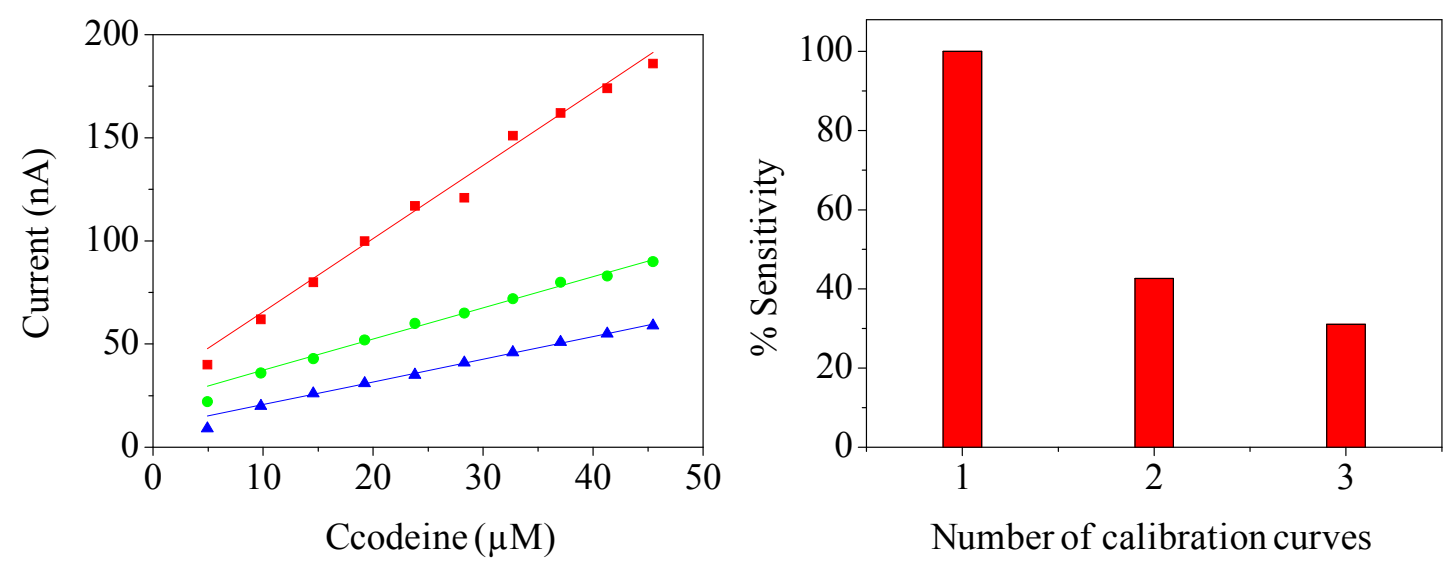

Figure 8.7.- Consecutive calibration curves performed with the same electrode.

Furthermore, storage conditions of the developed CYP2D6 based SPCEs were evaluated. Four CYP2D6 based SPCEs were built at the same time and kept at $4{ }^{\circ} \mathrm{C}$ prior to use. Calibration curves were then recorded, under the optimum conditions, during 3 consecutive weeks (Figure 8.8). The activity of the biosensor did not change in the first week, but a decrease is observed after the second one, keeping the $50 \%$ of its initial sensitivity after the third week. 


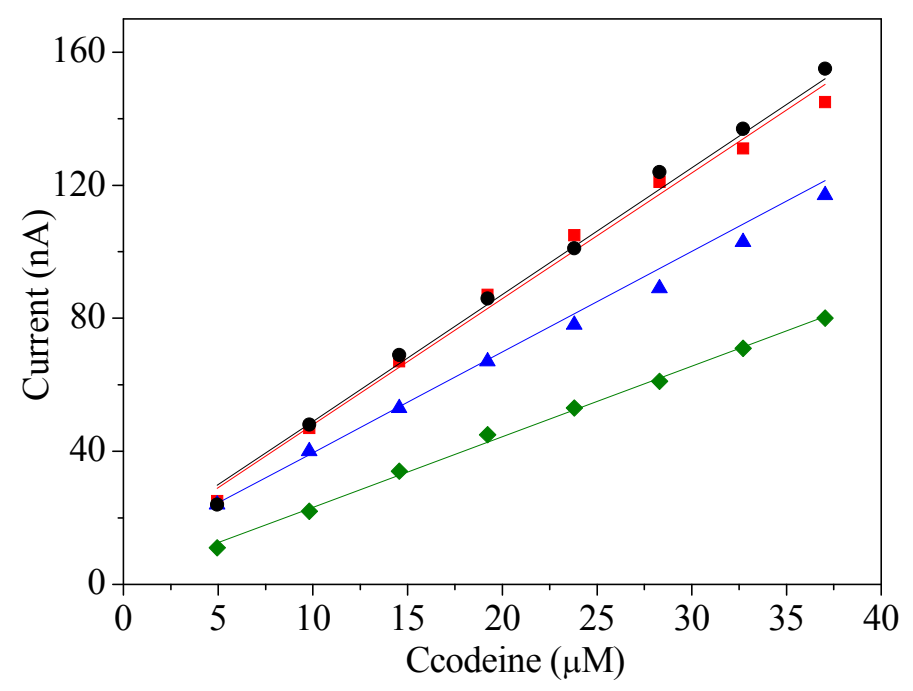

Figure 8.8.- Evaluation of the effect of the storage time on the sensitivity of covalently modified CYP2D6 SPCEs. Calibration curves recorded in the codeine concentration range from 5.0 to $37.0 \mu M$, under the optimum conditions, using four different CYP2D6 based SPCEs. Calibration curves recorded one week (-), two weeks ( $\mathbf{\Delta}$ ) and three weeks after the day that the biosensor was built $(\bullet)$.

\subsubsection{2.- Capability of detection}

The capability of detection of the biosensor was calculated for a given probability of false positive $(\alpha)$ and negative $(\beta)$ (Section 5.4.3.2) [40,41], using the validated parameters of calibration curves recorded under the optimum experimental conditions. The minimum detectable concentration was lower than the concentration of the first standard used to build the calibration curves, $4.9 \mu \mathrm{M}$. Consequently, from an analytical point of view, the latter has been taken as the capability of detection of this method [42].

This value highlights the great affinity of CYP2D6 based SPCEs to codeine, working under the optimum conditions, compared to the previously reported amperometric procedures (Table 8.3). 


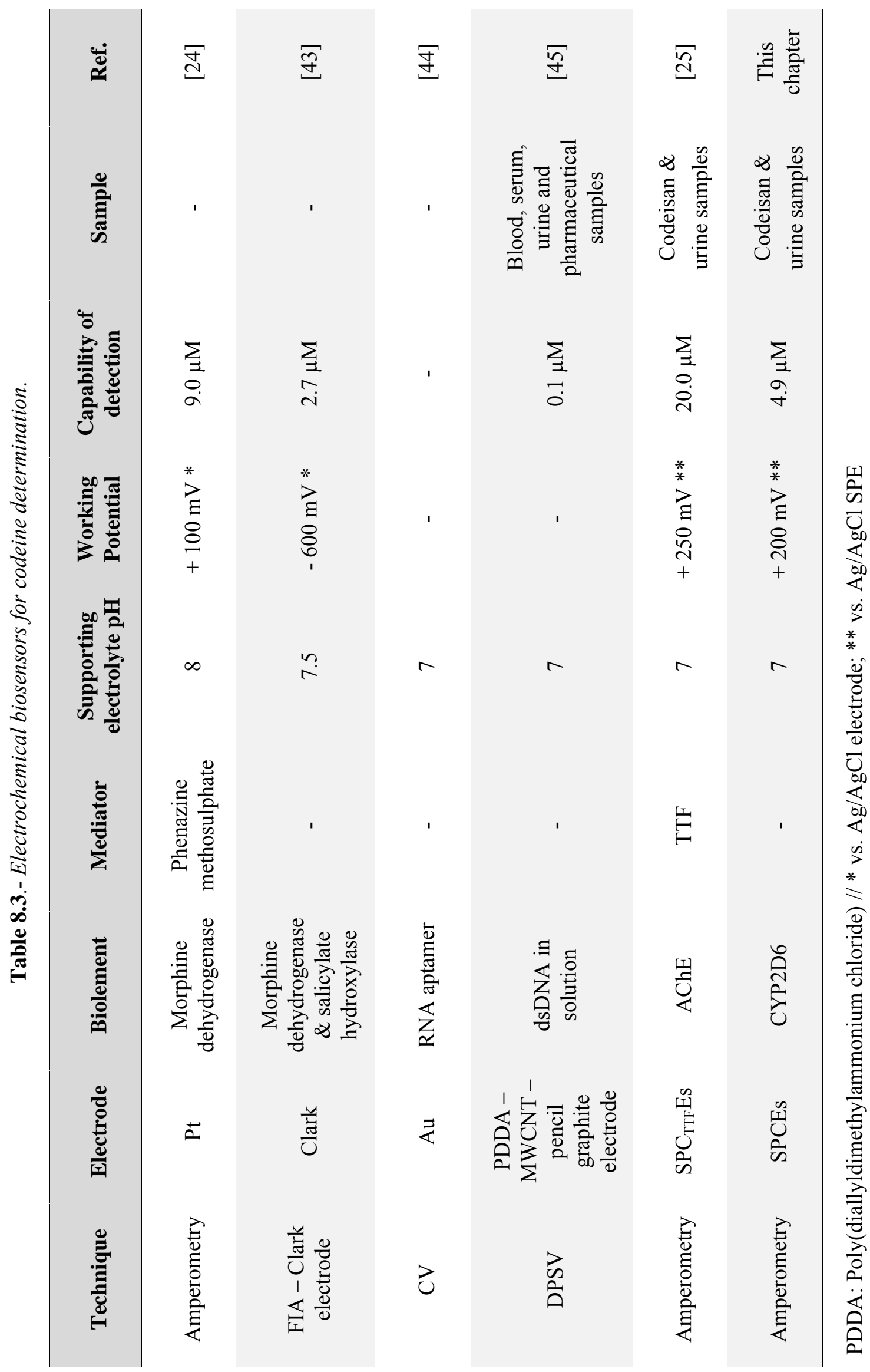




\subsubsection{3.- Accuracy}

Once the performance of the developed biosensor was evaluated, the CYP2D6 based SPCE was used for the determination of codeine in complex matrixes. Codeisan, a commercial pharmaceutical drug whose active ingredient is codeine phosphate $1 / 2 \mathrm{H}_{2} \mathrm{O}$, and urine samples were chosen for this study, using the standard addition methodology to minimise possible matrix effects.

Different calibration curves were performed under the optimum chronoamperometric conditions. After obtaining a stable baseline, a volume of $50 \mu \mathrm{L}$ of the studied solution was added into the electrochemical cell and then, successive additions of $50 \mu \mathrm{L}$ of a $0.5 \mathrm{mM}$ codeine solution were made.

The average concentration of codeine found in the pharmaceutical pill was $[29.9 \pm 2.0] \mathrm{mg} /$ tablet $(n=5, \alpha=0.05)$. According to the patient leaflet, each of the pills contains $28.7 \mathrm{mg}$ of the active ingredient, value that is included in the experimental interval (Table 8.4).

The same methodology was successfully carried out to quantify codeine in spiked urine samples to a final concentration of $10.0 \mathrm{mM}$. After the addition of the studied urine solution, consecutive additions of $50 \mu \mathrm{L}$ of a $10.0 \mathrm{mM}$ codeine solution were performed. The average codeine concentration found in the spiked urine sample was $[10.8 \pm 1.3] \mathrm{mM}(n=5, \alpha=0.05)$ (Table 8.4).

Urea is found in urine and has been checked as interference [26]. In this way, $50 \mu \mathrm{L}$ of a $300.0 \mathrm{mM}$ urea solution was added to the electrochemical cell, obtaining no signal due to this compound with the developed biosensor.

The analysis of these complex matrixes showed the great selectivity of the developed biosensor towards codeine. 
Table 8.4.- Analytical characteristics in the detection of codeine in pharmaceutical and spiked urine samples using covalently modified CYP2D6 SPCE.

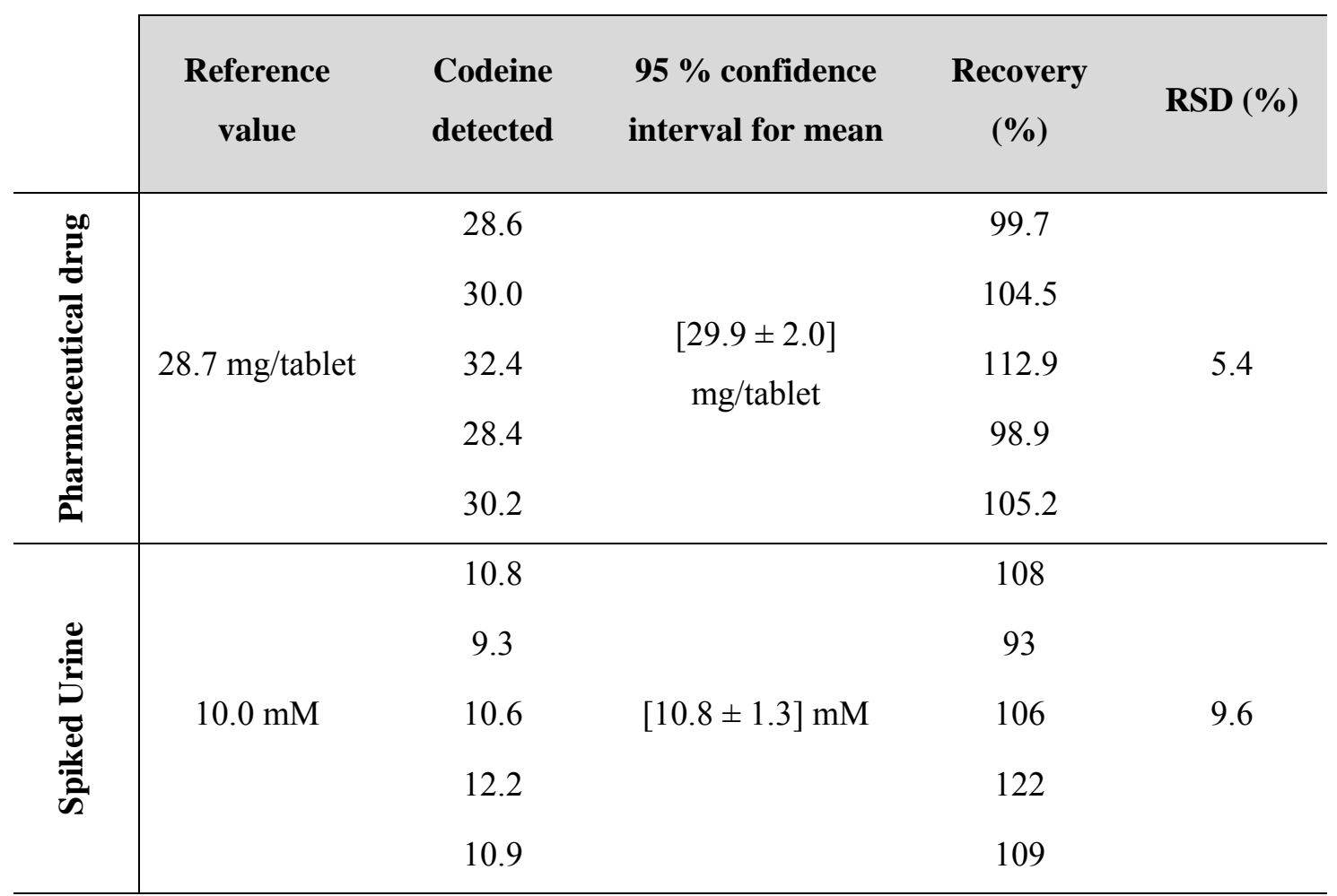

\section{5.- CONCLUSIONS}

The development of a biosensor based on the covalent immobilisation of the enzyme CYP2D6 on the surface of a carbon working electrode of a three SPE system allows the chronoamperometric determination of codeine. Although this enzyme has been also immobilised by cross-linking and adsorption onto the electrode, covalent binding has led to the best chronoamperometric signals. The chronoamperometric reduction current obtained under the optimum conditions, supporting electrolyte $\mathrm{pH}$ 7 and working potential of $+200 \mathrm{mV}$ vs. $\mathrm{Ag} / \mathrm{AgCl} \mathrm{SPE}$, can be related to the concentration of codeine in solution. In this way, reproducible CYP2D6 based SPCEs ( $\mathrm{RSD}=8.9 \%, n=6)$ have been obtained in a codeine concentration range from 4.9 to $45.4 \mu \mathrm{M}$, with a capability of detection of $4.9 \mu \mathrm{M}$ for a probability of false positive and negative of 0.05 . The biosensor has been successfully applied to the determination of codeine in pharmaceutical drugs and urine samples. 


\section{6.- REFERENCES}

1. Goldfrank, L.R. and N. Flomenbaum, Goldfrank's Toxicologic Emergencies. 8th ed. 2006, USA: McGraw-Hill.

2. Holmquist, G.L., Opioid metabolism and effects of cytochrome P450. Pain Medicine 10, 2009, p. S20-S29.

3. Testa, B. and J. Caldwell, The Metabolism of Drugs and other Xenobiotics. Biochemistry of Redox Reactions. 2004, London: Academic Press.

4. $\quad$ Frost, J., et al., Investigation of morphine and morphine glucuronide levels and cytochrome P450 isoenzyme 2D6 genotype in codeine-related deaths. Forensic Science International 220, 2012, p. 6-11.

5. Wasels, R. and F. Belleville, Gas chromatographic-mass spectrometric procedures used for the identification and determination of morphine, codeine and 6- monoacetylmorphine. Journal of Chromatography A 674, 1994, p. 225-234.

6. Bosch, M.E., et al., Morphine and its metabolites: Analytical methodologies for its determination. Journal of Pharmaceutical and Biomedical Analysis 43, 2007, p. 799-815.

7. Francis, P.S., et al., Chemiluminescence detection of opium poppy (Papaver somniferum) alkaloids. Journal of Pharmaceutical and Biomedical Analysis 48, 2008, p. 508-518.

8. Cruces-Blanco, C. and A.M. García-Campaña, Capillary electrophoresis for the analysis of drugs of abuse in biological specimens of forensic interest. TrAC - Trends in Analytical Chemistry 31, 2012, p. 85-95.

9. Garrido, J.M.P.J., et al., Electrochemical Analysis of Opiates - An Overview. Analytical Letters 37, 2004, p. 831-844. 
10. Campean, A., M. Tertis, and R. Sandulescu, Voltammetric determination of some alkaloids and other compounds in pharmaceuticals and urine using an electrochemically activated glassy carbon electrode. Central European Journal of Chemistry 9, 2011, p. 688-700.

11. Pournaghi-Azar, M.H., S. Kheradmandi, and A. Saadatirad, Simultaneous voltammetry of paracetamol, ascorbic acid, and codeine on a palladiumplated aluminum electrode: Oxidation pathway and kinetics. Journal of Solid State Electrochemistry 14, 2010, p. 1689-1695.

12. Bishop, E. and W. Hussein, Anodic voltammetry of codeine and dihydrocodeine at rotating disc electrodes of platinum and gold. Analyst 109, 1984, p. 143-145.

13. Garrido, J.M.P.J., et al., Electroanalytical determination of codeine in pharmaceutical preparations. Analytical Letters 35, 2002, p. 2487-2498.

14. Garrido, J.M.P.J., et al., Voltammetric oxidation of drugs of abuse: II. Codeine and metabolites. Electroanalysis 16, 2004, p. 1427-1433.

15. Kauffmann, J.M., et al., Voltammetry of pharmaceuticals using different types of modified electrodes. Fresenius Zeitschrift für Analytische Chemie 321, 1985, p. 172-176.

16. Komorsky-Lovric, S., N. Vukasinovic, and R. Penovski, Voltammetric determination of microparticles of some local anesthetics and antithusics immobilized on the graphite electrode. Electroanalysis 15, 2003, p. 544-547.

17. Li, F., et al., Simple and rapid voltammetric determination of morphine at electrochemically pretreated glassy carbon electrodes. Talanta 79, 2009, p. 845-850.

18. Pournaghi-Azar, M.H. and A. Saadatirad, Simultaneous voltammetric and amperometric determination of morphine and codeine using a chemically modified-palladized aluminum electrode. Journal of Electroanalytical Chemistry 624, 2008, p. 293-298. 
19. Pournaghi-Azar, M.H. and A. Saadatirad, Simultaneous determination of paracetamol, ascorbic acid and codeine by differential pulse voltammetry on the aluminum electrode modified by thin layer of palladium. Electroanalysis 22, 2010, p. 1592-1598.

20. Shih, Y., J.M. Zen, and H.H. Yang, Determination of codeine in urine and drug formulations using a clay-modified screen-printed carbon electrode. Journal of Pharmaceutical and Biomedical Analysis 29, 2002, p. 827-833.

21. Zen, J.M., et al., Determination of Codeine in Human Plasma and Drug Formulation Using a Chemically Modified Electrode. Electroanalysis 10, 1998, p. 536-540.

22. Li, Y., et al., Electrochemical behavior of codeine and its sensitive determination on graphene-based modified electrode. Sensors and Actuators, B: Chemical 182, 2013, p. 401-407.

23. Habibi, B., M. Abazari, and M.H. Pournaghi-Azar, Simultaneous determination of codeine and caffeine using single-walled carbon nanotubes modified carbon-ceramic electrode. Colloids and Surfaces B: Biointerfaces 114, 2014, p. 89-95.

24. Holt, P.J., et al., An amperometric opiate assay. Biosensors \& Bioelectronics 10, 1995, p. 517-526.

25. Asturias-Arribas, L., et al., Screen-printed biosensor based on the inhibition of the acetylcholinesterase activity for the determination of codeine. Talanta 111, 2013, p. 8-12.

26. Lewis, D.F.V., Guide to Cytochromes P450: Structure and Function. 2001, Florida: CRC Press, Boca Ratón.

27. Shumyantseva, V.V., et al., Direct electron transfer of cytochrome P4502B4 at electrodes modified with nonionic detergent and colloidal clay nanoparticles. Analytical Chemistry 76, 2004, p. 6046-6052. 
28. Bistolas, N., et al., Cytochrome P450 biosensors - A review. Biosensors and Bioelectronics 20, 2005, p. 2408-2423.

29. Alonso-Lomillo, M.A., et al., CYP450 biosensors based on gold chips for antiepileptic drugs determination. Biosensors and Bioelectronics 23, 2008, p. 1733-1737.

30. Alonso-Lomillo, M.A., et al., CYP450 2B4 covalently attached to carbon and gold screen printed electrodes by diazonium salt and thiols monolayers. Analytica Chimica Acta 633, 2009, p. 51-56.

31. Asturias-Arribas, L., et al., CYP450 biosensors based on screen-printed carbon electrodes for the determination of cocaine. Analytica Chimica Acta 685, 2011, p. 15-20.

32. Asturias-Arribas, L., et al., Electrochemical determination of cocaine using screen-printed cytochrome P450 2B4 based biosensors. Talanta 105, 2013, p. 131-134.

33. Cao, L., Carrier-bound Immobilized Enzymes: Principles, Applications and Design. 2005, Weinheim, Germany: Wiley-VCH.

34. Hermanson, G.T., Bioconjugate Techniques. 2nd ed. 2008, USA: Academic Press Elsevier.

35. Lewis, G.A., D. Mathieu, and R. Phan-Tan-Luu, Pharmaceutical experimental design. 1999, New York: Dekker.

36. Box, G.E.P., N.G. Hunter, and J.S. Hunter, Estadística para investigadores. Introducción al diseño de experimentos. Análisis de datos y construcción del modelo. 1989, Barcelona: Reverté.

37. STATGRAPHICS, STATGRAPHICS PLUS for Windows. 1994-2001, Statistical Graphics Corp. 
38. Mulaa, F.J. and P.M. Krämer, Biosensors, in Handbook of food safety engineering, D.-W. Sun, Editor. 2012, Wiley-Blackwell: West Sussex, UK. p. 313-351.

39. Rousseeuw, P.J. and A.M. Leroy, Robust Regression and Outlier Detection. 1989, New York: Wiley.

40. ISO11843, Capability of Detection, Part I, 1997 and Part II, 2000. Genève, Switzerland.

41. Inczédy, J., et al., Compendium of Analytical Nomenclature. 3rd ed. 2000, Baltimore: Port City Press Inc.

42. Alonso-Lomillo, M.A., et al., Sensitive enzyme-biosensor based on screenprinted electrodes for Ochratoxin A. Biosensors \& Bioelectronics 25, 2010, p. 1333-1337.

43. Bauer, C.G., et al., New enzyme sensors for morphine and codeine based on morphine dehydrogenase and laccase. Fresenius' Journal of Analytical Chemistry 364, 1999, p. 179-183.

44. Saberian, M., et al., Aptamer-based Nanosensors: Juglone as an AttachedRedox Molecule for Detection of Small Molecules. BioImpacts 1, 2011, p. 3136.

45. Ensafi, A.A., E. Heydari-Bafrooei, and B. Rezaei, Different interaction of codeine and morphine with DNA: A concept for simultaneous determination. Biosensors \& Bioelectronics 41, 2013, p. 627-633. 


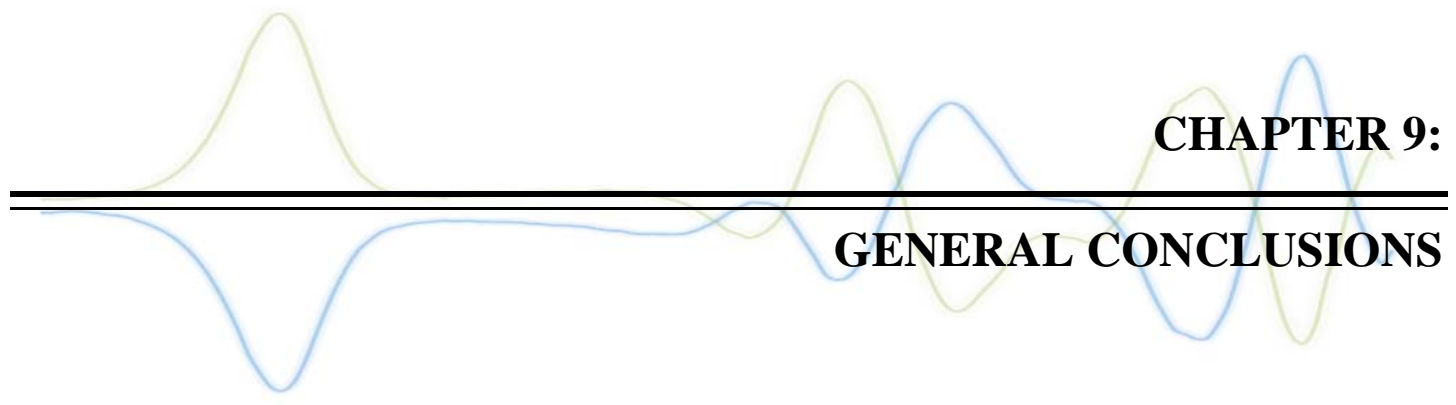



The following conclusions can be drawn from the preceding chapters:

1. The versatility of screen-printing technology allows obtaining electrochemical transducers with different characteristics. The wide choice of inks of different materials enables the manufacture of the most appropriate device for each analyte, and permits to obtain miniaturised SPE on demand.

2. PLS regressions are a useful tool to achieve the analysis of overlap signals in square-wave voltammetry. The use of this chemometric technique allows the discrimination of the cocaine voltammetric signal and its quantification, using SPCE, in presence of paracetamol, codeine and caffeine.

3. The modification of SPCEs with a suspension of MWCNTs in DMF simplifies the quantification of cocaine in complex matrixes, such as street samples, using OLS regressions.

4. The use of SPCEs leads to the development of enzymatic biosensors that can be manufactured as disposable devices.

5. Experimental design methodology has played an important role in the optimisation of the experimental variables that have a great influence in the chronoamperometric signal of the enzymatic sensors. This methodology simplifies the number of measurements to obtain the optimum experimental values.

6. CYP2B4 based electrochemical biosensors have been developed, since cocaine has been described to be one of its substrates, testing different enzyme immobilisation procedures to obtain the best biosensor in terms of precision and capability of detection.

7. Covalent immobilisation has led to the most sensitive CYP2B4 based SPCE for cocaine determination. 
8. The validation of the developed covalently modified CYP2B4 biosensor has been obtained performing calibration curves at $\mathrm{pH} 8.1$ and $-250 \mathrm{mV}$ vs. $\mathrm{Ag} / \mathrm{AgCl} \mathrm{SPE}$. The reproducibility in terms of the RSD of the slopes of the calibration curves is $3.6 \%(n=4)$ and the capability of detection for cocaine is $[23.1 \pm 3.5] \mathrm{nM}(n=3, \alpha=\beta=0.05)$. The biosensor keeps around the $40 \%$ of sensitivity after the fourth calibration plot (repeatability).

9. Screen-printing technology permits the screen-printed immobilisation of the enzyme CYP2B4, as an additional step in the fabrication of the device, suggesting the possibility of a fast and mass production of biosensors.

10. The incorporation of the enzyme CYP2B4 in the matrix of the carbon working electrode gives way to the voltammetric study of the redox peaks of the iron group of such enzyme and its catalytic effect on cocaine.

11. Calibration curves recorded under the optimum conditions, $\mathrm{pH} 8$ and -250 $\mathrm{mV}$ vs. $\mathrm{Ag} / \mathrm{AgCl} \mathrm{SPE}$, have been used to calculate the values of reproducibility $(5.9 \%, n=5)$, repeatability $(10.5 \%, n=3)$ and capability of detection $(200.0 \mu \mathrm{M}, \alpha=\beta=0.05)$ of manufactured SPC $_{\mathrm{CYP} E s}$ in the calibration range from 0.2 to $1.2 \mathrm{mM}$ of cocaine.

12. The success of the catalytic activity on the $\mathrm{SPC}_{\mathrm{CYP}} \mathrm{Es}$ has been additionally checked by spectrophotometric detection of the yellow compound, product of the reaction between the Nash reagent and the formaldehyde obtained as subproduct of the enzymatic reaction.

13. The purity of cocaine in street samples has been successfully determined using the two developed CYP2B4 biosensors, namely covalent modified SPCEs and $\mathrm{SPC}_{\mathrm{CYPES}}$.

14. A $2^{\text {nd }}$-generation $\mathrm{AChE}$ based biosensor has been developed to monitor the inhibition signal produced by codeine on $\mathrm{SPC}_{\mathrm{TTF}} \mathrm{E}$. 
15. Consecutive additions of ATI in absence and presence of codeine, using

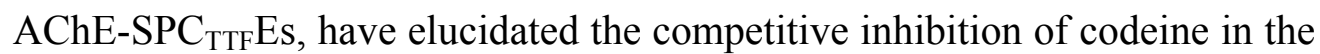
AChE activity.

16. Calibration curves have been performed with $\mathrm{AChE}_{\mathrm{SPC}} \mathrm{TTF}_{\mathrm{TT}} \mathrm{Es}$ under the

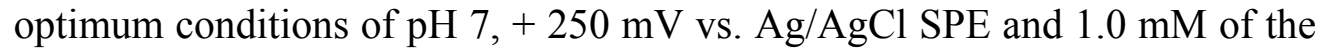
substrate ATI in the range from 20.0 to $200.0 \mu \mathrm{M}$ of codeine. These calibration plots have been utilised to estimate the reproducibility of the method in $3.3 \%$ (RSD, $n=6)$ and the capability of detection in $20.0 \mu \mathrm{M}(\alpha=$ $\beta=0.05)$ of codeine.

17. A non-mediated chronoamperometric biosensor for codeine has been described based on the interaction of this drug with the isoform CYP2D6. Experimental results show that the covalent immobilisation of this enzyme has been the optimum one, due to its orientation on the surface of the working electrode.

18. Successive additions of codeine, in the range from 4.9 to $45.4 \mu \mathrm{M}$, using covalently modified CYP2D6 SPCE under the optimum conditions, $\mathrm{pH} 7$ and $+200 \mathrm{mV}$ vs. $\mathrm{Ag} / \mathrm{AgCl} \mathrm{SPE}$, give way to reproducible devices $(\mathrm{RSD}=8.9 \%$, $n=6)$, with a capability of detection of $4.9 \mu \mathrm{M}(\alpha=\beta=0.05)$.

19. Both biosensors, $\mathrm{AChE}$ based $\mathrm{SPC}_{\mathrm{TTF}} \mathrm{E}$ and CYP2D6 based SPCE, have been successfully applied in the quantification of codeine in pharmaceutical tablets and urine spiked samples. 

ANNEX:

IMMUNOSENSORS FOR COCAINE DETECTION 

The development of immunosensors and aptasensors for cocaine has increased in the last years (Section 3.1.3.1). However, among all of them, two electrochemical immunosensors have been only reported for the determination of this drug.

This chapter describes the preliminary experimental results in the development of an optical and electrochemical cocaine immunosensor based on magnetic beads (MBs).

This work arose from collaboration between the Electroanalysis Group of the University of Burgos and the Analytical Spectroscopy and Sensors Group of the University of Zaragoza, carried out during a 4-month academic visit.

The obtained results have been partially presented at VI Workshop Nanociencia y Nanotecnología Analíticas in Alcalá de Henares, Madrid, Spain (July 2013). 



\section{A.1.- DEVELOPMENT OF IMMUNOSENSORS: AN INTRODUCTION}

The interaction of an antibody (biorecognition element) with an antigen (analyte) forms the basis of all immunochemical techniques. The regions responsible for the binding are the epitope in the antigen and the paratope or binding site in the antibody [1].

Antibodies are proteins synthesised by plasma cells in animals in response to the presence of a foreign substance, an antigen. The structure of an antibody, generally represented as the structure of an immunoglobulin $\mathrm{G}$ ( $\mathrm{IgG}$ ) molecule, consists of two heavy and two light chains held together by disulphide bonds. Each chain is composed of a constant and a variable region that comprises three hypervariable segments, which vary from one antibody to another, conferring on antibodies a large range of antigen specificity (Figure A.1) [1].

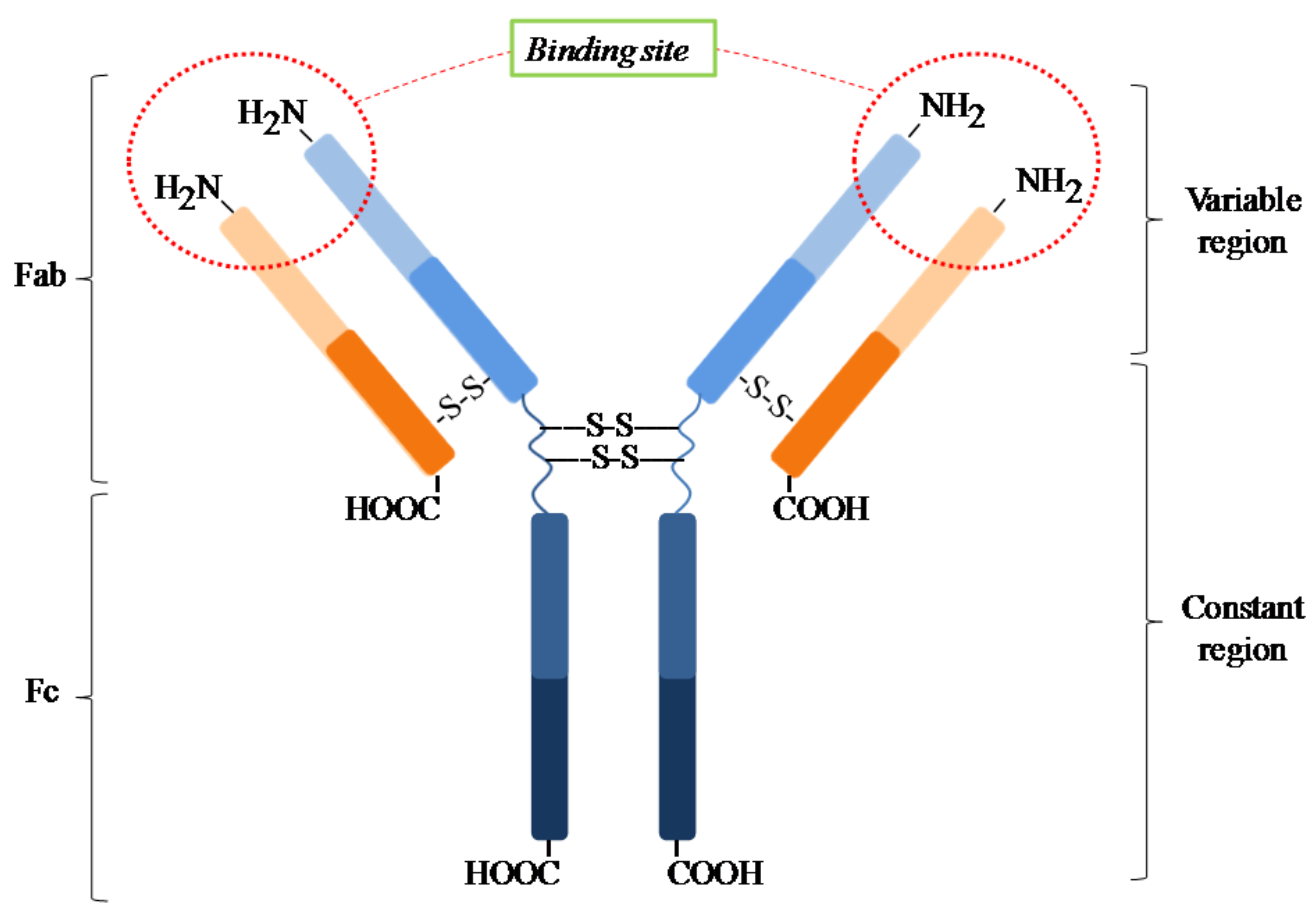

Figure A.1.- Schematic structure of the IgG molecule. 
Antibodies can be used for the purification of an antigen, as well as for recognition and quantification of its presence in a complex mixture. The properties of the antibody-antigen interaction can be characterised by its structure, its strength (affinity) and its stability (avidity) [1].

\section{A.1.1.- TYPES OF IMMUNOASSAYS}

The detection and quantification of the antigen-antibody interaction can be achieved by using a variety of different labels (radioisotope, enzyme, fluorophore, metallic particle, etc.), present either in the antigen or in the antibody. A variety of different techniques (colorimetry, fluorimetry, luminescence, electrochemistry, etc.) for detecting the antibody-antigen interaction can be then employed in the design and development of immunoassays [1].

Thus, immunoassays can be classified in: enzyme immunoassay (EIA), radioimmunoassay (RIA), fluoroimmunoassay (FIA), chemiluminescent immunoassay (CLIA) and counting immunoassay (CIA).

\section{A.1.1.1.- Enzyme immunoassays}

EIAs are a type of immunoassays where an enzyme is used to label the antibody or the antigen. The most common EIA is the enzyme-linked immunosorbent assay (ELISA). The principle of this technique relies on the specific recognition between a molecule (antigen or antibody) in solution and a partner molecule immobilised onto a solid surface [2].

The most widely used solid-phase materials in ELISA are plastics, such as microtiter plates (polystyrene), but microspheres or beads are also used for this kind of biosensors. 
MBs, microspheres and nanoparticles have been widely used in electrochemical immunoassay because of their unique properties of superparamagnetism, biocompatibility, low toxicity, and large specific surface area. Magnetic nanoparticles can be easily separated from solution by a magnetic field [3$5]$.

\section{A.1.1.1.1.- Standard immunoassay configurations}

ELISA is a heterogeneous system based on three main different steps.

- Firstly, a reactant (the antibody or the antigen) is attached to a solid phase.

- Next, the separation of bound and free reagents, which are added subsequently to the solid phase-attached substance, is performed by washing [6].

- Finally, as enzyme immunoassays make use of enzymes attached to one of the reactants in order to visualise and quantify the binding of the antibody to its target, two analytical techniques can be performed:

$\checkmark$ On one hand, the incubation of the enzyme with chromogenic substrates generates intensely coloured products that can be measured with a spectrophotometer [2].

$\checkmark$ On the other hand, the enzymatic transformation of a substrate generates an electroactive product that can be electrochemically measured [3].

Different configurations of ELISA have been described (figure A.2).

A direct ELISA is regarded as the simplest form of ELISA, where the antigen or the antibody is attached to the solid phase and its enzyme-labelled partner is next 
added to be specifically bound (Figure A.2.A). The indirect system is similar to the direct one, where the antigen is directly attached to the solid phase, but it is targeted by non-labelled antibodies. Additionally, these antibodies are targeted by antibodies linked to enzymes (Figure A.2.B).

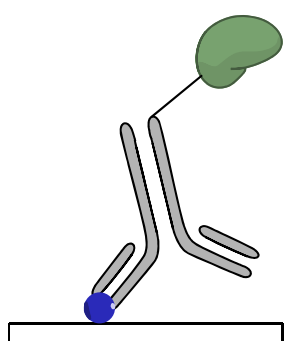

A

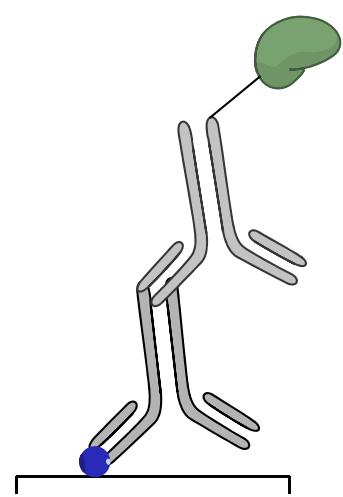

B

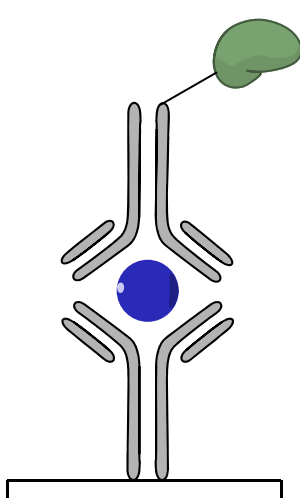

$\mathrm{C}$

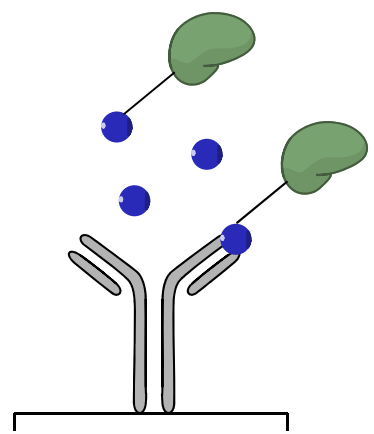

$\mathrm{D}$

Figure A.2.- Different ELISA configurations: direct (A), indirect (B), direct sandwich (C) and direct competitive $(D)$ immunoassays.

In the sandwich configuration the catcher antibody is immobilised onto the solid surface and binds to the antigen present in the sample. A labelled antibody is then bound to a different epitope of the antigen (Figure A.2.C). In the competitive configuration, the labelled compound (antibody or antigen) competes with the unlabelled one for the binding with the partner one, immobilised on the solid surface (Figure A.2.D). For sandwich and competitive configurations, both indirect and direct systems can be performed, where first a non-labelled reagent is attached and then targeted by a labelled one $[6,7]$.

\section{A.1.2.- IMMUNOASSAY APPLICATIONS}

Immunosensors have been used in a wide range of areas such as forensic, environmental, medical and agro-alimentary, to determine contaminants, drugs or 
diagnose human diseases. The availability of robotic systems and automated plate washers make the ELISA an excellent platform for high-throughput screening assays $[2,6]$.

In the field of drugs of abuse, EIA have played an important role, since they are suitable for providing such screens [8]. In this way, different optical [8-10] and electrochemical (Section 3.1.3.1) [10-12] EIA have been described in literature for the determination of cocaine.

The following sections summarise the experimental procedure and the initial results of a new optical and electrochemical immunosensor for the determination of cocaine, based on the use of MBs.

\section{A.2.- EXPERIMENTAL}

\section{A.2.1.- REAGENTS}

Standard 96-well polystyrene microplates were supplied from Sarstedt (Nümbrecht, Germany).

Magnetic microbeads Dynabeads Protein G (MBs-prtG), Dynabeads Protein A (MBs-prtA), Dynabeads sheep anti-Rabbit IgG (MBs-IgG(r)) and Dynabeads sheep anti-Mouse IgG (MBs-IgG(m)) from Invitrogen-Life Technologies (Oslo, Norway) were used as immobilisation surfaces.

A magnetic 96-well separator from Life-technologies (Carlsbad, CA, USA) and a magnetic separation stand for Eppendorf vials from Promega (Madison, WI, USA) were used to remove the supernatant from MBs. 
Polyclonal sheep anti-cocaine antibody (pAbcoc, ref. PAS10174) and cocaine-HRP conjugate (coc-HRP, ref. HRP9524) were obtained from Randox Life Sciences (County Antrim, UK).

Cocaine hydrochloride was supplied by Sigma (Steinheim, Germany). Stock solutions of the analyte were freshly made in phosphate buffer $\mathrm{pH}$ 7.2. Codeine hydrochloride from Alcaliber S.A. (Madrid, Spain) and benzoylecgonine from the Abnova commercial cocaine metabolite ELISA kit (Taipei, Taiwan) were used to study the cross-reactivity.

A solution of $20.0 \mathrm{mM}$ sodium phosphate dibasic anhydrous (Sigma Aldrich, Steinheim, Germany), $20.0 \mathrm{mM}$ sodium phosphate monobasic monohydrate (J.T. Backer, Phillipsburg, NJ, USA) and $138.0 \mathrm{mM}$ sodium chloride (Scharlau, Sentmenat, Spain) was used as phosphate buffer. All solutions were prepared in MilliQ water.

BSA was obtained from Sigma Aldrich (Steinheim, Germany) and Pierce Protein-Free and SuperBlock blockers from Thermo Scientific (Rockford, IL, USA).

3,3',5,5'-tetramethylbenzidine (TMB), hydrogen peroxide, hydroquinone and Tween 20 were supplied by Sigma Aldrich (Steinheim, Germany). A solution of 0.5 $\mathrm{M} \mathrm{H}_{2} \mathrm{SO}_{4}$ (Scharlau Chemie S.A., Barcelona, Spain) was prepared in water.

\section{A.2.2.- Apparatus}

An Eppendorf-Thermomixer (Eppendorf, Hamburg, Germany) was used in the incubation process to carry out the immobilisation of the pAbcoc on the MBs and an orbital shaker Rotamax-120 from Heidolph (Schwabach, Germany) was used to shake the microplates. 
Spectrophotometric measurements were made with a Bio-Rad Model 680 Microplate reader (Bio-Rad, Hercules, CA USA).

Electrochemical measurements were performed with a PalmSens interface (PalmSens BV, Utrecht, The Netherlands) connected to an eight-electrode screenprinted array (University of Florence, Italy) for multiple electrochemical detection, coupled with an eight magnet block. Each SPE consisted of a $3.1 \mathrm{~mm}^{2}$ carbon working electrode, silver pseudoreference electrode and a graphite counter electrode, printed on a polyester substrate $[13,14]$.

The $\mathrm{pH}$ of the solutions was checked with a Crison $\mathrm{pH}$ meter model 2001 (Barcelona, Spain).

\section{A.3.- METHODS}

\section{A.3.1.- IMMOBILISATION OF THE ANTIBODY ONTO THE MAGNETIC MICROPARTICLES}

The immobilisation of the pAbcoc was carried out on the modified surface of MBs, which allowed the orientated immobilisation of the antibody, leading to a better reproducibility of the biosensor.

Four different-modified commercial MBs were checked for the immobilisation of the antibody. pAbcoc was then immobilised on the protein Gmodified surface of the microbeads as follows:

- $5 \mu \mathrm{L}$ of a $30.0 \mathrm{mg} \mathrm{mL}^{-1} \mathrm{MBs}$ suspension were washed twice with phosphate buffer $\mathrm{pH} 7.2$ containing $0.02 \%$ Tween 20 . 
- Once the supernatant was removed, $500 \mu \mathrm{L}$ of a $20.0 \mathrm{mM}$ phosphate solution $\mathrm{pH} 7.2$ and $1.2 \mu \mathrm{L}$ of a $1.0 \mathrm{mg} \mathrm{mL}^{-1}$ solution of the pAbcoc were added to the MBs.

- The incubation stage was processed under shaking during 10 minutes at room temperature.

- After this time, the pAbcoc modified MBs were washed twice with a 20.0 $\mathrm{mM}$ solution of phosphate $\mathrm{pH} 7.2$ and suspended in $300 \mu \mathrm{L}$ of the same buffer $(0.5 \mu \mathrm{g}$ pAbcoc-MBs $/ \mu \mathrm{L})$.

\section{A.3.2.- BLOCKAGE OF THE POLYSTYRENE MICROTITERS}

The adsorption of molecules to a polystyrene surface is due to intermolecular attraction forces (van der Waals).

Passive adsorption, which consists of primarily hydrophobic interactions or hydrophobic/ionic interactions between the biomolecules and the surface, is desirable for the antibody immobilisation on the polystyrene surface of the wells [15]. However, this can be an inconvenience if the analyte or the conjugate are adsorbed on the polymeric surface.

In order to avoid the unspecific adsorption of the analyte or the conjugate to the walls of the polystyrene microplates, three different blockers were checked. The blockage stage was performed according to the manufacturer specifications. Therefore, $300 \mu \mathrm{L}$ of SuperBlock were added to each well and immediately removed. In the case of Protein-Free blocker, $300 \mu \mathrm{L}$ were added to each well and left to react for one hour, time after which the remaining product was removed. The blockage procedure with $1 \%$ BSA was performed by adding $300 \mu \mathrm{L}$ of this solution in each well, left to react during 30 min under orbital shaking and emptied after this time. A $\mathrm{N}_{2}$ flow was passed through all wells to dry them. 


\section{A.3.3.- DiRECT COMPETITIVE ASSAY OF COCAINE}

After the adsorption of the antibody to the solid phase, the direct competitive assay was carried out in the blockaded wells by adding $25 \mu \mathrm{L}$ of a $1 / 20$ coc-HRP

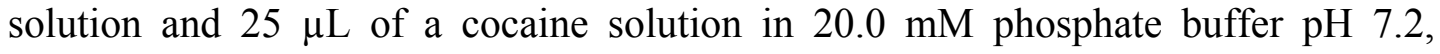
followed by the addition of $50 \mu \mathrm{L}$ of a suspension of $0.5 \mu \mathrm{g}$ pAbcoc-MBs $/ \mu \mathrm{L}$.

Subsequently to the addition of the reactants, the mixture was incubated at room temperature during 1 hour under orbital shaking, except for the optimisation step. Next, the pAbcoc-MBs were separated from the supernatant using a magnet, washed twice with $0.1 \%$ Tween in $20 \mathrm{mM}$ phosphate buffer $\mathrm{pH} 7.2$ and once with $20.0 \mathrm{mM}$ phosphate $\mathrm{pH}$ 7.2.

\section{A.3.3.1.- Spectrophotometric measurements}

After removing the washing buffer, a volume of $50 \mu \mathrm{L}$ of TMB (containing $\mathrm{H}_{2} \mathrm{O}_{2}$ ) was added in each well and left to react for $20 \mathrm{~min}$ at room temperature under orbital shaking. Then, the reaction was stopped by adding $50 \mu \mathrm{L}$ of a $0.5 \mathrm{M} \mathrm{H}_{2} \mathrm{SO}_{4}$ solution to each well. The bluish product of the enzymatic reaction turns into a yellow compound in acidic media, which is monitored at $450 \mathrm{~nm}$ (Figure A.3) [16, 17].

\section{A.3.2.2.- Electrochemical measurements}

After removing the washing buffer, $20 \mu \mathrm{L}$ of phosphate buffer $\mathrm{pH} 6.5$ were added to each well to suspend the pAbcoc-MBs. Then, they were pipetted and deposited on the surface of the working SPE, which incorporated a magnet holding block under it to retain the pAbcoc-MBs. 


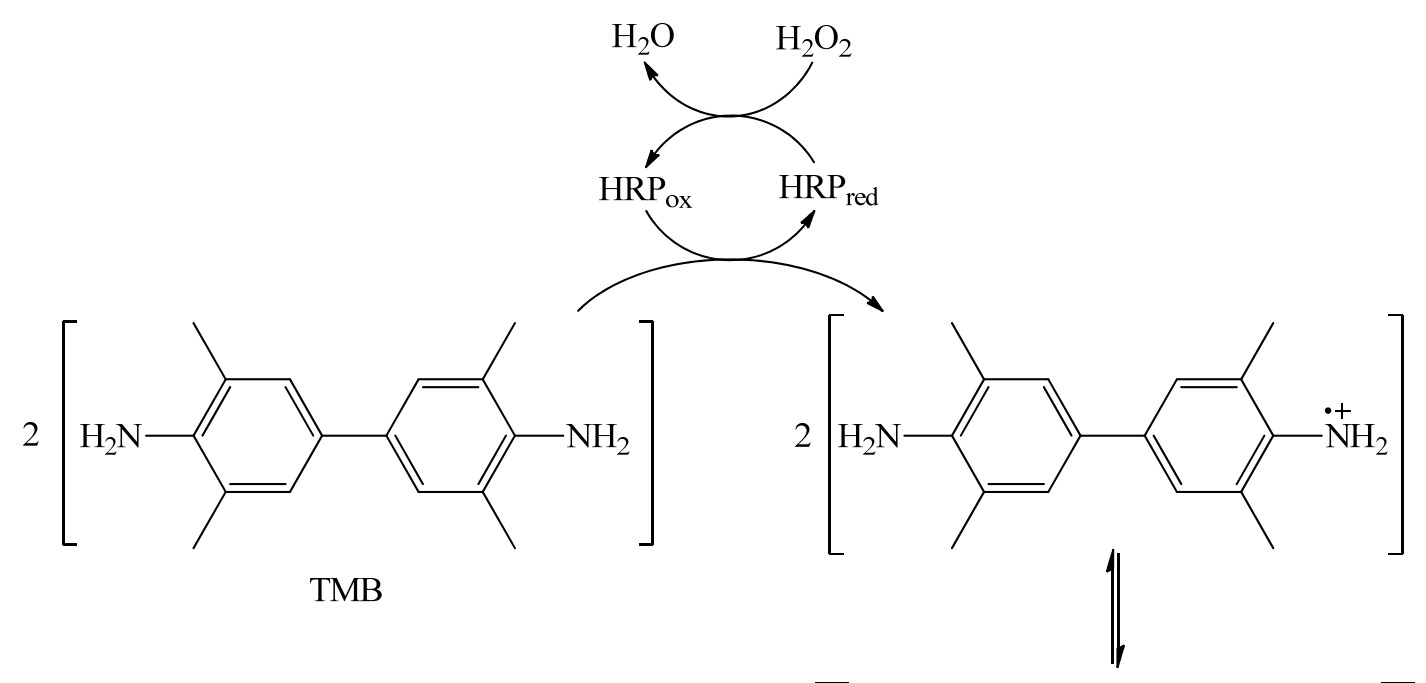

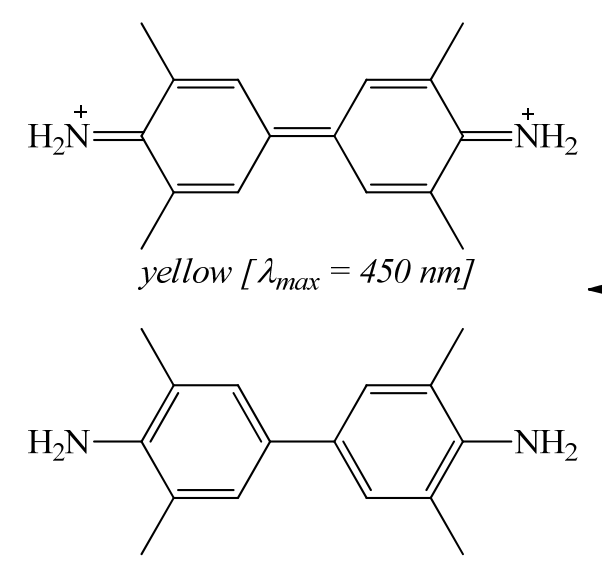

colourless

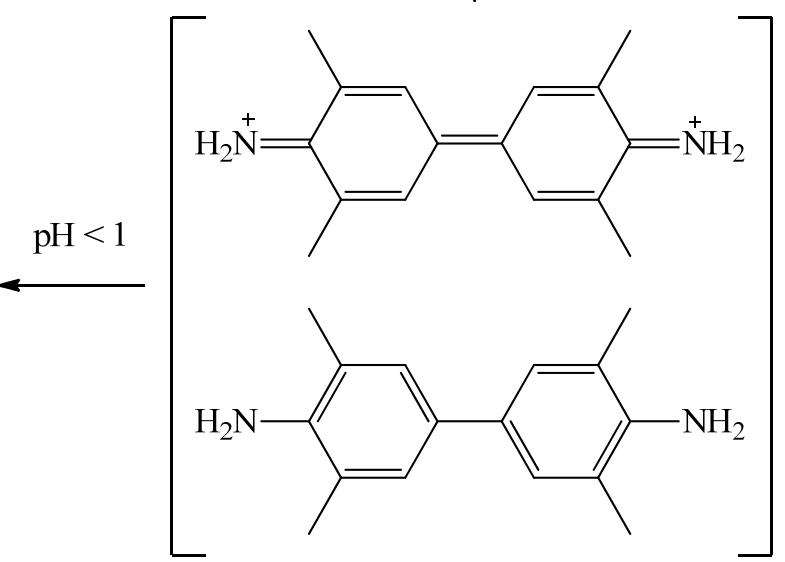

blue $\left[\lambda_{\max }=370 \mathrm{~nm}\right]$

Figure A.3.- Biotransformation of TMB and the yellow product generation to be monitored and related with the quantity of analyte.

Two different substrates have been used to perform this analysis. On one hand, a volume of $80 \mu \mathrm{L}$ of $\mathrm{TMB}$, which contained $\mathrm{H}_{2} \mathrm{O}_{2}$, was added to the electrochemical system and let it react during $10 \mathrm{~min}$. Next, a potential of $-200 \mathrm{mV}$ vs. $\mathrm{Ag} / \mathrm{AgCl} \mathrm{SPE}$ was applied during $90 \mathrm{~s}$ and the chronoamperometric signal was acquired (Figure A.4).

On the other hand, $40 \mu \mathrm{L}$ of a $4.5 \mathrm{mM}$ solution of hydroquinone in phosphate buffer $\mathrm{pH} 6.5$ followed by $40 \mu \mathrm{L}$ of a $24.0 \mathrm{mM} \mathrm{H}_{2} \mathrm{O}_{2}$ solution in the same buffer were added on the electrochemical system and left to react during $10 \mathrm{~min}$ [18]. After 
this time, a potential of $-350 \mathrm{mV}$ vs. $\mathrm{Ag} / \mathrm{AgCl} \mathrm{SPE}$ was applied during $90 \mathrm{~s}$ and the chronoamperometric signal was recorded (Figure A.4).

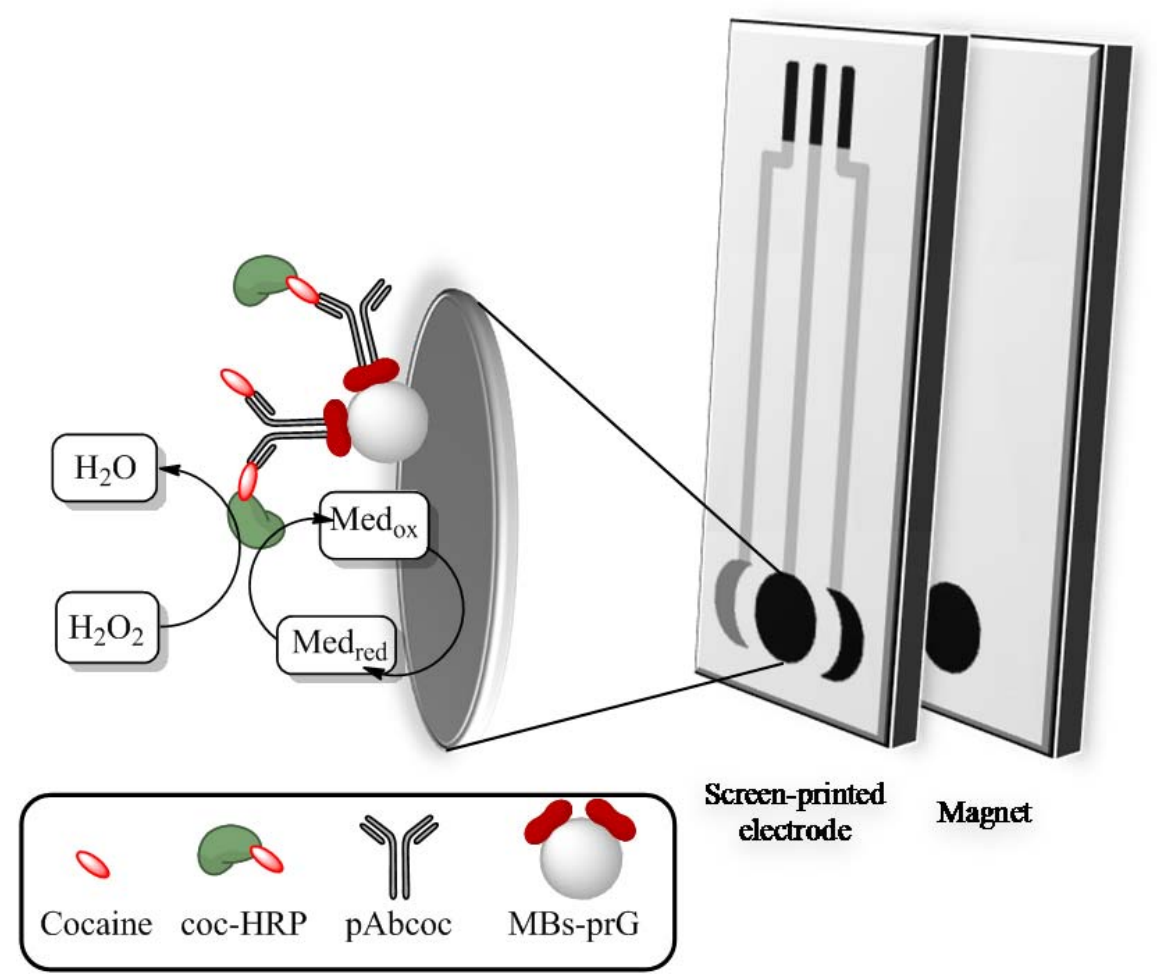

Figure A.4.- Schematic representation of the electrochemical determination. (Med: hydroquinone or TMB redox mediators).

The typical signal obtained in a direct competitive assay is represented in figure A.5.

Analysis data were processed with a GraphPad Prism 5 software package (GraphPad Software Inc., La Jolla, USA). The experimental data were adjusted to a sigmoidal equation (Figure A.5):

$$
f(x)=\min +\frac{\max -\min }{1+(x / I C 50)^{\text {slope }}}
$$


where: $\min$ and $\max$ are the asymptotic points.

the slope is the lineal part of the sigmoid.

IC50 is the inflexion point, the concentration of analyte needed to reach half of the intensity of the signal.
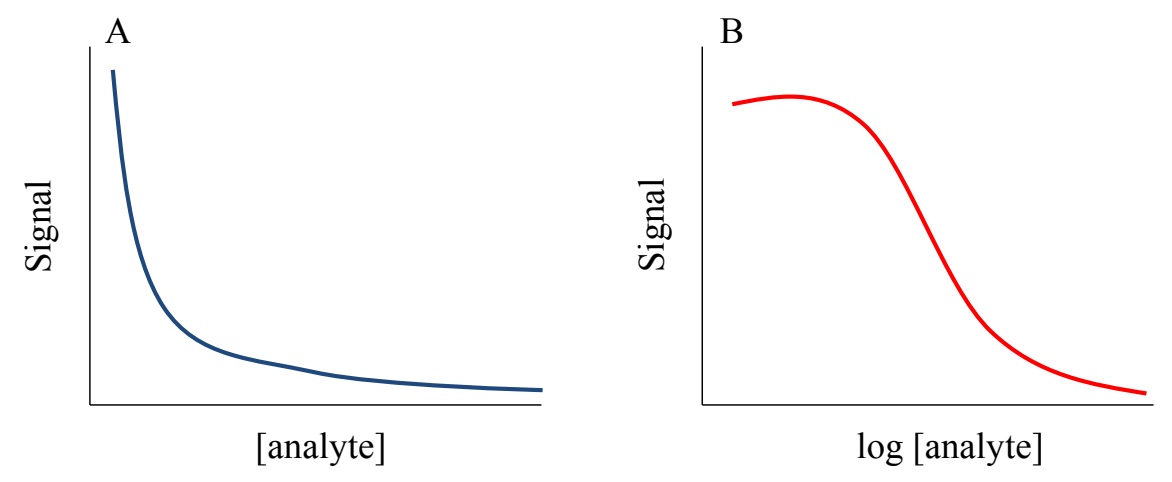

Figure A.5.- Response of a competitive assay (A) and its transformation into a sigmoid representation $(B)$.

\section{A.3.4.- SPIKED URINE SAMPLE PREPARATION}

Urine samples were obtained from a healthy person. The sample was decanted and the supernatant was diluted 1:10 with a $20.0 \mathrm{mM}$ phosphate solution $\mathrm{pH} 7.2$ and then spiked to a final concentration of $5.0 \mathrm{ng} \mathrm{mL}^{-1}$ of cocaine.

\section{A.4.- RESULTS AND DISCUSSION}

\section{A.4.1.- STUDY OF THE BLOCKAGE OF THE ELISA PLATE}

Due to the high unspecific union of coc-HRP to the polymeric surface of the well, the blockage of the plate was required. Three different blocking agents were tested, namely Pierce Protein-Free, SuperBlock and 1\% BSA (Figure A.6). Then, the 
study of the unspecific attachment of the conjugate coc-HRP was performed by adding $25 \mu \mathrm{L}$ of a $1 / 20$ coc-HRP solution and $75 \mu \mathrm{L}$ of a $20.0 \mathrm{mM}$ phosphate buffer $\mathrm{pH} 7.2$ in the well. The mixture was incubated at room temperature during 1 hour under orbital shaking and finally, measured according to the procedure described in section A.3.3.1.

As it can be seen in figure A.6, the blocking agent SuperBlock did not block and even incremented the unspecific union of the conjugate. Although Pierce Protein-Free slightly blocked the polymeric surface, $1 \%$ BSA was chosen for the blockage of the well as it avoided the unspecific adsorption of the conjugate.

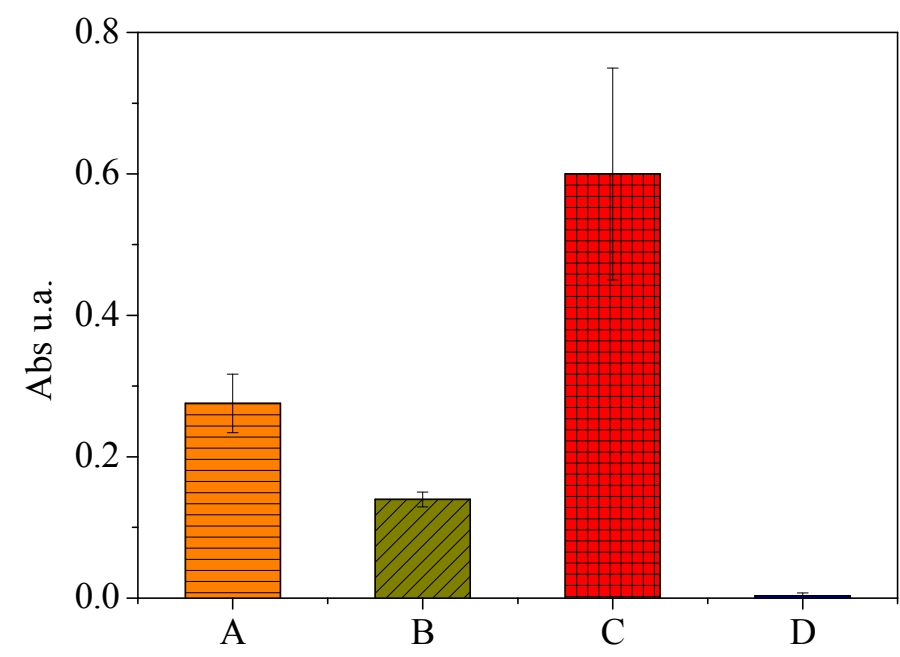

Figure A.6.- Study of the unspecific interaction of coc-HRP with the polystyrene surface of the wells (A), blockaded with Pierce Protein-Free (B), SuperBlock (C) or $1 \%$ BSA (D).

\section{A.4.2.- OPTIMISATION OF THE EXPERIMENTAL VARIABLES}

Different factors have an important influence in the development of a biosensor, such as time and temperature of reaction and $\mathrm{pH}$ of the media, among others. Thus, their optimisation is essential to obtain a good analytical response. 


\section{A.4.2.1.- Optimisation of the antibody immobilisation step}

The immobilisation stage is a critical step in the development of a biosensor. In this case, the good choice of the magnetic particles, on which the antibody is going to be immobilised, is crucial. Not only the type of MBs, but also the time and temperature, under which the antibody is immobilised, has a great influence in the success of the development of the biosensor.

\section{Optimisation of the MB type}

Different kinds of MBs were checked to obtain the best orientated immobilisation of the bioelement. In this case, the solid surface of the MBs was biofunctionalised by $\mathrm{Fc}$ receptors (protein $\mathrm{G}$, protein $\mathrm{A}, \operatorname{IgG}(\mathrm{m})$ or $\operatorname{IgG}(\mathrm{r})$ ) to attached the pAbcoc in an orientated way through its Fc fragment [19]. In this way, each type of MBs was modified with the optimum pAbcoc quantity recommended by the supplier. Then, unspecificity, affinity and competitive assays were spectrophotometrically analysed for each one:

- The unspecific attachment of the conjugate coc-HRP was performed by adding $25 \mu \mathrm{L}$ of a $1 / 20$ coc-HRP solution and $75 \mu \mathrm{L}$ of $20.0 \mathrm{mM}$ phosphate buffer $\mathrm{pH} 7.2$ in the well (Figure A.7.A).

- The affinity between the antibody and the conjugate was performed by adding $25 \mu \mathrm{L}$ of a $1 / 20$ coc-HRP solution in $20.0 \mathrm{mM}$ phosphate $\mathrm{pH} 7.2$ and $25 \mu \mathrm{L}$ of the same buffer followed by $50 \mu \mathrm{L}$ of a suspension of $0.5 \mu \mathrm{g}$ of pAbcoc-MBs/ $\mu \mathrm{L}$ (Figure A.7.B).

- The direct competitive assay was performed by adding $25 \mu \mathrm{L}$ of a $1 / 20$ cocHRP solution in $20.0 \mathrm{mM}$ phosphate $\mathrm{pH} 7.2$ and $25 \mu \mathrm{L}$ of a $40.0 \mathrm{ng} \mathrm{mL} \mathrm{mL}^{-1}$ cocaine solution in the same buffer followed by $50 \mu \mathrm{L}$ of a suspension of 0.5 $\mu \mathrm{g}$ of $\mathrm{pAbcoc}-\mathrm{MBs} / \mu \mathrm{L}$ (Figure A.7.C). 


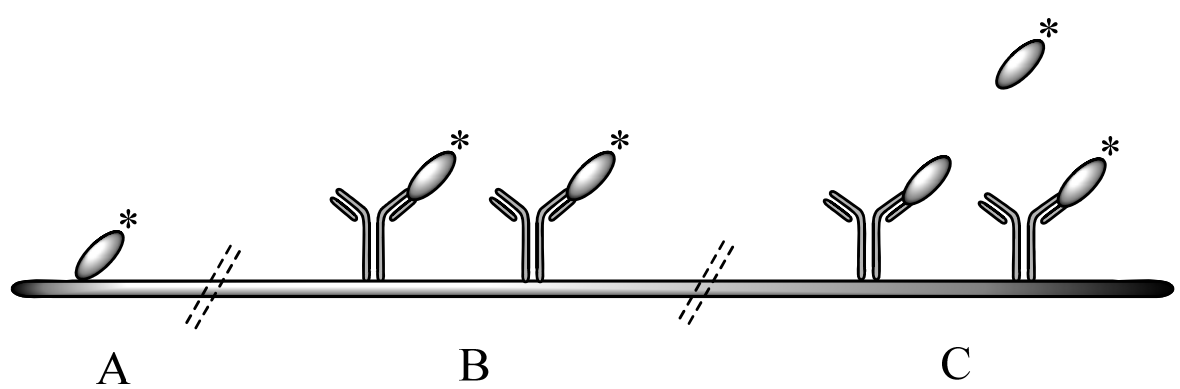

Figure A.7.- Schematic representation of the unspecific attach of the conjugate to the solid phase (A), the affinity between the antibody and the conjugate $(B)$ and the direct competitive assay (C).

As it is seen in figure A.8, MBs-prtG were the chosen ones as immobilisation surface for the pAbcoc, since they showed the highest affinity signal in relation to the unspecific attachment and the competitive assay.

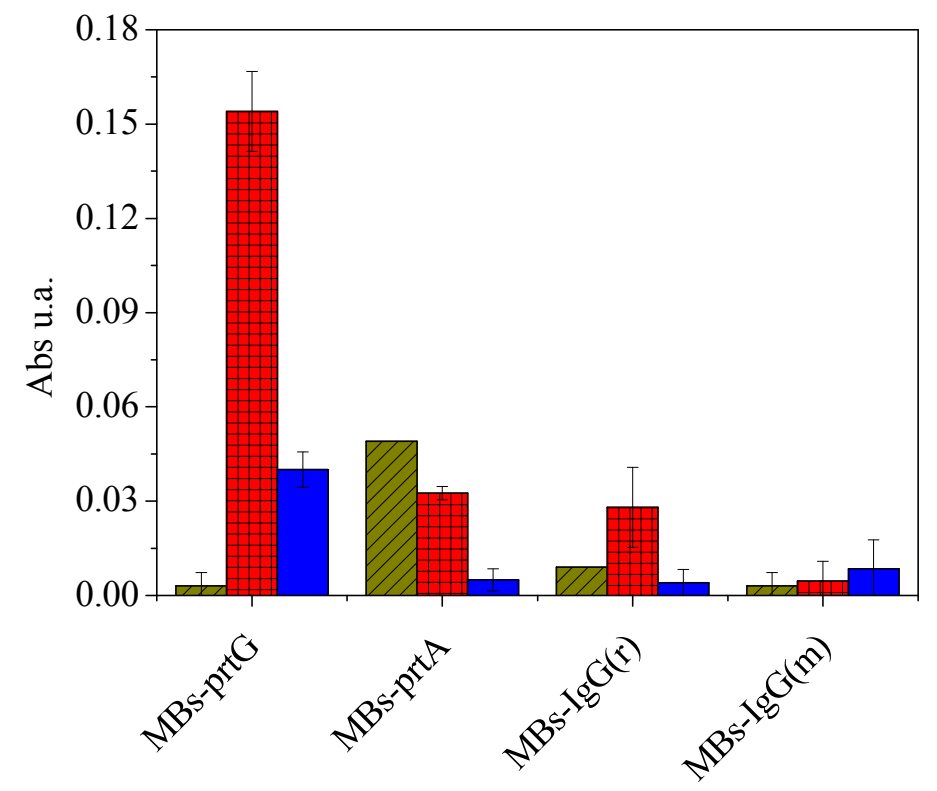

Figure A.8.- Comparison of the unspecificity (striped green), affinity (squared red) and competitive (plain blue) assays of the different pAbcoc modified MBs. 
Optimisation of the time of incubation and the quantity of the pAbcoc immobilised on the $M B S$

The best conditions to carry out the incubation process of the pAbcoc with the MBs-prtG were at room temperature during 10 min under shaking. Besides, the optimisation of the ratio pAbcoc:MBs was studied. According to the process described in section A.3.1, $5 \mu \mathrm{L}$ of a $30.0 \mathrm{mg} \mathrm{mL}^{-1}$ MBs suspension were modified with $0.6,1.2$ and $2.4 \mu \mathrm{L}$ of a $1 \mathrm{mg} \mathrm{mL}^{-1}$ solution of pAbcoc. Calibration curves were performed by direct competitive assay in the concentration range from $2.5 \mathrm{pg} \mathrm{mL}^{-1}$ to $12.5 \mathrm{ng} \mathrm{mL}^{-1}$ of cocaine in well.

As it is shown in figure A.9, the concentration of $8.0 \mu \mathrm{g} \mathrm{pAbcoc/mg} \mathrm{MBs-}$ prtG was chosen as optimum, being this concentration the one suggested by the supplier.

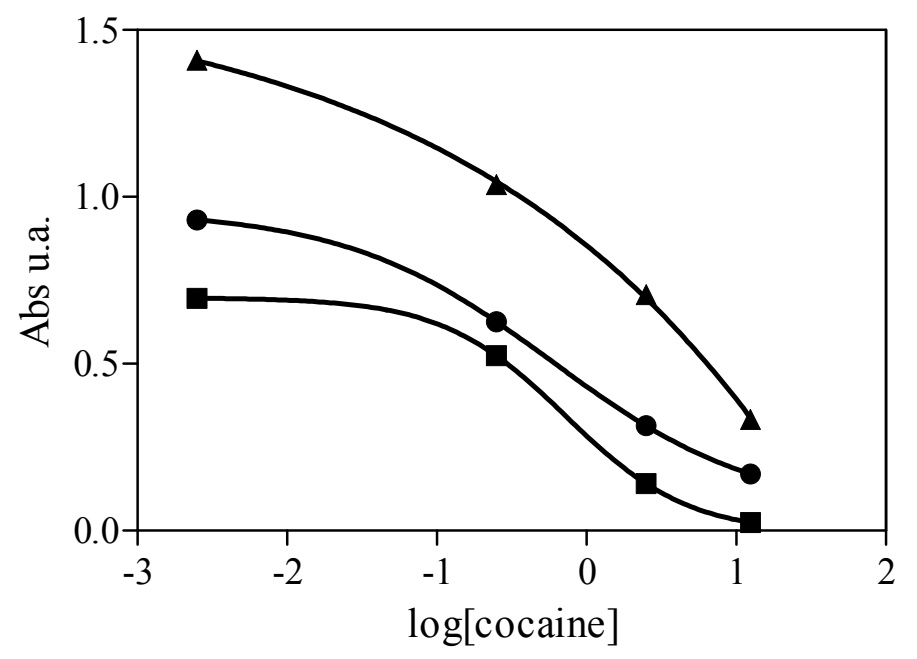

Figure A.9.- Competitive assays using different concentrations of pAbcoc immobilised on MBs-prtG: $4.0(\mathbf{O}), 8.0$ (ם) and $16.0(\mathbf{\Delta}) \mu g$ pAbcoc/mg MBs-prtG. 


\section{A.4.2.2.- Optimisation of the direct competitive reaction}

The interaction between the antibody, the antigen and the conjugate is influenced by factors such as $\mathrm{pH}$ of the buffer, temperature and time of reaction.

According to the specifications of the supplier of the antibody, a $20.0 \mathrm{mM}$ phosphate buffer solution of $\mathrm{pH} 7.2$ was chosen.

\section{Time and temperature of reaction}

Unspecificity, affinity and competitive assays were performed according to section A.4.2.1, varying the temperature and time of reaction. As it is depicted in figure A.10, the highest signal was obtained at $37{ }^{\circ} \mathrm{C}$ during $60 \mathrm{~min}$. Nevertheless, the signal at $25^{\circ} \mathrm{C}$ during $60 \mathrm{~min}$ was good enough, so taking into account the associated energetic savings, this temperature was selected to perform the analysis.
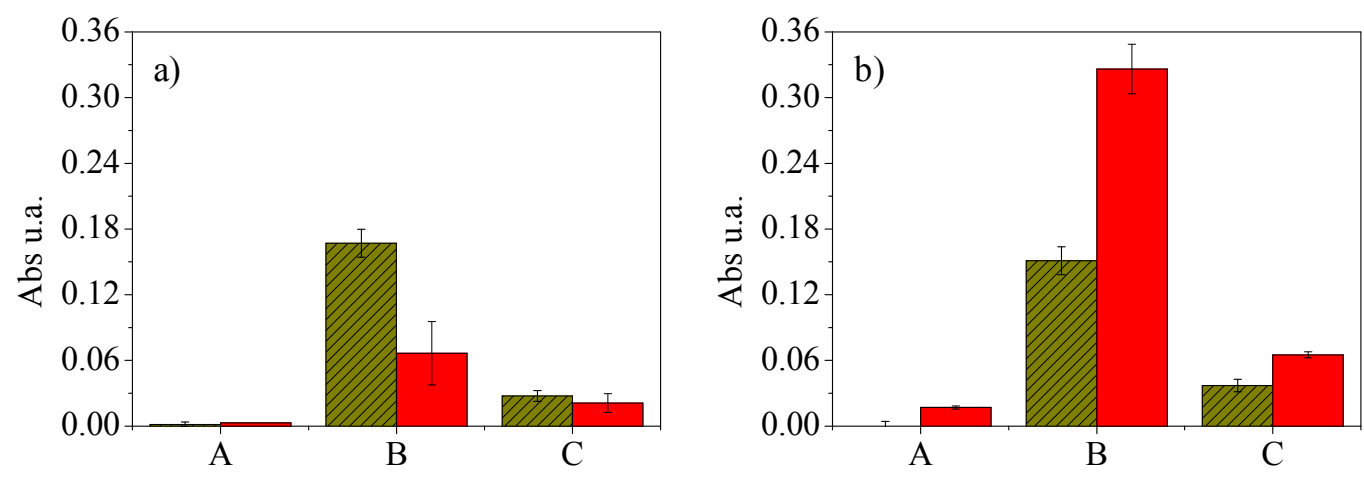

Figure A.10.- Unspecificity (A), affinity (B) and competitive (C) assays carried out varying a) the time at $25^{\circ} \mathrm{C}$ during 60 (striped green) and 30 (plain red) min and b) temperature during 60 min at 25 (striped green) and 37 (plain red) ${ }^{\circ} \mathrm{C}$ of the reaction. 


\section{Quantity of MBs and conjugate}

The quantity of pAbcoc-MBs and coc-HRP was optimised to obtain the best signal.

The competitive immunoassay was performed spectrophotometrically according to section A.3.3, where the concentration of coc-HRP was varied, for the study of the conjugate, and the concentration of pAbcoc-MBs for the study of the antibody present in the reaction.

First, the concentration added to each well was studied in two levels, adding $50 \mu \mathrm{L}$ of a suspension of 0.5 and $0.3 \mu \mathrm{g}$ pAbcoc-MBs $\mu \mathrm{L}$ (25.0 and $15.0 \mu \mathrm{g}$ pAbcocMBs per well, respectively). Figure A.11 shows the results of such study, giving as a better signal the use of the $0.5 \mu \mathrm{g}$ pAbcoc-MBs/ $\mu \mathrm{L}$ suspension.

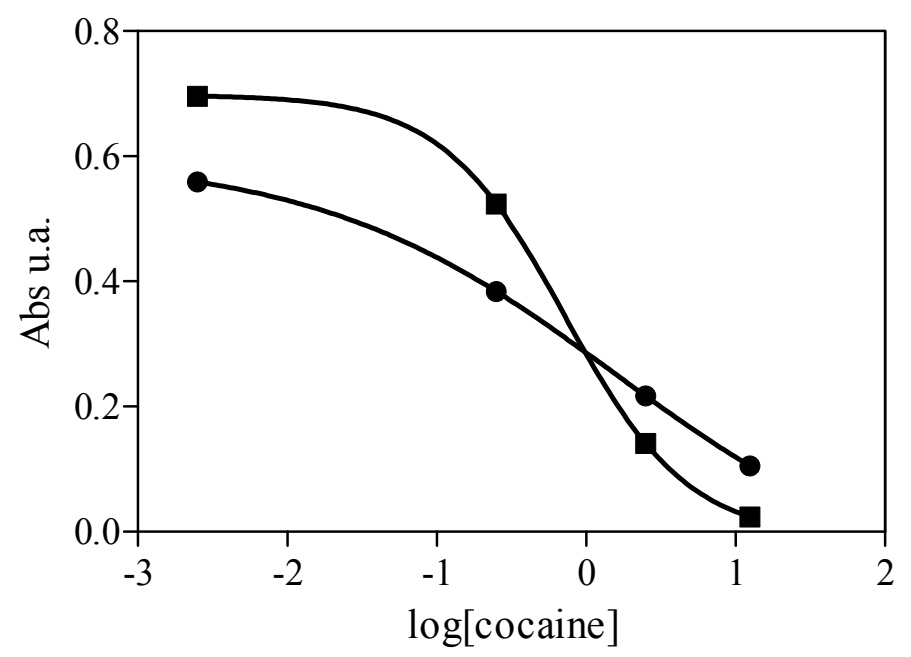

Figure A.11.- Competitive immunoassay in the range from $2.5 \mathrm{pg} \mathrm{mL}^{-1}$ to $12.5 \mathrm{ng} \mathrm{mL}^{-1}$ and varying the quantity of pAbcoc-MBs in each well: 15.0 (O) and 25.0 (ם) $\mu \mathrm{g}$ pAbcoc-MBs. 
The study of the optimum dilution of coc-HRP was carried out in the same way as for the concentration of pAbcoc-MBs. Taking into account the optimum concentration of pAbcoc-MBs, $25 \mu \mathrm{L}$ of $1 / 20,1 / 50$ and 1/75 coc-HRP solutions were added to each well to perform a direct spectrophotometric competitive immunoassay (Section A.3.2) (1/80, 1/200 and 1/300 coc-HRP concentration well, respectively). The chosen concentration was 1/75 of coc-HRP to be added in the competitive immunoassay (Figure A.12 and Table A.1). As the conjugate concentration was lower, the IC50 also decreased, giving a better sensitivity.

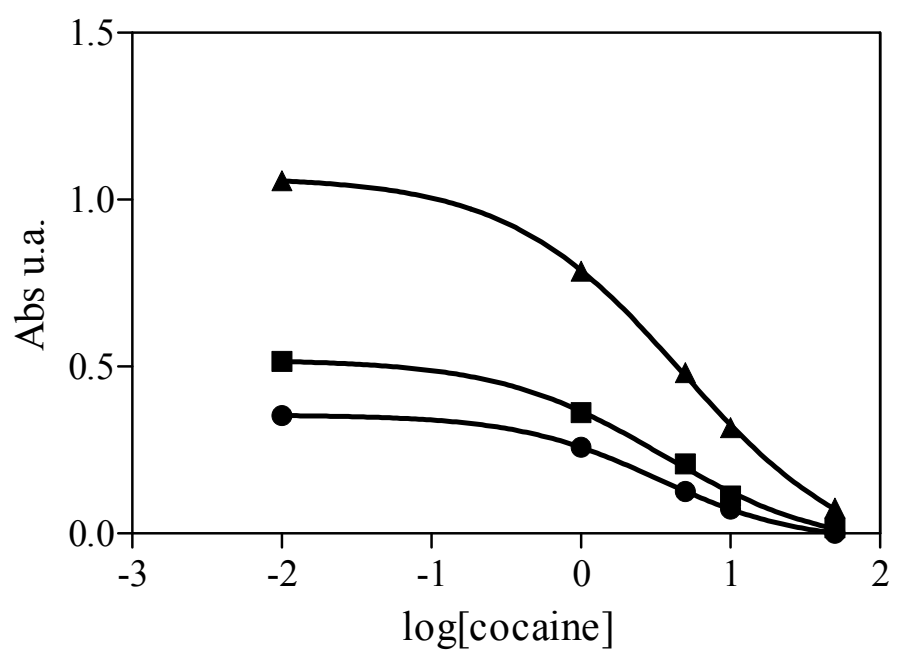

Figure A.12.- Competitive immunoassay varying the quantity of conjugate coc-HRP:

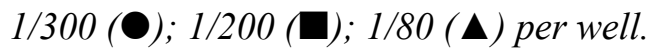

\section{A.4.2.3.- Calibration curve}

Calibration curves were performed under the chosen conditions of pAbcocMBs, coc-HRP, time and temperature. The direct competitive assay was carried out in the range from $2.5 \mathrm{pg} \mathrm{mL}^{-1}$ to $12.5 \mathrm{ng} \mathrm{mL}^{-1}$ of cocaine for the spectrophotometric measurements (Figure A.13), and from $10.0 \mathrm{pg} \mathrm{mL}^{-1}$ to $50.0 \mathrm{ng} \mathrm{mL}^{-1}$ of cocaine for 
the electrochemical measurements (Figure A.14). As it is shown in table A.2, both electrochemical assays give similar IC50 values.

Table A.1.- Experimental parameters of the sigmoidal adjustment of the spectrophotometric data in the optimisation of the concentration of the conjugate in the competitive immunoassay.

\begin{tabular}{lccc}
\hline [Coc-HRP] & $\mathbf{1 / 3 0 0}$ & $\mathbf{1 / 2 0 0}$ & $\mathbf{1 / 8 0}$ \\
\hline Min & 0.0 & -0.1 & -0.1 \\
Max & 0.4 & 0.5 & 1.1 \\
$\mathbf{I C 5 0}\left(\mathbf{n g ~ m L}^{-\mathbf{1}}\right)$ & 3.2 & 3.4 & 4.7 \\
$\mathbf{R}^{2}$ & 1 & 0.998 & 0.999 \\
Slope & -0.9 & -0.8 & -0.7 \\
\hline
\end{tabular}

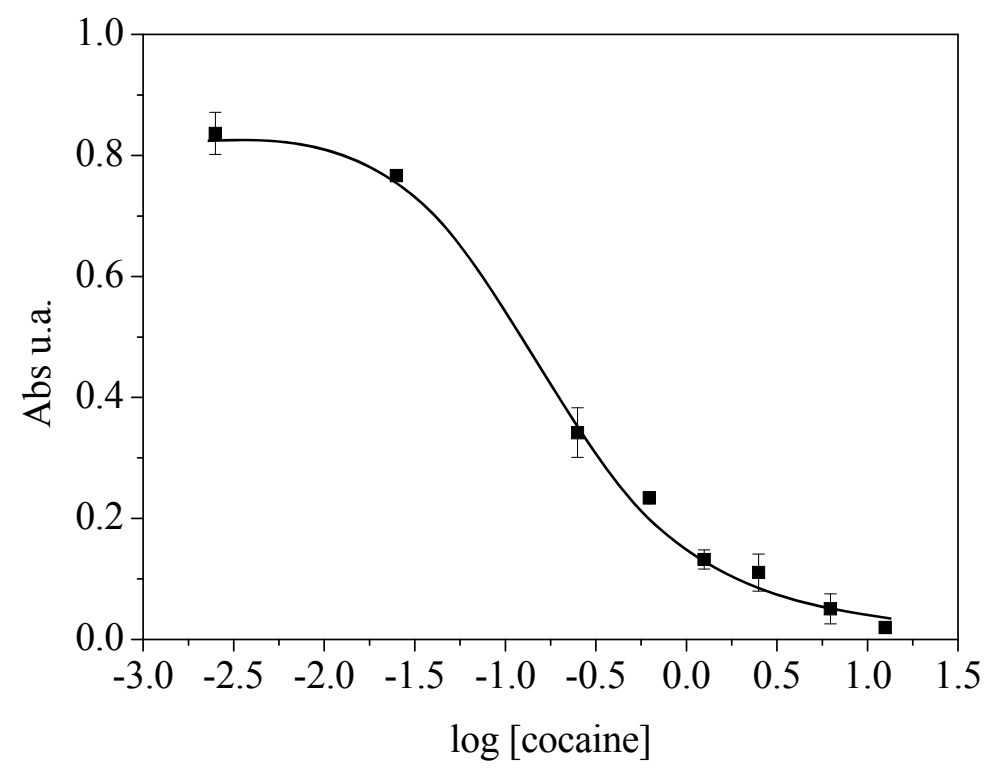

Figure A.13.- Spectrophotometric measurement of the direct competitive immunoassay in the range from $2.5 \mathrm{pg} \mathrm{mL}^{-1}$ to $12.5 \mathrm{ng} \mathrm{mL}^{-1}$ of cocaine. 

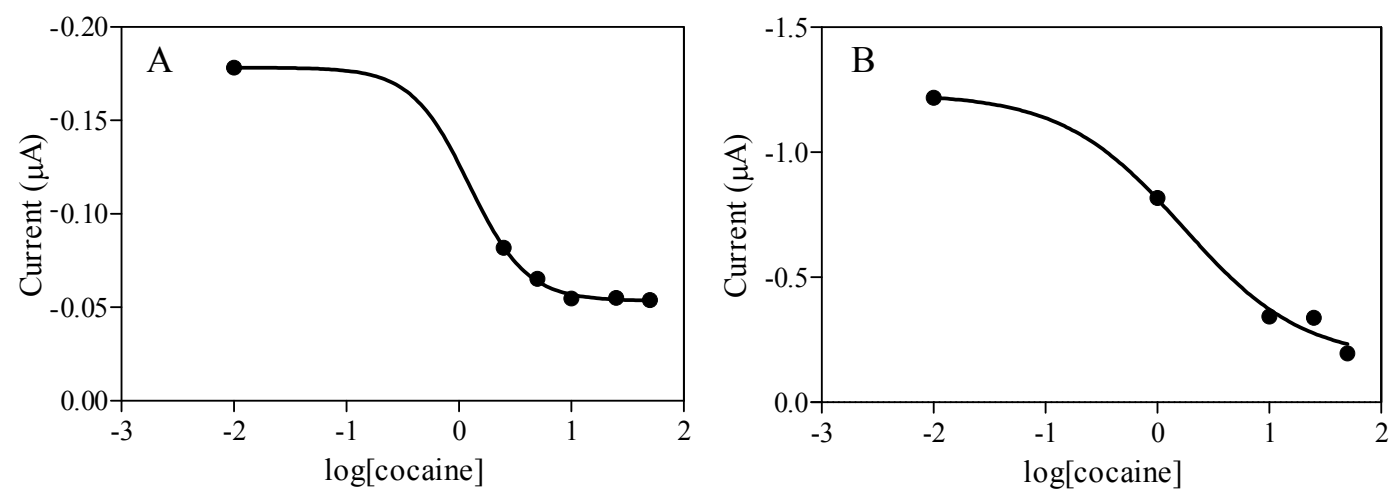

Figure A.14.- Electrochemical measurements of the direct competitive immunoassay in the range from $10.0 \mathrm{pg} \mathrm{mL}^{-1}$ to $50.0 \mathrm{ng} \mathrm{mL}^{-1}$ of cocaine monitoring $T M B(A)$ and hydroquinone (B).

Table A.2.- Experimental parameters of the curves of calibration of the spectrophotometric and electrochemical results in the competitive immunoassay.

\begin{tabular}{l|c|cc}
\cline { 2 - 4 } & Spectrophotometric & \multicolumn{2}{|c}{ Electrochemical } \\
& $\mathbf{T M B}+\mathbf{H}_{\mathbf{2}} \mathbf{O}_{\mathbf{2}}$ & Hydroquinone $+\mathbf{H}_{\mathbf{2}} \mathbf{O}_{\mathbf{2}}$ \\
\hline min & 0.0 & -0.2 & -1.2 \\
max & 0.9 & -0.0 & -0.2 \\
Slope & -0.9 & 1.7 & 0.8 \\
IC50 (ng $\left.\mathbf{~ m L}^{-\mathbf{1}}\right)$ & 0.2 & 1.2 & 1.7 \\
$\mathbf{R}^{\mathbf{2}}$ & 0.996 & 0.999 & 0.992 \\
\hline
\end{tabular}

\section{A.4.3.- Cross-REACtivity}

The cross-reactivity measures the extent to which different antigens appear similar to the immunological system [20]. In this way, codeine (Figure 3.3) and benzoylecgonine (Figure A.15), the main cocaine metabolite, were checked. 


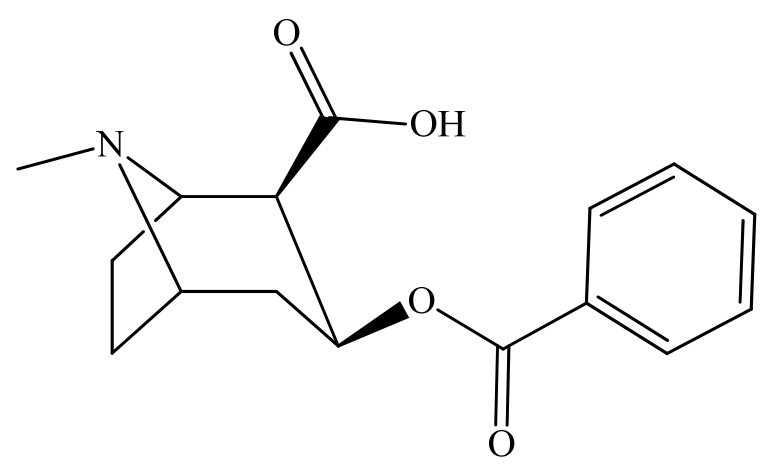

Figure A.15.- Benzoylecgonine structure.

The study was performed in the optimum conditions of 1/300 coc-HRP and $25 \mu \mathrm{g}$ pAbcoc-MBs according to the procedure explained in section A.3.3. As it is depicted in figure A.16, codeine had almost no response towards the pAbcoc, while benzoylecgonine showed a $25.5 \%$ of cross-reactivity with cocaine for a concentration of $12.5 \mathrm{ng} \mathrm{mL}^{-1}$ of the analytes.

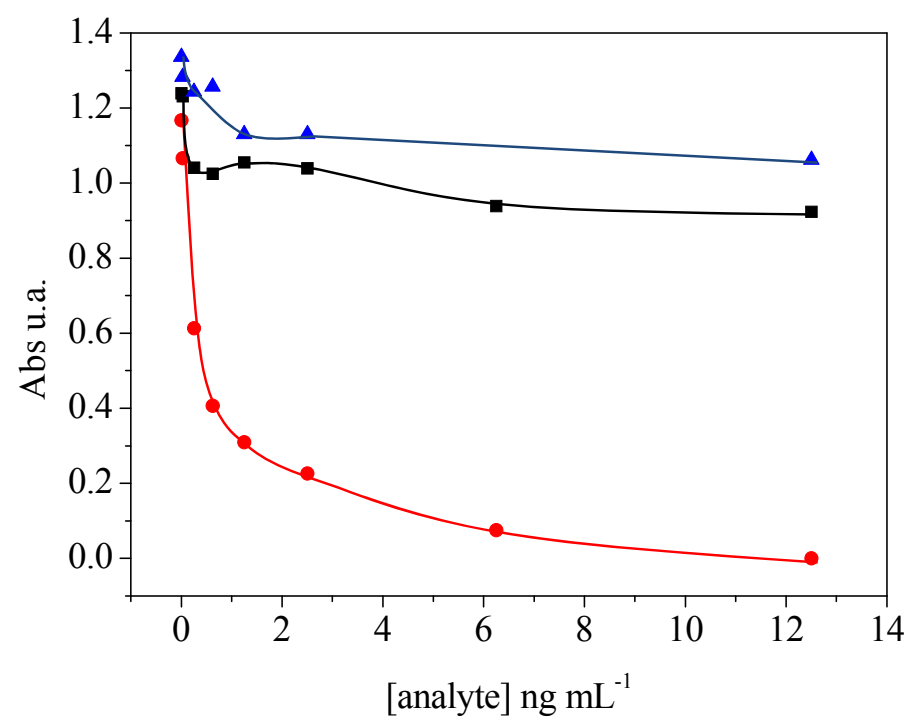

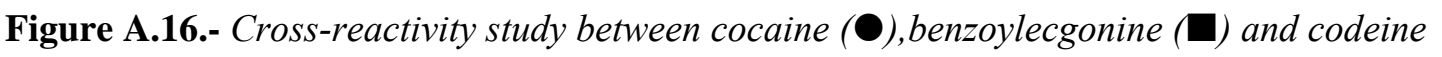
( $\Delta)$ towards the pAbcoc. 


\section{A.4.4.- URINE SAMPLE ANALYSIS}

The developed immunosensor was used for the determination of cocaine in spiked urine samples. As it is shown in figure A.17, the urine matrix provoked a diminishing in the signal. On account of this, a dilution of the biological sample was required. A dilution of 1:10 was enough to perform the assay.

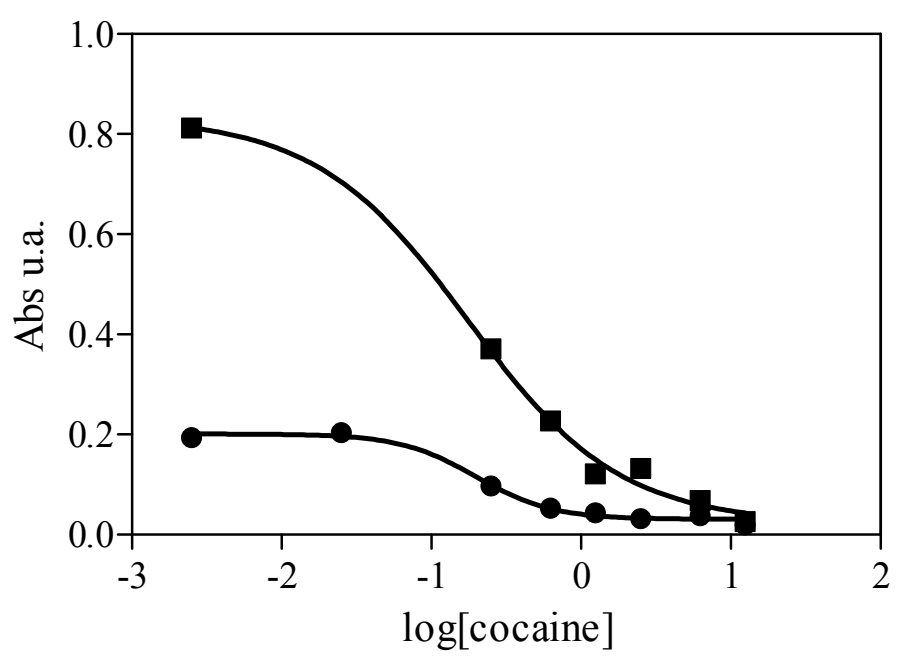

Figure A.17.- Comparison of the spectrophotometric signal for the direct competitive

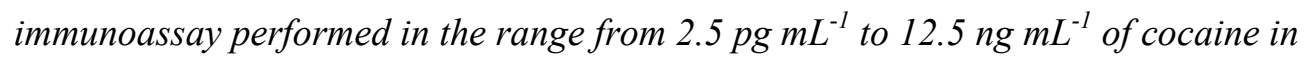

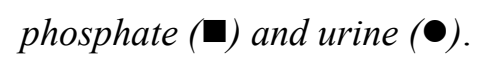

A solution of $5.0 \mathrm{ng} \mathrm{mL^{-1 }}$ of cocaine in 1:10 urine was used as studied solution. $25 \mu \mathrm{L}$ of this solution were added to the ELISA wells to perform the immunoassay. The final cocaine concentration in the well was $1.25 \mathrm{ng} \mathrm{mL} \mathrm{m}^{-1}$. The spectrophotometric signal was then inserted in the calibration curve, obtaining a value of $1.28 \mathrm{ng} \mathrm{mL}^{-1}$. 


\section{A.4.5.- VALIDATION OF THE COCAINE IMMUNOSENSOR}

A commercial cocaine metabolite ELISA kit from Abnova was used to compare results with the developed immunosensor. The cross-reactivity and the analysis of spiked urine samples were checked.

The cross-reactivity assay was performed comparing the competitive response of cocaine with benzoylecgonine and codeine towards the same antibody. As it is shown in figure A.18, codeine did not show cross-reactivity. Nevertheless, benzoylecgonine presented around $90 \%$ cross-reactivity with cocaine for a concentration of $50 \mathrm{ng} \mathrm{mL} \mathrm{m}^{-1}$ of the analytes. This fact highlighted that pAbcoc was more selective to cocaine than to benzoylecgonine (Figure A.16), while the antibody immobilised on the ELISA Abnova kit was not as selective (Figure A.18).

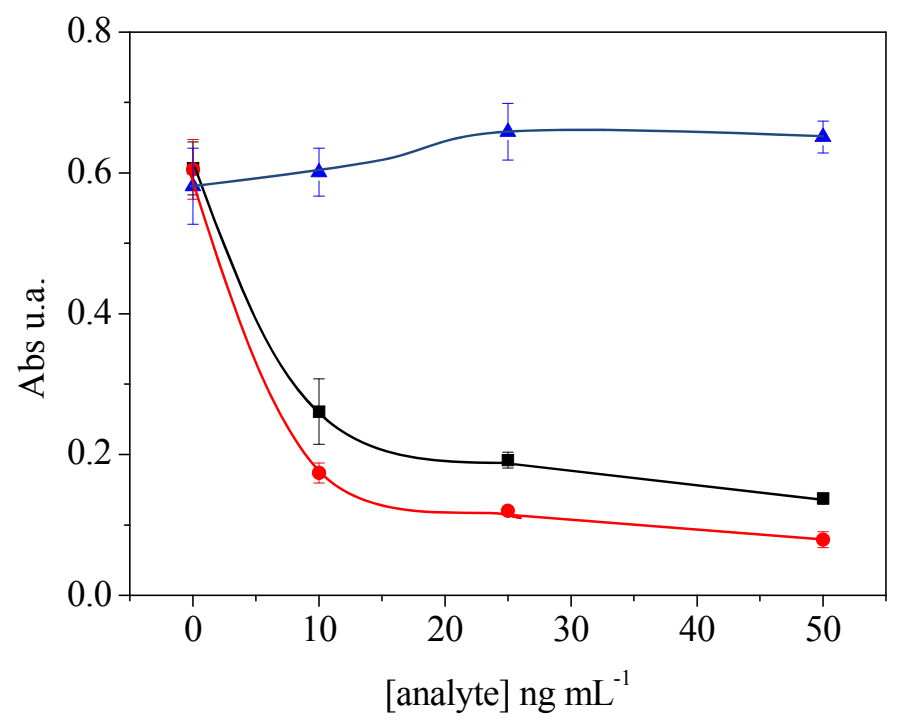

Figure A.18.- Cross-reactivity assay for cocaine (৩),benzoylecgonine (ם) and codeine $(\mathbf{\Delta})$, performed with the commercial Abnova kit.

Additionally, urine samples were diluted 1:10, spiked with 20.0 and $40.0 \mathrm{ng}$ $\mathrm{mL}^{-1}$ and checked with the commercial immunoassay. After the competitive assay in 
the ELISA kit, the concentrations found for the cocaine in the spiked samples were 18.3 and $42.2 \mathrm{ng} \mathrm{mL}^{-1}$, respectively. These values agree with the spiked quantities.

\section{A.5.- CONCLUSIONS}

The first steps in the development of a new optical and electrochemical immunosensor for the determination of cocaine have been described. Optimisation of main factors, which influence the development of the biosensor, has been carried out. MBs-prtG are the MBs that give a better immobilisation of the pAbcoc. Direct competitive assays have been carried out in blockaded ELISA wells containing 50 $\mu \mathrm{L}$ of a $0.5 \mu \mathrm{g} \mathrm{mL}^{-1}$ pAbcoc-MBs dispersion, $25 \mu \mathrm{L}$ of a $1 / 75$ coc-HRP solution and $25 \mu \mathrm{L}$ of cocaine solutions. The competitive interaction has been monitored by spectrophotometric measurement of the TMB and electrochemical detection of TMB or hydroquinone.

The developed immunosensor has been also compared with a commercial ELISA kit, showing less cross-reactivity with its main metabolite, benzoylecgonine, than the commercial one. Both biosensors have been used to determine the concentration of cocaine in spiked urine samples.

\section{A.6.- REFERENCES}

1. González Oliva, A., H.J. Cruz, and C.C. Rosa, Immunosensors for diagnostics. Sensors Update 9, 2001, p. 283-312.

2. Donahue, A.C. and M. Albitar, Antibodies in biosensing, in Recognition receptors in biosensor, M. Zourob, Editor. 2010, Springer: New York (USA). p. 221-248.

3. Li, J., S. Li, and C.F. Yang, Electrochemical Biosensors for Cancer Biomarker Detection. Electroanalysis 24, 2012, p. 2213-2229. 
4. Elyacoubi, A., et al., Development of an amperometric enzymatic biosensor based on gold modified magnetic nanoporous microparticles. Electroanalysis 18, 2006, p. 345-350.

5. Vidal, J.C., et al., Electrochemical affinity biosensors for detection of mycotoxins: A review. Biosensors and Bioelectronics 49, 2013, p. 146-158.

6. Crowther, J., R., The ELISA Guidebook. 2nd ed. Methods in molecular Biology 516, ed. J.M. Walker. 2009, New York, USA: Humana Press.

7. Cruz, H.J., C.C. Rosa, and A.G. Oliva, Immunosensors for diagnostic applications. Parasitology Research 88, 2002, p. S4-S7.

8. Yamaguchi, M., et al., A rapid enzyme immunoassay for cocaine and benzoylecgonine using glucose oxidase. Journal of Health Science 47, 2001, p. $419-423$.

9. Lachenmeier, K., F. Musshoff, and B. Madea, Determination of opiates and cocaine in hair using automated enzyme immunoassay screening methodologies followed by gas chromatographic-mass spectrometric (GCMS) confirmation. Forensic Science International 159, 2006, p. 189-199.

10. Eremenko, A.V., et al., The development of a non-competitive immunoenzymometric assay of cocaine. Analytica Chimica Acta 358, 1998, p. 5-13.

11. Bauer, C.G., et al., Automated amplified flow immunoassay for cocaine. Analytical Chemistry 70, 1998, p. 4624-4630.

12. Suleiman, A.A. and Y. Xu, An amperometric immunosensor for cocaine. Electroanalysis 10, 1998, p. 240-243.

13. Piermarini, S., et al., An ELIME-array for detection of aflatoxin B1 in corn samples. Food Control 20, 2009, p. 371-375. 
14. Volpe, G., et al., Towards the development of a single-step immunosensor based on an electrochemical screen-printed electrode strip coupled with immunomagnetic beads. Analytical and Bioanalytical Chemistry 405, 2013, p. 655-663.

15. Gibbs, J., Immobilization principles - selecting the surfase, in ELISA technical bulletin - No. 1. 2001: New York, USA.

16. Muhammad, N., et al., Engineering of the E. coli Outer Membrane Protein FhuA to overcome the Hydrophobic Mismatch in Thick Polymeric Membranes. Journal of Nanobiotechnology 9, 2011.

17. Baldrich, E., F.J. del Campo, and F.X. Muñoz, Biosensing at disk microelectrode arrays. Inter-electrode functionalisation allows formatting into miniaturised sensing platforms of enhanced sensitivity. Biosensors and Bioelectronics 25, 2009, p. 920-926.

18. Vidal, J.C., et al., An electrochemical immunosensor for ochratoxin A determination in wines based on a monoclonal antibody and paramagnetic microbeads. Analytical and Bioanalytical Chemistry 403, 2012, p. 15851593.

19. Dugas, V., A. Elaissari, and Y. Chevalier, Surface sensitization techniques and recognition receptors immobilization on biosensors and microarrays, in Recognition receptors in biosensors, M. Zourob, Editor. 2010, Springer: New York, USA. p. 47-134.

20. Frank, S.A., Immunology and evolution of infectious diseases. 2002, New Jersey, USA: Princeton Univeristy Press. 